LECTUURES

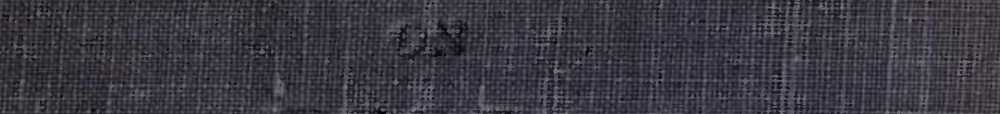

centet the

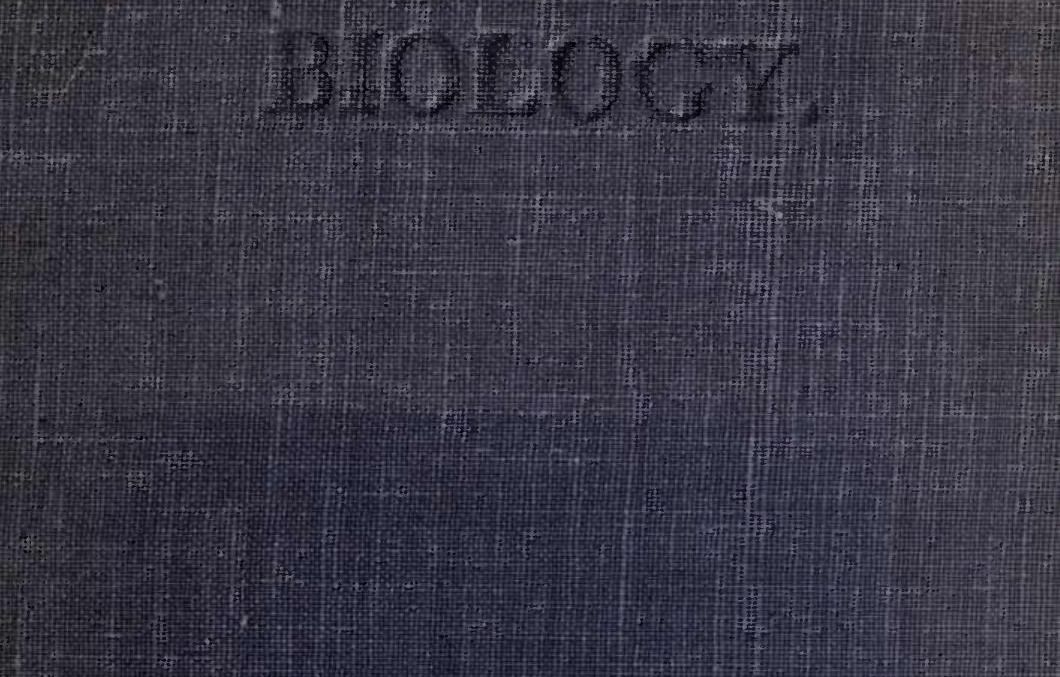

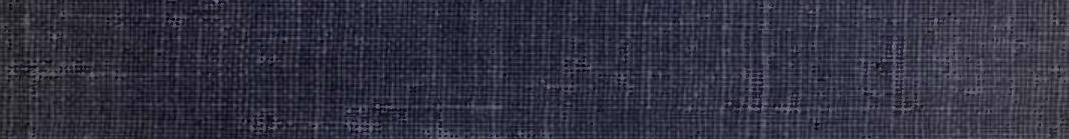

1.

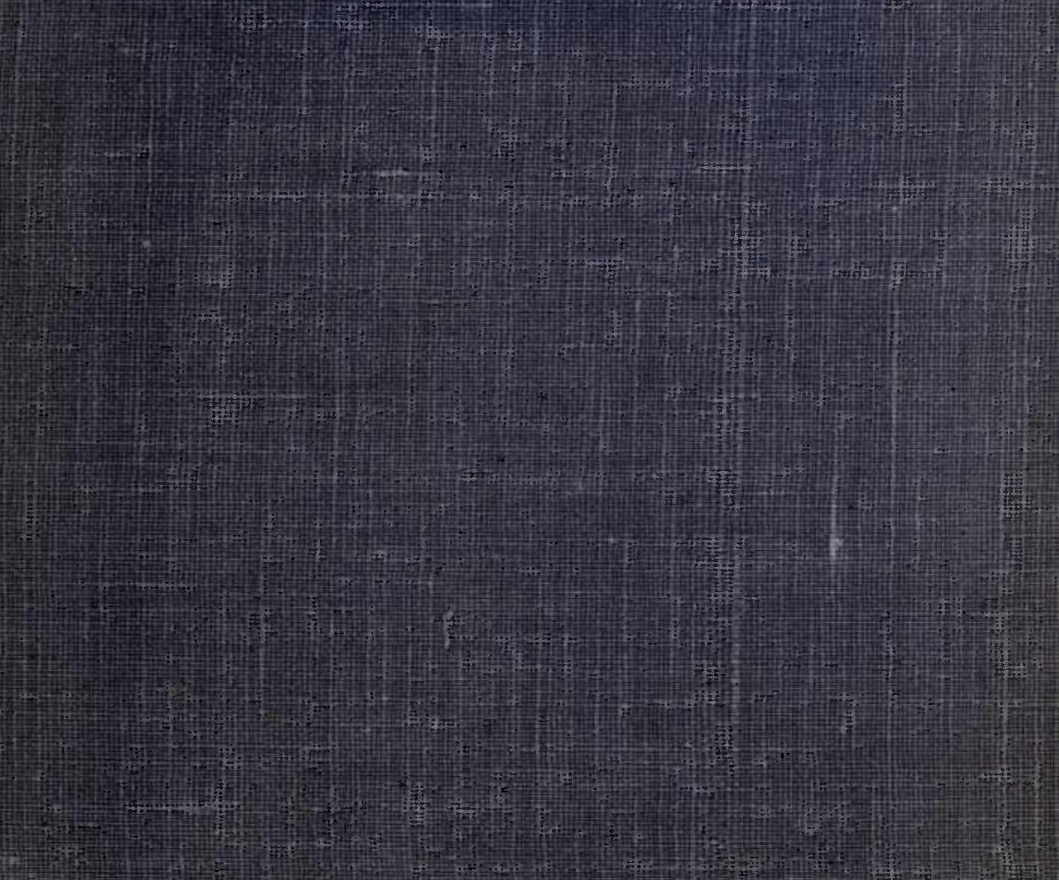

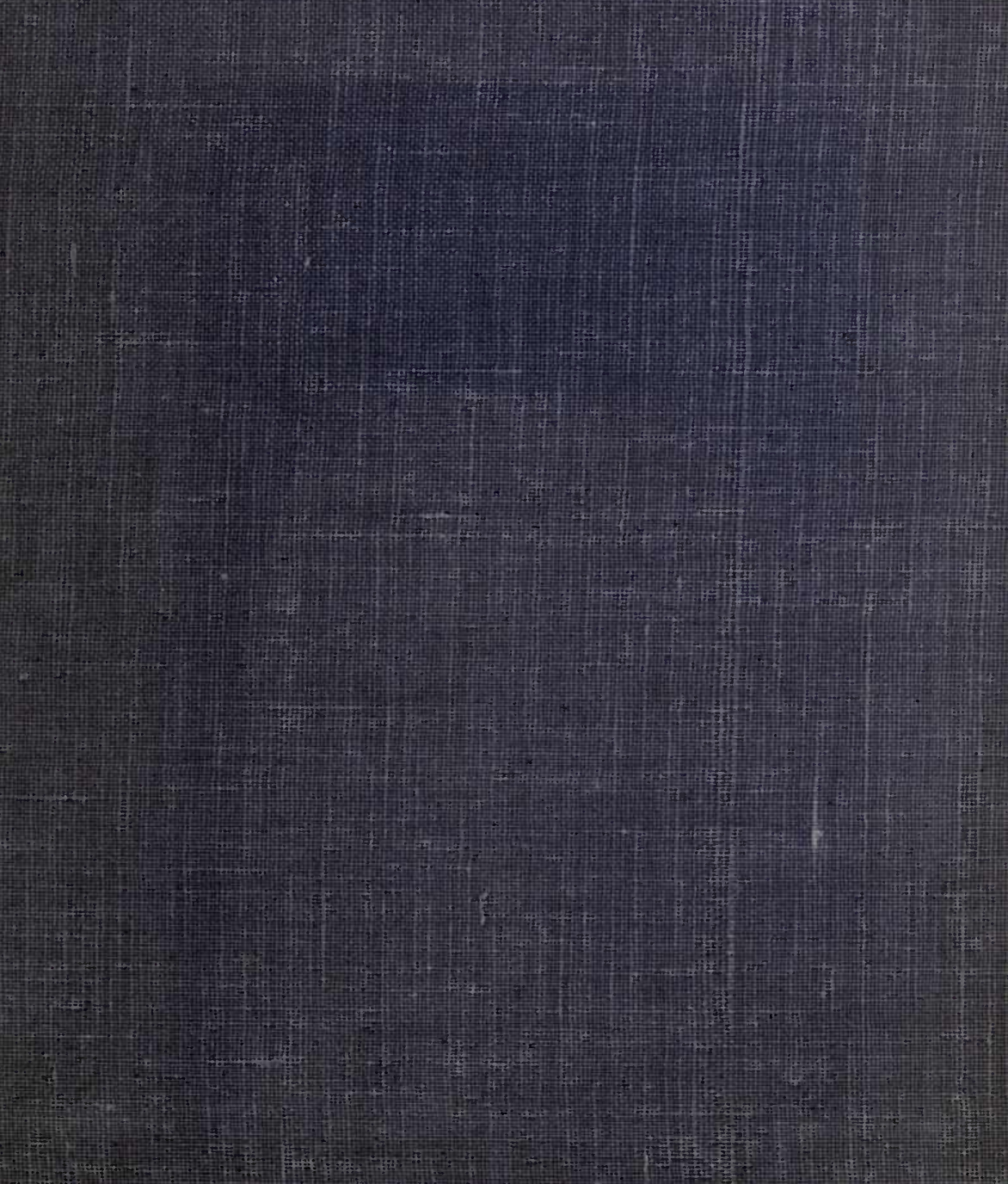




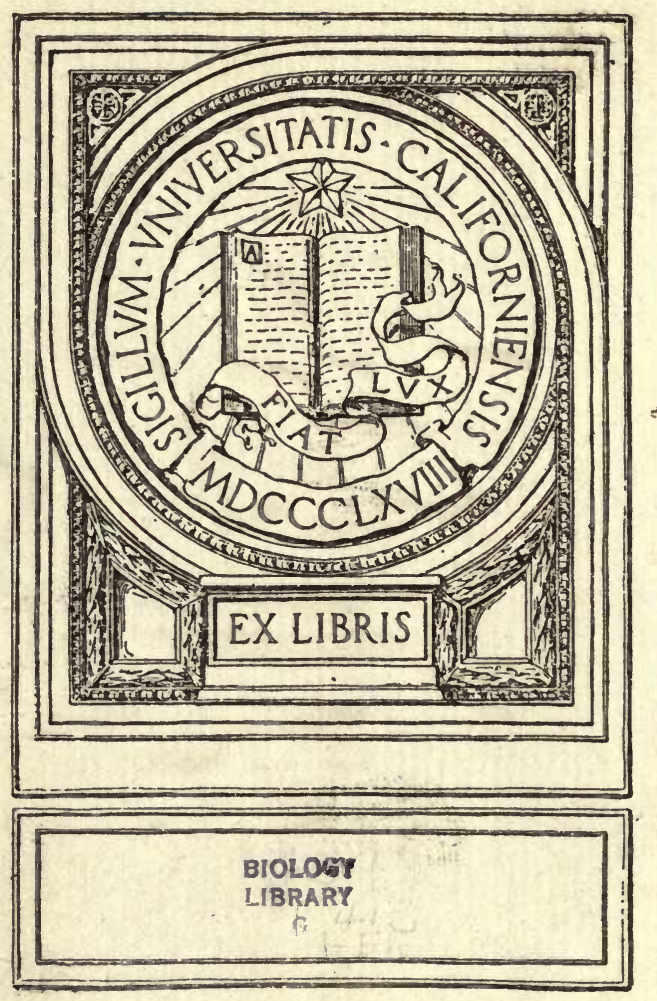






\section{Lectures on Biology}

BY

DR. CURT THESING

TRANSLATED FROM THE SECOND EDITION BY

W. R. BOELTER

WITH THE ORIGINAL COLOURED AND OTHER ILLUSTRATIONS

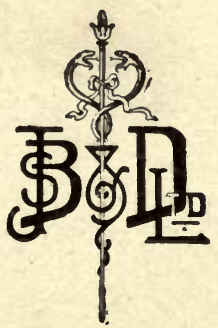

Tolloon

JOHN BALE, SONS \& DANIELSSON, LTD.

OXFORD HOUSE

83-91, GREAT TITCHFIELD STREET, OXFORD STREET, W. 
$\because$
$\therefore$ 


\section{PREFACE.}

THIs book consists of Lectures which were given by me during the winter terms of 1905 to 1907 at the Humboldt Academy and the Urania in Berlin.

My object in delivering them was to show that it is no longer possible, having regard to the advances of modern research, to find complete satisfaction in being an out-and-out believer in the Darwinian or Lamarckian or any other theory.

Each of these doctrines has rendered important service in promoting our knowledge, but the marks of their limitations have . of recent years become increasingly distinct.

The factors which the different doctrines assume to be at work in the genesis and evolution of the organic world are, however, not exclusive, for the Theory of Selection, the Doctrine of Adaptation and of Use and Non-use, and finally de Vries' Theory of Mutations, offer each for a certain section of organic evolution a sufficient and satisfactory explanation.

That, on the other hand, a vast field of vital processes remains still hidden and unexplained only dogmatic prejudice will venture to deny.

If I have succeeded in conveying to a wider circle this conception of conflicting theories, and if I have further succeeded in showing that "incomprehensible" does not mean "impossible to comprehend," my object in publishing these Lectures in book form has been attained. 


\section{ERRATA.}

Page 6, line 21 from top, for " animals" read "mammals."

, 9,20, , , " "but rather" read " as."

, 58, , 9, , , "(Triebewegung)" read "(Triebbewegung)."

,, 136, lines 7 and 10 for " ues centrale" read "os centrale."

, 138, line 14 from top, for " princates" read "primates."

, $169, \quad 9$, , , , " "trees " read "tree," and line 20 for " if " read " is."

, 178 ", 1, read "use and natural selection."

, 181 , 5 from top, insert after " Aid " " - a factor."

,, 293, lines 14 and 15 from bottom are transposed. 


\section{CONTENTS.}

\section{CHAPTER I.}

From Thales to, Lamarck

Ca PAge

CHAPTER II.

$\begin{array}{lllllllll}\text { Phenomena and Conditions of Life } & \ldots & \ldots & \ldots & \ldots & \ldots & 27\end{array}$

CHAPTER III.

$\begin{array}{llllllllll}\text { The Forces in the Organism } & \ldots & \ldots & \ldots & \ldots & \ldots & \ldots & 50\end{array}$

CHAPTER IV.

The Building-stones of the Organic World

CHAPTER V.

$\begin{array}{llllllllll}\text { The ORigin of } \operatorname{Life} & \ldots & \ldots & \ldots & \ldots & \ldots & \ldots & \ldots & \ldots & 85\end{array}$

CHAPTER VI.

$\begin{array}{llllllllll}\text { The Evolution Theory } & \ldots & \ldots & \ldots & \ldots & \ldots & \ldots & \ldots & 103\end{array}$

CHAPTER VII.

$\begin{array}{lllllllll}\text { The Factors of Evolution } & \ldots & \ldots & \ldots & \ldots & \ldots & \ldots & \ldots & 140\end{array}$

CHAPTER VIII.

$\begin{array}{llllllllll}\text { The Conservation of Life } & \ldots & \ldots & \ldots & \ldots & \ldots & \ldots & \ldots & 211\end{array}$

CHAPTER IX.

Reproduction and Hereptity $\quad \ldots \quad$. 


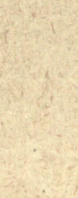

eforis 


\section{LIST OF ILLUSTRATIONS.}

FIG. 1.-The Lancelet (Branchiostoma lanceolatum) $\quad \ldots \quad \ldots . \quad \ldots \quad 13$

Fig. 2.-Haddock (Gadus aglefinus) ; and Tub-fishes (Trigla hirundo)... 15

Frg. 3. -The African Mud-jumper (Periophthalmus koelreuteri)... $\quad \ldots \quad 18$

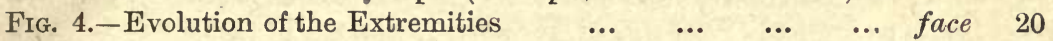

FIG. 5.-Skeletons of the Anterior Extremities of various Vertebrates ... 21

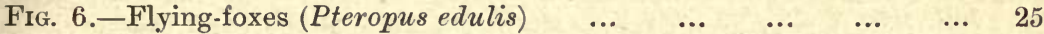

FIG. 7.-Skeleton of the Anterior Extremities of the Bat and the Flying

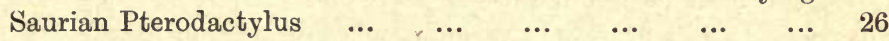

FIG. 8.-Amoba limax at different Temperatures $\quad \ldots \quad \ldots \quad \ldots \quad \ldots \quad \ldots \quad 32$

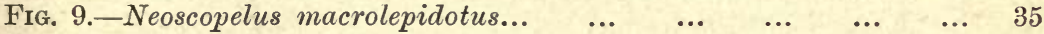

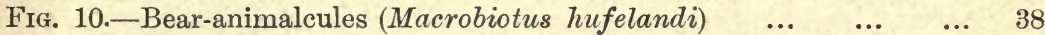

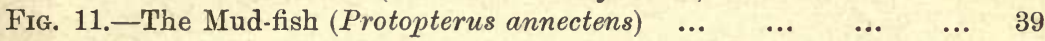

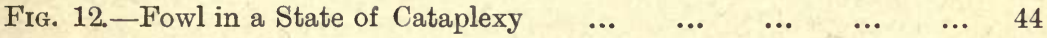

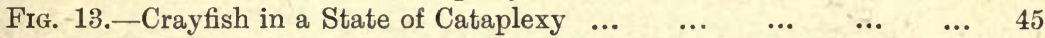

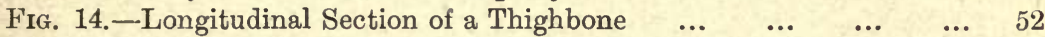

FIG. 15.-Struggle of the Germ-cells in the Male Glands of a Cuttle-fish (Rossia macrosoma)

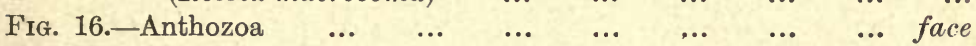

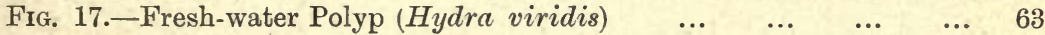

FIG. 18.-Symbiosis of Sea-anemone and Unicellular Algæ $\quad \ldots \quad \ldots 4$

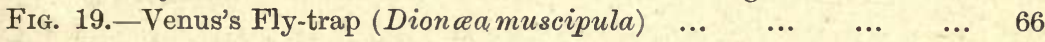

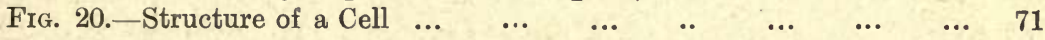

Frg. 21.-Leucocytes of the Frog devouring a Bacillus $\quad \ldots \quad \ldots \quad \ldots \quad \ldots 73$

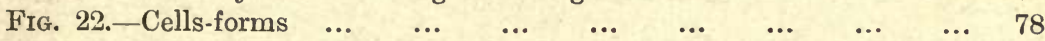

$\begin{array}{llllllllll}\text { FIG. 23.-Mitosis } & \ldots & \ldots & \ldots & \ldots & \ldots & \ldots & \ldots & \text { face } & 80\end{array}$

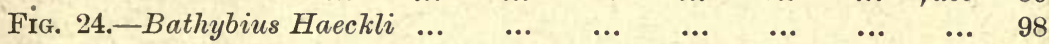

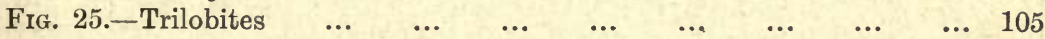

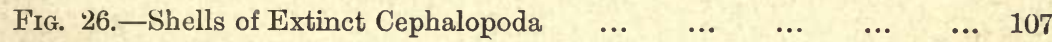

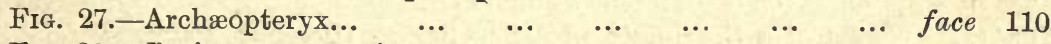

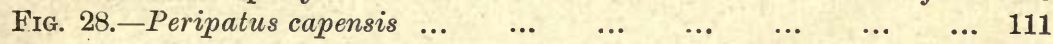

Fig. 29. -Development of the Foot of the Horse $\quad \ldots \quad \ldots \quad \ldots \quad \ldots \quad \ldots \quad 113$

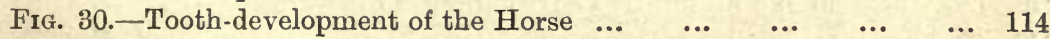

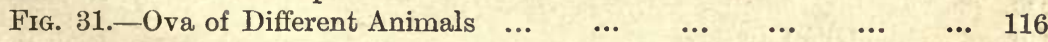

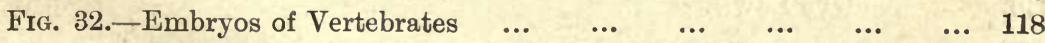

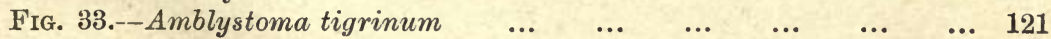

FIG. 34.- Shifting of the Eyes during the Development of a Young

$\begin{array}{llllllllll}\text { Flat-fish } \quad \ldots & \ldots & \ldots & \ldots & \ldots & \ldots & \ldots & \ldots & 123\end{array}$

FIG. 35. - The Common Rorqual (Balanoptera musculus) $\quad \ldots . \quad \ldots \quad 124$

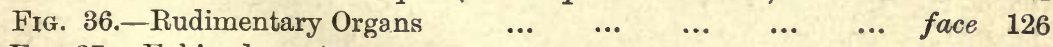

$\begin{array}{llllllllll}\text { FIG. 37.-Echinodermata } & \ldots & \ldots & \ldots & \ldots & \ldots & \ldots & , & & \ldots\end{array}$

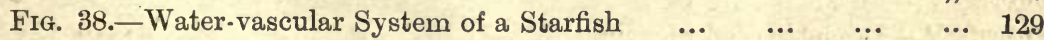

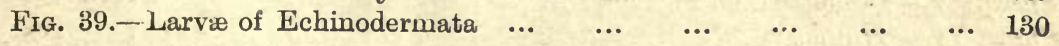


FIG. 40.-Fornaria-larva of a Marine-worm (Balanoglossus)

FIg. 41.-Larval Form a Crinoid

Fig. 42.-Trochophora Larva of Polygordius, a Marine Annelid ... $\quad$... 132

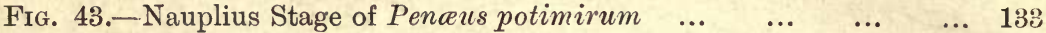

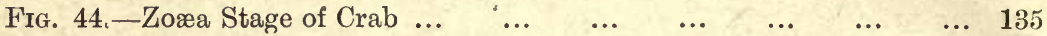

FIG. 45.-Life-history of the Liver-fluke (Fasciola [Distomum] hepatica) 154

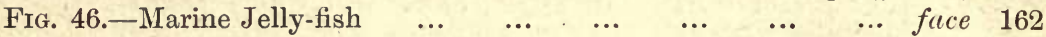

Fig. 47.-Colour-adaptation and Mimicry $\quad \ldots \quad$..

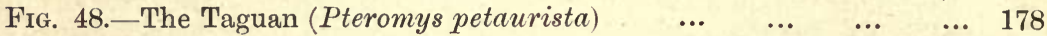

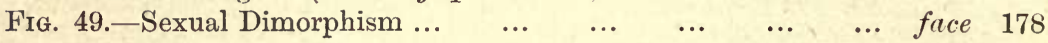

FIG. 50.- Influence of Temperature during the Pupa Stage upon Colour

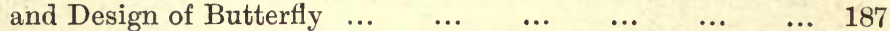

Fig. 51.-Amœba proteus in various Stages of Motion $\quad \ldots \quad$... $\quad \ldots \quad 213$

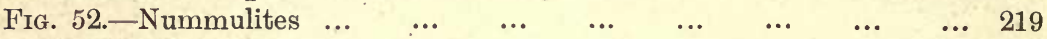

Fig. 53.-A Micro-aquarium $\begin{array}{llllllllll} & \ldots & \ldots & \ldots & \ldots & \ldots & \ldots & \ldots & 220\end{array}$

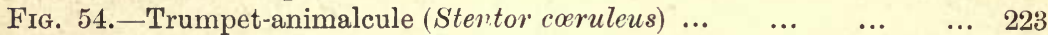

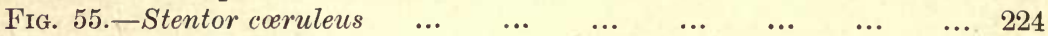

Fig. 56.-Conjugation of Paramæcium in Six Stages $\quad \ldots \quad \ldots \quad \ldots \quad \ldots 227$

FIG. 57.-Life-cycle of the Malaria Parasite of Man $\quad \ldots \quad \ldots \quad \ldots \quad \ldots 235$

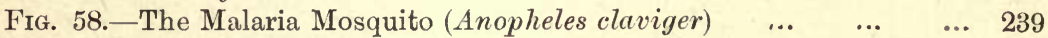

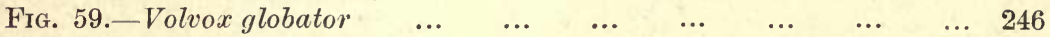

Fig. 60.-Green Fresh-water Polyp (Hydra viridis) $\quad \ldots \quad \ldots \quad \ldots \quad$.. 256

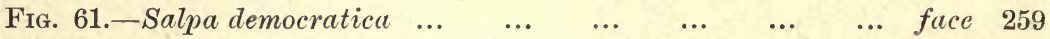

Fig. 62.-Development of Aurelia aurita $\quad \ldots \quad$...

FIG. 63.-Caterpillar covered with Cocoons of Microgaster glomeratus... 272

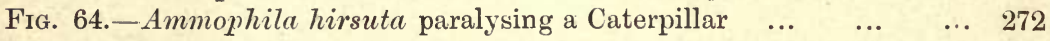

FIG. 65.-(1) Rhynchites populi, with Leaf-roll. (2) Leaf-rolls of

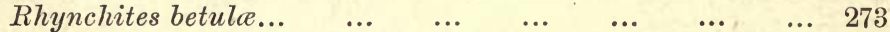

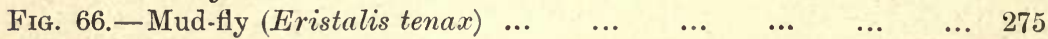

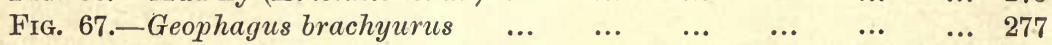

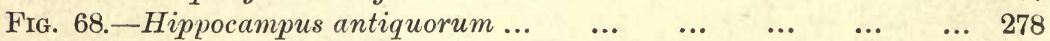

FIg. 69.-Brazilian Frog (Pipa americana), with young $\ldots . \quad \ldots \quad \ldots \quad \ldots 280$

Fig. 70.-Spermatozoa of Different Animals $\ldots \quad \ldots \quad \ldots \quad \ldots \quad$... face 283

Frg. 71.-Change of a Spermatid in a Scuttle-fish (Octopus Defilippi)

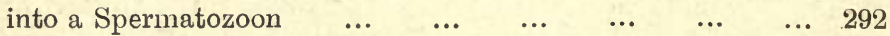

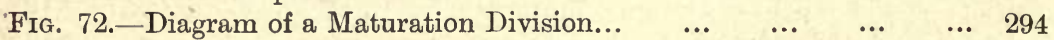

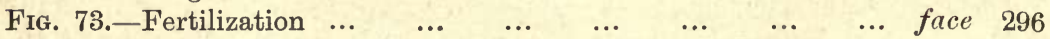

Fig. 74.-Mendel's Law... $\quad \ldots \quad$...

\section{COLOURED PLATES.}

Plate I.-Animal Life in the Antarctic ... $\quad . . . \quad$... to face page 32

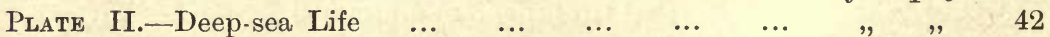

Plate III.--Reptiles of the Triassic and Jurassic Periods $\quad, \quad, \quad, \quad 108$

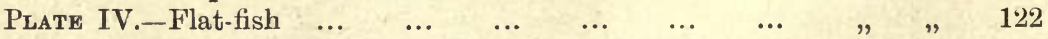

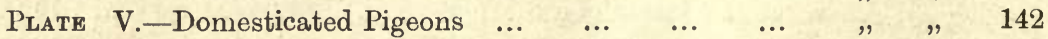

$\begin{array}{llllllllll}\text { Plate VI.-Symbiosis } & \ldots & \ldots & \ldots & \ldots & \ldots & \ldots & \ldots & , & ,\end{array}$ 


\title{
LECTURES ON BIOLOGY.
}

\author{
CHAPTER I. \\ FROM THALES TO LAMARCK.
}

Two characteristics are ineradicably fixed in the human mind : the desire for action, and the thirst for knowledge. We see their origin in the infant when in the first awakening of consciousness it longingly puts forth its tiny hands. The play of the child is but the consciousness of its desire to be busy. Play to the child means living. In play it forgets itself and its bodily wants: a day of enforced idleness will harm it more than a day without food.

When, later, the growing child breaks up its playthings, we observe in that action the awakening of the desire for knowledge. It is no longer content with the bare fact that its doll squeaks when it is squeezed; it wants to know how the doll looks inside, why it squeaks. Destructiveness and inquisitiveness are to the child as yet identical. In the act of destruction reveals itself the desire to analyse, to dissect a phenomenon into its elements, to fathom the cause of things.

As in the early life of the individual, so we perceive in the history of the nations and of mankind the need to trace each phenomenon to a cause-in other words, we observe the conscious pursuit of knowledge. It is true that, as with the child, so with primitive man, the impulse is as yet not clearly perceived; but it exists, nevertheless, no matter how far we may go back in the history of primitive man. Like the child 
questioning persistently because it wants to know, so savage man asks after the Why of all things. Why does the sun rise morning after morning? Why does the sun set in the evening behind the mountains in the distant horizon? Why is there sickness, why death? Why is one year healthy and fruitful, why does the next bring famine and epidemics?

But the greatest question of all that have agitated the mind of man is that of his own place in Nature, of his origin, and of the future of his soul after death. Unable to find a satisfying answer to his yearning, he created gods in his own image, regarding them as the cause of all that is, to whom the world and he owed their existence, and into whose presence his soul could fly when death had claimed him.

As man is, so is his god; the degree of man's knowledge determines the perfection of his deity. The gods of the savage and barbarous tribes, even those of the Greeks and Romans, are endowed with every human passion and weakness, and it is not until the Jewish-Christian period that we find a god who rises to the purity of a perfect being. All that man has perceived to be high and noble: mercifulness, love, righteousness, wisdom, truth, and goodness, he attributes to his deity. 'First, man unconsciously creates god in his image,' says Feuerbach in a brilliant paraphrase, 'then this god consciously creates man in his image.'

In this dark yearning after knowledge and truth, in this eternal desire of the human mind to find an answer to the innumerable questions with which he is confronted on all sides, and a solution of the great riddle of his existence and life, we find the origin of all religion. But there we find also the beginning of science, for science, too, searches after a cause for each phenomenon, and after the final cause of all phenomena. Thus religion and science have the same aim though they approach it by different roads : to find the cause of all causes.

Why is it, we may ask, that in spite of like objects and like aims there exists between them a growing abyss? Why do science and religion oppose each other in bitter strife? As both arise from the same desire, why do they not help each other? Why did the Church in the dark Middle Ages put to the stake or sword men who had found and proclaimed the truth? To-day, when manners are milder, the stake and sword 
are replaced by harsh and bitter words which the protagonists in both camps hurl at each other unsparingly.

The cause of this deadly enmity lies deep down in the nature of both schools of thought. For whilst religion-that is, religious dogma-represents the 'origin of all that is' as something absolute, unalterable, and visits with severe punishment any enquiry after that which lies beyond, science is ever conscious, or should be, that each hypothesis promulgated, each law formulated, are but steps in the pursuit of knowledge, the aim of which lies, an eternal task, in the infinite. 'There is no finality to our pursuit of the knowledge of life, and though we may now and then attempt to cast a balance, we know that even the best which we are able to give can but be a step to the better.' These words, which form the introduction to the Lectures on the Evolution Theory by the great zoologist of Freiburg, August Weismann, fittingly describe not only the value of biological research, but also of all science.

It is not our object to deal with the various creation-theories contained in the mythology of the Indians, Assyrians, and other nations, nor need we refer to the biblical story of the creation of the world and man, for on the one hand it is familiar to all, and on the other of no value for the advancement of scientific knowledge. We may therefore at once direct our attention to the classic period of the Ionic Natural Philosophers.

At the head of the Greek philosophy, and, indeed, as the first Greek philosopher, is usually mentioned Thales of Miletus who was counted one of the Seven Wise Men. In his teachings we find, for the first time, an attempt to establish a uniform principle of all phenomena, a universal theory of reality. Thales declares that water is the original principle from which all proceeds; his successors gradually establish the Infinite, the Fire, the Air, and the Atoms as fundamental principles. These are according to modern conceptions crude and primitive theories, but they are nevertheless the first attempts to comprehend the reality scientifically.

There will be no time in this lecture to deal with every phase of this period of more than 2,000 years, nor shall we be able to deal, except in the briefest manner, with the most important epochs and the men to whom biology owes its 
greatest advancement. The object of this lecture is not to give a complete record but rather to present briefly the gradual rise of the natural sciences, the first dawn of the evolution theory; afterwards, the rapid decay of science, and finally, its brilliant development during the eighteenth century.

If one looks back upon the history of natural sciences in the Middle Ages and modern times, their rapid rise, in particular that of the descriptive branches, above all of zoology and botany, seems almost inconceivable. On one side we see the grossest superstition, or, at the best, defective and inaccurate knowledge; on the other, an almost inexhaustible wealth of facts and accepted principles. One may indeed regard with pride the results of the untiring labour of the two preceding centuries.

According to Ben Akiba there is nothing new under the sun. Looking backwards from the ignorance and suspicion of the Middle Ages, the loftiness of Greek civilization, evidenced by the high state of their knowledge of nature, seems equally incomprehensible; and it is still more difficult to understand that such great wealth of knowledge as was stored in the mind of an Aristotle should pass from the memory of man, almost without leaving a trace behind.

Anaximander, a contemporary, disciple, and countryman of Thales, already taught the gradual natural evolution and change of the Universe and the organisms. He perceives the original principle in the 'Apeiron,' the Infinite. It has no origin and no end, changing only its forms. He conceived that from this unlimited original matter there proceeded by spontaneous division the warm and the cold. From these was formed the moist, and out of it, through drying, the earth, the air, and an all-surrounding fireball which finally burst and gave rise to the sun and the other heavenly bodies. The influence of the sunrays developed out of the primordial mud the first degree of organic life, certain vesicular formations which gradually developed into fish-like animals. In proportion as the drying process went on, some of the fishes left the moist element and under the influence of changed external conditions and a new mode of life changed into the various species of land animals. Finally the species man naturally evolved from animal ancestors. 'But whence all beings have sprung thence they must return, as a penance for 
the injustice of their existence, in the order of time.' Thus worlds follow worlds in a never-ending cycle.

It is remarkable to encounter thus early a theory of the mechanical creation of the organic world, and a hypothesis of a natural evolution. A philosopher of the fifth century B.c., Empedocles of Acragas, equally famous by his teachings as by his death which he sought and found in the crater of Etna, does not only take his stand on the theory of descent but sounds also the first distinct note of the Darwinian Theory of the Survival of the Fittest. These doctrines are, indeed, as yet intermixed with many crude and phantastic conceptions, but their appearance is all the more surprising when one considers the very small store of information in natural history which was then available.

According to Empedocles the origin of all things lies in the four elements of the ancients: water, fire, air and earth. In the beginning of time all four elements rested with one another, unseparated and unmixed; completely beld together in the form of a self-contained sphere by the union of love, or as we should say to-day, by the force of attraction. But hatred found an entrance, and with it came separation which led to the foundation of the world and all organisms. Through this eternal strife between love and hatred, and the consequent perpetual mingling and separating of the four elements, there gradually arose on the earth organic life. First the plants sprouted from the lap of the maternal earth, then came the animals. But according to Empedocles only single organs developed in the beginning, legs without bodies, noses and eyes without faces, heads without trunks, and so forth. At first different organs became united by chance, thus originating chiefly awful monstrosities unfit to live and doomed to death as soon as they had begun to exist. But as like attracts like and repels unlike, here and there certain creatures originated whose organs fitted and complemented each other. Thus organisms were formed which were fit to live, and if the fitness had been complete capable of reproducing their kind and transmitting their own qualities to their descendants.

However extravagant and wild these ideas may at the first glance appear, they contain a profound thought: the mechanical origin of the fittest in nature and the survival of the fittest forms. It is the same thought which 2,000 years after arose to 
new life with Darwin and, cleansed of all dross of mysticism, opened to research undreamt-of paths.

The zenith of natural philosophy in classic time is reached with the age of Aristotle. Posterity has justly bestowed upon this great man the name of Father of Natural Sciences. In hin we do not only find embodied the sum-total of the knowledge of his time, but there are also numerous branches of knowledge which he vastly enriched. It was he who first attempted a classification of the animal kingdom according to the degree of relationship. The boldness of this undertaking will be better understood when we call to mind the fact that Aristotle knew only some 500 different species, whilst we know to-day between 300,000 to 400,000 . Yet so clearly saw this master-mind in spite of this difficulty that the Aristotelian division has in its main points been retained up to the present day.

Aristotle was aided by a surprising store of detailed information, much of which was re-discovered during the last century by the great naturalist of Berlin, Johannes Müller. Thus Aristotle knew, to mention only two instances, that many sharks are viviparous, and that whales and dolphins are not fishes but animals. That such a mind should ponder on the origin of the organic world and endeavour to find a natural explanation cannot therefore excite surprise.

With the death of the great Stagirite natural sciences rapidly decay; instead of scientific research we find the grossest superstition. Even Pliny the Elder who perished during an eruption of Vesuvius A.D. 79 whilst commanding the Roman fleet at Misenum is at the best only a very untrustworthy compiler. If of anyone, it may be said of him that

Viele Dinge wusste er freilich,

Doch alle wusste er schlecht.

Pliny piled up whatever he found, without troubling himself about the scientific value of his 'finds.' There is nothing of the Aristotelian mind in him, and his division of the natural world into 'land, water and air animals' is no more scientific than if he had divided it, as Weismann tersely remarks, according to the alphabet.

The decay of sciences proceeded apace, first under the Roman 
emperors, still more during the Middle Ages. Even Galen, the founder of scientific physiology, who lived in the third century, was unable to arrest it. Nothing will better indicate the low ebb at which science had arrived than a few quotations from the so-called 'Physiologus,' which was during the Middle Ages the most celebrated and best known work on natural history. It was written about the third century and has been translated into almost every civilized language. It draws its facts of natural history mainly from the Bible and various Roman and Greek authors. Altogether forty-one animals are mentioned in this book, and of each we hear remarkable news. Thus it is said of the panther: ' $\mathrm{He}$ is multi-coloured, after a meal he sleeps three days, wakes up roaring and emits such pleasant odours that all animals go to him.' Of the lion we are told that 'after his birth he is dead three days, but on the third day his father comes, blows into his face and thus awakens him into life.' Similar stories are told of the hyena, the pelican, the phœnix, the unicorn, the siren and other 'species of the animal kingdom.'

Blind belief in dogma and all theories, encouraged by a fanatic priesthood, is the sign of that period. Only with the founder of astronomy, Nicolas Copernicus, with Galilei and his undying 'E pur si muove' flung from his dungeon out into the world, with Kepler's discovery of the course of the planets, and finally with Newton's demonstration of the Law of Gravitation, the blind belief in authorities breaks down, the tyranny of the Church collapses and we see the dawn of the new age of scientific research.

Prominent among the leaders in this new era is Cuvier, famous alike as the founder of comparative anatomy and as the bitterest and most powerful opponent of the Doctrine of Descent.

His chief merit is that he, for the first time, examined the different species from the standpoint of comparative anatomy and thus built up a system which has remained the basis of modern classification. He formed the following four groups:-
(1) Vertebrata.
(2) Articulata.
(3) Mollusca.
(4) Radiata. 
According to Cuvier, each of these groups is entirely independent of all others, forms a distinct type, and is in no wise correlated with another type. Moreover, not only are these main groups entirely distinct, but each individual species again represents a definite invariable unit. This constancy and immutability of the species is the corner-stone of Cuvier's theory. To this he clung with incredible tenacity up to the hour of his death, defending it in the face of all facts and with the most patent sophisms. When, for instance, palæontology had proved that in past periods animal forms had existed widely differing from the present species, Cuvier established his Doctrine of Catastrophism, in order to preserve his dogma of the immutability of the species. According to this theory each period of the earth's history had been distinguished by a fauna and flora peculiar to itself. Enormous revolutions of the surface of the earth, floods, earthquakes, volcanic eruptions, and glacial floods had then at one blow wiped out the entire plant and animal world, and thus terminated one period. On the new virgin soil a new fauna and flora had been created, by a divine act, thus possessing no connection either with the organisms in the preceding or in the subsequent earth periods.

During Cuvier's time the great naturalist, Jean Baptiste Lamarck, and with him, Geoffroy St.-Hilaire, strongly opposed this dogma of the fixity of the species, but could not avail against the almost unlimited authority of Cuvier who had then been raised to the peerage of France. On the contrary, the theory of descent suffered complete defeat in the debate between Cuvier and St.-Hilaire before the French Academy in 1830, and consequently disappeared for years from the scientific agenda. How deeply this controversy affected the leading spirits of those restless times is shown by a dialogue between Goethe, then a very old man, and his friend Soret. It was on August 2, 1830 ; the news of the expulsion of Charles $\mathrm{X}$. from the throne of France had just reached Germany and all the world was talking about it. On the morning of this day Soret had called on Goethe who greeted him with these words: 'Ah! what do you think of this great event? The volcano is in full eruption, everything is aflame, and it is no longer possible to deal with the matter behind locked doors.' 
'It is indeed a terrible thing,' replied Soret; 'but what else could you expect, with such conditions and such a Cabinet, than the expulsion of the Royal Family?'

'You seem to misunderstand me,' said Goethe, 'I am not thinking of those people; I am speaking of the rupture which has taken place before the French Academy between Cuvier and St.-Hilaire! This matter is of the utmost importance to science and you can have no idea of my feelings at these news. We have now in St.-Hilaire a powerful ally.'

It was only some time after Cuvier's death, when K. E. A. Hoff and the great English geologist Charles Lyell had proved irrefutably that the evolution of the earth had taken place in obedience to the same laws that still govern it and that the various periods of the earth's history were connected by gradual stages, that the theory of catastrophism fell, and with it the hypothesis of the invariability of the species.

That even such a clear thinker as Cuvier came to assume the coming, at certain periods, of enormous catastrophes which annihilated all life was probably not so much due to the influence of traditions-Indian, Arabic, Biblical-but rather to the fact that at that time it was general greatly to underestimate the periods which had elapsed since the earth had become a unit in the universe. To compress within a few thousand years the evolution of what Nature had used millions of years to achieve meant of necessity the assumption of all-destroying catastrophes. Indeed, the history of the world would be nothing but a bloodstained record of murder and destruction if we were to assume that it had covered but a few decades.

The first man who clearly enunciated the idea of evolution is the poet and naturalist Dr. Erasmus Darwin, the grandfather of Charles Darwin. The works of this man, in particular his 'Zoonomia, or The Laws of Organic Life' (1794), contain by the side of numerous profound observations, often almost of a prophetic character, many childlike conceptions even of the simplest processes of life. On one side we find the free outlook of the far-seeing naturalist; on the other, the shortsightedness of teleological dogma. But that fact cannot lessen his merits, for Erasmus Darwin was the first who taught the variability of the species and the adaptation of an organ to its 
use, though what the forces were that affected variation and adaptation was a question to which he was unable to give a satisfactory answer.

In Germany it was above all Goethe who advocated the theory of descent in numerous important works, but the most prominent predecessor of the great Darwin is doubtless Jean Baptiste Lamarck. In vain Lamarck waited during a long laborious life, the last seventeen years of which were spent in total blindness, for the recognition of his contemporaries. His numerous writings remained either unknown or were misunderstood. Only now, when almost a century has passed since his death, it seems as if his work shall at last receive its due share of praise, for during recent years a strong tendency has shown itself not only among botanists but also zoologists to turn back to the teachings of this great, unhappy man.

According to Lamarck, the simplest organisms originated by spontaneous generation (Urzeugung) out of inorganic matter when the earth had 'sufficiently cooled to permit of the existence of life. In the course of vast periods the living species of plants and animals developed out of these lowest forms by slow and gradual changes. The last and highest development was man. In contrast to modern biogenetic conceptions which represent the evolution of the organic world in the shape of a tree of many branches, Lainarck conceived the animal world as a uniform series of stages ascending from the unicellular protozoon to man.

Lamarck perceived the cause of the changes in the organic world and the origin of new species to be that with the progressing cooling of the earth's crust the conditions of life for both plants and animals underwent a continuous if gradual change. If the organisms had not possessed the faculty of adapting themselves to the new conditions it would have been inevitable that after the lapse of thousands or millions of years forms that once were well adapted would cease to be so and perish. But we can clearly see that the animals of the present day are as well adapted to present conditions as were the animals of earlier periods to the conditions then existing. It is, therefore, indubitable that hand in hand with the changes of the earth there must have gone on a continuous change in the organisms. Hence the question arises, 
Which forces have been responsible for this development? To this Lamarck replies, that 'it is the change of function of the individual organs which brings about this seeming miracle.'

We may at any time observe in our own body the effects of the use or disuse of an organ. Systematic exercise produces better and stronger muscles; the fibres not only increase in volume, but are also able to act and contract more quickly. Conversely, want of action produces slackness and degeneration of the fibres. A person whom illness or accident keeps to the bed and from all action knows that after a few weeks the legs will be so weakened as scarcely to be able to support the weight of the body. Like a child, the patient must perforce once more strengthen the muscles by gradual exercises, that is, he must again learn to walk. Supposing that it were possible to transmit to the next generation the primary constituents (Anlagen) of such characters newly acquired by exercise-(in this case the invigoration or degeneration of the muscle fibres)-and that this and following generations would act similarly, organisms might eventually be found which would be widely differentiated from their original parents ; for it is obvious that a radical modification of the muscles would in one way or another influence also the development of the other parts of the body.

Who does not know Lamarck's instance of the giraffe? In earlier times giraffes were probably, like other ruminants, of normal build, nor differing greatly in the neck from their congeners. The severe competition arising on the ordinary grazing grounds from the presence of other herbivorous animals forced the giraffes to profit by their comparative height and seek nourishment on the branches of trees. The continual stretching and exercising of the neck caused a richer circulation, a better feeding of the muscles and other tissues, and a slight addition to its length which was transmitted to the offspring. Continued in subsequent generations, this process gradually produced in the course of many thousands of years an abnormally long neck such as we see to-day.-The web between the toes of the waterfowl is said to have been caused through the habit of these birds of seeking their prey on the water and of spreading out their toes as widely as possible in order to swim better. The continued stimulus acting upon the skin between the toes gradually effected 
a stronger development of these parts. Similarly one might explain with more or less probability of truth the origin of most organs.

On the other hand, as we have already seen, disuse leads to reversion and degeneration of the affected parts. If an organ was deprived of work owing to altered conditions of life, gradual degeneration followed of necessity. Thanks to the conservatism of heredity, the organs may for some time be retained in the successors, but finally the last vestige is lost. The numerous rudimentary organs form ample illustrations of this phenomenon. We need only mention, among many other similar instances, the loss of eyes in many cave-animals, the degenerate eyes of the mole, the breast glands of male animals, and the muscle of the human ear, whereby it can be pulled upwards or twitched forward or backward.

In all nature there is hardly another case in which one may so clearly see the adaptation of an organ to its functions and the improving or degenerating influence of use and disuse as in the development of the arms and legs of the vertebrates. However different the extremities of vertebrates may externally appear, it is possible to demonstrate, if not in the adult, at any rate in the embryonic stage, that on the whole they possess similar bones and are thus proved to be of common origin.

Fishes represent the lowest stage of the vertebrates. In these denizens of the water the extremities have developed into instruments of rowing, or fins. These are either paired or unpaired. We know that the unpaired extremities are derived from a continuous dorsal fringe which commences immediately behind the head and continues to the anus. In earliest youth this uniform fringe divides itself in most fishes into dorsal and anal firs, and the great locomotor fin of the tail. In a similar manner the paired fins originate from two at first continuous lateral folds which divide later into the two anterior pectoral and ventral fins. Soon afterwards solid skeleton parts appear in the skin folds, giving to the whole the necessary stability. Of these two kinds of extremities, the unpaired are phylogenetically the earlier, for we find them already in the lower types of fishes, the primitive fish Branchiostoma (Amphioxus), and in the Lampreys (Cyclostoma), which are as yet without paired fins. Being 
specially adapted to a life in the water, the unpaired fins disappear with the departure from the moist element. In the amphibians we find in the larval stage a complete rudimentary fringe, though without skeleton parts; but it becomes, as a rule, degenerate in the adult stage. The paired extremities, however,

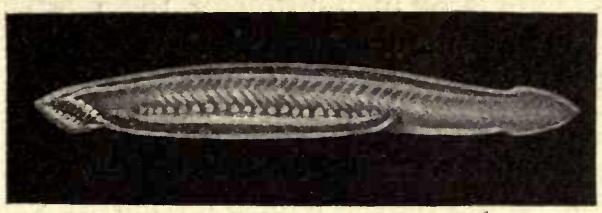

Fig. 1. The LANCelet (Branchiostoma lanceolatum). reach in the higher vertebrates a more and more perfect development, for they help the animals to add to the conquest of the water that of the land and the air. They are therefore of special interest from the standpoint of comparative anatomy.

All extremities of the higher vertebrates, however widely they may differ in construction, may be traced back biogenetically to the so-called Ichthyopterygium, as we see it in the fins of the lower shark-like fishes. Unequal growth of the single skeleton parts and a considerable reduction in their numbers transformed the Ichthyopterygium into the five-fingered extremity characteristic of all vertebrates from the amphibians upwards. But yet another change is demanded by the changed conditions of life. As long as the extremities served as oars or rudders it was an advantage that they developed into broad 'blades,' acting with their entire surface. But on land the arms and legs are to act as levers in carrying and moving the body. To do this, the extremities must divide into small parts united together and movable one upon the other; in other words, they must form joints.

Everyone who has seen the skeleton of a bird will no doubt object that in the denizen of the air nothing is to be seen of a five-fingered extremity, and in most cases indeed nothing but one finger. This objection is true, but it is obviously the different function which causes the deviation from the rule and produces frequently in the skeletons of adult animals considerable reversion or a combination of the single skeleton parts, thus making the affected parts better adapted to their special work. 
But it can be proved biogenetically and phylogenetically that most of these animals have descended from five-fingered ancestors, or at any rate from such as had more than one finger. At an early stage of incubation of the embryo of the penguin we can readily distinguish three well-developed fingers and the rudiments (Anlagen) of a fourth. The Archæopteryx of the Jurassic period when fully developed had three movable fingers. Let us endeavour to make clear the radical influence of changed conditions of life by the consideration of a few prominent instances.

If we observe a fish in its natural element and notice how perfectly adapted are its fins to life and movement in the water we would hardly think it possible that these specially developed organs could be used for other than swimming actions. Yet we know fishes who, with the aid of their fins, are not only able to run, climb, and jump, but even to traverse not inconsiderable distances flying. It was, of course, necessary for the fins of these privileged animals to undergo extensive changes to qualify them for their different functions.

In fishmongers' shops one may now and then see a very quaint and awkward-looking fish, the Sapphirine Gurnard or Tub-fish (Trigla hirundo). It is from 40 to $60 \mathrm{~cm}$. long and a well-known inhabitant of the North Sea. It has a rounded body and a thick, square head, protected by an armour of rough skin. When touched it makes a peculiar noise which reminds one of the creaking of a badly-oiled door, by rubbing together its hard gill-covers. We know that the fins of fishes are supported by cartilaginous rays which are generally firmly joined to the fin. But in the gurnard the strongly developed pectoral fins have in front three free, fin-like rays which seem fixed to the body after the manner of joints. In swimming, these free fin-rays are folded backwards against the body, but on the sea-floor the fish uses them skilfully as legs and is thus able to walk. It is a curious sight to see it deliberately putting one ray before the other and drawing its plump body slowly along the sea-floor when in search of its prey.

A near relative of the gurnard is the Flying Gurnard (Dactylopterus volitans), abundant in the Mediterranean, and a representative of the flying-fishes. The structure of this fish reminds one strongly of his cousin of the North, but is much smaller, at 
the most $40 \mathrm{~cm}$. It is distinguished from its relative by the extraordinary development of its pectoral fins, the posterior section of which broadens into a fan and is supported by cartilaginous fin-rays which are nearly $30 \mathrm{~cm}$. long. Every passenger through the Mediterranean may in clear weather sometimes see great shoals of these fishes suddenly emerge from the water, rise to a height of about $18 \mathrm{ft}$. and traverse fairly quickly a

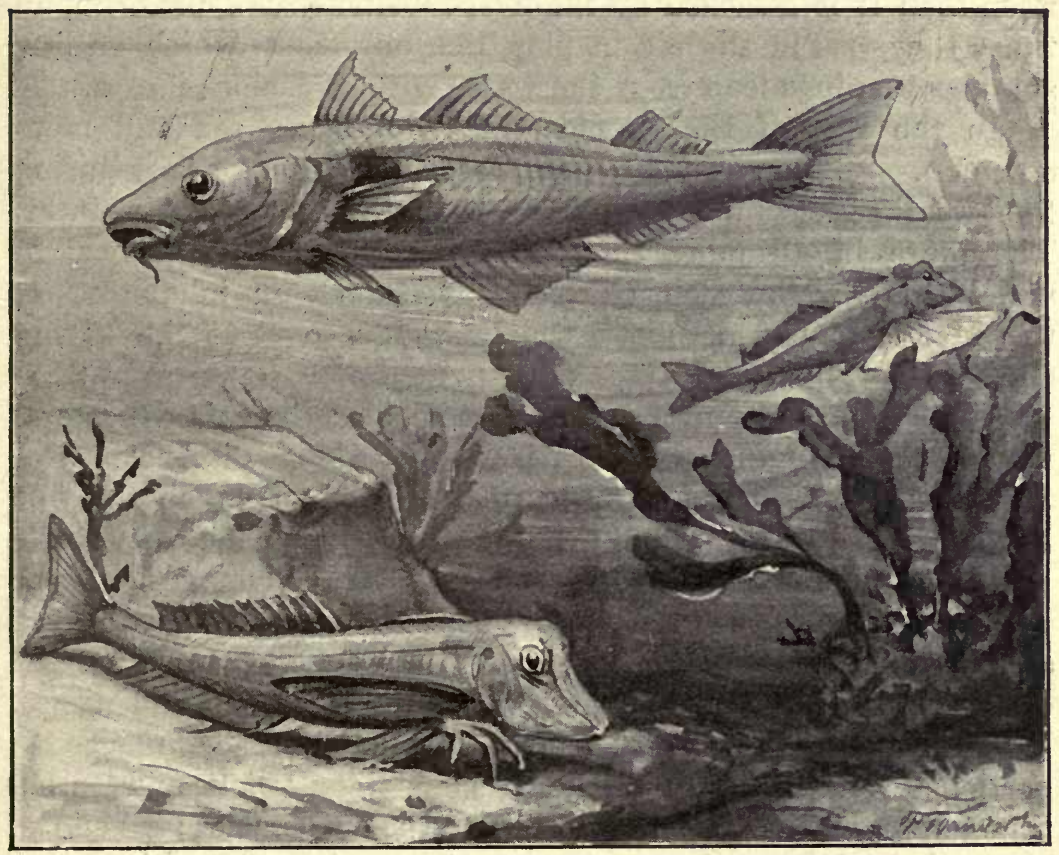

FIG. 2.-ABOVE, HADDOCK (Gadus aglefinus); BELOW, TUB-FISHES (Trigla hirundo).

distance of more than $300 \mathrm{ft}$. They then descend and disappear under the water to rise again in another place. Sometimes these fishes miss their direction and fall on the deck of the ship which happens to cross their course.

This curious mode of locomotion cannot be properly described as flying, for it is rather a rising and gliding like that of a paper kite, By means of a vigorous jump these fishes propel themselves 
with widely extended breast-fins from the water and are carried in a direction opposite to that of the wind and kept suspended for some distance by the current which is caught under the wing-like fins. It is also probable that they assist their flight by an up-and-down movement of the breast-fins. It seems that the flying-fishes use their ability chiefly for escaping from their numerous enemies among the fishes of prey, often only to fare worse. For no sooner has a swarm of gurnards risen than it is attacked by the ever-ravenous sea-gulls. Sometimes they rise in the air in play, like our trout, which on fine summer evenings leap from the water with audacious jumps.

In the seas of the Tropics the flying-fishes are still more common. As soon as a ship has passed the Equator it is during fine weather accompanied by shoals of these curious creatures. There are in all more than fifty species of flying-fishes, of which the Swallow-fish (Exocotus volitans), an inhabitant of the Mediterranean, is most widely known next to the Flying Gurnard.

Whilst the extremities, and in particular the paired pectoral fins, of the flying-fishes have developed to large dimensions, we know on the other hand numerous species in which the fins have degenerated into small insignificant forms which are of little use in locomotion. All such fishes-I will only mention eels, murence, ribbon-fishes and needle-fishes-are distinguished by a striking elongation of the body-axis. This phenomenon may be easily explained, with Lamarck, as a result of use and disuse. When body and tail are growing longer they commence to participate in the locomotion by snake-like twists and turns, thus tending more and more to relieve the extremities; when the elongation of the axis becomes extreme, the extremities cease to be active and consequently become degenerate.

All that is said here of the fishes is equally applicable to the higher classes of the vertebrates. The short, tailless frogs have very strong legs which are equally well adapted to swimming, jumping, and climbing. In the long-tailed salamanders and newts the extremities are less strongly developed; in the Amphiuma (A. means), and still more so in the snake-like Cæcilians (Gymnophiona), they become rudimentary or disappear altogether. The same observation applies to the reptiles. Tortoises, lizards, 
and crocodiles possess very strongly developed front and hind legs. In the long thin Skinks (Chalcides) only four feet-stumps are developed which have no functions. Reversion has gone still further in the blind-worms, which are even without external vestiges of extremities, whilst finally in the snakes not only the extremities themselves, but also their connections with the vertebral column, shoulder, and pelvic girdle have been lost. Only the pythons and boas still possess rudiments (Anlagen) of a pelvis and the hind extremities; these are, however, no longer preserved as means of locomotion, but for purposes of copulation. It is interesting to note that in the snakes the want of extremities is not only balanced by the enormous elongation of the body, but also of the ribs, which, having become free and movable, are made to assist in locomotion. This law does not even fail in the highest vertebrates, the mammals, for it is well known that, for instance, monkeys with very long tails possess proportionally weaker arms and legs than the short-tailed or tailless baboons and anthropoid apes.

But let us return to the fishes. One of the quaintest among them, a veritable clown among fishes, is the African Mudjumper (Periophthalmus koelreuteri) (fig. 3). It is found all along the West Coast of Africa, but varies according to its habitat in colour and marking. It is usually greyish-green or brown, with silver spots and stripes. The fins are blue, the very prominent eyes red. Its length does not exceed $15 \mathrm{~cm}$. Its life-habits are more those of a newt or frog than of a fish, for it feels both at home in the water and out of it. At ebbtide one may see them in tribes of dozens, lying on the wet sand in numerous parts of the West African coast, or moving along by means of curious short jumps. Because of their temporary sojourn on the land the pectoral fins of the Mud-jumper have assumed a leg-like appearance and are used even for climbing, for they may frequently be seen ascending the air-roots of mangrove trees on which they hold their siesta. Still more wonderful than the change of their fins into instruments of walking and climbing is the adaptation of their respiratory organs to a life in the air. We know how sensitive most fishes are to want of water and how soon they perish when removed from their proper element. But the Mud-jumper is able to loaf about on the land 
for whole half-days, hunting its prey and moving as freely as in the water. In order to be able to do so it carries under the tightly closed gill-covers a good supply of water so that even on dry land the gills are kept continually moist.

This adaptation to a terrestrial life has made still further progress in the Lung-fishes (Dipnoi), and particularly in an Australian species, the Barramunda (Neoceratodus forsteri).

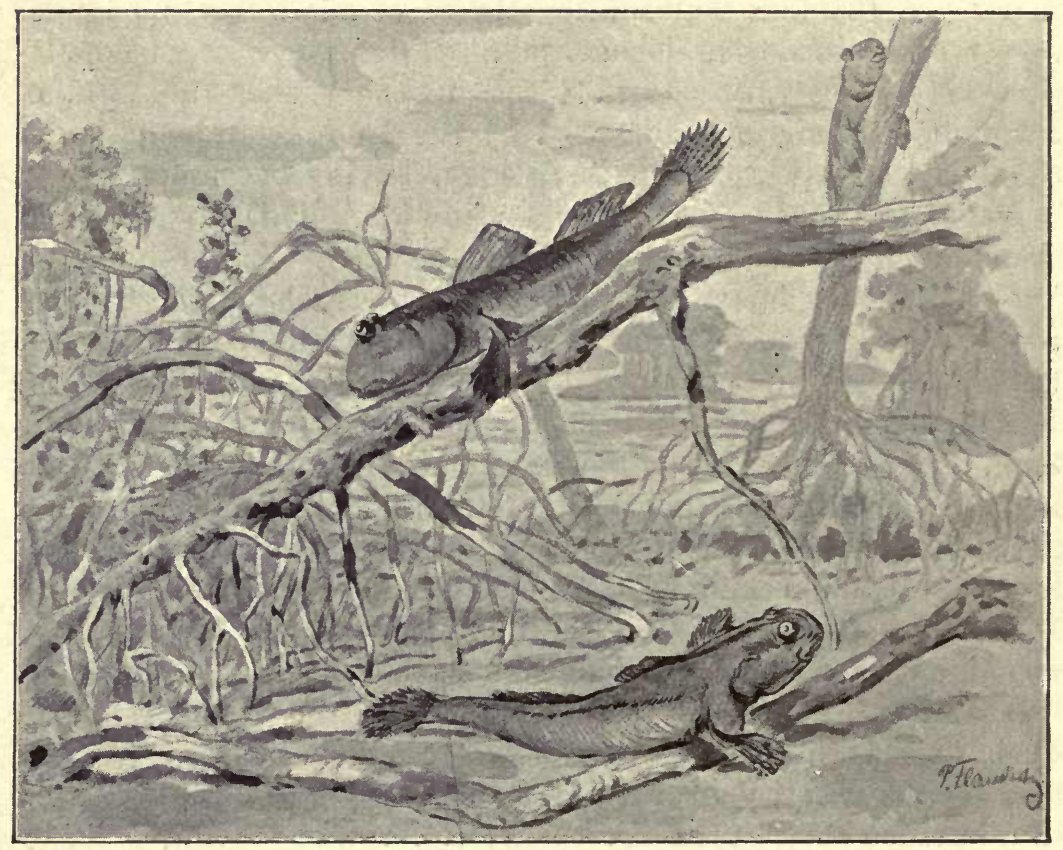

FIG. 3.-THE AFRICAN MUD-JUMPER (Periophthalmus koelreuteri).

These fishes do not only possess the normal respiratory apparatus, the gills, but their swim-bladders, too, have been transformed into lungs, so that they are able to breathe both in the water and on land. The two pairs of extremities of Neoceratodus are uniformly developed, one might almost say, like legs, but they are probably too weak to support the big body on land, for the Barramunda reaches a length of $6 \mathrm{ft}$. It is therefore question- 
able whether this fish leaves the water voluntarily for any length of time.

Evolution having reached this point, the transition to a 'life ashore,' to amphibious animals, was not difficult. But with a sojourn on dry land the extremities are confronted with the solution of fresh and more difficult tasks, and thus we see in the higher vertebrates, especially in the typical terrestrial animals, the Reptiles, Birds, and Mammals, that these organs assume a marvellous wealth of forms and functions.

It will only be possible for us to consider one order, the lizards. The typical lizards are running animals, possessing five-fingered extremities, but exhibiting great differences according to their different modes of life. The South American Teju (Tupinambis teguixin), a large scaly lizard, about $3 \mathrm{ft}$. long, has assumed the habit of digging, under the roots of trees, deep caves, into which it may retire in a moment of danger. Consequently its front legs are strongly developed and furnished with sharp claws, thus forming powerful digging-tools. In species that live in deserts we frequently find that the toes have been broadened into a shovel-like shape and furnished with lateral fringes so that the animals are able to run even over the finest sand without danger of sinking into it. Numerous species of Geckos, among them the common Wall Gecko (Tarentola mauritanica), an inhabitant of the Mediterranean countries, are furnished with adhesive digits which enable them to run about on steep, smooth walls, and even on the ceiling. In many districts in Africa Geckos are kept as domestic animals, for as soon as night has come they emerge from their hiding-places to prey on spiders, flies, mosquitoes, and other pests of man. But in spite of their usefulness they are persecuted by man in the most unreasonable manner.

Typical inhabitants of trees are the Chameleontidæ, famous for their striking colour-changes and fantastic shapes. Their extremities, too, have become transformed corresponding to their mode of life, for in them the toes have grown together in twos and threes into uniform plates (laminæ) which stand opposite to each other, as the parts of pincers. They possess, therefore, an ideal gripping and climbing organ by means of which they are able to walk safely even on thin branches. 
Let us now turn to the birds and observe the flight of the sea-gull. It skims over the surface of the water, now rises into the air, circles round and round, or hangs in mid-air, motionless. Suddenly it darts down, quick as lightning, to capture its prey with unerring aim. All is lightness, elegance, power. Let us see how the development of its extremities will demonstrate the fitness of its organization and the transforming influence of function.

The first feature noticed in a comparison of the wing of a bird with the forefoot, for instance, of a salamander or lizard is the great elongation of the various skeleton-parts. Everything seems to have been arranged with a view to obtaining a long and strong lever to which to join the feathers. The more skilful the flier, the more pronounced the lengthening of the bones of the arm and hand. We also find that not only the carpal and metacarpal bones but also those of the fingers have decreased in number and that some have become fused together into a uniform bone. This fusion caused a considerable lengthening of the skeleton of the hand without affecting its firmness. The skeleton of the Archæopteryx shows that this bird was a very awkward flyer, making only a faint attempt to conquer the air ; it also proves its descent from lizard-like ancestors, for its hand had three well developed free-maving fingers armed with sharp claws which probably enabled it to climb rocks and trees.

In spite of the wonderful adaptation of the wing of birds to flying, numerous birds have felt themselves induced to return to terra firma and to depend more upon their legs. The cause of this action is obscure. But we find that a more frequent use and consequently stronger development of the hind-organs entail a degeneration of the wings and a corresponding decrease in the power to fly. There is a complete chain, perfect in every link, which leads from the Gallinaceous Birds to the Ostriches and from them to the Kiwis. Whilst the Pteroclidæ (Sand-Grouse) are still able to fly well and move chiefly by means of their wings, the Phasianidæ (game-birds, fowls, \&c.) occupy a half-way position, for they use fore and hind extremities in about equal proportions. The Tinamous (Tinamus), finally, greatly dislike flying, and in case of danger prefer to trust to their legs. These different degrees in the use of wings are indicated externally by their decreasing size. 


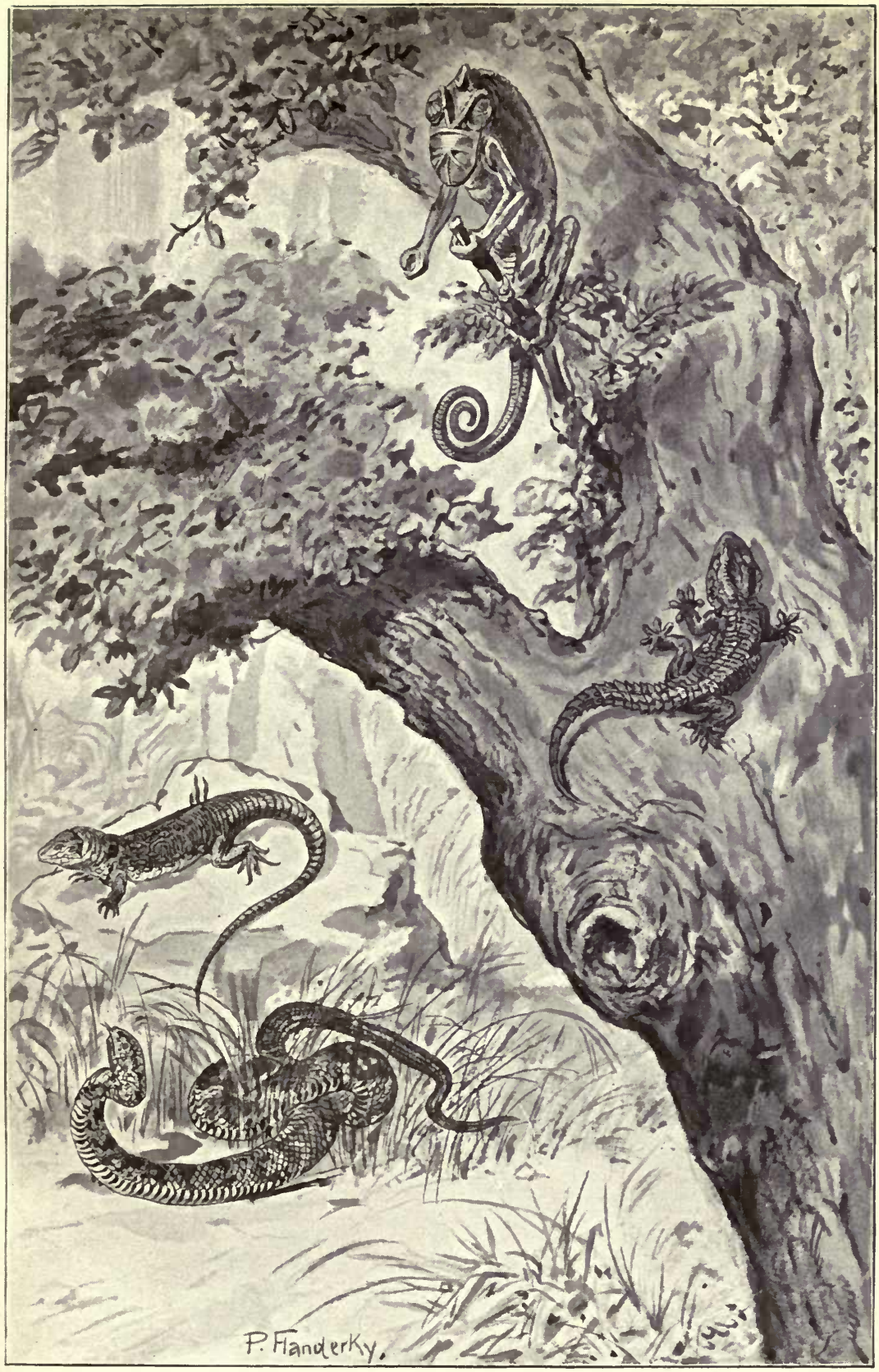

FIG. 4.-THE DEVELOPMENT OF THE EXTREMities. CHAMELEON (Chamøleon vulgaris); WALL-GECKO (Tarentola mauritanica); EXED LIZARD (Lacertaocellata), AND Zamenis gemonensis viridiflavus. 



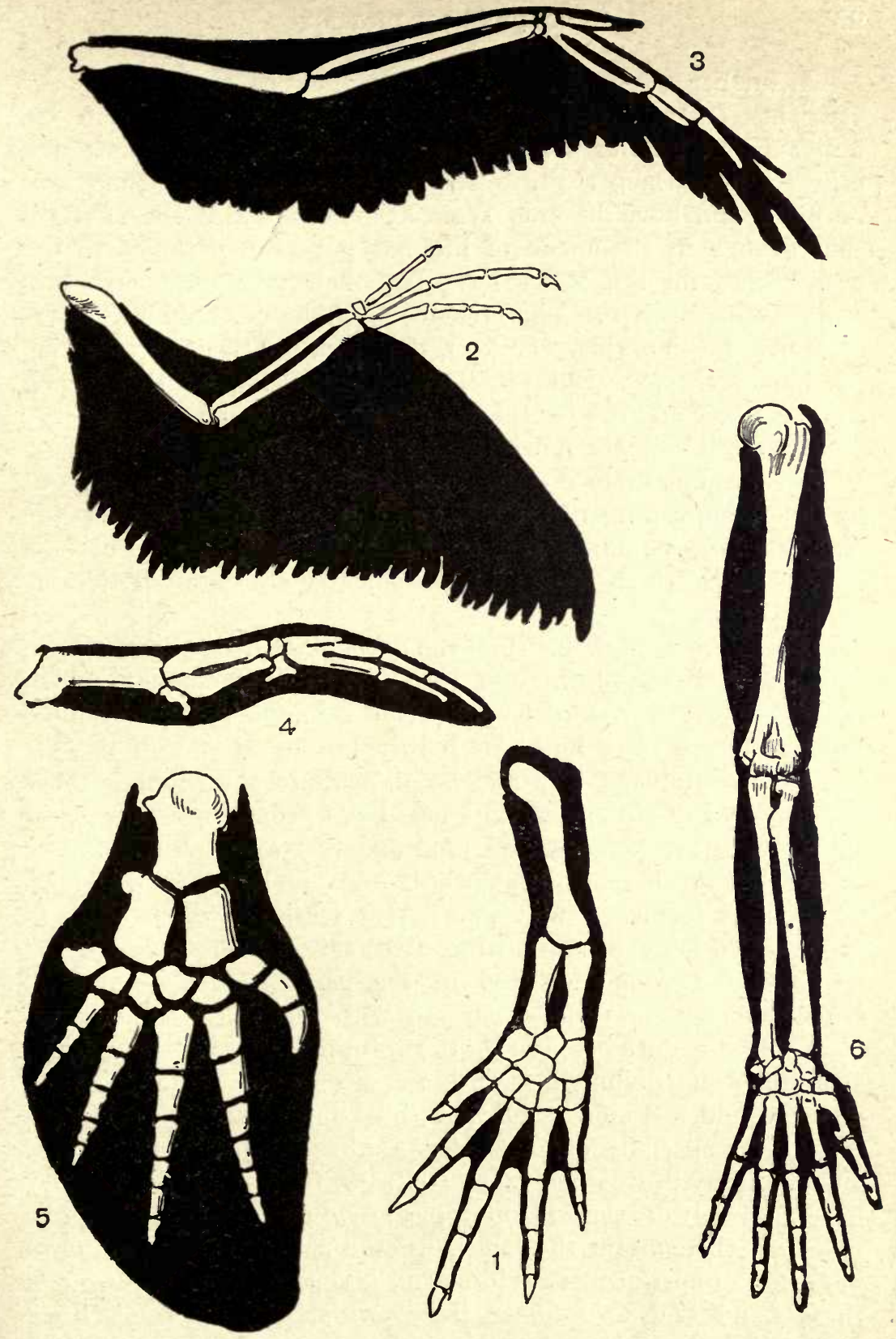

FIG. 5.- SKELETONS OF THE ANTERIOR EXTREMITIES OF VARIOUS VERTEBRATES.

(1) Diagram of a typical five-fingered extremity ; (2) extinct bird Archaopteryx ;

(3) eagle; (4) penguin; (5) greenland whale; (6) man. 
A further stage of wing-degeneration is reached in the Ostriches (Struthionidæ). The skeleton-parts of the arm are still existent but far too weak to exercise their functions and raise the heavy body aloft. Ostriches have entirely lost the power of flight and have become typical runners. But the effect of this change in the mode of life has not been confined to the extremities, for the bones have lost their pneumatic structure and become massive. The breastbone of the normal bird carries a strong, median ridge, or keel, the so-called 'crista,' to which are joined the powerful muscles of flying. But as the ostrich has no longer any use for the crista it has entirely disappeared.

But of all birds the Kiwis (Apterygidæ) of New Zealand supply the most remarkable instance of transformations brought about by the relinquishing of the power of flight. In these birds the feathers have come to resemble hair and the wings become mere stumps which fulfil no functions and are barely noticeable externally.

Still more remarkable than the degeneration of wings due to disuse is their tranformation into fins, a phenomenon which may be observed in the Penguins (see coloured plate). A more radical change in a bird can hardly be conceived. If it were not for the plumage it would be difficult to say whether these creatures really are birds. The legs have been shifted far back, thus giving the penguins on land an erect appearance; in the water they are extended backwards and employed as a rudder. The tail is furnished with short, stiff feathers which have to support the body in the sitting attitude. In the place of the large jointed wings we find in the penguins broad-uniform 'rowing-plates' or paddles covered with scale-like feathers.

Those who see a penguin for the first time in its watery element swimming and diving like a fish and keeping for minutes under water would feel convinced that these birds had in the beginning been specially endowed for a 'life on the ocean wave.' But anatomy proves the exact contrary, for it shows that they have gradually developed from typical flying birds : the fins of the penguin still contain the same skeleton-parts as the well-known fliers (one upper-arm, two fore-arm, and two carpal bones, and three hand and two finger bones which have become fused together). But while in these the tendency is all towards the 
lengthening of the wing, in the penguin the single bone-parts have become shorter and stronger, and flattened, in order to provide a broad 'rowing-surface.' (See fig. 5, 3 and 4.)

There are other birds which provide, as it were, the transition from the aërial to the aquatic life. The wings of the Common Guillemot (Uria troile), a bird of the Northern Seas, often found in Heligoland hatching its eggs, show a distinct shortening, the bones a broadéning. But these birds still possess well-developed wings and use them for short-distance flights. They derive, however, greater advantage from their wings on their extensive swimming tours on and under the water by using them as oars.

Another step further has been taken by the Great Auk (Alca impennis), once very common in the Northern Sea, but now almost extinct, owing to the senseless persecution of this bird by sailors. Its fish-like wings still bear feathers, but they are much too short for flight and serve now only for locomotion in the water.

The best proof for the statement that it is the function which determines the form of all organs is supplied by animals of different classes but with the same life-habits. Whales and dolphins are even to-day regarded by many as fishes, so completely has their shape been altered by a continual sojourn in the water. Their spindle-like body, the absence of hair, the strong tail terminating in a double fin, the formation of an unpaired dorsal and paired pectorals, and finally the absence of a neck make this mistake pardonable. But the zoologist knows that whales and dolphins are mammals. They are viviparous and suckle their young. They have warm blood and breathe air through lungs like other mammals. There are, however, sharp distinctions. All other mammals have two pairs of extremities, but dolphins and whales have only two pectoral fins, which may perhaps be compared to forelegs; of a second pair, however, there is no external trace. But as whales have been gradually transformed from mammals into denizens of the deep we find on examination that the breast fins, while externally resembling the unjointed fins of fishes, are internally supported by the same skeleton-part as are, for instance, the arms of man or the foreleg of a lion. (Compare fig. 5.) But in order to obtain a strong 'rowing-surface' the bones are much shortened and flattened, 
and instead of being jointed are held rigidly together by strong bands. The hind extremities, however, being relieved of their functions through the immense lengthening of the body and the formation of a fleshy tail-fin, have in most species degenerated without leaving a trace behind. Only in the Greenland Whale (Balana mysticetus) and a few others do we find hidden away in the flesh and unconnected with the vertebral column the insignificant remains of a short thigh and leg.

As Uria troile forms the transition from the air to the water, so are the seals (Pinnipedia) the transition form between land and sea. We still find in them four. strongly developed extremities which have been transformed into fins. The pectoral fins not only contain internally the complete parts of the mammalian arm, but have also five fingers which are armed with claws and firmly jointed together by exceedingly strong webs. The posterior fins, which also clearly betray their origin, are turned backwards and fulfil in swimming the function of a caudal fin: they serve as a rudder. Locomotion on land is effected chiefly by an alternate lowering and raising of the fore and hind part of the body and an eel-like bending and stretching of the whole body. The legs are only used for support in climbing inclines.

Among the many other known instances it will only be possible to mention the Mole (Talpa europœa), whose short and strong arms, combined with a hand armed with sharp shovelclaws, seem admirably adapted for digging his long subterranean runs. It is curious to observe that similar babits of life have brought about a similar development in the forelegs of an insect, the Mole-cricket (Gryllotalpa vulgaris).

The conquest by mammals of the elements became complete with their conquest of the air. The hair of mammals, as compared with feathers, does not seem adapted to flight, but Nature, never at a loss, knows how to overcome this difficulty, and thus we see bats and flying-foxes share with birds the "liberty of the air.' In the absence of feathers the skin is used for the formation of a flying-apparatus. This necessitates a radical transformation of the arm-skeleton; it is not enough that the single bones of the anterior extremities are enormously elongated, but it is also necessary to provide a strong frame on which the delicate flying-membrane may be expanded. This task is solved by a 
most remarkable elongation of the finger-joint, which is so considerable that three of the inner fingers reach a length equal to the joint length of the upper and fore arm. As the thumb has no function to fulfil in flying it remains short but develops a strong claw, by means of which the animals can climb or suspend themselves. Between the fingers of this giant hand on one side

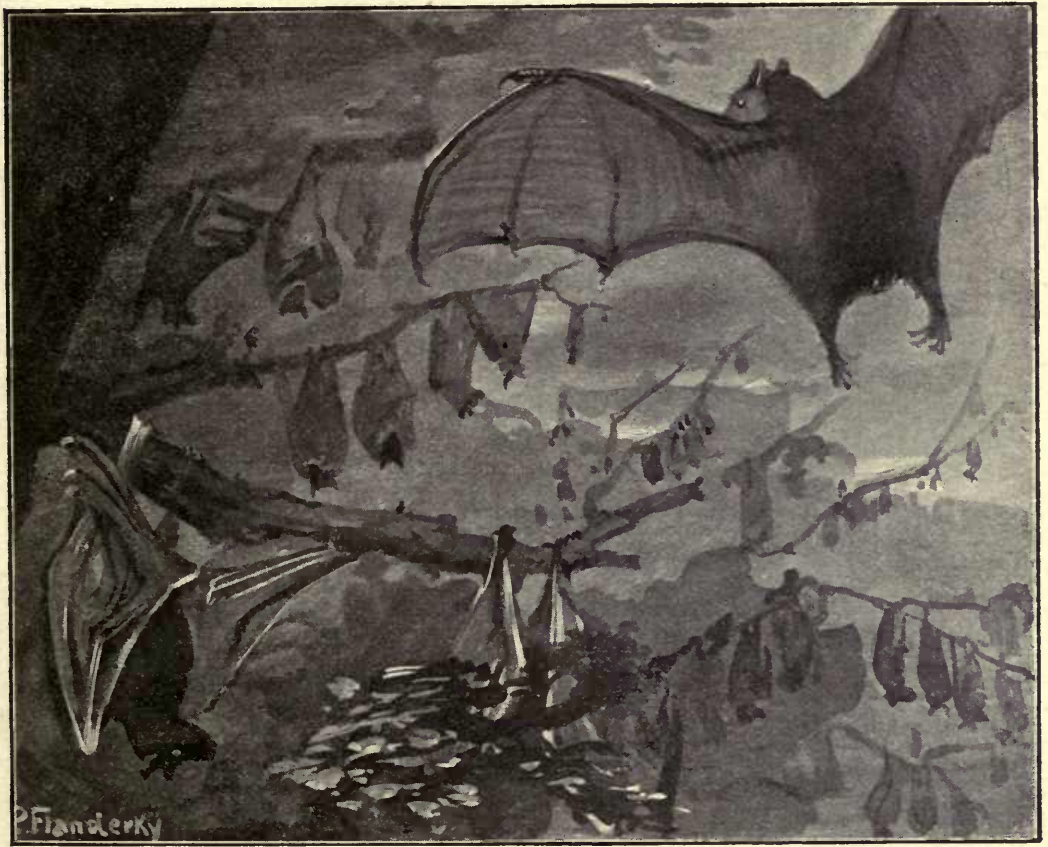

FIG. 6. - FLying-FoXes (Pteropus edulis).

and the hind extremities and the body on the other the thin skin is expanded like a parachute.

Some years ago geologists found in the upper strata of the so-called lithographic slate of Bavaria (belonging to the Jurassic Period) the fossil remains of a strange animal which was called a Pterodactylus. A layman would at the first glance have unhesitatingly declared it to be a bat, because of the enormous 
elongation of one finger, and because the wing-membrane extended between the hand and the body, exactly as in bats. But as a matter of fact these fossils are the remains of a long-extinct genus of reptiles, the Flying Saurians. Here, again, like functions have produced likeness of organs in widely differing classes of animals.

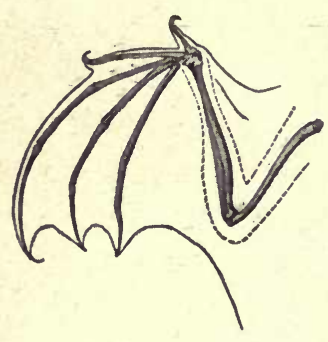

FIG. 7. - SKELETON OF THE ANTERIOR EX. TREMITIES OF THE BAT AND THE FLYING SAURIAN PTERODACTYLUS.

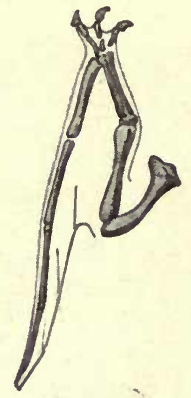

Having reviewed these facts, we can now understand why Lamarck came to proclaim his theory of evolution. The most important question which we shall have to answer before we can adopt bis views is, whether a transmission of functional increase or modification of an organ to subsequent generations is
ther we have a right to conceivable, or, in other words, whether we have a right to
assume the transmission by heredity of acquired characters. With an answer to this question Lamarck's theory stands or falls. We shall attempt to decide the important question in the seventh lecture, where we shall also see how Darwin explained the fitness of the organic world and the adaptation of animals and plants to the ruling conditions of life. 


\section{CHAPTER II.}

\section{PHENOMENA AND CONDITIONS OF LIFE.}

THE Ancients regarded motion as the most important criterion of life. 'All that moves lives.' The murmuring well, the burning fire, the rapid lightning were to them living beings. The same conception governs the untaught even to-day. We read in 'Robinson Crusoe' that Friday, the child of Nature, who has never come in contact with civilization and does not know the use of fire, explains to himself the bubbling of the boiling water by believing that it is stirred up by an animal which is hiding in the kettle.

Motion is doubtless the most prominent characteristic of living substance, and we may define life as a series of extremely complex and varied motions. But for all that the conception of motion is not identical with the conception of life nor are we able to say of any form of motion that it is specific to life, for as there are inorganic bodies the parts of which are in active motion, so there are living organisms which exhibit no trace of any perceptible movement. It often needs prolonged investigation to decide whether a certain object is dead or alive; superficial inspection frequently leads to wrong conclusions.

If we observe under the microscope a drop of human blood we perceive at first in the fluid only the red and white corpuscles. But soon numerous minute, round, pear- or star-shaped particles become visible, which dart about with a constant vibrating motion. No one would doubt that these minute motile bodies are alive, for as no external cause of their movements is perceptible we seem justified in assuming that they are actively motile. But this assumption would be wrong, for these minute bodies are nothing but the products of decomposition of the red blood corpuscles, and their motion is due to the molecular 
movement present in all fluids. We may obtain a similar effect by adding very fine particles of soot to a drop of water, when these tiny grains of soot will be observed to dance and vibrate within the field of vision as if they were alive.

That, on the other hand, rest, or the absence of perceptible motion, may make it very difficult to distinguish between life and death, has been demonstrated by the following experiment made by Verworn. If we examine under the microscope a drop of the sediment in a bottle of white Berlin beer we shall see in the fluid numerous minute globules of a pale colour, being suspended singly or in rows of twos and threes. However long we may continue our examination, these globules always remain in perfect rest, without exhibiting the least trace of movement. Similar formations, exactly alike in appearance, may be observed in milk. But whilst the latter are nothing but inanimate particles of fat, the globules in the beer are organized unicellular vegetable growths, the familiar yeast-cells which cause fermentation of the beer. Many other analogous cases might be mentioned. Even the trained microscopist frequently finds it difficult to decide whether certain minute bacilli, spirilla, or cocci occurring in preparations are bacteria or decomposition-products of the surrounding tissues. Mere appearance is not sufficient for deciding whether an organism is an animal or a plant, or for determining whether an object is animate or inanimate.

Physiology has therefore always striven to determine the difference between dead matter and an organism. But the results at which the different investigators arrived were widely divergent, according to the view-point of the investigator. While one side denies that there is anything in common between the two and will at the most admit that organisms are built up with the same chemical elements that are found in inorganic nature, the other side recognizes none of these distinctions as valid. The extreme standpoint among modern physiologists is taken by Verworn, who even refuses to accept metabolism as an exclusive characteristic of organic substance.

As long as each organism lives it performs work, and work requires force. As a steam engine can only continue to work as long as it is fed with fuel, so each organism must consume food, from the combustion of which its energy is obtained, 
unless its life-functions are to cease temporarily or permanently. Whilst the substance of the body is renewed from the food, the matter that has become decomposed and useless is voided. This continued breaking-down and building-up of organic substance is called metabolism; it is on this process that all the life phenomena of animals and plants rest, and it is therefore generally regarded as a specific function of life.

According to Verworn, however, metabolism is only a characteristic which distinguishes the living organism from the dead, but not from the inorganic substances, for it is possible to observe the same process in inorganic bodies. As an example this scientist chooses the behaviour of nitric acid in the manufacture of so-called English sulphuric acid. If we bring together nitric acid with the anhydride of sulphurous acid, the sulphurous acid takes away oxygen from the nitric acid, thus becoming sulphuric acid, while the nitric acid becomes hyponitric acid. If we now regularly admit fresh air and water, nitric acid continues to develop from the hyponitric acid, and gives off part of its oxygen to new volumes of sulphurous acid, so that the molecule of the nitric acid is continually being disintegrated by giving off oxygen, and restored by absorbing oxygen. In this manner we are able, with a definitive quantity of nitric acid, to change unlimited quantities of sulphurous acid into sulphuric acid. Verworn thinks, therefore, that the process observed here in the simplest form, that is, in a simple chemical compound, the succession of decomposition and reconstruction of the substance with taking-in and giving-off matter, corresponds in every detail to the metabolism of organism.

But it seems to me that in spite of the apparent similarity there is a fundamental difference in these two processes, for whilst in an organism metabolism proceeds automatically, it proceeds here on the supposition that the constant access of air and water is being duly regulated; in other words, it proceeds with the assistance of a rational being. As soon as this assistance fails, as soon as the supply of air and water is not so regulated as to bring the hyponitric acid in a certain manner and in certain proportions successively into contact with air, sulphurous acid and water, metabolism ceases. But it is in the spontaneity that the essence of the life-processes rests, and 
the definition of metabolism holds, therefore, still good as a function specific only to living substance.

Nevertheless, this criterion does not suffice for the strict definition of the animate and inanimate, for though real metabolism is not to be found in dead nature, we shall see later that there are nevertheless organisms in which this function is, for shorter or longer periods, absent.

We have already heard that the normal course of life depends upon the presence of certain conditions, the absence of which leads inevitably to deatb, or at least to the temporary discontinuance of the life-functions. One of these conditions is nutrition. Without nutrition there is no life. The substances which furnish the different organisms with the required force and heat and renew the substances which have been used up, are of a very varied nature; further, the substances required for the nutrition of animals are different from those required by plants. Whilst the former are only able to use complex organic compounds for building up living albumen, the food-sources of plants lie in the surrounding air, water, and the salts of the soil. But however great the wealth of such food-sources may be, the plants are unable to use them except under the influence of the sunlight. It is only with the help of the sunlight that the chlorophyll is able to decompose the carbon dioxide of the air into carbon and oxygen-the first step that must be taken in the building up of the organic compounds. And as all nutrition of animals depends finally upon this activity of the plant cell, we must see in the sun one of the fundamental conditions of life.

Next to nutrition stands respiration as a function specific to all organisms. All that lives breathes. In a room wholly devoid of air, in water wholly devoid of gas, life is impossible. But just as no particular article of nutrition can be mentioned as being of absolute necessity to all organisms, so there is no gas which is absolutely necessary to the life of all organisms. Often that which is necessary to the life of one brings death to another. Formerly it was thus believed that oxygen is needed for the growth of all organisms. This is still true of all higher plants and animals, for though plants give off oxygen during the day they absorb it again, like animals, during darkness. We know, however, thanks to Pasteur, that among the lowest known 
organisms, the bacteria, there are many for which life is only possible if free oxygen is completely excluded-indeed, they die when brought into contact with it. They are known as anaërobic bacteria. It is, however, not improbable that even anaërobic microbes use oxygen which they obtain from the various stable compounds of their nutrient media, and that only a liberal supply of free oxygen is fatal to their existence.

Another of the fundamental conditions of life is water. Whatever animal or plant we may examine, we shall always find that their cell-protoplasm contains water. Indeed, water is the chief component of all organisms. The human body contains about sixty parts of it, the tissues of the muscles from seventy-five to eighty. That many plants and parts of plants, in particular fruits, consist largely of water is well known. Many denizens of the sea, especially the jellyfishes and ctenophores, contain two parts of solid matter and ninety-eight of water. It is remarkable how under such conditions a structure can be maintained. One may frequently see on the sea-shore a large brilliantly coloured medusa, stranded high and dry, in a short time disappear before one's very eyes, leaving nothing behind but a little heap of crumpled membrane.

Warmth is another conditio sine qua non. The limits of temperature between which active life is possible are very narrow, for great heat and great cold are equally hostile to it. Though many organisms may, owing to the warmth of their bodies, exist for considerable periods in a temperature far below zero, all active life is doomed to cease as soon as the interior of the body has cooled down to the freezing-point of water, for only when water can retain its liquid form nutrition and respiration are possible. In the higher organisms life ceases in temperatures which coagulate albumen. Between these two extremes the lifefunctions of all organisms operate, though the optimum of wellbeing is, in the various species of plant or animal, subject to considerable variations of temperature.

If we observe a protozoon, the minute Amœba limax, in a temperature of $\pm 0^{\circ} \mathrm{C}$. we shall see that it rests suspended in its drop of water, contracted into a globule, devoid of any action. It is said to be in a state of 'chill-coma.' But if we now increase the temperature we observe that at $2^{\circ}$ to $5^{\circ} \mathrm{C}$. a slight 
protoplasmic motion takes place in the interior of the cell : slowly and lazily a short pseudopodium emerges here and there, though the movements are as yet so slow that they are capable of demonstration only by persistent observation. But the higher the temperature rises the more active become the functions until the maximum is reached at $26^{\circ} \mathrm{C}$. If we now continue to increase the temperature beyond that point we observe that a retrogressive process is taking place: the protoplasmic motion slows down, the pseudo-feet are retracted, the amœba gradually assumes its globular form, and when an upper limit of $35^{\circ} \mathrm{C}$. has been reached, become once more motionless; it now lies in a state of 'heat-coma.'

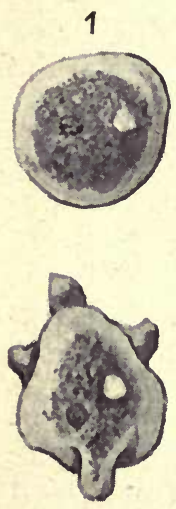

5
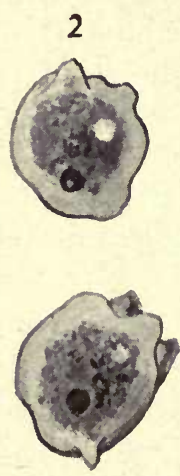

6
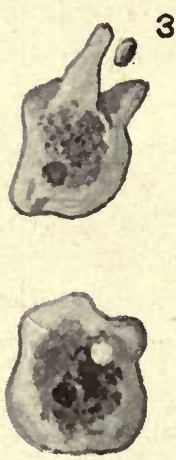

7
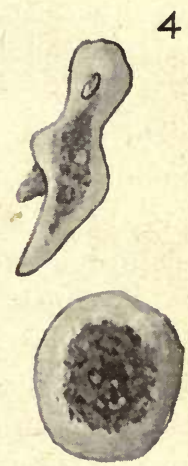

8

FIG. 8.-Amœba limax AT DIFFERENT TEMPERATURES.

(1) In a state of chill-coma at $\pm 0^{\circ} \mathrm{C}$.; $(2-8)$ the temperature is being gradually increased; $(4)+26^{\circ} \mathrm{C}$., maximum of vital activity; (8) in a state of heat-coma at $+35^{\circ} \mathrm{C}$.

Like warmth, the conditions of air and water pressure have a far-reaching influence upon the normal course of life. Here, too, there are upper and lower limits which may not be transgressed except at peril to life. Unfortunately our knowledge of the effects of increased or decreased air-pressure is as yet very primitive, but the experience gained in various balloon ascents is nevertheless of interest. It has been shown that it is impossible, at any rate for a human-being, to ascend beyond a certain 


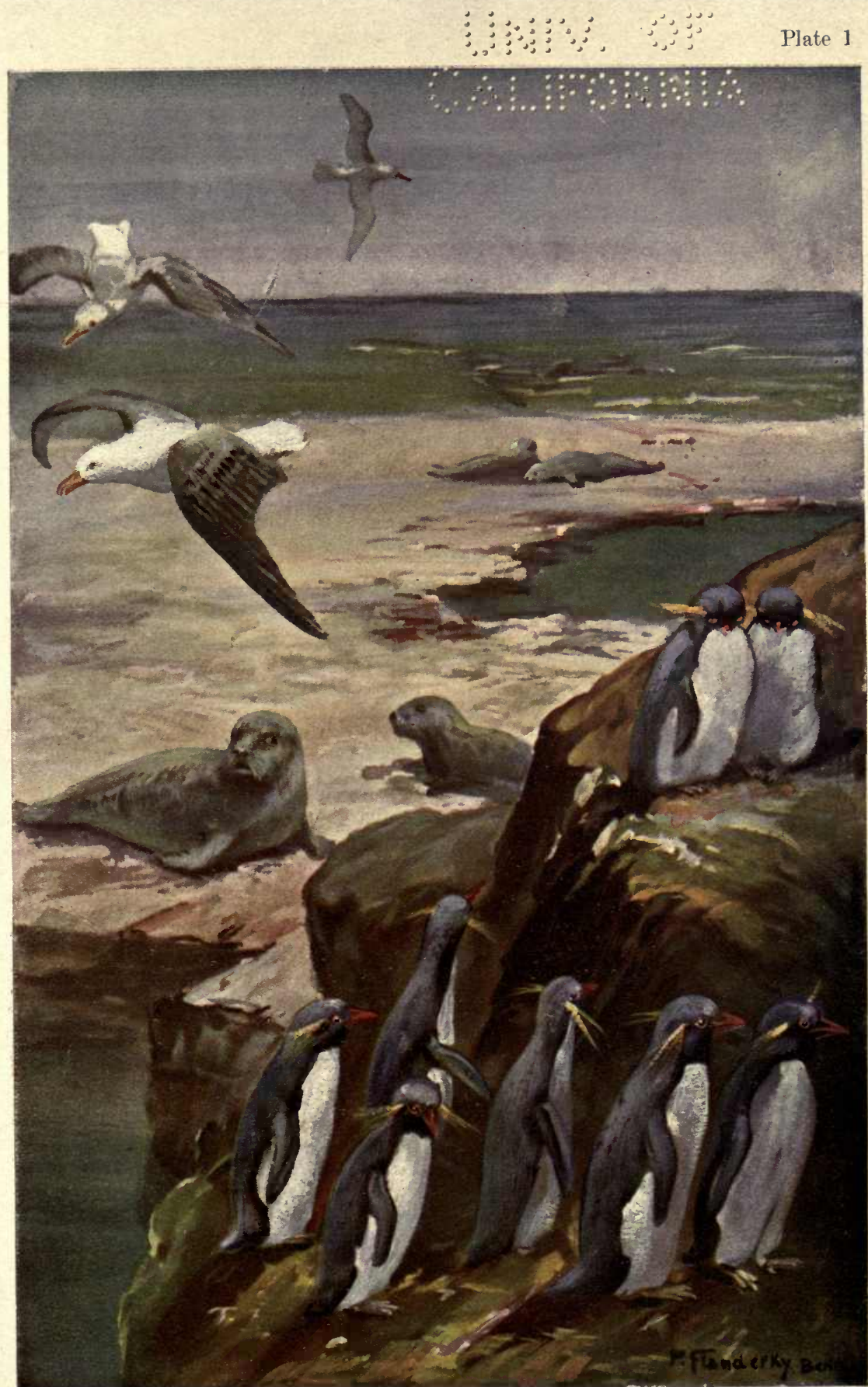

Animal Life in the Antarctic.

Yellow-billed Albatros (Diomedea chlororhynchus), Rock-hopper (Eudyptes chrysocome) and Elephant Seals (Macrorhinus leoninus). 
$\because \because \because \quad \vdots \because \vdots \because \vdots \vdots \vdots$

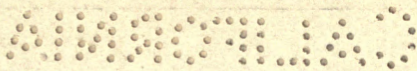


height without seriously endangering his life by the resultant decrease in the air-pressure. We must, however, bear in mind that the evidence on this point is far from conclusive, as in addition to the diminished air-pressure there are other injurious factors to be taken into account, as, for instance, the want of oxygen and the lowered temperature.

One of the most instructive ascents was the unfortunate journey of the French aeronauts, Sivel, Crocé-Spinelli and Tissandier. They ascended from Paris on April 15, 1875, and soon reached a height of 7,000 metres. On ascending higher, according to Tissandier, the only survivor, they began to feel a faintness which increased from second to second. Soon they were unable to make the least movement, even speaking having become impossible. The senses, however, remained acute and the mind clear. Having passed a height of 8,000 metres, they lost consciousness. When they had regained it they found that they were drifting at an altitude of 7,000 metres. Again they threw out ballast, again the balloon rose, and again these aeronauts lost consciousness. When at last Tissandier had once more recovered consciousness the balloon was floating at a height of 6,000 metres. His two comrades were dead.

Sixteen years later Berson and Süring reached the greatest height ever gained by man, 11,000 metres, the barometer showing $193 \mathrm{~mm}$. This ascent confirmed the experience that if a certain height is exceeded consciousness is lost and other functions are seriously disturbed.

Bert has shown that the maximum and minimum of pressure, under which animals may safely live, is in a certain degree dependent upon the volume of oxygen in the air. We know that the atmosphere of the earth consists (apart from other components) of 21 parts of oxygen and 78.06 of nitrogen. The pressure exercised by this amount of air upon the earth surface is called an atmosphere and has been calculated as being 1.033 kilogrammes to the square centimetre. It is generally constant for all terrestrial animals and plants. But the researches of Bert and others have shown that it is possible, even in the case of the higher animals, to alter these conditions without disturbing the vital activity. For instance, mammals, including man, can permanently exist in an atmosphere which contains only fourteen 
parts of oxygen. If, however, this percentage is lowered to ten, we observe in man and the higher mammals serious difficulties of breathing. A further decrease down to seven per cent. inevitably produces death by suffocation.

There is a wide divergence in the behaviour under equal conditions of warm-blooded and cold-blooded animals. If we place a rabbit in a room containing an insufficient percentage of oxygen it will after a few minutes have convulsions and die ; frogs, however, will remain alive for many hours, even in an atmosphere from which all oxygen has been removed. These facts are obviously connected with the varying consumption of oxygen by the various species. While, for instance, the small songsters consume 12 grammes of oxygen per kilogramme of body-weight per hour, the rabbit consumes 1 gramme, man about 0.5 , and the frog only 0.07 .

Just as we are able to decrease the supply of oxygen without a resultant disturbance of the functions of life, so we are similarly able to increase it. Thus mammals are able under ordinary pressure to live in pure oxygen. If, however, the pressure is increased to three atmospheres, death results, curiously enough, from suffocation. In ordinary air, however, animals can support a pressure up to fifteen atmospheres. The researches by Bert show, further, that a low percentage of oxygen may be balanced by an increase in air-pressure, whilst, conversely, the deleterious effects of high pressure may be balanced by a decrease in the supply of oxygen. This operates, however, only within certain very narrow limits.

The power of resistance of aquatic animals to water-pressure is remarkable. The results of deep-sea expeditions undertaken by various Governments have clearly shown that the greatest depths of ocean, abysses of 6,000 to 8,000 metres, are inhabited by organisms able to withstand a pressure of several hundred atmospheres. And not only do we find at these depths primitive forms, but also representatives of the higher species, cuttlefishes, crustaceans, and even fishes. (See coloured plate, No. 2.) Plants are found at a depth of about 4,000 metres, but beyond that depth existence becomes to them impossible, owing to the total absence of light.

If fishes from such depths are rapidly brought to the surface 
in nets, it frequently happens that owing to the tremendous decrease in the external pressure the air in the swim-bladder expands so suddenly and enormously that the whole fish explodes, or that at any rate its abdomen and pharynx are forced forward and outward, into the shape of a drum (fig. 9). This phenomenon may often be observed in the numerous fishes of the deep Alpine lakes, in particular in Coregonus hiemalis. According to von Siebold these fishes live at a depth of 80 to 90 metres. Consequently its air-filled swimbladder has to sustain a constant pressure of eight to nine atmospheres, that is, a weight of 8 kilogrammes to the square centimetre. If now this fish is suddenly brought to the surface the air in the swim-bladder suffers a decrease in pressure of seven to eight atmospheres and must expand in proportion as the pressure

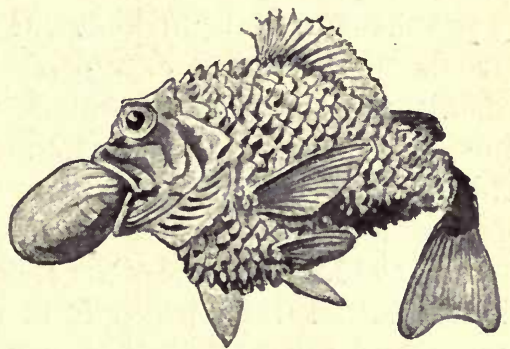

FIG. 9. - Neoscopelus Macrolepidotus BROUGHT TO THE SURFACE FROM $\triangle$ DEPTH OF 1,500 METRES. (AFTER KELLER.)

diminishes. But as the walls of the swim-bladder and the abdomen are unable to withstand such pressure the body swells so enormously that death soon follows.

The researches made by Regnard into the effects upon different organisms of extreme pressure shows that under a pressure of 700 atmospheres the activity of putrefactive organisms completely ceases. Meat and blood which had been kept under such pressure exhibited no signs of putrefaction even after the lapse of several weeks, whilst similar quantities, kept for purposes of comparison under ordinary conditions, had long since become decomposed. Various infusorians, vermes, crustaceans and molluscs, exposed to similar enormous pressure, exhibited after a few minutes a retarding and finally a cessation of all vital functions. If after a short time they were brought back to normal conditions, life sometimes returned, but a prolonged stay under extreme pressure always produced death.

The question why the inhabitants of the deep sea can safely sustain such abnormal conditions is answered by the considera- 
tion that there a gradual adaptation has taken place, whilst in the experiments mentioned the organisms were exposed suddenly to extreme pressure. Nevertheless, we are justified in assuming that there exists an upper limit of pressure beyond which life becomes impossible.

Besides these external conditions of life there are internal conditions of structure and chemical composition of the organic substance. As far as we know, all life that exists to-day on this earth is bound to the form of the cell, and to the reciprocal action of protoplasm and nucleus. It may be that in earlier earthperiods there existed organisms which had not yet reached the organization of the cell but were a shapeless mass of plasm, though possessing the function of metabolism and reproduction. This theory has indeed been retained by Haeckel until the present day. Accurate investigations, however, have always demonstrated that these so-called monera already exhibited a differentiation into protoplasm and cell-nucleus. Nucleus and protoplasm must, therefore, according to the present state of knowledge, be regarded as essential to the running of the engine of life. Only where all these external and internal conditions are present life becomes possible.

As varied as is the structure of organisms, as numerous are the disturbances which are caused by a change of these conditions. We have already heard that protoplasm is rich in water. The withdrawal of water renders it hard and tough, and its vital activities become suspended, but are not necessarily destroyed; for numerous organisms may be gradually called back to life from complete 'dry-coma' by the supply of water. Many cells are able to retain life for many years in such a state of rest. The spores of many species of bacteria, for instance, remain alive up to ten years, and dry-preserved grains of corn germinated even after twenty years. But this rest is not unlimited, as many seem inclined to think. The stories of the germination of wheat taken from Egyptian pyramids where they were said to have rested for more than 5,000 years have been exposed as gross deception. When the native guides saw that the foreign tourists were willing customers for this ' wheat from the Pyramids,' they put this knowledge to a highly remunerative use and smuggled into the venerable monuments the ordinary 
commodity. No wonder that this wheat grew directly after it had been sown. The real wheat from the Pyramids has a dark, almost black, colour and when placed into water dissolves intc a powder.

It has long been a much debated question whether the vital activity in the resting seed has ceased absolutely or has only been lowered to that point where our senses are not able to perceive it. If life is still existent, then respiration and metabolism must of necessity go on. The following experiment by W. Koch seems, however, to prove that this is not the case.

He placed a large quantity of plant seed into a glass tube, obtained as perfect a vacuum as possible, and then fused both ends of the tube. If respiration had taken place even to the most minute degree, traces of carbondioxide would have been observable, but when after several months the tube was opened it was found impossible, even with the most exact methods, to demonstrate the presence of a vestige of carbondioxide. Though life, therefore, had been completely at a standstill, the seeds were nevertheless found to have retained their power of germination.

It seems to me that no fundamental objection can be raised against this assumption. Just as much as we are not prepared to deny that a falling stone, brought to a halt by an intervening obstacle, will continue to fall as soon as such obstacle has been removed, and is therefore at that moment not at perfect rest but in a state of motion however infinitesimal, just as little cause is there for denying that the functions of life may sometimes come to a temporarily absolute standstill. But as we may not call such organisms alive, because life implies the presence of life-functions, nor dead, because they contain within them potential life, we must introduce a new term and call them lifeless or apparently dead (scheintot).

Preyer vividly illustrates this difference between dead and lifeless by the action of a clock. Whilst the lifeless organism is comparable to a clock, with spring wound and pendulum arrested, but needing only the right impetus to set it in motion, so is the dead animal or plant comparable to a clock, the works of which have been irreparably destroyed.

The phenomenon of 'dry-coma' is most remarkable in the 
various animalcules which owing to their frequent occurrence in the lichen on roofs or in the dirt of gutters are comprised in the name of 'gutter fauna.' As early as the end of the seventeenth century the famous Dutch zoologist Leeuwenhoek discovered by means of a home-made microscope that in the dirt of gutters or lichen-covered rocks and trees there lived minute organisms which were able to dry up into insignificant particles of dust and come to life again when moistened by the rain. Recent investigations have removed all doubts that were long cast upon this discovery, and also demonstrated the existence of other similar organisms.
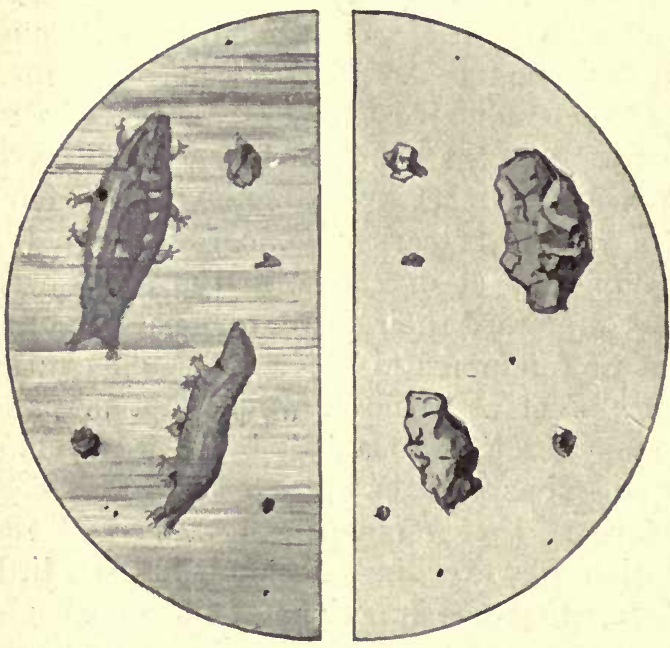

FIG. 10.-BEAR-ANIMALCULES (Macrobiotus hufelandi), ALIVE, AND IN A STATE OF DRY-COMA.

If, for instance, we place the dustcrust of dried moss on a piece of glass and examine the whole under the microscope we shall see after a short time that some of the seeming grains of sand begin to swell, extend, and show distinct signs of independent motion (fig. 10). Soon the stillness of death becomes replaced by active life, and numerous awkward

bear-animalcules, dainty rotatoria and minute amœbæ crawl and swim about in search of food. But no sooner do we let the water evaporate than the movements of these strange organisms become slower and slower, their forms shrivel up, and we observe once more nothing but particles of dust and sand.

The power of resistance of these minute organisms is extraordinary. Particles of dust which had been kept dry several years developed into Wheel and Bear-animalcules and even minute crustaceans. They seem equally insensible to heat and cold and 
to dryness. All these phenomena we have to regard as perfect adaptations to the conditions of life, for as these animalcules have to sustain in their normal habitation, the roof-gutter, not only frequent changes of moisture and dryness, but also, unprotected, the heat of the sun and the cold of winter, life without such high power of resistance would to them become impossible.

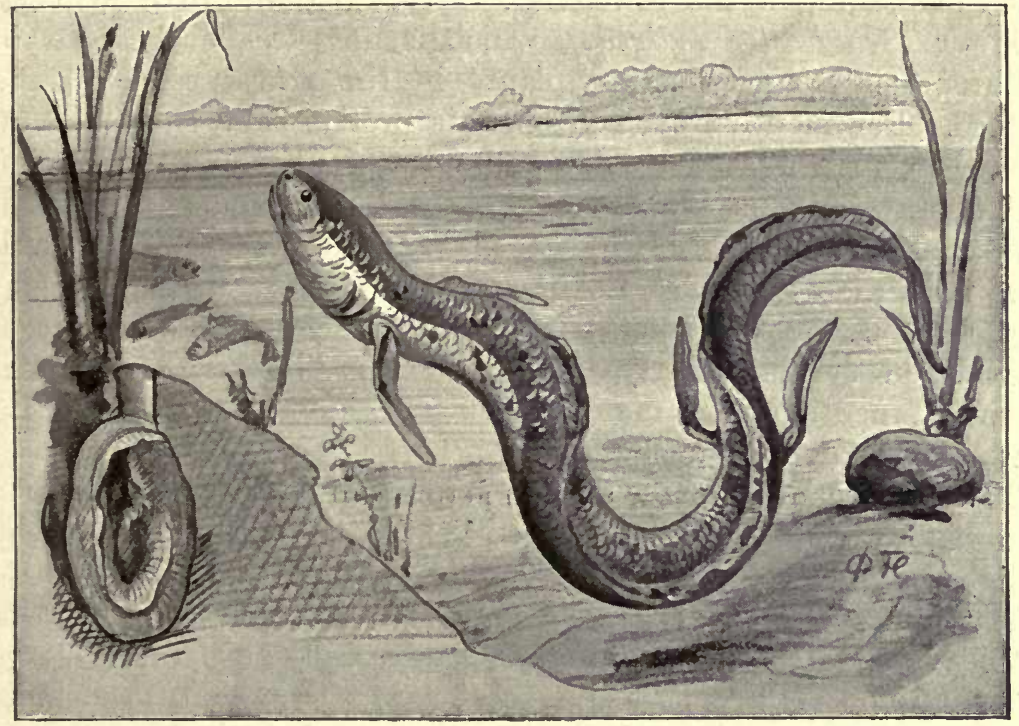

FIG. 11. - THE MUD-FISH (Protopterus Annectens). ON THE LEFT, A FISH RESTING IN ITS MUD-SHELL.

Cases of 'dry-coma' are known even among the higher animals. The best instance is that of the mud-fishes or Dipnoi, a small order of fishes that do not only breathe through gills but also through lungs, the air-bladder having become transformed into a single or double lung. When the dry weather comes these curious animals build out of mud and slime a solid shell in which they roll themselves up and pass the dry period, apparently quite dead. As this state lasts for several months it has been found possible to bring them, shell and all, to Europe. 
As soon as the rainy period commences they awaken from their torpor, the mud-shells dissolve in the water, and though at first the fishes appear sleepy and awkward, in a few hours they have regained their natural vivacity. (Fig. 11.)

The frequently described reviving of the 'Rose of Jericho' does not fall into this category. There we have to do with a completely dead organism, and the unfolding of the dry branches, the so-called blossoming, is a purely mechanical process due to the swelling of the leaf-stalks. But the Californian Miracleflower (Selaginella rediviva), which is now frequently seen in Europe, is a 'resurrection plant' in the truest sense of the word. For months, even years, this pretty plant, shrivelled up into an insignificant greyish ball, may lie about at the bottom of a drawer or on the top of a shelf, but no sooner is it taken out and moistened with water or planted in a flower-pot and well watered, than it unfolds its branches after a few hours, becomes green, and begins to sprout. The instantaneous rise of a vegetation on the bare, dark rocks of the Cordilleras after a short rainfall, mentioned by many travellers, is due to the sudden reawakening of Selaginella.

Some organisms show also an astonishing power of resistance to high and low temperatures. Whilst the protoplasm of the higher animals and plants is highly sensitive to the effects of heat and cold, coagulating at $+50^{\circ} \mathrm{C}$. and thereby losing its ability to live, certain of the lower plants, many algæ and bacteria, can, without injury, permanently sustain a temperature of more than $+70^{c} \mathrm{C}$. Indeed, some of them find there the most favourable conditions of their life. In the water of the Karlsbad Sprudel one may observe numerous filamentous algæ (Oscillaria), and in the hot springs of Albano and in the Solfatarra near Naples I observed with astonishment quite a flora of simple plants, and, at a temperature of $+60^{\circ} \mathrm{C}$., even minute crustaceans and larvæ of insects, all in a flourishing condition. But most astonishing of all is that in the hot springs of Yellowstone Park various species of algæ and bacteria thrive at a temperature of $+75^{\circ} \mathrm{C}$.

A still more remarkable power of resistance is observed in bacteria. The spores of many species will sustain without injury being exposed for hours to a heat of $100^{\circ} \mathrm{C}$. Dry spores of 
anthrax are killed only after having been exposed for three hours to a heat of $140^{\circ} \mathrm{C}$. Even seeds of grass and corn, which had previously been desiccated, sustained for hours a dry heat of $100^{\circ}$ to $110^{\circ} \mathrm{C}$. without losing their power of germination.

A similar tenacity is displayed by many of the lower organisms in the presence of cold. According to MacFadyen and others, certain species of bacteria survived being exposed for seven days to a temperature of $-190^{\circ}$ to $-225^{\circ} \mathrm{C}$.

That many multicellular organisms are almost insensitive to rapid changes of temperature is shown by the behaviour of the 'gutter-fauna,' in particular, the Wheel and Bear-animalcules. We are not only able to expose these delicate organisms to severe frost, but also to a heat of over $100^{\circ} \mathrm{C}$., and yet revive them by restoring the normal conditions of their life.

One might think that such extraordinary tenacity is specific only to the simplest and lowest organisms. In a certain sense that is true, for sensitiveness to external influences increases with increasing differentiation, a fact that may be observed in everyday life. The coarse strength of the robust countryman will easily endure hardships under which the more finely organized and therefore more delicate townsman collapses. But the countryman is denied many pleasures which to the more highly differentiated townsman are his ' real life.' Thus everything in the organic world is interdependent, and each ' higher' in one regard is balanced by one 'lower' in another. In natural science we should not, therefore, speak of higher and lower organisms, but of simple and complex. Indeed, if we took the degree of success in adaptation as our standard we should have to regard protozoa and bacteria as the highest and most perfect organisms.

Turning for a brief moment to the vertebrates, we find among them similar cases of great resistance to unusual external conditions. Like a romance sounds the history of a newt, as related by Erber. Destined to serve as food for a snake, it had succeeded in escaping its intended fate, and was found many weeks after in a corner of the room, completely shrivelled up. Placed in its natural element it revived rapidly, ate well, and soon regained its original appearance. But there was worse in store for the newt, for an unexpected night-frost came, froze the water in the aquarium, and the next morning found the newt frozen 
inside a solid block of ice. It was dead at last, but since it seemed befitting to preserve its body in spirit, the piece of ice was placed in a pot on an oven to thaw and-forgotten. When at last some one went to take the newt for its final funeral it was trying its hardest to escape from what seemed very much like a Turkish bath. None the worse for being nearly frozen and nearly boiled to death, the little animal lived in the best of health until it died of natural causes.

I have personally repeatedly observed that fishes, in particular the mud-fishes (Cobitis fossilis) and frogs, may be several times successively frozen and thawed without suffering any fatal injuries, provided that the thawing is done very slowly and carefully.

It was formerly believed that as soon as the interior of the body of animals had cooled down to zero death was inevitable, but numerous experiments made with various animals by Power, Preyer, Pictet, myself and many others contradict this belief. Preyer, for instance, slowly froze two frogs, gradually lowering the temperature to $-2 \frac{1}{2}^{\circ} \mathrm{C}$. One frog was then opened, and it was shown that all organs, even heart and blood, were frozen to ice. The frog was then carefully taken into a warm room, when the heart began to beat and drive the blood which had again become liquid through the arteries. (On account of its extraordinary resistance the frog is a favoured object for experiments of this kind, for its heart will continue to beat long after the animal is dead, even when it has been removed from the body.) When the second frog, which had been exposed to the same conditions, had been thawed, it revived and did not appear to have in any way suffered. Pictet's recent experiments prove that frogs and snakes are not adversely affected by a temperature of $-28^{\circ} \mathrm{C}$., and that snails can successfully withstand a temperature of $-120^{\circ} \mathrm{C}$, even when exposed to it for several days. As at such low temperatures all chemical processes cease, we have here another proof that life has temporarily come to an absolute standstill.

What we attained by artificial means Nature performs regularly year after year in all countries with a cold climate, for a large number of mammals, such as the bat, hedgehog, badger, hamster, and brown bear, become torpid as soon as the 

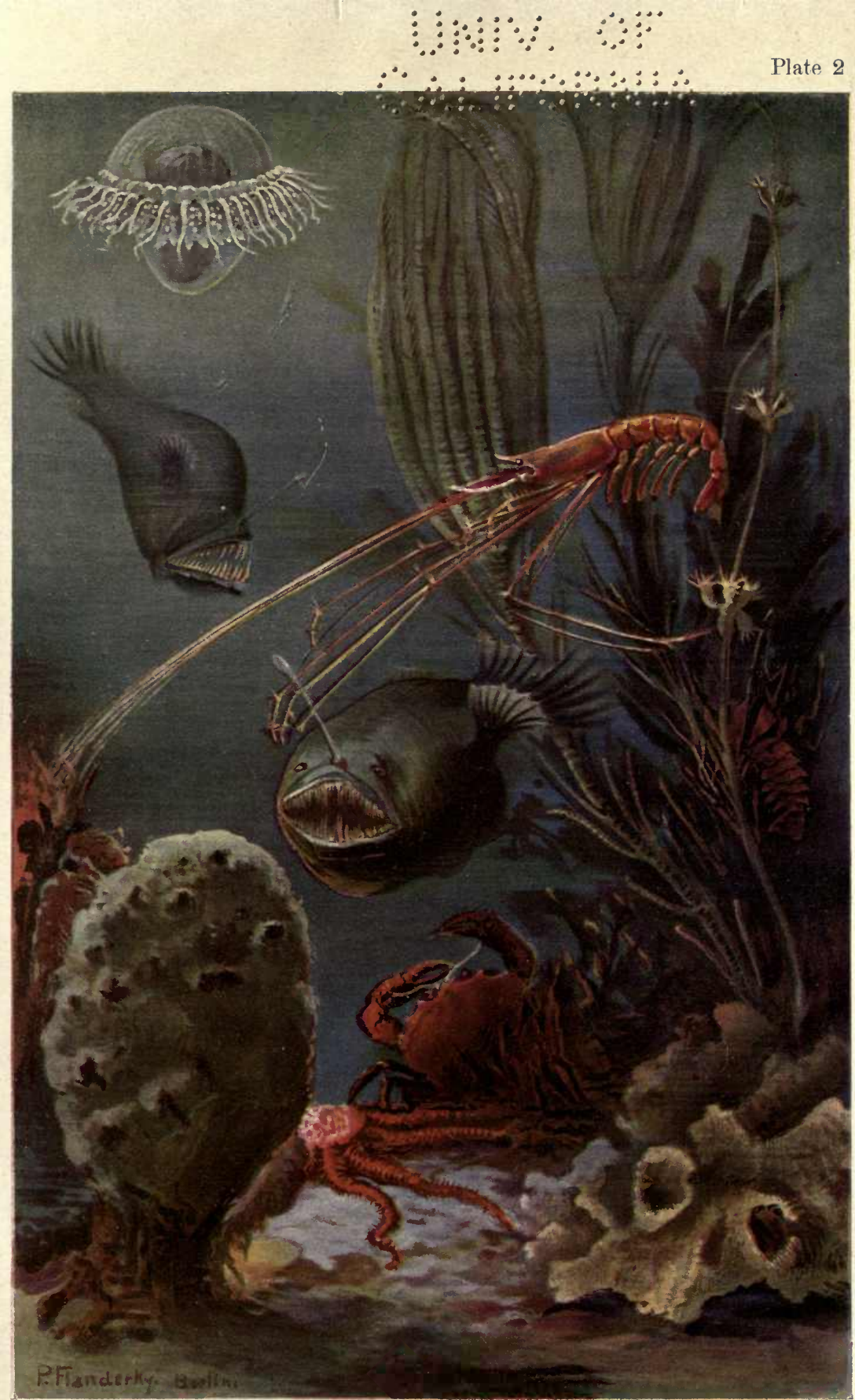

Deep-sea Life.

Deep-sea jelly-fish, Atolla; Melanocetus, a fish belonging to the family of the Lophiidae; Deep-sea crustacean, Nematocarcinus. On the sea-floor, on the left; a glass-sponge, Hexactinellida, in the centre, a starfish, Brisinga elegans, and a crustacean, Geryon. On the right, skeleton-part of a glass-sponge, Aphrocallistes; an Alcyonaria, and a Crinoid, Melacrinus. 


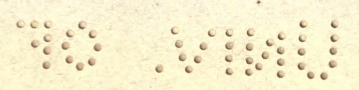

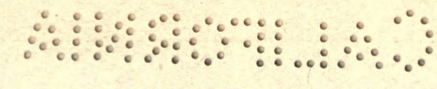


cold weather sets in. These animals hibernate during a period, the extent of which varies with the different species, but there is always noticeable a great decrease in metabolism. Respiration ceases, the actions of the heart are hardly perceptible, and the body temperature of the sleepers, which otherwise about equals that of man, almost falls to freezing point. When the mild weather returns vital activity gradually recommences, and emaciated and exhausted the animals come out of their winterquarters.

For many animals hibernation is a direct necessity. As their food consists of insects or plants, and as they cannot, like some birds, undertake long journeys to some more hospitable country, they would die from hunger if they could not sleep the time away. But as in hibernating animals metabolism is not entirely suspended but only reduced, a certain quantity of substance is naturally used up even during sleep. The animals live during this time on the fat which they have accumulated during the good season. If we examine a bat which we find hibernating in a cellar or chimney, we notice that all organs, muscles, intestines, \&c., are surrounded with thick layers of fat. But in spring, on re-awakening, the bat is thin and emaciated, having lost about a quarter of its body-weight.

Some of the hibernating animals make the period of hunger easier to sustain by carrying together, in the autumn, stores of food which they consume whenever a sunny winter day awakens them. While most animals, when hibernating, are insensible to almost every external stimulus, and most difficult to rouse, others-as, for instance, the bear-awaken at the least suspicious noise.

To the decrease of vital activity corresponds a considerable increase in insensibility to injuries. Wounds, to which these animals would in the waking state succumb almost instantaneously, are frequently sustained for days. The heart of a hibernating hedgehog beats for hours after the spinal cord has been severed.

We have so far seen that the withdrawal of water, variation of air-pressure, and extreme cold and heat, will cause in animals temporary torpor. But the same effect can also be produced by purely 
psychic influences. Already in olden times it was said that many persons possessed the faculty voluntarily to reduce their vital activity short of total cessation, to lapse into a state of torpor from which they would re-awaken after a longer or shorter period. The best known illustration is offered by the Indian fakirs and Egyptian dervishes who, it is said, even cause themselves to be buried in the earth, and rise from their graves after having been buried for weeks and even months.

However, as often as such 'miracles' have been thoroughly investigated they have usually been found to be clever deceptions. Nevertheless, it would be unwise to dispute the possibility of such phenomena. We know that as a result of illness persons

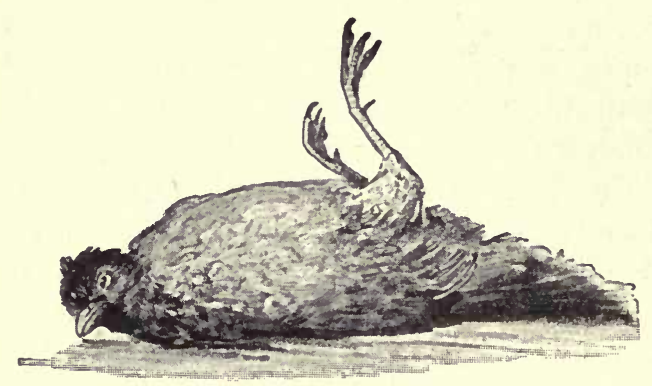

FIG. 12.-FOWL IN A STATE OF CATAPLEXY.

not unfrequently fall into a state of such complete debility that a superficial examination is unable to find even a vestige of vital activity. Cases of apparent death or suspended animation are known whi ch lasted for several days. The only miraculous part in the action of fakirs and dervishes is, therefore, that they are seemingly able to place themselves into a state of hidden life voluntarily, and for considerable periods. But though we cannot explain these things they may be true, nevertheless. Even to-day "there are more things in heaven and earth than are dreamt of in our philosophy." Let us only remember the strange phenomena of hypnosis which are still awaiting a satisfactory explanation; here, too, vital functions may be so reduced as to lead to a state of complete catalepsy.

In the animal kingdom we observe similar phenomena due to hypnotic influences. Many will here recall the celebrated "experimentum mirabile de imaginatione gallina," described in 1646 by Athanasius Kircher in his "Ars magna lucis et umbra." If we firmly grasp a fowl and carefully put it on its back it 
will at first make feeble defensive movements, but then lie still as if paralyzed. Kircher prescribed that this experiment should be conducted in the following manner: "Tie together the legs of a fowl and place it on the floor, and it will at first endeavour to free itself from its fetters by beating its wings and moving its body. But after a few futile attempts to escape it will remain quiet. Then draw on the floor a straight chalk line, commencing from the eye of the fowl, and remove its fetters, and though the fowl is no longer bound it will not run away even if it be encouraged to do so." The phenomenon is caused by the effects of an intense feeling of fright-the fowl is in a state of 'cataplexy,' as Preyer calls it.

It has been known for thousands of years that the dreaded cobra, whose bite invariably causes death, may be paralyzed by a slight pressure exerted in the region of the neck, and that its body may then be placed into any desired shape. The ancient miracle, performed by Moses by

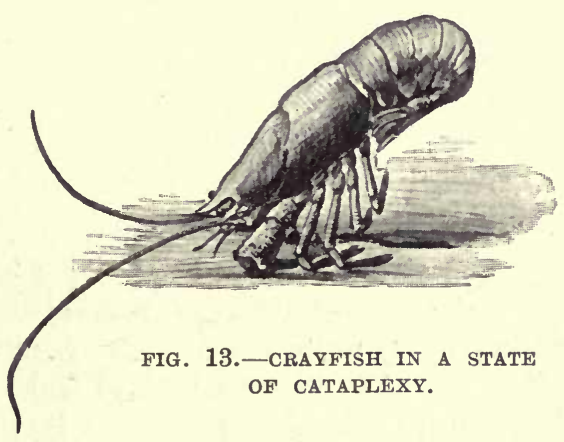
changing the serpent into a staff, thus probably finds a natural explanation.

Every one knows that small animals at the sight of a serpent become so frightened as to remain quite motionless, thus falling an easy prey. Moreover, a great fright has a paralyzing effect upon a large number of animals. If one suddenly seizes a crayfish and presses it on the floor in the manner shown in the illustration (fig. 13) it will remain in this unnatural position for a considerable time without moving a limb. Many similar cases could be quoted.

If in the instances mentioned the animals derived no advantage from this state of cataplexy, other animals owe to it often escape from dire peril, and we are therefore justified in regarding cataplexy as a form of adaptation to the conditions of life. It is very common among insects and spiders, and its advantages are 
obvious. Many beetles and spiders collapse on the floor as soon as they are touched, draw in the limbs close to the body and 'pretend to be dead.' In this state they frequently remain a considerable time. As a resting object is notoriously more difficult to discern than a moving one, especially if its colour does not greatly differ from that of its surroundings, they frequently escape by this artifice from the persecutions of their enemies. As, further, many animals seize only living and moving prey, but pass by motionless objects, this 'pretence to be dead' is of considerable advantage to those animals which practise it.

An interesting observation is reported by Belt. Several locusts had met a detachment of the murderous Driver-ants. Some of the locusts forthwith became paralyzed with fright, and being rigid and motionless, escaped death; others sought salvation in flight, but were quickly caught, overpowered and devoured.

It is necessary to say a word about the attitude of many organisms to chemical influences. Here we see that conditions which are fatal to one organism have often not the least deleterious effect upon others. In zoological practice pure alcohol and osmic acid are two of the strongest and most frequently used means of preserving. With the majority of the smaller animals an immersion lasting only a few seconds, or, at the most, minutes, is sufficient to kill them and harden the tissues. But if we place the aquatic larva of Corethra plumicornis, a species of gnat, into either of these liquids it swims placidly about, just as if it were in its proper element. After a considerable time it begins to show signs of unrest, but frequently it is only after several days that this delicate little animal succumbs to the effects of the poison.

Still more wonderful appears the life of a little worm (Anguillula aceti) which lives in vinegar. Where no other life can exist this tiny worm, which does not exceed $2 \mathrm{~mm}$. in length, grows and multiplies, feeling as comfortable as a fish in water. If one holds up a bottle of vinegar to the light one may frequently see many of these 'thin threads' swimming gaily about.

Nature places before us riddle after riddle. Inexhaustible are her ways and means of providing for her creatures suitable conditions of existence, and even to unlock for them such regions as according to our idea of living organisms would seem to 
preclude every possibility of living. For do not numerous parasitic bacteria, protozoa and vermes live in the digestive juices of the intestinal canal of the higher animals, which are fatal to all other organic life? The question has often been asked, How is it possible that the intestinal parasites are not digested in the same manner as all other organic substances introduced into the intestines? But this fact is no more remarkable than the fact that the intestinal cells are not themselves decomposed by the juices produced by them. This does actually occur in cases of intestinal affections, for it is frequently observed, especially during the summer season, in a human corpse examined soon after death, that certain larger or smaller portions of the walls of the stomach and intestines have been digested.

Formerly it was believed, on the ground of these observations, that each living organism possessed a protective agent in a special vital force (vis vitalis), and that digestion of the stomach-wall set in after the death of this protective force. As for a long time no other reasonable explanation was forthcoming, this belief was held even in expert circles. It is a common weakness of the human mind to substitute for the mysterious an equally mysterious phrase, pretentious of being an explanation, and thus to deceive ourselves into believing that we know, rather than frankly admit our ignorance of that subject. When it was proved by various experiments - first by Pavy, who introduced the ear of a living rabbit into the gastric fistula of a dog-that parts of an animal still alive are digested by the juices of the stomach, the convenient assumption of the effects of a mysterious vital force had to be abandoned. To-day it is generally believed that the impregnability of the healthy intestinal mucous membrane, as well as the power of resistance of intestinal parasites, rests in their ability to secrete a substance which acts as an antidote to the gastric juices and renders them harmless.

This assumption is in perfect accord with our knowledge of the effect of poisons. It is well known that every animal and human body is able to become accustomed to poisons-as for instance nicotine, alcohol, morphia, opium, arsenic-by gradually increasing the dose to such a degree that a quantity of poison, fatal under natural conditions, will cause very little or no harm. It is said of Mithridates, the great ruler of Pontus, that having 
hardened himself in this manner against poison, as a protective measure against the poisoner, no poison was found strong enough to kill him when on the collapse of his sanguinary career he wanted to make an end of his miserable life.

The power of the living organism to become accustomed to poisons rests on the faculty peculiar to it of creating for each toxin an antitoxin which will neutralize the ill-effects of the toxin, unless the quantity introduced has been too large. But prudent Nature always forms more antitoxins than are required for the relevant purposes of neutralization. This surplus is stored up in the tissues of the body where it lies ready for any subsequent attack. Unfortunately, the curative effect of these antitoxins is strictly specific, so that, for instance, an acquired habit of taking arsenic is a protection only against arsenical poisoning, but not against the ill-effects of morphia or opium.

We know to-day that the devastations of many species of bacteria - the causes of most of the infectious diseases - are due to the effects of certain specific toxins which, themselves the results of the mode of life of these minute organisms, far exceed in destructive power all other animal, plant, and mineral poisons. Whilst 120 to 130 milligrammes of strychnine constitute a fatal dose, only 0.23 milligramme, i.e., about the fivehundredth part, of Bacillus tetani, the cause of lockjaw, is sufficient to kill a man of about 70 kilogrammes body-weight. But in spite of this truly awful power the animal body is capable, to a certain extent, of becoming accustomed to bacterial poisons. An instance of this experience is protective inoculation, as it has been practised in Germany and in other countries against smallpox and other infectious diseases for many years. Vaccination does nothing else but cause in the body of the vaccinated individual the production of a small-pox antidote which retains for several years the power to annihilate, in the event of an epidemic, automatically any small-pox disease germs that may invade the organism. We cause, in fact, at first artificially such slight cases of small-pox as the organism is able to withstand, in order to enable it in the future to escape severer attacks. The great reduction in the number of cases of smallpox in Germany since the passing of the Compulsory Vaccination 
Law is the best proof that this method is right. Everyone knows that persons who have had the measles, scarlet-fever, whooping-cough, \&c., are almost perfectly immune against renewed infection, a phenomenon which can only be explained by the formation in the body of a protective substance which remains effective for some time.

This immunity which, as we have seen, may be acquired artificially by the living organism against various toxins is a natural property of many animals. We find that many infectious diseases fatal to man are not transmissible to animals, and vice versâ. Further, while among closely related animals one species is highly susceptible to a certain disease, another species is absolutely immune. It is still more remarkable that the same phenomenon is observed in individuals of the same species. Why that should be so remains for the present obscure.

Many serpent-hunters, among them the useful hedgehog, are almost immune against the effects of snake poisons. One may often see the hedgehog devour, with the greatest relish and without the least discomfort to himself, a viper, poison-glands and all. That the bite of the viper does not injure the hedgehog I have been able to ascertain on various occasions.

A still more remarkable instance of immunity is presented by a tiny beetle. The fresh juicy leaves of the deadly nightshade, Belladonna atropa, almost seem to provoke the appetite of all plant-eaters. Yet, no matter how scarce the food supply may be, the nightshade is carefully avoided by all the large grazing animals, for its leaf and juice contain a deadly poison. Without this terrible weapon of defence this plant would long ago have been defeated in the struggle for existence. But even the most powerful protection can only grant a qualified security, for the poison which frightens away the largest animals has no terrors for the little Haltica atropa, for the leaves and juices of the deadly nightshade constitute its sole food. 


\section{CHAPTER III. \\ THE FORCES IN THE ORGANISM.}

No living naturalist is able to give an accurate definition of an organism or life itself. However great the progress made in biology during the last century, however great the store of observations made and facts discovered, we are as far as ever from the desired goal of a definition of life and from a real knowledge of the conditions of life, the most important object of our researches. Though girders, stones, and mortar are indispensable to the builder of a house, the main thing is the plan of the architect who unites the scattered parts in one harmonic whole. While former ages and naturalists were content to describe the structure and shape of animals and plants, to give them names and classify them according to the degree of similarity, we demand to-day to know not only how an organism is constructed, but also why it is so constructed, how it originated, how its various organs were evolved, what their functions are, and by what laws the different vital functions are regulated.

Not so long ago there existed between the inanimate, inorganic Nature and the world of animals and plants an abyss over which no bridge led, nor, indeed, could lead, according to the then almost general belief. Whilst in inorganic Nature all changes took place according to the unalterable laws of mechanics, physics and chemistry, the phenomena of life remained a profound mystery. But as science was unwilling to renounce even an attempt to explain the seemingly inexplicable, there arose the convenient assumption of the presence in each organism of a specific, mysterious, unknowable source of force, which under the sonorous name of vital force-vis vitalis-long haunted the realms of science. Though by this assumption knowledge had not been advanced a single step, and though 
this vis vitalis expressed no rational thought, there existed now at any rate a sounding phrase which covered a mass of ignorance :-

"Denn eben wo Begriffe fehlen,

Da stellt ein Wort zur rechten Zeit sich ein."

Only slowly and gradually did the conviction gain ground that there is no foundation for such a radical difference as that which superficial observation had created between the organic and inorganic world.

The school of Vitalism suffered a severe blow when chemistry, daily extending the boundaries of its knowledge, proved that the bodies of all living beings are built up with the same element as dead matter, and that the difference between organic and inorganic compounds is only the difference in the combination of the individual elements. And when in 1828 the famous chemist Wöhler succeeded in producing artificially in the laboratory an organic compound, urine, by synthesis from inorganic bodies, the doctrine of vitalism lost one supporter after another; further discoveries completed its decay. Other animal and vegetable compounds-spirits of wine, vinegar, sugar, starch, \&c.-were produced out of their elements by chemical synthesis, and we are now within measurable distance of the day when chemists will succeed in making artificially the foundation of all phenomena of life, the albumen. Quite recently an important advance in this direction has been made by the brilliant work of Emil Fischer.

But not only do similar chemical elements build up alike animate and inanimate matter, both are also subject to the same physico-mechanical laws. With each advance of science this fact becomes clearer and more convincing. A few instances will suffice.

On looking at a longitudinal section of a human femur we observe that the fibre-ducts and bone-corpuscles are arranged on strict architectonic principles. The femur is a tube with strong walls. In the so-called neck and head of this bone-the parts which carry the greatest load-the spongy cancellous tissue is arranged from wall to wall in slender bars or lamellæ, which unite together to form an open lattice-work, like that of an iron 
bridge, running exactly in the direction of the greatest pressure. "Nature," aptly says J. Wolff, "has built the bones as the engineer builds a bridge, obtaining a maximum of strength and suitability of form with a mimimum of material."

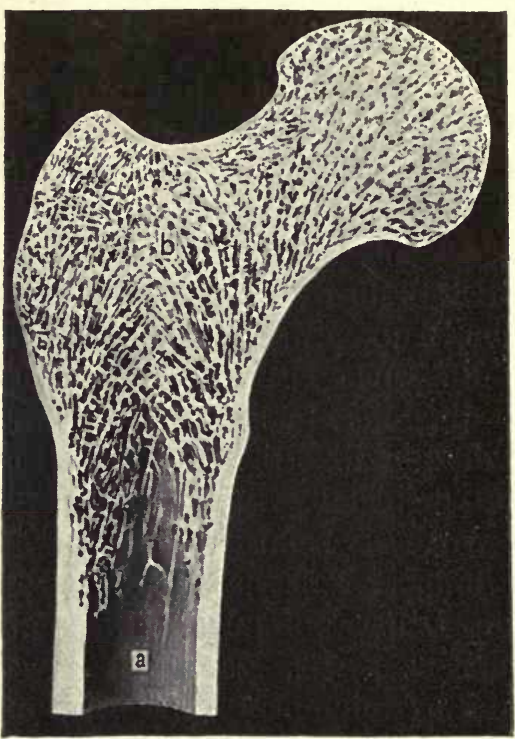

Fig. 14.-LONGITUDiNAL SECTION OF A THIGHBONE.

a, Marrow-shaft; b, spongy tissue. (After v. Hanstein, "Naturgeschichte des Tierreichs.")

But it may be objected that this instance refutes our arguments and proves what we are refuting. Granted that the strength of the bone rests on simple mechanical laws; but to what cause is its perfect construction due? Does not the very perfection testify to the influence of some mysterious source of force? Is it conceivable that blind mechanical forces can create perfection?-The credit of having shown the way out of this difficulty to a natural explanation of the apparently inexplicable belongs to Roux and his Theory of the Struggle of the Parts in the organism.

We have already seen that constant use strengthens our organs, whilst non-use leads to degeneration and atrophy. This rule does not only apply to the muscles and other organs of the body, but also, as everyone may ascertain in himself, to our mental faculties, in particular the memory.

Roux stated that this strengthening is produced by a specific function of the organ itself-in other words, that it is the functional stimulus which strengthens the organs. For though the increased use and more intense activity cause an increased metabolism, this is not only balanced, but there is even a large credit balance, owing to increased power of assimilation. It may therefore be said that the stimulus has a direct nutritive 
effect. If, on the other hand, the normal stimulus is absent there follows of necessity a weakening and decrease. The much-exercised muscle grows in volume and correspondingly in working power, the unused muscle becomes powerless and atrophied.

Most clearly is the degeneration of muscular tissue observed in pathological changes, as, for instance, in a badly healed joint. Here the blood supply is exactly the same as in the healthy organs, but the functional stimulus is absent, and thus degeneration sets in. A similar result is observed when we sever the nerve conveying the stimulus: decrease in volume and symptoms of degeneration become quickly noticeable in the muscle, and complete destruction of the structure is not, infrequently the final result. Or, to give another instance, when in a human being one kidney degenerates and loses its functions, or is removed by an operation, the other kidney, owing to the greater demands made upon it, increases enormously in volume, often to more than double its usual size.

But as the organism has at its disposal, at any rate within certain limits, a circumscribed amount of building material in which all its various parts share, it follows that the excess of food used by a certain organ or tissue, owing to increased activity, must be taken away from another less used organ. In proportion, therefore, to their importance or "output of work" the various parts of the animal body maintain an unstable equilibrium, and, on the whole, prevent that one part exceeds its normal "allowance" at the expense of the rest, at any rate as long as the welfare of the whole body does not justify the excess. There is going on, metaphorically speaking, a restless competition-a struggle of the parts-for the available sources of food in the living body. Though perhaps this point would be more appropriately mentioned in another place, it seems nevertheless advisable, on account of its great importance, to anticipate some of the points and deal with them here.

An organ in which this struggle of the parts may be most clearly observed-for it is here the entire cells which enter into direct competition-is the male and female generative gland of many animals. A little cuttle-fish from the Gulf of Naples may serve as an illustration. If we observe thin transverse sections 
of the testicles of this animal, under the microscope, magnified about 2,000 times, we can distinguish numerous heterogeneous cell-elements, which represent different stages of development from the so-called spermatoblast to the fully developed spermatozoon which is furnished with a thin caudal filament. The spermatoblasts develop by direct metamorphosis from the so-called protoblastic cells, i.e., the cells which evolve from the epithelial covering of the vesicles. Each of these spermatoblasts splits up into two cells of equal value, called spermatocytes of the first degree, which in their turn split up each into two cells, called spermatocytes of the second degree, or spermatides. These, again, change by a highly complex metamorphosis into the complete spermatozoa. From each spermatoblast originate, therefore, normally four complete spermatozoa-supposing that the cells are favoured by luck, for many cells perish at an early stage. How are we to explain this remarkable phenomenon? When I observed this development for the first time in Rossia macrosoma I felt greatly puzzled, but accurate comparisons with the conditions obtaining in other species of cuttle-fishes and many tedious researches solved the mystery.

It is known that in the generative glands of most animals, -in a most highly developed form in insects, crustaceans, \&c.there is found, in addition to the sex-cells proper, a large number of accessory cells whose task it is to supply the growing spermatozoa and ova abundantly with food. Of the numerous methods by which these cells fulfil their task I will mention only the two most important. They either take nutriment from the surrounding body-cells of the organism and transmit it to the sex-cells, thus playing the part of a middleman, or they themselves serve as food and are gradually devoured by the spermatozoa and ova.

No such special feeding apparatus has been evolved in the cuttle-fish, but Nature knows how to help herself without it. At certain times there are formed in the seminal tubules of the testicles of Rossia enormous numbers of germ-cells. As these cells are themselves only sparsely furnished with food, the store being insufficient for the growth and metamorphosis of the complete spermatozoa, there takes place in consequence among this 
vast number of germ-cells a fierce competition for the food contained in the vesicles. But as there are among the germ-cells, as among animals, strong and weak individuals it happens that the stronger cells seize great quantities of food at the expense of the weaker cells. The result of this struggle is that a large number of the germ-cells, owing to insufficient nutrition, atrophy
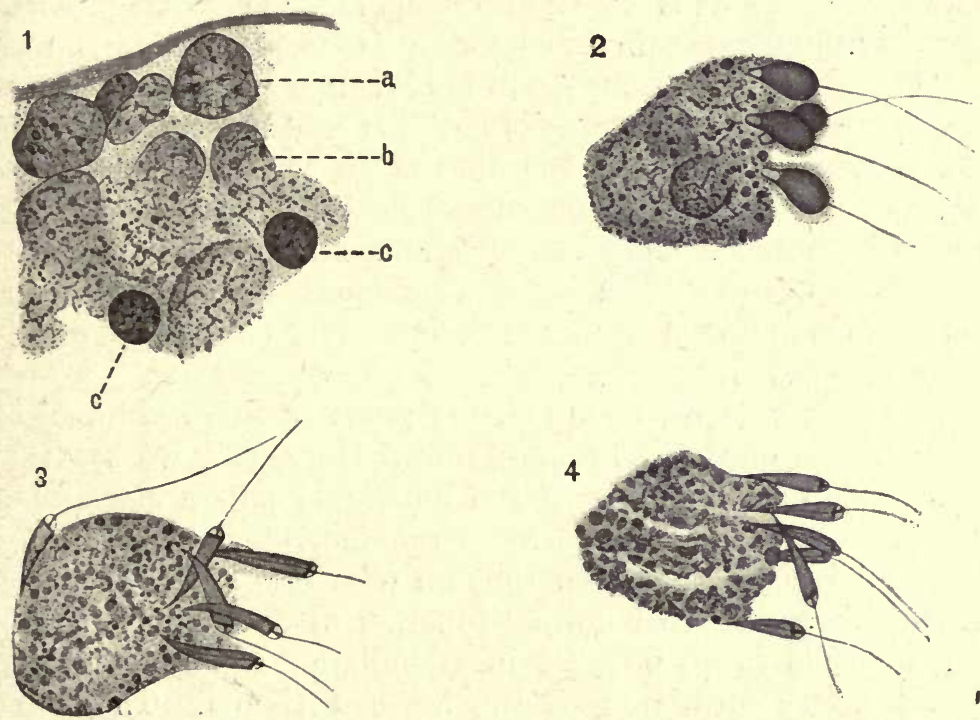

FIG. 15. - THE STRUGGLE OF THE GERM-CELLS IN THE MALE GLANDS OF A CUTTLE-FISH (Rossia macrosoma).

(1) Spermatoblasts in process of disintegration : (a) normal ; (b) disintegrating ; (c) two young spermatozoa (spermatides) which have entered into the disintegrating mass. (2) The completely disintegrated cells, forming an amorphous lump of food. at the expense of which the surviving spermatozoa develop. (3) and (4) The "foodmass" is being gradually devoured. (After Thesing, "Notes on the Spermatogenesis of the Cephalopods.")

and finally disintegrate. One may sometimes observe entire colonies of many hundreds of cells in this state of incipient dissolution. First the margins become indistinct, then the nucleus disintegrates and its component parts mix with the rest of the cell-fluid. Finally, confluence takes place of the adjoining cells, thus forming a uniform substance (see fig. 15). 
Forthwith the more favoured germ-cells take advantage of the unfortunate position of their brothers; numerous normal and healthy spermatozoa penetrate with their heads into the disintegrated cells and commence to feed vigorously and to grow. At no stage of their development are the germ-cells quite secure against destruction, for it may not infrequently be observed that almost fully developed spermatozoa disintegrate and are assimilated by the survivors. It is a veritable struggle for existence in which apparently the fittest gain the victory here as elsewhere in Nature.

This secret fight to the death is of double importance for the species. In the first place, it is only the healthy, vigorous spermatozoa which will reach the final stage of development, and these, again, are during the entire period of growth abundantly supplied with food. But vigorous and healthy germ-cells are the surest guarantee of a vigorous generation, and a rational result is thus obtained by a crude, mechanical selection of the strongest cells.

But let us return to the starting point of this examination, the conditions observed in the femur. Here, too, we see that the purposeful arrangement of the individual pillars and arches proceeds from a struggle between the individual bone-forming cells. We have already seen that an increased stimulus consequent upon an increased normal function of an organ or part of an organ leads to an increase in assimilation and a strengthening and better formation of the affected tissues. The bone, however, does not consist of a homogeneous substance but of heterogeneous elements; in this case, therefore, the burden placed upon the femur is not equally distributed but stimulates different parts to a different degree. It is therefore quite natural 1, hat the largest amount of bone-tissue is formed and deposited in the direction of the strongest pressure, for there the boneforming cells are most frequently and intensely stimulated into activity and growth. The interspersed parts, however, which participate in the work but slightly or not at all, suffer a corresponding want of nutrition and lag behind in their development. In this way we obtain a typical pillar-and-arch structure, as shown in the picture, reminding us of the rational plan of the expert engineer.

In one respect, however, the natural structure far sur- 
passes all human work -in being able to adapt itself suitably to altered conditions of pressure. The necessity for this arises very frequently in those cases of fracture in which the two ends have healed together obliquely. The course of the pillars and arches is now no longer in the direction of the strongest pressure and pull. The parts which previously did most of the work, qualified for it by their stronger formation, have now become inactive and useless. But this state does not last long, for soon the course of the lamellæ once more proceeds in what is now the direction of the strongest pressure. But everything has happened quite naturally, and there is no need to assume the existence of a mysterious vital force in order to explain the purposeful construction of the bones or any other organs.

A different question is: What enables an organic substance to react suitably upon a functional stimulus? How does it happen that the awakened need carries with it its own satisfaction? It seems as if we are here confronted with a fundamental difference between the living, and the dead and inorganic matter. But as we observe hourly that living matter changes into inorganic substance, and as we are forced to assume that in distant earth-periods living matter originated from inorganic, there is no necessity for believing this faculty of the living body to be a new force created mysteriously out of nothing, but we must rather assume that it is an essential quality of matter which is non-apparent in the inorganic. Just as electric energy, slumber ing potentially in bodies, only reveals its presence and effects when a certain combination of matter has taken place, so it is with this assumed force of living matter.

We cannot escape the conclusion that the inorganic carries within itself the conditions of its organization, nor can we deny the justice of the claims advanced by those inclined to postulate a specific psychic form of energy besides the chemical, mechanical, electric energy.

It is true that modern biologists confess to an open distrust of everything psychological ; they regard it as mystic, and many would prefer to exclude it entirely from the field of natural science. But that would at the same time exclude an understanding of most of the physical processes and phenomena. "Because," says Wundt, "a superficial observation of the 
phenomena of evolution easily leads to the conclusion that with the perfection of the physical organization an increase takes place in the psychic activities, we meet with the still current belief that the former is the cause of the latter. But a deeper insight into the evolution of psychical phenomena leads to the opposite belief; through the motion which it causes the stimulus reacts upon the physical organization, and leaves behind in it those permanent traces which facilitate at first the renewal of the stimulus-motion (Triebewegung), and then, when the reactions of other stimulus-actions are added, permits the origination of more complex stimulus-expressions." We are even " impelled to believe that the physical development is not the cause but the effect of the psychic development." In fact, without this assumption an understanding of the purposefulness of the lifephenomena is impossible. It will be clear that this statement is only apparently anti-mechanical, for the postulated psychic energy does not represent something imperceptible like the vital force, but is like every other form of energy definable quantitatively and thus perceivable scientifically.

If we now attempt to define the aim and object of modern biology we shall say that they consist in reducing all functional processes comprised in the term "life" to chemico-physical causes. But only when we have succeeded in reducing an organism to simple mathematical formulæ, to predetermine its life-phenomena, changes, \&c., just as the astronomer calculates the course of the stars and predicts eclipses of the sun and moon accurately to the minute, only then can we claim to have satisfied this demand. That this goal is as yet far distant, that neither modern chemistry nor physics is able to perform this task, and that in the end we shall only be able to approach our aim but never reach it, need not be specially mentioned. The phenomena of life are so many, the structure and conditions of the living substance so exceedingly complex, that in the majority of cases we shall have to be content with a mere description, because no explanation is available.

But however far. we may be privileged to penetrate into the mysteries, one will always remain hidden-consciousness. We may possess a perfect knowledge of the structure of the 
human eye, understand every detail of the laws of optics, know how the rays which focus an image on the retina are converged, refracted and reflected; but how it comes about that we have a sensation of the image, how we become conscious of it still remains an impenetrable mystery. We may know the delicate structure of the brain, follow each change, every chemical process and motion of the atoms during the process of thinking; but how a thought arises, how we become conscious of an object, remains a question to which there is no answer, nor ever will be. As Du Bois Reymond said: "It will for ever remain inexplicable why a certain number of atoms of carbon, hydrogen, nitrogen, and oxygen should not be utterly indifferent as to how they lie and move, how they did lie and move, and how they will lie and move. It is impossible to see how their correlated action produces consciousness. The mental processes which are going on in the brain side by side with the material processes offer no explanation acceptable to our reason. They stand outside the law of causality, and are for that reason alone as incomprehensible as a perpetuum mobile. As the world and all individual thought originate in consciousness, so consciousness is the final law to which we can reduce a phenomenon." But though this greatest riddle may remain unsolved, the need, deeply ingrained in our mind, of conceiving all processes and changes as effects, and of searching for the causes of these effects, finds, nevertheless, a high degree of satisfaction in the endeavour to reduce each phenomenon to its cause. Even the conviction that we shall never be able to fathom the truth will not prevent us from striving after the truth for ever. 


\section{CHAPTER IV.}

\section{THE BUILDING-STONES OF THE ORGANIC WORLD.}

IT often happens that long before patient research has reached, at a snail's pace, a new goal of knowledge, genius has attained it by the mere force of thought, by speculative thinking. Goethe taught that "nothing that lives is an individual but a plurality; even in so far as it appears to us as individual it remains an aggregation of living independent beings which are alike in conception and disposition (Anlage), but may in appearance become like or similar, unlike or dissimilar. These beings are either originally correlated or they meet and become united. They part and once more seek one another, and thus effect an infinite production of every kind and on all sides. The more imperfect a being is, the more alike or similar are these parts to each other and the more alike are they to the whole. The more perfect the being becomes, the more dissimilar become the parts. In that case the whole is more or less like the parts, in this the whole is dissimilar to the parts. The more similar the parts are to each other, the less they are subordinated to one another. The subordination of the parts indicates the more perfect being." These words embody the views of the modern naturalist, for they contain already the essential elements of the cell-theory.

What is life? Every time that a great discovery has been made in natural science there is new hope that a nearer approach has been gained to this question which is all-important to the mind of man. Never seemed the hope of solving the riddle of life nearer its realization than when the invention of the microscope opened new paths to scientific research. So overwhelmed were the first investigators by all the wonders of this new world of minutest organisms revealed by this remarkable instrument 



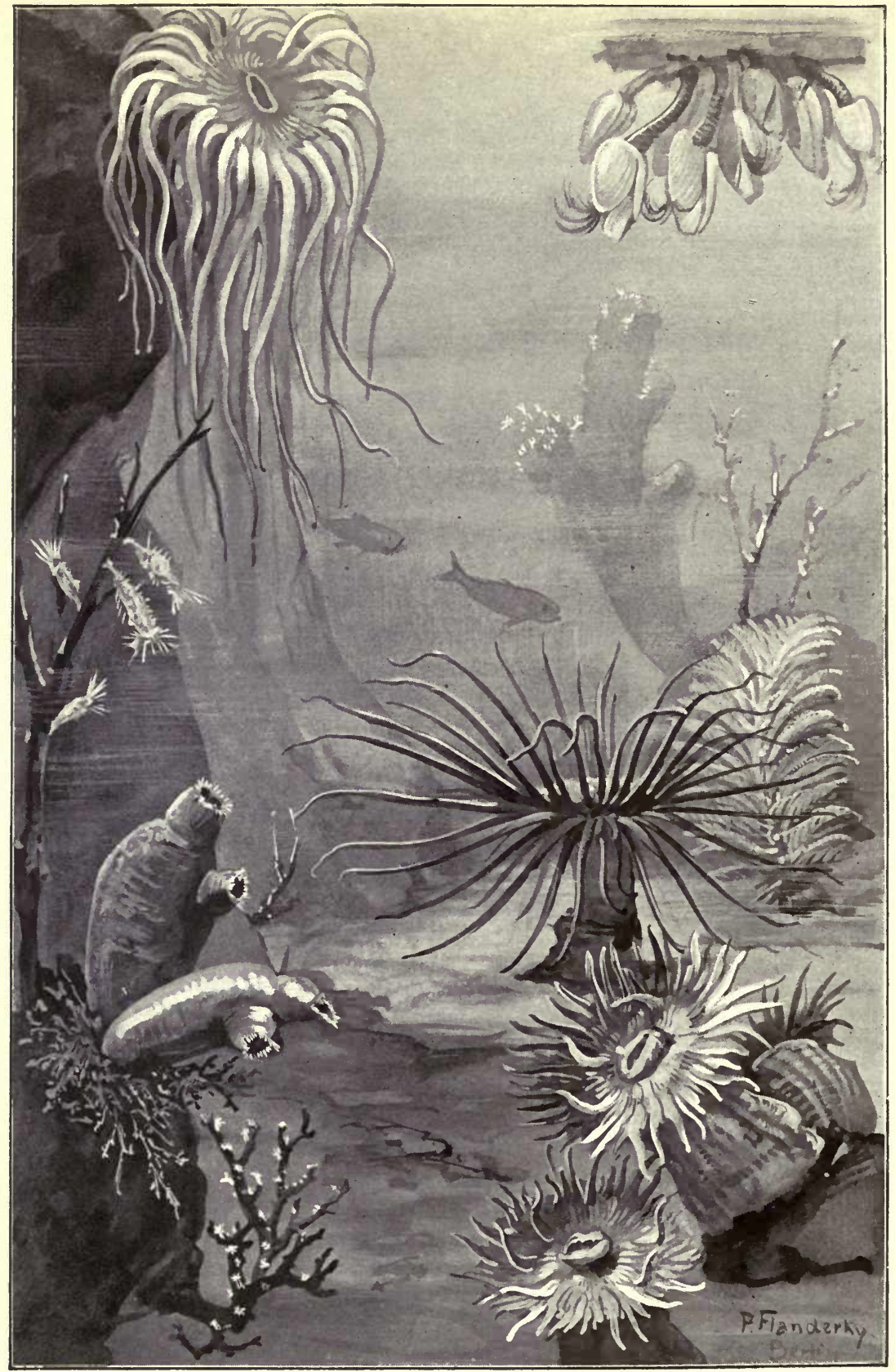

FIG. 16. -ANTHOZOA.

On the left, below, fixed on the rock, Noble or Red Coral (Corallium nobile s. rubrum) ; above, two Tunicates (Cynthia papillosa); in the corner, a Sea-anemone (Anemonia sulcata); on the right, above, a colony of Barnacles (Lepas anatifera); below, in the back ground, Leather-coral (Alcyonium palmatum); in front of it, Sea-pen (Pennatula phosphorea); in the centre, Sea-anemone (Cerianthus membranaceus) ; in the foreground, on the right, three Sea-anemones (Adamsia rondeletii). 
that they regarded it as sacrilege to peer deeper into the 'secrets of Nature which, according to Divine will, were to be for ever hidden from human eyes.' It was only very gradually that objective investigation availed itself in full of the new achievements of technical skill, and to-day we owe almost all the vast progress of modern science to the insight into the interior of organic bodies granted by the microscope.

When we observe the world of animal and plant organisms we find in the structure of their bodies a fundamental and complete likeness: they are composed of an immense number of minute homogeneous building-stones which we are accustomed to call cells. Whichever organ we may examine with the microscope, we shall always find that it is composed of single cells; and when we descend into the world of invisible organisms, known to most men not even by name, and observe the simplest and lowest animals and plants, we shall find that they are nothing else but free-living single cells.

But the most important discovery was that even the highest and most complex organism, composed of many million cells, whether man, animal, or plant, consists at the startingpoint of its individual existence of but a single cell-the ovum, or, more accurately, the impregnated cell, for, as a rule, it is necessary that two cells, the female ovum and the male spermatozoon, become united in order to render the production of a new organism possible. Through many divisions of the eggcell, the differentiation of the individual parts, according to the duties which they will later be called upon to perform, and the fusion of homogeneous cells, tissues are formed; these unite to form the various organs which constitute the fully developed organism, whether animal or plant.

We may conveniently point here to an error committed by many persons. If they are asked to state the difference between an animal and a plant they will not hesitate to mention a large number of seeming distinctions. They do so because most persons think in such a question only of the types of both natural kingdoms known to them, that is, the most highly organized and most complex. The distinctive features between a pear-tree or a poplar, a fern or a blade of grass on one side, and a lion, horse, worm, butterfly or crab on the other are, of course, so obvious and 
so radical that the existence of any relationship seems excluded. But the boundary becomes less distinct when we come to simpler forms. Let us, for instance, examine the coral-stock with its tree-like branches, its many hundreds of individual inhabitants and, simultaneously, builders - the polyps-which peep like tiny blossoms from the branches of this tree; or the closely related sea-anemone, large numbers of which clothe the rocks at the bottom of the Southern seas as with a brilliant flower-carpet. Here even a trained observer might often be doubting whether he is looking at an animal or a plant. As recently as the end of the seventeenth century even naturalists counted both corals and sea-anemones among plants. When the French physician and zoologist, Peysonnel, endeavoured to prove the animal nature of these organisms, and submitted his discovery to the Academy of Sciences in Paris, the President of the Academy, the famous physicist Réaumur felt it his duty to suppress the name of the author of such an improbable assertion. And yet the organization of the polyps shows that they are undoubtedly animals.

Everyone knows the skeleton of the bath-sponge. Who would think that sponges are animals? Firmly fixed to the bottom of the sea, the sponge is betraying with not a single motion that it is a living creature. Only the most accurate microscopic examination and observation of its development enable us to demonstrate its animal nature. The young sponges leave the body of their mother as minute ciliated larvæ and swim gaily about. This free life lasts several days, and then the little animals attach themselves to stones or similar objects and become motionless sponges.

These few instances, and particularly a glance at our illustration, will show that external appearance alone is not sufficient to enable us to distinguish between animal and plant. Let us now briefly consider the various distinctive features upon which science has based the division of the organic world into two large kingdoms.

The greatest distinction is represented by the difference in the process of metabolism. Whilst the animals are for their nutrition restricted to organic matter, that is, other living things, we have already seen that plants possess the faculty of extracting 
their food directly from the surrounding atmospheric air. Thanks to the presence of a certain substance contained in the plantcells, the chlorophyll or plant-green, plants are enabled to absorb the carbon dioxide of the air and, under the chemical influence of the sunlight, split it up into carbon and oxygen. The oxygen is then largely exhaled whilst the carbon enters with the water introduced into the plant from the earth through the roots into the first visible organic compound, starch. Starch is the first and the only product of assimilation from which all other organic compounds of the plant are formed by means of chemical metamorphosis. From starch we obtain all other carbohydrates, fats, and, finally, the highly complex albumen. Animals, on the other side, inhale oxygen and exhale carbonic acid, so that between the two kingdoms a never-ending exchange takes place. It seems, therefore, as if the presence or absence of the chlorophyll, and the kind of alimentation conditioned by it, is a fundamental factor in differentiating between plant and animal.

But there is found in every ditch and pool a minute relative of the magnificent sea-

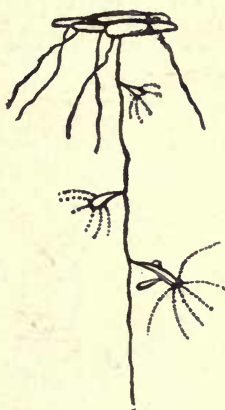

FIG. 17.

FRESH - WATER POLYP (Hydra viridis) oN THE ROOTS OF DUCKWEED (Lemna).

(From v. Hanstein, "Naturgeschichte des Tierreichs.") anemone, the little fresh-water polyp Hydra viridis. This delicate little organism is distinguished by its beautiful green colour, which on examination proved to be due to chlorophyll. When this discovery was first made it seemed to destroy the most important factor in distinguishing between animal and plant, until it was further discovered that these chlorophyll-corpuscles are not produced by the Hydra and do not belong to its body, but are independent unicellular plants (Algæ), which penetrate from the outside into the body of the Hydra and grow and multiply.

Whenever we observe in Nature such intimate living-together of two different organisms our first thought is that we have before us a case of parasitism in which one part lives at the expense of the other. But in this case we are observing an intimate alliance, a so-called symbiosis, into which Hydra and 
Algæ have entered to their mutual advantage. Confined within the cells of the polyp the Algæ do not only find shelter for an undisturbed growth, but share at the same time in the carbon dioxide which the polyp exhales. In return the Algæ supply the polyp with the necessary oxygen, and also with a part of the starch produced by them.

In some of the marine polyps which, like the Hydra, give shelter to Algæ, mutual adaptation has made such progress that, for instance, the sea-anemones have lost the power of taking their
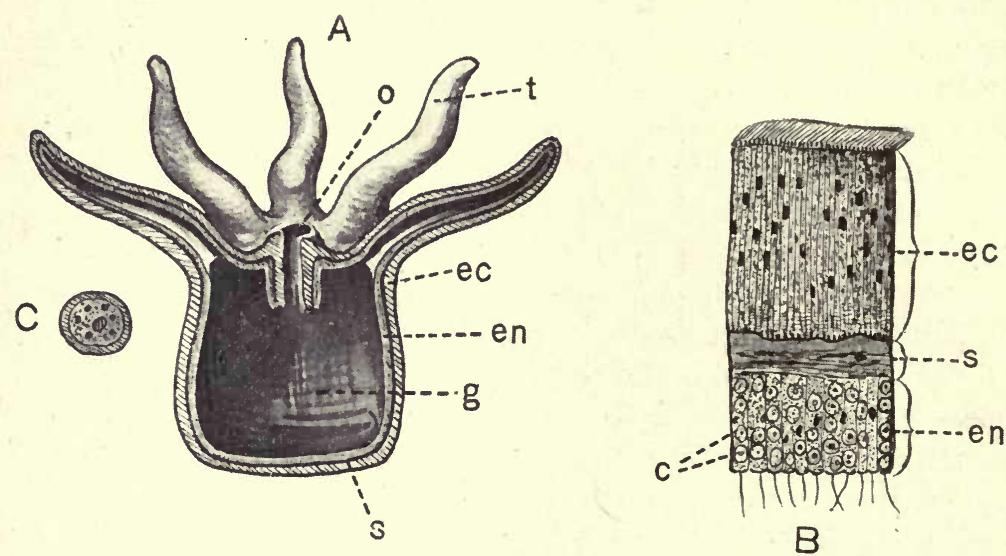

FIG. 18. - SYMBIOSIS OF SEA-ANEMONE AND UNICELLULAR ALGA.

$A$, Section of Sea-anemone: o, Mouth aperture; $t$, tentacles ; $g$, stomach cavity ; ec, ectoderm : en, endoderm ; g, supporting lamella. B, Transverse section of the body-wall (magnified): c, Unicellular algæ within the endoderm. C, Unicellular algæ (greatly magnified). (After O. Hertwig.)

food independently, but are fed entirely by their 'lodgers.' Experiments have shown that without Algæ they are invariably doomed to die from starvation. We may even regard Algæ and the polyp as one individual, for these minute plants even invade the growing ovum of the polyp and are thus 'inherited' by the descendants from the mother.

There is, however, a large class of plants the species of which possess no chlorophyll at all. These are the fungi. As a result of this defect fungi have lost the power of extracting their food from the inorganic world and are, like animals, restricted to 
organic food. Numerous other parasitic growths have no chlorophyll, but are nevertbeless true plants.

Since the time of Linnæus the faculties of nutrition and reproduction have been generally ascribed to plants, whilst animals were said to possess in addition the faculties of sensation and motion. These distinctions, however, can no longer be maintained.

We have already seen that numerous lower animals-sponges, corals, and sea-anemones-possess no power of locomotion. Sponges do not even exhibit any externally noticeable signs of motion, and are all but insensible to every kind of stimulus. Even among the higher animals many have given up their free life; various species of crabs, for instance, Acorn-shells and Barnacles, as well as numerous tunicates which for various reasons are regarded as the precursors of the vertebrates, are fixed to the ground. On the other hand, there are plants which in response to certain stimuli are able to execute distinct vivid movements.

In hot-houses we often meet with the famous sensitive plant (Mimosa pudica), known in tropical countries as a most objectionable weed. The leaves of this plant are 'beautifully divided, again and again pinnate, with a great number of small leaflets of which the pairs close upwards when touched. If we shake the plant, the leaflets close together, the pinnæ sink down, then the leaf-stalks sink down, and the whole leaf hangs as if withered.' For this reason popular fancy has called the mimosa the ' chaste flower.'

Striking and apparently voluntary movements are executed by various 'carnivorous' plants of which we know at present about five hundred species. The ability to react to a stimulus has in some of these plants reached a very high degree. Darwin's investigation showed that in the well-known Sundew (Drosera rotundifolia) a curving of the glandular 'hairs' took place in response to a stimulus exerted by a particle of hair $\frac{1}{5} \mathrm{~mm}$. in length, or of $\frac{1}{30,000} \mathrm{mg}$. of phosphate of ammonia. It is a remarkable fact that it is impossible to deceive these 'tentacles' and entice them to useless exertions, for the movements are only executed if the leaves are touched with a nitrogenous body, that is, one that may be used for food; when touched with nonnitrogenous minerals no reaction takes place. 
More striking still are the movements of the Venus's Flytrap (Dionca muscipula), a native of North America, where it occurs on moorlands. 'It has a circle of more or less prostrate leaves round the base of the stalk which rises 4 to 6 in. from the ground. The leaves, about $4 \mathrm{in}$. in length, consist of

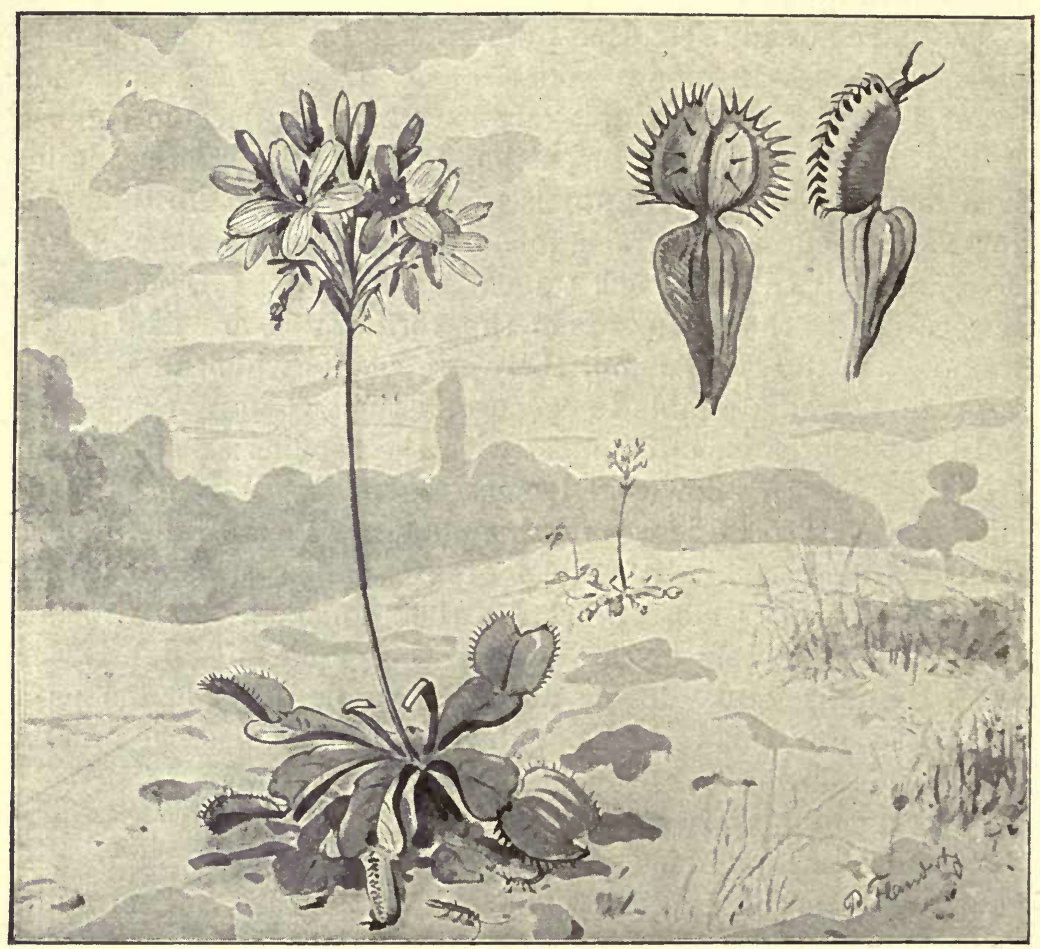

FIG. 19.-VEnUS's FLY-Trap (Dionca muscipula).

Above, two leaves of Dionæa, one prepared for a capture, the other with a captured insect.

a spatulate stalk which is constricted to the mid-rib at its junction with the broad blade. The halves of the blade are movable on one another along the mid-rib, and close together, as this book would do if fitted with an automatic closing spring. Round each margin are twelve to twenty long teeth which inter- 
lock in rat-trap fashion with those of the opposite side. The centre of the leaf bears numerous digestive glands, and there are on each half of the blade three sensitive hairs which rise obliquely, but bend flat on a basal joint when the leaf closes. The blade shuts up in eight to ten seconds when one of the sensitive hairs is stimulated, and if an insect is caught in the fly-trap a profuse secretion is exuded from the glands; after a week or a fortnight the insect is digested and the leaf then reopens.'-(Thomson.)

It has long been known that the leaves can carry out movements calculated to place themselves in the most favourable position to the light. Haberlandt's investigations showed that these movements are made by organs situated in the upper epidermis, which not only perceive the light-stimulus but also the direction of the light. In the simplest forms the entire upper epidermis of the leaf has become a light-sensitive epithelium. In other plants, for instance Fittonia verschaffelti, a few specifically formed cells have assumed the rôle of primitive eyes, called ocelli, like the analogous organs in the lower animals. In Fittonia these ocelli consist of two cells, one above the other. Protruding from the other homogeneous epidermis-cells are in different places large cells with strongly vaulted outer walls, each of which carries on its head a small biconvex lens-cell. The interior of this lens-cell is filled with a clear, highly refractive substance. Probably these ocelli were evolved from cilia. But not only light-sensitive organs but also specific forms for the reception of mechanical stimuli and stimuli of gravitation have been made known as the result of laborious research, and thus what once appeared to be a fundamental distinction between plant and animal has become a new connecting link.

Many experiments have further demonstrated the inaccuracy of the assertion that only plants are able to form cellulose, for this substance is not only found in the protective covering of many of the lower animals but forms also the chief constituent of the mantle of the tunicates.

More vague still does the line of demarcation become when we come to unicellular organisms; for here in the majority of cases it becomes really a matter of choice whether we count certain organisms among animals or plants. With each advance made by science it becomes clearer that a natural division of 
the organic world into two separate kingdoms does not exist. However much each highly organized animal may differ from the higher plant, the history of their development proclaims their common origin. Animals and plants are but two branches of one tree of life. If, nevertheless, a line of demarcation is still drawn, such a proceeding is justified only by considerations of utility.

The discovery and establishment of the modern cell-theory is of comparatively recent date, for it is only since the beginning of the past century that the work of Mathias Schleiden, Schwann, v. Mohl, Max Schultze and others brought about a complete revolution in the methods of scientific research and made possible an undreamt-of advance in the whole of our knowledge of Nature.

As early as 1667 an English scientist, Robert Hooke, succeeded in demonstrating by means of a microscope constructed by himself that a particle of cork is built up of an immense number of single homogeneous parts. He it was, too, who first used the name of cell in this connection, because of the similarity of these forms with the cells of bees and wasps. Not many years afterwards (1672) the English botanist Grew published a comprehensive work ("Anatomy of Plants"), with numerous microscopic pictures of sections of various parts of plants, in which the cell-like structure may be distinctly observed. Even then it was already perceived that the individual 'bee-cells' differed in structure and appearance, and that homogeneous cells joined together and formed larger structures; nor did these investigators fail to observe that in growing parts the cells grew in size and multiplied in number. But the true cause of all these phenomena, the seat of life in the plant organisms, remained nevertheless hidden in darkness, for what the early investigators saw and described was but a dead, unimportant component, a secretion of the cell, its membrane. Only with the discovery by v. Mohl and Schleiden of the living contents, the cell-body, with the perception of the uniform construction of the whole plant-world out of homogeneous elementary organs, and finally with Schwann's demonstration of analogous conditions in animals, the cell-theory took the field and gradually gained its present importance. 
Each cell we must conceive to be a minute chemical laboratory within the narrow space of which there goes on the sum total of all the processes, changes, and movements which we are wont to designate as life. Whenever and wherever on earth we may find life, we shall always find it bound to a cell, that is, to an elementary organism, the body of which consists of two different substances or parts, the protoplasm and the nucleus.

Until recently numerous investigators maintained the existence of more primitive organisms, so-called Monera or Cytodes, which had not yet attained the organization of the cell. But since Haeckel established his class of the Monera, the number of those elementary organisms which were said to be without a nucleus has decreased year by year in proportion as our optical instruments and staining methods have become more perfect. It is not difficult with modern instruments to demonstrate a typical nucleus-cell in many cells which were formally believed to be without a nucleus, for instance, various species of amœbæ, myxomycetes, \&c. It is not necessary for the nucleus to be formed homogeneously; in many cases, for instance in the protozoon Pelomyxa pallida, the nuclear substance is distributed in numberless minute granules throughout the entire protoplasm. Of other cells which at the mature stage are without a nucleus -in particular, the red blood-corpuscles of mammals-we know that they have originated from nucleated cells.

The only remaining non-nucleated cells, therefore, are the bacteria and the yeasts, but evidence is accumulating tending to show that even these are typical nucleated cells. Quite recently Wagner succeeded in demonstrating not only that yeast-cells have a nucleus, but also that they are cells with a highly organized nuclear apparatus. According to the investigations made by Bütschli it seems further probable that the bacteria, too, are differentiated into plasm and nucleus. This excellent investigator found that in some of the larger bacteria-spirilla, spirochætæ, \&c.-it is possible with a high-power microscope and the aid of special nuclear dyes to demonstrate the presence in the body of the bacterium of two different substances, one of which represents the protoplasm, the other probably a primitive nucleus. All but those that are bound by prejudice must therefore admit that science knows not a single non-nucleated 
organism, and that there is therefore no justification for retaining the belief in the existence of such ' simplest organism.' When and whether Monera lived in times past can only be a matter of speculation.

The size of the different species of cells varies between fairly wide limits. By far the larger majority is minute, standing close to the limits of visibility. Often it is just barely possible to observe them with the naked eye or a magnifying glass as minute points. But there are cells so incomprehensively minute that they can be observed only with the most powerful instruments, magnifying 2,000 to 3,000 times. To these infinitely minute bodies belong numerous bacteria, several protozoa, and the male germ-cells of many animals. Some of these protozoa and bacteria attain only a length of $\frac{1}{2.000} \mathrm{~mm}$. The cocci of pus attain a volume of only $\frac{1}{1,700,000,000} \mathrm{c.mm}$. In one drop of water there is ample room for thousands of millions of these bacteria, and a glass of water would to them be more immense than the earth is to the human race. In spite of this minuteness, attempts have been made to calculate the weight of one of these cocci; the result given is $\frac{1}{6,000,000,000} \mathrm{mg}$. In order, therefore, to obtain 1 gramme of them it would be necessary to heap up six billions of these minute organisms. But even with these minute measures the lowest limit of life has apparently not yet been reached, for the germs of pleuro-pneumonia, for instance, are so minute that they pass even through the densest porcelain filter; indeed, there seems little hope of our ever perceiving them with modern microscopes; we know the effects of these dangerous organisms, but the organisms themselves remain invisible.

Many cells, on the other hand, reach considerable dimensions, and may be easily perceived with the naked eye. Veritable giants among them are the eggs of different animals, in particular of reptiles and birds, for they are nothing but single enormous cells. It must, however, be taken into consideration that by far the greater part of these eggs consist of the store of food which is to serve later for the support of the growing embryo.

In plants, too, we know cells of considerable magnitude, as, for instance, the bast-cells, which reach a length of 10 to $20 \mathrm{~cm}$. Caulerpa, one of the marine Algæ, though it often reaches a length of 1 metre and has a body with stem and leaves, is nevertheless but a single multi-nucleated cell. 
In the living state the cell represents a minute drop of lightcoloured, almost opaque liquid. Like every other drop of liquid, this cell has in the free state the desire to contract itself into the smallest possible volume, that is, to assume globular form. The sphere is theoretically the ideal form of the cell, but we find it only rarely realized in Nature. Even the simplest protozoa assume the form of a sphere only temporarily when about to rest. In the body of the higher organisms there is hardly a shape which the cell is not able to assume. Here we find cubic and flat, cylindrical and oval, spindleshaped and branched cells, and even in the unicellular organisms the variety of forms is astonishing. But however different the various species may appear, however radical the difference may be in the form of the protozoon and the unicellular Alga or the cell of the metazoon, there is one point

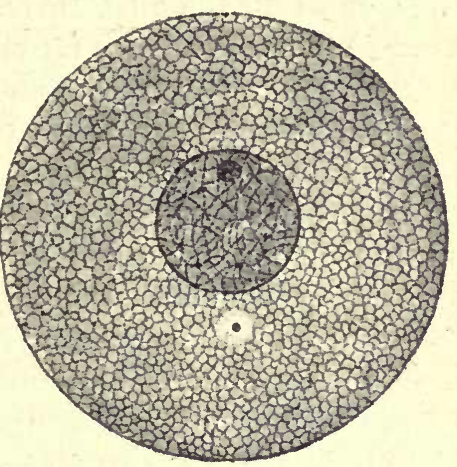

Fig. 20.-STRUCTURE OF A CELL. in which their structure always agrees : their composition of protoplasm and nucleus.

The most important and largest part of the cell, the substance with which all functions of life appear to be connected, is the protoplasm. But when we ask what this protoplasma really is we are regretfully compelled to admit that at present we know very little of its nature.

Chemically, protoplasm is no homogeneous body, but a highly complex compound in a continual state of change, consisting mainly of albumen, which is formed chiefly of the five elements hydrogen, carbon, oxygen, nitrogen, and sulphur. It is always rich in water. When we withdraw the water, protoplasm becomes hard and tough and the functions of life cease, without, however, necessarily becoming extinct. We have already seen that many cells are able in such a state of rest to remain alive for a great number of years and, on a renewed supply of water, to awaken to renewed activity.

In slightly magnified protoplasm we can easily distinguish 
a homogeneous opaque main substance, and embedded in it numerous strongly refractive granules; higher magnification shows that the refractive granules lie on the fine meshes of a delicate network embedded in the opaque main substance. According to modern opinion we must regard these meshes as the optical transverse section of a cell-system, in other words, we must assume that the cell is built after the manner of a beehive. The walls of the single cells are formed of a more solid substance, whilst their interior is filled with a clear liquid, the cell-juice. But not all cells have such complex organization. In many cases even the most powerful microscope reveals only the hyaline main substance with numberless granules distributed throughout the cell.

In order to gain an insight into the life-functions of these minute elementary organisms let us examine a simple protozoon, an Amoba, which we may find at any time in a ditch. At first, frightened by the dazzling light in the microscope, it contracts itself into a sphere, and only the trained eye is able to decide whether the motionless little lump is a living organism or a particle of dirt. But soon the Amoba adapts itself to the altered circumstances; it becomes hungry, and with the hunger, active. Slowly, almost cautiously, the protoplasm begins to bulge in one spot and forms a minute pseudopodium. Remaining undisturbed, the Amœba gains courage and stretches its little foot further forward; soon other feet follow. At last the little animal is in full activity and moves along with flowing, crawling, lazy movements.

But in addition to these external amœboid movements there is the restless motion of the protoplasm itself : the granules move backwards and forwards, here and there, as ants in an ant-heap. This flowing of the granules is characteristic of the protoplasmic movements. It can also be demonstrated in the cells of the higher animals and plants, whose form usually becomes rigid in consequence of the secretion of a firm cell-wall, which prevents the amoboid motion. It is unnecessary to mention that these movements of the granules are not automatic, but are effected by the flow of the cell-juice.

This process may be very distinctly observed in protozoa with long pseudopodia, as, for instance, the sun-animalcules (Heliozoa). 
Like persons promenading, these granules slowly wander away from the body on one side of the little foot, and then turn round and come back on the other side. But as all persons do not walk at the same pace, so of these granules some travel quickly, some slowly; sometimes one overtakes the others, then apparently rests itself and yields the lead to others. We are able to influence the rapidity of motion, increase it or arrest it, through stimuli of different kinds, chemical influences, or the effects of warmth or cold. This is the best proof that protoplasm is irritable, that it possesses sensation. How, indeed, could life exist without the possibility of purposeful reaction, and how, again, could this be possible without sensation. If the Amoba felt no sensation of hunger, what could suggest to her the "thought" of eating?

These animalcules have no oral aperture, but they are able to absorb nourishment in an exceedingly simple manner. When on its chase the Amœba encounters an organism suitable for food, it seizes it with its pseudopodia and wraps itself around it. Then in the interior of its protoplasm all the nutritive parts of the prey are extracted and the indigestible remainder ejected. Certain cells of the body of higher animals - the white bloodcorpuscles or leucocytes - feed in this primitive manner, to the great advantage of the organism, for the leucocytes represent, as it were, the natural bodyguard whose duty is to take care that no dan-
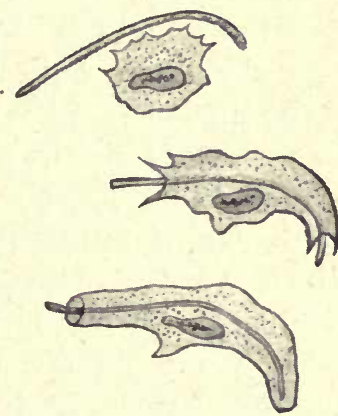

FIG. 21.-LEUCOCYTES OF THE FROG DEVOURING A BACILlUS. THREE SUCCES. SIVE STAGES.

(After E. Metchnikoff.) gerous germs settle down in the body.

Differing but slightly in outward appearance from the Amobæ, and being, like them, motile, the leucocytes leave the blood-channel and traverse all the tissues of the body. When on these scouting expeditions they encounter any bacteria or any other minute parasites they dispose of them by the simple process of eating them up. Many illnesses are probably warded off by the watchfulness of these phagocytes (see fig. 21). The leucocytes are also believed to fulfil a useful part in the nutrition of the body-cells by charging themselves with liquid food from the intestinal glands and 
distributing it throughout the body. Sometimes, however, when morbid changes of the organism facilitate an excessive increase in the number of leucocytes they may become a serious danger. They are then no longer content to feed on bacteria and senile body-cells which are no longer able to do useful work, but make raids upon the healthy tissue. In contrast to the phagocytes, most of the other body-cells are unable to absorb solid particles but are restricted to fluid food.

If we observe an Amœba under the microscope we might easily be led to conclude from the fact that the changes take place only in the protoplasm that only this substance is essential to the course of the functions of life. This would, however, be wrong, for though invisible it is the cell-nucleus which regulates the various processes. Only when nucleus and protoplasm cooperate normal life becomes possible.

I shall here only be able to give a very general description of the nucleus. Like the cell itself, it is greatly variable in size. As a rule, its size is proportioned to the amount of surrounding protoplasm. Thus we find in the large ganglion cells, and in particular in immature ova, nuclei of considerable dimensions, which we can observe with the naked eye and take out of the cell-body with a pin. But this rule is not without exception, for in ripe and fertilized ova the nucleus becomes sometimes so minute that it is difficult to demonstrate its presence. The normal position of the nucleus is in the centre of the cell, but sometimes it leaves its place and wanders to other positions. But wherever it may be, it remains always surrounded by protoplasm. According to their behaviour towards certain stains we distinguish in the nucleus two main substances, of which one, chromatin, exhibits a strong inclination towards dyes such as hæmatoxylin, carmine and others, and stains intensively, whilst the other, achromatin or linin, does not as a rule stain.

In its morphology the nucleus repeats on a minute scale the structure of the whole cell (see fig. 20). Here, too, the main substance is a light-coloured, filamentous fluid which is known as the nuclear juice. Its volume mainly decides the size of the nucleus. Embedded in the nuclear fluid is a very fine meshwork formed of linin-threads which according to many investigators must be regarded as the optical expression of the alveolar 
or "cell" structure. In the resting nucleus the chromatin is usually lying on the linin-threads in the form of granules. This is particularly noticeable at the corners of the meshes.

Of all the parts of the nucleus the chromatin requires the most thorough consideration, for it is said to be the agent which transmits the qualities of the parents through the germ-cells to the children. We shall in another place consider at greater length the reasons which compel us to this assumption. That the chromatin is a most important substance is proved by the striking part played by it in the reproduction of the cell.

Whether the nucleus is divided from the protoplasm by a special membrane is a question which is at present undecided; probably different nuclei act in a different manner.

It remains to mention a minute globule of a deep black colour frequently found in the nucleus, the 'nucleus-corpuscle.' What influence it has upon the life of the cell is at present unknown, but as it is absent from many cells it is doubtful whether any great importance is to be attached to it.

Each cell contains usually only one nucleus, but we know many vegetable and animal cells which contain two, three, and even a hundred nuclei.

Next to the nucleus we observe in most animal cells a little strongly refractory granule surrounded by a halo. This is the so-called centrosome which, according to many investigators, represents the organ of locomotion. We shall deal with it in detail when we come to consider the division of the cell.

The organization of plant-cells differs from that of animalcells in that in the former we have to deal regularly with a cell-wall or membrane secreted by the protoplasm. In addition the plant-cell contains the chlorophyll, which we have already mentioned. It is these minute green corpuscles which render it possible for all animal life on earth to exist, for only they possess the faculty of changing inorganic matter into organic compounds.

Let us now endeavour to gain an insight into the function of the single cell-parts. Though the layman will no doubt wonder how it is possible to obtain accurate information from examining such minute forms, he may rest assured that the task looks more 
difficult than it really is. There are two methods by which we can gain this knowledge-direct observation, and experiment.

If, for instance, we observe under the microscope a plant-cell about to strengthen its membrane in any one point by fresh lamellæ of cellulose it will be noticed that the nucleus leaves its normal position in the centre of the cell and wanders to the point under discussion. Here it remains until the work is completed, when it returns to its original place. Does not this observation suggest that the nucleus takes an active part in the construction of the cell-wall? Korschelt showed, further, that in the developing ova of many animals the nucleus sends forth during the preparation of the food-yolk long pseudopodia-like shoots, and that the production of yolk is most intensive in the direction of these pseudopodia. It is therefore very probable that the nucleus exercises also a certain influence upon the formation of yolk.

Still more convincing are the replies which we obtain to our questions from experiments ; minute though the protozoa are, they are not so small that we cannot perform certain operations with them. If we dissect the body of an Amœba into a nucleated and non-nucleated half the fate of the parts is very different. At first the two animalcules thus created seem to have suffered in nowise from this operation; they round themselves off, protrude their pseudopodia, crawl about, and may even be observed to absorb food like healthy Amœbæ. But whilst the nucleated part digests and assimilates the nutriment the non-nucleated part is unable to derive any advantage from its food which remains undigested in the protoplasm. Soon we observe in the non-nucleated part distinct signs of decay, and finally it disintegrates into a minute heap of granules. In the meantime the other Amœba has repaired the damage and grown once more to normal size. Hence it is impossible to doubt that the protoplasm without a nucleus cannot live, and that the nucleus plays the leading part in metabolism, the nutrition of the cell. We must, however, be careful to guard against an exaggeration of the significance of the nucleus. As the protoplasm needs the nucleus, so the nucleus needs the protoplasm. Verworn succeeded, by a clever operation, in taking the nucleus from a marine protozoon, Thalassicola pelagica, a little ball of nearly $0.5 \mathrm{~cm}$. in diameter. This experiment proved that the nucleus invariably 
dies after having been entirely separated from protoplasm, whilst it was able to reconstruct another complete animal as long as only a trace of protoplasm had been left adhering to it. We are therefore able to say, by way of summing up, that the functions of the cell-body are chiefly locomotion and the absorption of food, whilst the nucleus controls the metabolism and regulates most of the vital functions of the cell. Only as long as both parts collaborate will the life-machine be able to do its work.

However simple the structure of the cell may appear from the foregoing remarks, it can nevertheless assume the most manifold forms. Just as the body of a higher organism is divided into a great number of single organs and tissues, and as each of these parts performs a definite vital task, so we observe in the single cell a far-reaching division of labour. This is most striking in the unicellular protozoa in which the one cell, depending upon itself alone, must minister to all the wants of life. We find, therefore, that in them the protoplasm frequently proceeds to the formation of certain minute organs of motion, organella, as we will call the different instruments of the single cell, as distinguished from the multicellular 'organs' of the metazoans and metaphytes. We are able principally to distinguish two types: thin delicate hairs or cilia, which are mostly distributed in immense numbers along the surface of the body, or a few long, whip-like forms, or flagella. By means of whipping movements these cilia or flagella enable the cell to glide easily through the water. In numerous protozoa we find, further, that the cell-body is divided into several sharply defined layers, each of which performs a separate task. The external plasm is capable of becoming rigid, thus forming a protecting cover ; another part forms special weapons of defence, and only the inner protoplasm containing the nucleus continues to perform its original task of assimilation. We even know numerous unicellular protozoa which have proceeded to the formation of a cell-mouth and cell-anus, possess a complex system of excretion, and even simple organella of sight and touch. Like the protozoa, the body-cells of the higher animals may be differently constructed, corresponding to their special functions. An ovum differs in appearance from a spermatozoon, a nerve-cell from an epithelial cell. A glance at the illustration ( $p$. 78) will show these radical differences. 
When we describe the cells as the building-stones of the organic world we are doing justice only to one side of their nature, for they are not only building-stones, but at the same

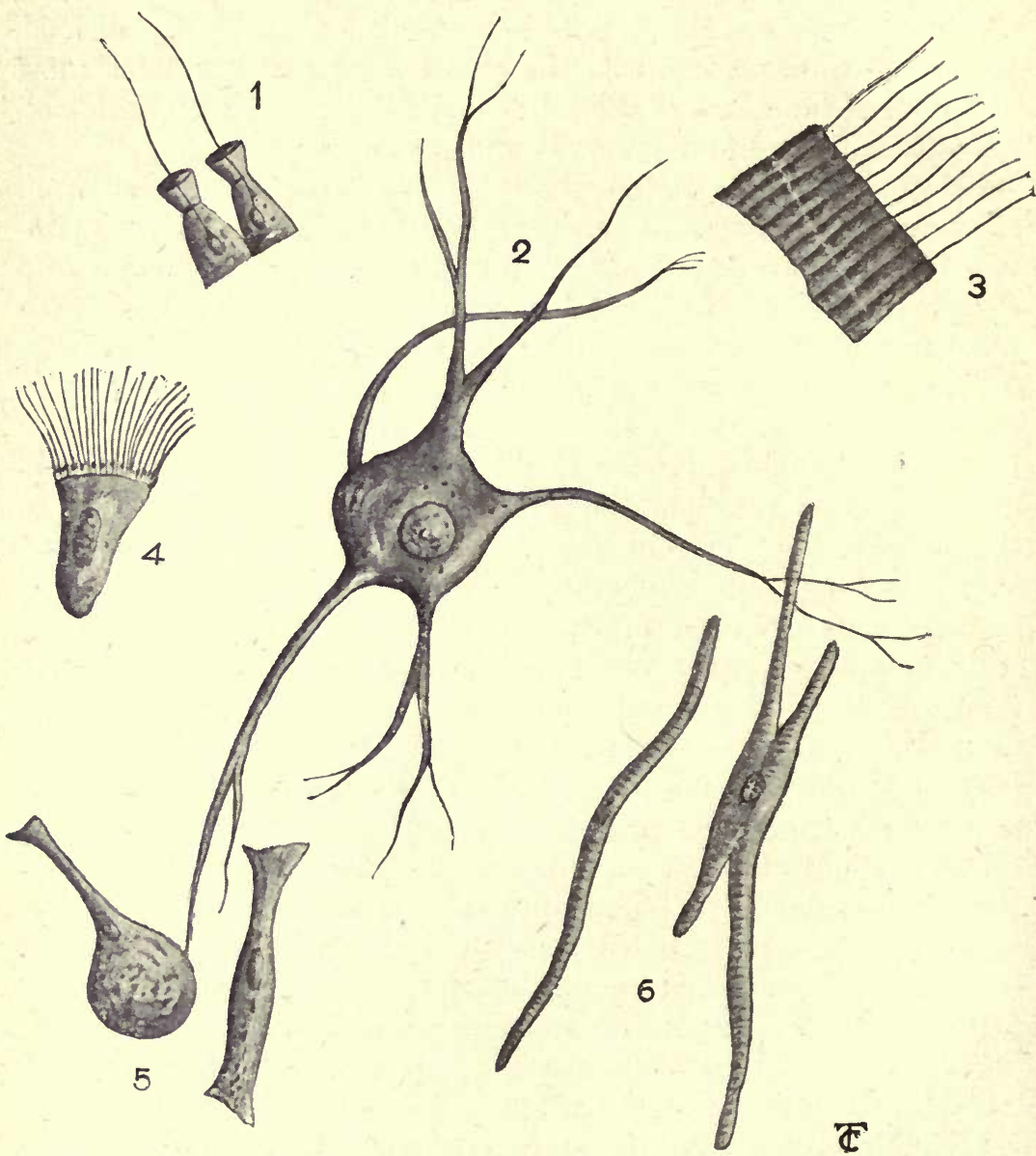

FIG. 22. - CELL-FORMS.

(1) Flagellate cell of a sponge; (2) ganglion-cell from the spinal cord of man; (3) epithelium of a flagellate cell from the stomach cavity of a sea-anemone;

(4) ciliated cell of a mussel; (5) cell from the intestinal epithelium of man;

(6) striated muscle-cells from cardiac wall of frog.

time builders. The growth of each higher multicellular organism depends upon the power of each individual cell to enlarge and multiply, to produce out of itself new building material. It 
needed the laborious research of many decades before science gained an accurate conception of the multiplication of the cell, and even to-day we are still far from an accurate understanding of all the details of this process which is of the utmost importance for the preservation of life.

Formerly it was usual to compare cells with crystals. It is probably due to this wrong conception that Schleiden and Schwann, the founders of the cell-theory, formed such faulty ideas regarding the genesis of new cells: they thought that cells crystallized, as it were, out of a mother-liquor, the germinal matter. By his observations Schleiden had been driven to the conclusion that the light-coloured fluid which fills the adult plant-cell forms this germinal matter; according to him this liquid first forms by condensation a minute granule - the nucleolus, around which afterwards the nuclear substance aggregates. The nucleus then becomes a formative centre for the protoplasm. Schwann went yet a step further in his error and taught that free cell-formation also permanently takes place outside the cells, in the so-called intercellular substance of the animal body. The first scientist who opposed this doctrine of the spontaneous generation (Urzeugung) of the cell was the botanist v. Mohl. He demonstrated that at least in the plant kingdom the new formation of cells can only take place in correlation with, and by the division of, already existing cells. It took, however, many years before this erroneous conception was finally disposed of by Remack, Virchow, and others who demonstrated that the law enunciated by Mohl applies to the whole organic world, and that therefore no free cell-formation can take place in the body of animals. Virchow coined the farmous sentence, "Omnis cellula e cellula," a pronouncement which has been brilliantly justified by all subsequent researches. But not only do the cells not form themselves anew, their most important organ, the nucleus, too, owes its origin to a pre-existing nucleus, and we may therefore further say " Omnis nucleus e nucleo."

We have already had an opportunity of dealing with the white blood-corpuscles, the leucocytes. In addition to this 'sanitary police' which represents only a very small part of the blood we find in human blood enormous numbers of small round discs, the red blood-corpuscles. T'hough they are non-nucleated in the 
adult stage, they have nevertheless descended from typical nucleated cells, having lost the nucleus as they grew up: as their task has been fulfilled they are no longer in need of it. After having circulated for a short time through the arteries and supplied the tissues of the body with oxygen from the lungs these red blood-corpuscles decay and are disintegrated in the liver, other new corpuscles taking their places. When they are young we are able to observe quite distinctly the process of reproduction. First the body of the cell extends longitudinally and the nucleus assumes the form of a dumb-bell. The groove in the centre grows deeper and deeper, and soon we observe in the protoplasm, in the place of one large nucleus, two smaller nuclei. Now the two nuclei commence to move, each to an opposite pole. Here they remain, for their part in the process of division is over. While these alterations went on in the nucleus the protoplasm did not remain idle. We saw that the cellbody commenced to extend longitudinally. Soon it begins to constrict in the centre of its axis, and the originally round blood-corpuscle gradually assumes dumb-bell form. We have now before us two small nucleated cells beld together by a thin cord of protoplasm. Finally, this last connecting link is severed and the act of reproduction is over: one blood-corpuscle has become two, which soon replace by growth the loss of substance and then proceed in their turn to division, or develop into red bloodcorpuscles.

But division proceeds only in rare cases in this simple manner, for only cells whose descendants will shortly cease to live are able to transmit to them parts of the nuclear substance in this roughand-ready manner. That with this primitive method of multiplication the distribution of the nuclear substançe is very unequal must be clear to everyone. We see, however, that as a general rule the process of division is much more difficult. In place of the crude constriction there is a mechanism which carries out the division with wonderful accuracy, effecting an absolutely just and equal distribution of the chromatin. This process is called indirect nuclear division, or mitosis. Generally mitosis takes place in four different phases which have been described as prophasis, metaphasis, anaphasis, and telephasis.

In a resting cell (compare fig. 20) all the chromatin is 

distributed in the nucleus along the nuclear framework. The first step to the indirect nucleus-division is that the fine chromatin granules arrange themselves into one long much-intertwined coil of thread. Simultaneously characteristic changes appear in the centrosome. It divides in two minute grains which become the centre of a system of most delicate fibres ranged like rays; these two central bodies lie in the protoplasm like two little suns (fig. 23,1).

Gradually the distance between them increases, and slowly they wander to opposite poles of the nucleus. During this process the ray-system becomes more and more distinct. The origin of these rays or, as they are usually called, 'spindle-figures' is a much-disputed subject. While some say that they come from the protoplasm, others believe that they arise from the 'lininframe' of the nucleus. Probably their origin is different in different cell-species; they may be formed either by the protoplasm or the nuclear substance, or it may be that both substances participate in their production.

The next important change affects the nucleus. The long uniform chromatin-thread suddenly breaks up into a definite number of separate sections, the nuclear-loops, or chromosomes. The number of the chromosomes is always the same in all bodycells of the same animal or plant species, and all organisms with bisexual reproduction possess always an even number of chromosomes. I would mention in anticipation that this phenomenon finds its explanation in the fact that one half of the chromosomes is of paternal, the other of maternal origin. For instance, a nematode common in the horse, A scaris megalocephala univalens, possesses in all body-cells only two chromosomes, whilst another of the nematodes, Acaris megalocephala bivalens, has four. The human body-cells have sixteen, Helix pomatia, some Amphibians, the mouse, the lily, and numerous other organisms have twenty-four. In Artemia, a small crustacean, the number of chromosomes reaches one hundred and sixty-eight. The statement that the number of chromosomes is in all bodycells of the same animal species always the same expresses a rule to which one species of cells, the mature male and female sex-cells, forms a remarkable exception. In these the number of 
chromosomes is reduced by one-half. We shall deal with this fact later on.

If we observe highly magnified chromosomes we may sometimes see a fine crevice extending over their entire length, but in most cases they appear as yet uniform. Gradually the nuclear membranes become indistinct, and finally disappear altogether. It now seems as if the chromosomes lay perfectly free in the cell-protoplasm. Further observation will, however, show that to each chromosome there have become attached some of the 'spindle-filaments' radiating from the central bodies. Along these rays the chromosomes wander towards the centre, and finally range themselves in a plane perpendicular to the longitudinal axis of the spindle, the so-called 'equatorial plane.' This process finishes the first stage of mitosis, the prophase, and now commences the metaphase, the climax of indirect nuclear division (fig. $23,{ }_{2}$ and ${ }_{3}$ ).

It is a strange and surprising spectacle which unrolls itself before our eyes. Suddenly, and with absolute-one might almost say mathematical exactitude-all the chromosomes split along their length, like logs of wood. This division proceeds with such precision that it seems unquestionably a process of vital importance. The result of it is that the chromatin of the mothernucleus is distributed among the two newly formed daughternuclei on the principles of strictest justice. There is no other substance in the whole cell the distribution of which is watched over with such care, and it is therefore not surprising that a special function is ascribed to it. Quite early it was discovered that chromatin was the 'bearer of the hereditary qualities,' an hypothesis which, as we shall see later on, was afterwards confirmed by many investigators.

Events now rapidly tend to the end. Just as in a dolls' theatre the operator regulates at will the movements of his marionettes by means of numerous strings held in his hands, so the central bodies appear here to control each step of the chromosomes. One gains the impression that the spindle-fibres adhering to the chromosomes suddenly shrink, as if impelled by an invisible force, thus forcing the longitudinal sections of the chromosomes nearer to the corresponding central bodies. In this way we obtain the stage of the two daughter-plates (fig. 23, 4 ). 
At first the two chromosome-halves are still connected with each other by fine colourless filaments or fibres, but soon a dividing wall arises from the margin of the cell towards the centre, and with it the last connection between them disappears (fig. $23,{ }_{5}$ ). The division is now essentially complete; it only remains for the chromosomes in the young daughter-cells to change into new resting nuclei. This is done in the last act of indirect nucleus-division, the telephase. As soon as the chromosomes have arrived in the neighbourhood of the central bodies they all range themselves in close formation. They form projections and in the interior we observe the appearance of vesicles which become greatly enlarged by the absorption of fluid from the cell and drive apart the chromatin particles. Thus the original chromatin frame is once more restored. Finally a new nucleus membrane is formed, and with that act the nucleus reaches once more a stage of rest (fig. $23,{ }_{6}$ ).

There is now no trace of individual chromosomes to be seen: they have been completely dissolved into their chromatic constituents. But this is only apparently so, for as in each new division the chromosomes appear once more in the same form and number, we may assume that, though invisible, they retain their individuality in the nucleus at rest. Several facts confirm this hypothesis. If it accidentally happens during a division that a supernumerary chromosome enters iuto one nuclear half, it will reappear afterwards in all descendants of this particular nucleus.

On reviewing this wonderful process of mitosis one fact seems to be incontrovertible, namely, that all these complex processes have for their final object the most accurate distribution of the chromatin, the hereditary substance, among the nuclei of the daughter-cells. But the nature of the forces here at work, tending with such wonderful precision towards one definite aim, is a deep mystery. It is true that we are able to observe accurately with a microscope every morphological change that takes place during the nucleus-division; we gain the immediate impression that the central bodies exercise a controlling influence upon all processes and are the real 'kinetic centre' from which the various motions result, but from a real understanding of this strange play of the forces we are as yet far distant. We are here confronted with one of the deepest riddles of the Universe. 
The attempt has often been made to explain the nucleusdivision mechanically. Comparisons have been instituted between the nuclear 'spindle-figures' and magnetic force-lines; it has been possible to produce similar figures artificially in gelatine, \&c., but no success has ever been recorded in passing in such attempts beyond superficial analogies. We must agree with Yves Delage who says that "it would be as futile to regard the Lion, Balance and Fishes in the zodiac as a real lion, a real balance and real fishes, as to regard mechanically formed cell-structures and nucleus-division forms as real cell-structures and real nucleidivision forms." We must, therefore, for the present be content with a simple description of the processes, in the hope that the restless research of later times may lead us to a deeper understanding. 


\section{CHAPTER V.}

\section{THE ORIGIN OF LIFE.}

ALL our speculations about the first appearance of life on our planet must be based upon the assumption that in times immemorial the earth revolved in the universe as an incandescent sphere like those nebulous spots which we still see on the firmament. The process of cooling and condensation brought about the present form of sun, earth, and the other stars. The Law of Evolution, to which every living thing is subject, still rules the world-systems, and if there is one statement in science which we may make with every appearance of truth it is that our earth, which is to the simple mind the prototype of the permanent, was not created spontaneously but has evolved in accordance with this law.

It is true that experience deserts us here; it tells us nothing, or only very little, about the history of the world-bodies, but we may, nevertheless, regard the Nebular Theory of Kant-Laplace, at least in its fundamental principles, as one of the surest foundations of our conception of Nature.

Science can never dispense with hypothesis. The most important foundation of our natural philosophy, the Law of Causality, which is so intimately connected with our consciousness that without it we are unable to conceive any change, is but a hypothesis which we formulate and force upon Nature so that we may bring order into the chaos of phenomena. To direct observation the causal nexus between two changes is as deeply hidden as, for instance, the origin of the solar system; what we see and observe is only a variety, a multitude of concurrent or successive phenomena. When we observe that a certain change is regularly followed by another certain change we formulate the hypothesis that the second change is a necessary consequence 
of the first, and we now describe the first change as cause and the second as effect. By conceiving the Law of Causality to be necessary and universal we admit that it does not proceed from experience, for experience can only give us probability and comparative universality, but never necessity.

Let us consider the atomistic theory. An atom of the above has never been observed by any human eye, yet on the hypothesis of the atom has been reared the proud edifice of modern chemistry which owes to the atomistic theory its greatest successes. But what precisely are atoms? They are the ultimate particles, divisible neither chemically nor physically, from which all elements are said to to be constructed. But indivisibility is inconceivable. However minute we may conceive atoms to be, they always remain bodies possessing all the properties of bodies-volume, form, weight, solidity, \&c. But a body possessing volume and being indivisible is in itself a contradiction. For if we persist in dividing a body into more and more minute particles we shall finally arrive at a point where mechanical divisibility seems no longer possible, though the mind does not recognize a limit to the idea of divisibility. We see, therefore, that even the doctrine of the atom is a hypothesis which to a certain extent is in conflict with our conceptions, yet it has achieved enormous advances in our knowledge. But just as once the Ptolemaic system, though proceeding from false premises, provided a satisfactory explanation for most astral phenomena, and ruled science for thousands of years until it was replaced by the more comprehensive system of Copernicus, so it is conceivable that in future times scientific progress will remove the bounds of the atomistic theory and substitute for it a more comprehensive law.

Without hypothesis there is no science, nor is there any justification for fighting shy of hypotheses. One might even be tempted to say to the supporters of pure empirical research, who seek in experience alone the 'last word of wisdom,' that it is theory, not experience, which grants absolute certainty. How often are we not deceived by our senses? How often does not experience desert us? And even if according to Kant all our perception begins with experience, it is not by any means all knowledge that springs from experience. Hypothesis, however, must not be carried to the limitless, but at every stage prove its value by the results of experience and observation. 
So far as direct observation goes, it teaches us that every living organism which originates to-day presupposes another homogeneous organism from which it originates. The old doctrine of the great English physiologist Harvey, Omne vivum ex ovo, or more correctly, Omne vivum e vivo, is true to-day if we are content to consult our own experience gained from observation. It would, of course, be most convenient to assume that life on earth has existed in its present variety since eternityin other words, that this wealth of animal and plant life was called forth by a spontaneous divine act of creation, and had maintained itself by reproduction. Indeed, as long as man clung to the traditions of the Church this theory remained victorious. Even to-day we find in certain orthodox circles the attempt to defend the biblical creation myths as scientific facts. Science, however, has long since passed over these endeavours 'and proceeded to the first item of the business of the day.'

To-day we can admit no justification for tendencies of this kind without doing violence to our reason. The results of researches made in geology, palæontology, comparative anatomy and biology impel us in an equally convincing manner to assume for the world of organisms a gradual law-governed development from the simplest forms to more and more complex and higher organisms.

The number of investigators who have tried the edge of their speculative powers since ancient times on this most difficult and most interesting problem of all is legion. We have already seen that Anaximander and Empedocles attempted to give a natural explanation of the origin of organisms, but the state of contemporary knowledge being what it was, these theories did not exceed the value of an ingenious fancy sketch. We are even inclined to regard with derision the conception of Aristotle, according to which even the higher organized animals, such as eels and frogs, were generated spontaneously out of mud, or insects out of putrifying wood. But we have very little cause for feeling superior to him, for it is not so long since similar views were discussed seriously even in scientific circles. Everyone knows that in mediæval times, when alchemy was flourishing, serious men were endeavouring to generate in the retort of the chemical laboratory a little mannikin, the Homunculus. 
"A man is being made !' . . .

'Heaven forbid!' As nonsense we declare

The ancient precreative mode;

The tender point, life's spring, the gentle strength

That took and gave, that from within has pressed

And seized, intent itself to manifest.

The nearest first, the more remote at length,-

This from its dignity is not dethroned!

The brute indeed may take delight therein,

But man, by whom such mighty gifts are owned

Must have a purer, higher origin.

It flashes, see !-Now may we trustful hold

That if of substances a hundredfold

Through mixture-for on mixture it depends--

The human substance duly we compose

And then in a retort enclose

And cohobate, in still repose,

The work is perfected, our labour ends.

What Nature's mystery we once did style

That now to test our reason tries ;

And what she organized erstwhile,

We now are fain to crystallize."

-Goетнe, Faust II., Act ii.

He who had been created in this miraculous manner was to repay his human creator for this labour of love by rendering unnecessary all further speculating and giving him an answer to every question. The days of the Homunculus are gone, but even to-day the firm belief remains, especially among the agricultural population, that fleas and other vermin are generated by pouring urine on sawdust.

But let us relinquish these 'grey theories' and turn to the question: How must science conceive the first appearance on earth of organisms? That there was a time once when no life existed on earth can no longer remain doubtful, for we are forced on all sides to the conclusion that the earth itself has passed through radical changes during a development which is still going on. If we make these considerations our starting-point, how are we to conceive the origin of life? When we have definitely declined a divine creative act there are obviously two possibilities: either life has been transmitted to our planet from outside, from another cosmic body, and has gradually developed 
to its present variety, or it originated on the earth itself from inorganic matter by spontaneous generation (Urzengung).

But even here we proceed from the assumption that life originated. Is there no other possibility? Even if we assume that the earth was once a mass of molten matter, are we in that case compelled to assume an origin of organisms? Is it not possible that even in the red heat of the revolving nebular masses there was already life, and that therefore our questions are not justified?

However improbable this theory may sound, it has nevertheless found powerful advocates. No less a man than the eminent physiologist Preyer, an original and acute thinker, strongly advocated this idea in his book, "Die Hypothesen über den Ursprung des Lebens," published in 1880, nor did he hesitate to accept the last consequences of his theory. Basing his arguments on Harvey's law that every living organism descends from another living organism, Preyer thinks it arbitrary and inconsistent to assume that this was ever otherwise. The human eye has never seen an organism which was not descended from another organism, but observation and experiment show how dead inorganic matter is daily and hourly formed of living matter. Why should we not assume that it was always so? Why should we not be more justified in concluding that living substance was first, and that inorganic elements were later excreted from it? "It is only because of our narrow conception of life," says Preyer, "that this idea appears to us strange and fantastic. But if we free ourselves from the entirely arbitrary thought, rendered probable by not a single fact, that protoplasm always possessed the nature which it does now, and give up the ancient prejudice, due only to laziness in thinking, that in the beginning there was only the inorganic, we shall not hesitate to take another step forward, drop the theory of abiogenesis, and acknowledge that there is no beginning of life. Omne vivum e vivo."

To Preyer's imagination the entire incandescent mass of the solar system appears as one gigantic organism. Its life is the motion of its matter. Out of it came our earth. This, too, consisted at first only of animated matter, and only later, as the cooling process proceeds, the substances, which can no longer remain at the molten stage, are deposited as a solid nucleus. 
They do no longer participate in the life-motion of the whole, but have become the first inorganic matter.

"Only when these combinations in the course of time became rigid on the earth-surface-i.e., died and became extinct-compounds were formed of the elements that so far had remained gaseous and liquid, which become more and more similar to the protoplasm which is to-day the basis of everything that lives. With the fall in the temperature and the diminution of dissociations it was necessary that there were formed still more complex compounds, chemical substitutions, still more compact bodies, still more complicated interacting motions of parts becoming more intimately correlated, and only these primary forms of the plant and animal kingdom, made possible by progressing differentiation, were able to persist. We do not say (continues Preyer) that protoplasm existed as such since the beginning of the formation of the earth, nor that without a beginning it immigrated as such from a point outside in the cosmic space to the cooled earth, much less that it originated from inorganic matter on the planet, as the theory of spontaneous generation would have us believe; but we contend that the beginningless motion in the universe is life, that protoplasm necessarily remained after the bodies which we now call inorganic had been excreted on its cooling surface by the more intensive life-activity of the red-hot planet. The heavy metals, once organic elements, were unable to melt again or to re-enter into the circulation from which they had been excreted. They are the symptoms of rigor mortis of prehistoric, gigantic, red-hot organisms whose breath was glowing iron-vapour, whose blood molten metal, and whose food probably meteorites."

Do we not seem to see the over-heated dreams of an exorcist rather than the calm arguments of a serious scientific mind? The conception of the ancients that life proceeded from the fire is here once more revived. All that moves, lives. Life is said to be without beginning, but finds its end in death. For that the state of life in which our earth, the sun, and the planets are at the present time is only temporary, and that the bodies of the universe hasten with inexorable necessity towards a state of complete torpidity such as the moon has shown for thousands of years, even Preyer could not doubt. Life is eternal, it is true, 
but it is a limited eternity, an eternity which finds its end in time. To what ends will fancy and speculation lead an otherwise acute mind when it leaves the safe grounds of reality!

Apart from these considerations, natural science has very few objections to Preyer's theory. He has a perfect right to define life as he does, and no one can gainsay him if he regards molten metal as animate; though in that case he understands by life something very different from what all other men mean by it. But when all has been said, the whole fight is one about words. In any case, Preyer's theory rests on the accurate perception that, as Fechner had already demonstrated, there is no hard-andfast dividing line between organic and inorganic nature, but that both are different phenomena of the same law.

According to modern knowledge the conception of life is identical with that of metabolism, and so far as our experience goes this is always bound up with certain albuminoids. In that case, however, neither sun nor any other astral body can be called a living organism. Matter is eternal and indestructible. But as it is certain that the earth will some day sink into the icy night of deatb, so there was certainly once a time when no life existed on earth nor could exist. The soil must first be prepared before the seed can germinate.

We are, therefore, again confronted with the alternative that either life on earth is the result of spontaneous generation (Urzengung), or that it originated on other bodies in the universe from which it reached the earth. If this latter assumption, the so-called cosmozoic theory, has few prominent supporters to-day, we must nevertheless mention it, if only for the sake of the famous men who have broken a lance on its bebalf-Sir William Thomson (now Lord Kelvin), Liebig, and Helmholtz. According to this hypothesis the first germs of life reached the earth hidden in the crevices of meteorites, and then developed on earth.

It was in the year 1871, at the Congress of the British Association, that Thomson, in his presidential address, endeavoured to prove the scientific admissibility of his bypothesis. "When we retrace," he said, "the physical history of the earth according to strict dynamic laws we arrive finally at a red-hot molten sphere upon which there was as yet no possibility for life to exist. When afterwards conditions on earth became suitable 
for the existence of life no living beings existed. There were solid and disintegrated rocks, water, and air all around, a warming and illuminating sun, and everything ready to become a garden. Did grass, trees, and flowers in all their wealth of variety and beauty spring into existence by the fiat of a creative power, or did vegetation originate from seeds which had been sown upon the earth?

"If a volcanic island emerges from the sea and after a few years is clothed with vegetation we do not hesitate to believe that the seed was carried to it through the air or by the sea. Is it not possible, and, if possible, is it not probable, that the beginning of plant-life on earth can be explained in a similar manner? Each year there fall upon the earth thousands, probably millions, of fragments of solid matter. Where do they come from?

"If two large bodies collide in space it is certain that a large part thereof is fused, but it appears equally certain that in many cases a large mass of débris must be hurled in all directions; and that among them many suffered no greater injury than parts of a rock in a landslip, or during blasting operations. If the moment when our earth collides with an equally large body should occur whilst it is still clothed with vegetation, many large and small fragments bearing seed, living plants and animals would doubtless be distributed throughout space. Therefore, and because we all firmly believe that there exist at present, besides our own, many other worlds with life, and have existed since time immemorial, we must regard it as highly probable that innumerable seed-bearing meteorites are moving through space. If, therefore, no life existed upon earth at this moment a meteorite falling upon this planet would lead to the production of vegetation by what we call a natural cause.

"The hypothesis that life originated on our earth through seed-bearing fragments from the ruins of another world may appear strange and fanciful, but I contend that it is not unscientific."”

The theory of a cosmic origin of life on earth arose probably from the fact that it is sometimes possible to demonstrate in meteorites traces of carbon compounds equal to those which come from organisms. Even humus-like matter has been found preserved in the interior of meteorites. If these formations were 
able to survive the red heat to which meteorites are exposed when entering the atmosphere of the earth there is no fundamental objection to the assumption that primitive germs of life may reach us in this manner uninjured by the heat. Some investigators, endowed with a particularly rich imagination, were even able to recognize in thin slabs of meteorites the most diverse organisms, such as corals, star-fishes, \&c., which looked as much like their terrestrial cousins as one egg looks like another, except that their dimensions were considerably smaller; but this pretty support soon crumbled away when more accurate investigation showed that these alleged animals and plants were nothing more nor less than crystalline formations which anyone may at any time produce by artificial means.

Other objections of a fundamental nature were soon raised against the cosmozoic theory from the most different directions. Thus it was said that it provided no solution at all of the problem but merely removed the question of the origin of life from our earth to some other star, thus leaving the riddle itself unaffected. This objection, however, cannot be regarded as sound, for there is no cogent reason, assuming the possibility of transmission of living germs from one star to another, why life should not be eternal, like inorganic matter. But as space is conceived as infinite and as the number of astral bodies is infinite, the assumption that life has come to this earth from another star which in its turn received it from yet another star, and so on, does not remove the question to another fixed period of time, but to eternity. And with that the question of the origin of life becomes a question of transcendental philosophy; it is now as incomprehensible as the origin of the world or the conception of matter, for it is placed beyond the boundaries of the possibilities of our perception.

There is another reason which compels us to decline this hypothesis. Though it might be possible, according to Helmholtz, for the germs hidden in the interior of the meteorites to pass through the atmosphere of the earth without losing their vitality or, if they adbered to the surface of the meteorites, to be wafted down by the air when the fragments entered the earthatmosphere and thus descend slowly and safely to the earthsurface, it is yet almost inconceivable that any organism should be able to endure the intense cold and absolute desiccation to 
which it would be exposed during a journey lasting untold years through the icy space entirely devoid of water. It is true that in a former chapter we have become acquainted with living organisms which exhibit an astonishing power of resistance to all injurious influences of the external world, heat as well as cold, and preserve latent life for a considerable time, but in all these cases the span of life is not without limit, and even in the most favourable cases restricted to a few years.

But even though we cannot refute the cosmozoic hypothesis on strictly scientific grounds-just as science does not enable us to prove that a divine creative act is an impossibility-it appears nevertheless highly improbable. To fall back upon it would mean doing violence to reason, because we possess in the doctrine of spontaneous generation (Urzengung) of the organisms a theory which stands in better accord with the facts derived from observation.

We have thus come back once more to earth itself as the place of the origin of life. As we have already seen, the investigators of the earliest times had no difficulty in explaining the spontaneous generation of even highly organized animals -insects, fishes, frogs and snakes-and even in mediæval times a line of demarcation between inorganic matter and animated nature was unknown. But the more science investigated the nature of the living organisms, the clearer became the view that, if any, only the most primitive unicellular organisms could be considered from the point of view of abiogenesis.

It is but a few decades ago that it was a universally accepted dogma that infusoria were generated by infusions of water upon hay, and that bacteria originated in putrifying flesh or other fermenting matter by spontaneous generation. Even at the end of the nineteenth century a French investigator, Pouchet, endeavoured to produce such organisms artificially in the retort. According to him it was only necessary to mix together the various parts which composed the body of a living being - For on the mixture it depends '-and to procure the most favourable external conditions, in order to obtain unicellular organisms. Truly an attempt worthy to be compared with those of the alchemists. No one has so far succeeded in producing by syn- 
thesis the simplest albuminoid; even the chemical structure of the organic substance still remains an impenetrable mystery, and yet some one will attempt to make a living plant or animal.

These experiments by Pouchet, which sometimes really appeared to be crowned with success, were soon proved to have been abortive. Subsequent experiments showed beyond doubt that the fungi, bacteria, \&c., which sometimes did appear in the cultures had developed from germs which had entered the test tubes from without. As long ago as 1838 Ehrenberg demonstrated that the entire atmosphere is filled with desiccated animal and plant germs, that these are carried by wind and weather over vast distances until by chance they fall upon favourable soil and there re-awaken to new life. Moreover, Ehrenberg had rendered it highly probable that in all those cases in which infusoria or fungi are observed it is not a generation out of nothing or out of inorganic matter which we are observing, but merely a development out of already existing germs.

But an opinion once formed is not easily eradicated. As Schopenhauer aptly observed, "A hypothesis leads in the mind in which it has settled, or was perhaps created, a life which resembles that of an organism, in so far as it absorbs from the outer world only that which is homogeneous and digestible and rejects the heterogeneous and injurious, or excretes it in toto if it was unavoidably introduced." In the same manner the idea of generation without ancestors, and even of an artificial generation of unicellular organisms, reappears from time to time in a few fantastic minds.

Later investigators-at first Theodor Schwann, afterwards Ferdinand Schultze, Pasteur and others-proved definitely that neither bacteria, nor fungi, nor any protozoa could be generated in vessels with infusions of meat or hay in which at first all germs of life had been carefully killed by exposing them for some time to a boiling temperature and then enclosing them in air-tight tubes. (This is the well-known process adopted in the preservation of various foodstuffs which retain their wholesomeness for a very considerable time if sterilization has been sufficiently thorough.) But if afterwards the tubes which had thus been rendered free from germs were opened and thus enabled freely to admit ordinary air it did not, as a rule, take 
long before a rich variety of life began to spring up in the tubes in spite of the preceding boiling. When, however, air was admitted which had previously been passed through a redhot tube or sulphuric acid or caustic potash and thus rendered germ-free, no organism was ever observed to originate.

These experiments were almost universally regarded in scientific circles as an absolute proof against the spontaneous generation of these organisms. But this is in my opinion a hasty conclusion, for it is not only possible but even certain that the air undergoes in its composition, as a result of the various processes, more or less radical changes. The carbon dioxide of the air is, for instance, more or less decomposed by caustic potash, and the ammonium by the sulphuric acid, and there is, therefore, at least the possibility that these changes, no matter how slight, are the cause of rendering an abiogenesis of organisms impossible. At any rate, the possibility is not excluded, even if the probability has become extremely slight.

However, as shown later by Schröder and by Dusch, it is not even necessary to adopt such circumstantial precautionary measures in order to prevent an appearance of living organisms in sterilized test-tubes, for it is sufficient merely to close the tubes with pads of cotton-wool. Like extremely fine filters these plugs of wadding keep back all germs and permit only the purified air to enter. Further, according to Pasteur's exhaustive experiments, it is only necessary to conduct the air to the germfree nutrient medium through long sinuous tubes in order to prevent fermentation and putrefaction. The air itself passes freely through the windings of the tubes, but all particles of dust or germs of organisms are deposited at the lowest points of the bends.

Confronted with these results, even a sceptic must now admit that abiogenesis of bacteria and protozoa does apparently not take place. Indeed, if at the time when these investigations excited scientific circles scientists had possessed that knowledge of the structure of the protozoa and of the still more delicate structure of bacteria which we possess to-day no one would probably ever have conceived the idea that these differentiated forms could owe their existence to a transformation from inorganic matter. We shall have to deal with these 
lower organisms later on in a more detailed manner. We shall then see that unicellular animals and plants are not by any means primitive but highly complex organisms, and that even the lowest bacteria and protozoa whose structure the microscope has revealed to us bear such distinct vestiges of a long historical development that it is impossible to regard them as owing their existence to spontaneous generation.

When we ask ourselves how those organisms would be constituted that might have been 'crystallized' from inorganic matter, the only answer which sound reason can find is that they must stand on the lowest conceivable step of organic life. We shall agree with Ernest Haeckel, the great but dogmatic protagonist of the theory of descent, "that the organisms that came into existence by spontaneous generation were not cells at all, but perfectly homogeneous, structureless, amorphous lumps of albumen." But all organisms, animals as well as plants, which are known to-day show structures, and differentiations in their structures, and have, therefore, apparently reached the stage of cells. On the ground of Pasteur's experiments and these considerations we seem, therefore, justified to infer that for all these organisms the old saying applies: Omni vivum e vivo.

But are we now entitled to deny the possibility of a generation without ancestors? I am inclined to answer, No. It is true that the perfection of optical instruments has unlocked a whole world of life of which former generations had no conception. Our microscopes, with a power of magnifying 3,000 times, enable us to perceive organisms so minute that they far transcend our power of imagination, and yet we know that the last boundary of the infinitely small is as yet far off, and that there exists life which lies beyond the present limit of our senses. Indeed, in order to prove the existence of many organisms which singly are too minute to be made visible we are compelled to offer them in suitable artificial nutrient media an opportunity for enormous multiplication, so that they may betray their presence by the clouding of the medium, or by other signs. Of their structures, however, whether they are cells or structureless lumps of albumen, we know nothing. Whether such organisms originate to-day is a question which lies where experience ceases and faith begins. A number of years 
ago it was thought that an undoubted case of spontaneous generation had been found in a remarkable structure described by the English zoologist Huxley, the celebrated Bathybius haeckeli. During a survey of the ocean-bed sailors found in the greatest depths of the sea, in abysses between 4,000 and 8,000 metres, that the whole bottom of the sea was covered for long distances by a formless mass of non-differentiated, apparently organic slime which executed slow, crawling movements. According to Haeckel and other investigators this Bathybius represented a primitive organism,

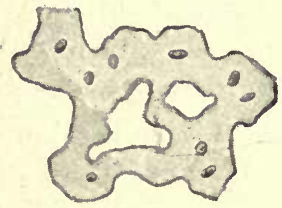

FIG. 24. - Bathybius haeckeli-A PSEUDOORGANISM. originating permanently at the bottom of the sea by abiogensis.

Unfortunately this apparently conclusive proof rested on an error. For the celebrated Bathybius is nothing but gelatinous gypsum, a sediment of the sea-water, which may be artificially produced by mixing seawater with alcohol. With what joy this discovery was hailed in certain circles, and how capital was made out of it against the Theory of Descent is only too well known. Where facts are absent, every little error made by an opponent is used by some people to serve as a weapon with which to beat him.

It is more for the sake of completeness than because of any particular importance which this observation possesses that I mention the latest attempt to produce life artificially. Radium, which since its discovery has astonished us with so many remarkable phenomena, is this time the magic wand which is to call forth life. Burke, of the Cavendish Laboratory in Cambridge, who made this discovery, describes it thus: A test-tube with the culture-medium, a nutrient gelatine such as is used for the culture of bacteria, was sterilized in the most careful manner possible. A small quantity of radium salt was then added. After a lapse of twenty-four hours there appeared on the surface a peculiar culture-like structure which during the next fourteen days continued to grow downwards. A casual observer would have taken it for a bacterial growth, but (according to Burke) this assumption was wrong, because the mysterious growth was soluble in water. 
What could it mean? The fact that there was an uninterrupted growth and continuous development by division proved that the structures were not crystals, as had been suggested by various observers. They were apparently more than simple aggregates because they appeared capable not only of growth but also of subdivision, and certainly of disintegration. "But if these products are not crystals," said Burke, "we are not able to refuse the inference that we have before us living, highly organized bodies which owe their existence to the independent, self-acting influence of the radium salt upon the culture-medium." In order to indicate the history of the genesis of these structures and their similarity to microbes, the discoverer bestowed upon them the name of 'radiobes.'

But however well sounding this name may be, however acceptable this 'fact' communicated by Burke might have been as a support of the theory had it been proved to be true, it cannot stand before criticism. No less a man than the famous physicist Ramsay was chosen to commit the 'radiobes' to merited oblivion. According to his experiments the radium salt added by Burke to his nutrient gelatine did in fact cause peculiar alterations, but these had nothing whatever to do with life and growth. Through the emanations of radium the water of the culture-fluid is decomposed into oxygen and hydrogen, causing at the same time a coagulation of the albumen. Thus there are produced in the nutrient gelatine small air-bubbles surrounded by a film of coagulated albumen which naturally increase hand in hand with the increase in the development of gas, thus deceiving the uncritical eye-into the belief that it is observing the growth of organisms. When will the fantastic hope be abandoned that we shall be able to tear away the veil from this greatest problem of the origin of life by such coarse methods?

If we must now admit that up to the present hour spontaneous generation has never been directly observed and that it is very questionable whether spontaneous generation under modern conditions of life is at all possible, we must, nevertheless, accept abiogenesis as a just postulate of reason unless we are prepared on this sole point to put a miracle in the place of 
a natural, law-governed development. At what period in the earth's history life appeared for the first time and what were the external conditions will always remain a matter of speculation. Nevertheless, the attempt to form an idea of the conditions which then existed might not prove entirely futile. Let us, therefore, return in imagination to the original state of our earth, to the time when it was a sphere of incandescent gases.

It is known that very high temperatures suspend all chemical compounds and decompose them into their single elements. We must, therefore, assume that this glowing nebular mass contained within itself all the numerous constituents disintegrated into the last elements, which build up the earth and all objects at present upon it. It is even conceivable that, seeing the enormous temperatures which then existed, the substanceswhich we regard at the present state of our knowledge as being incapable of further division-i.e., carbon hydrogen, oxygen, nitrogen and sulphur or, iron, lead, gold and silver-were decomposed into still more elementary substances. This fiery ball, continually emitting its heat into the icy space, continually lost warmth; thus slowly but steadily the cooling process went on. Then came the time when the first chemical compounds came into existence, followed by the period of the formation of a strong earth-crust. Nevertheless, we must assume that the temperature of the earth and the gases surrounding it - the atmosphere-was at that time yet so high that water could only be present in the atmosphere in a gaseous form.

The period of the formation of the earth-crust was probably followed by a very long waterless period. When afterwards, corresponding to the continued loss of heat, water became deposited on the solid earth-crust and when this primeval ocean had further cooled there were then at last present the conditions of the possibility of existence of organisms like those that exist to-day. But who would venture to say what enormous periods of time had to elapse even then before the first life appeared on the earth? It is possible to defend with good reason the assumption, though it may appear at the first glance as a contradictio in adjecto, that there first followed a time in which organic compounds were formed before plants and animals came into existence. 
The problem of the origin of life has probably been most thoroughly considered by Pflüger, to whom we are indebted for a luminous theory dealing most comprehensively with the chemical details of this subject. But as his arguments presuppose a comprehensive knowledge of chemistry we must unfortunately omit it here.

Since chemistry has proved that the body of an organism is constructed of the same chemical elements of which inorganic bodies are composed, and since Wöhler succeeded, first of all, in producing artificially an organic compound, urine, out of inorganic constituents, the hypothesis of spontaneous generation does no longer constitute a leap into the dark, but follows as a logical conclusion. For, we may ask, is it a lesser miracle that a tree absorbs the carbon dioxide of the air, water and different salts from the soil and uses them all for the formation of its organs, stem, leaves, flowers and fruits? Life, highly complicated and differentiated, is here being created from inorganic matter. The tiny millet seed which we confide in spring to the soil becomes in a few weeks a plant of considerable size with many leaves, representing an enormous quantity of organic substance which has in a short time been formed in this minute natural laboratory. It is true that the change in these cases proceeds in, and by the agency of, an already existing organism. But though it is not possible to trace accurately each single process of change and repeat it experimentally we know, nevertheless, that there is no mystic something, no unknowable vitalistic force at play, but that it is strict chemical processes which produce the effects observed. Is it, therefore, so very extraordinary to assume that in earlier earth-periods, when the temperature, the composition of the atmosphere, and the conditions of pressure were utterly different from those existing to-day, they formed the conditions requisite for the free generation of simple organized living matter?

It must be pointed out once more that of the manner in which the formation of these original ancestors of modern animals and plants took place we do not and cannot know anything. Experience deserts us here. It is a doctrine of faith that a Creator outside the cosmos, an omnipotent God, made by his fiat the first germs of life arise. But it is also a doctrine of naturalists when we assume that the lowest organisms have 
come into existence out of dead, inorganic substance by spontaneous generation. Here, as there, we move on the unstable ground of hypothesis, but with this exception that the creationmyth denotes to our minds an inexplicable miracle, a breaking through the laws of Nature, whilst the doctrine of a generation without ancestors, even if we cannot prove it, may, nevertheless, be brought into accord with the laws of Nature, and-this is the least that may be said in its favour-does not come into conflict with logic. The hypothesis of spontaneous generation is after all the best theory which has been promulgated for the solution of this difficult question. Until science shows a better way we must assume the doctrine of spontaneous generation to be true. But though we cannot say with certainty whence life came we know at any rate how life has been preserved after it had been generated. With that subject I shall deal in another lecture. 


\section{CHAPTER VI.}

\section{THE EVOLUTION THEORY.}

WHEN we review the history of research in the last two centuries we see that there are two opposite views: on one side that of Cuvier and his school who try to prove the immutability of the species; on the other, Lamarck, Geoffrey St. Hilaire, Charles Darwin and their supporters who declare a species to be an artificial arrangement carried into nature by man, and proclaim the descent of all living beings, man included, from the simplest organisms by gradual changes.

Before we examine the different theories which undertake to explain the causes of this assumed evolution of the organisms, we may suitably enquire whether such change of species and progressive development has actually taken place; in other words, whether the Evolution Theory can be proved.

Let us go back to those far-distant earth-periods from which have come to us the first vestiges of organic life, but let us also moderate our expectations, for during the many cataclysms to which the earth's crust has been exposed most germs of life have been destroyed without leaving a trace behind. We can see in our cemeteries how rapidly decay takes place; frequently after a few decades a few bones are the only signs left to show that once a human corpse was here committed to its final rest; very soon these too will crumble into dust.

Thus it seems almost miraculous that so many prehistoric organisms have in the form of fossils been preserved for our days. It is obvious that the older the strata are and the more remote their date in the history of the earth, the rarer become the fossils until at last they cease altogether. It is further clear that almost without exception only those animals were preserved that had a firm endo-skeleton, like the vertebrates; strong armour 
of chitin or lime, like the arthropods or echinoderms; or shells and houses of lime, silicic acid, \&c., like snails, mussels, and many species of unicellular protozoans. It is very rare to find animals with soft bodies preserved, or at any rate their forms impressed on stone, as for instance in the case of the famous find of Medusa in the lithographic slates of the Upper Jura, near Solenhofen and Eichstätt. The impressions left by these delicate animals on the hard stone are sometimes so perfect as to make an exact systematic determination possible. But unfortunately such treasure-troves are rare exceptions for which the inaccuracy of the fossil-documents found elsewhere cannot compensate us. Above all, the most primitive forms of life which had probably not yet reached the organization of the cell and would therefore be of particular interest to us have completely and for all times been expunged from the geological record : a fundamental reason why we shall never be able to substitute exact knowledge for the present vague guesses concerning the first appearance of organisms upon our earth.

Another proof of the inadequacy of the palæontological evidence is that generally only the remains of aquatic animals were preserved in large numbers, but terrestrial animals only exceptionally in favourable places, that is, where there was a possibility that the animal corpses would be rapidly covered by a crust of mud or earth, and thus saved from destruction.

Geologically the oldest stratum in which we meet with fossilized life is the Cambrian stage. We see here chiefly quaintly constructed crustaceans, called Trilobites, on account of the tri-partition of their bodies. These ancient animals were thorough cosmopolitans, for they, or related species, have been found in the Cambrian strata of North America, England, and Bohemia. As they cannot be credited with having been able to undertake long journeys we must assume, for the purpose of explaining their world-wide distribution, that they were probably carried by sea and wind in the larval state over enormous spaces.

One of the most important types of the Cambrian Trilobite fauna is a specimen of the genus Paradoxides (fig. $25,{ }_{1}$ ). The many distinctive features are the divisions of the body into three parts, an impaired median axis, the so-called spindle, and the paired lateral parts or pleuræ. The anterior end is formed by a cephalic 
shield which in Paradoxides is ornamented with long horns. The thorax consists of sixteen to twenty segments. At the posterior end is the tail or pygidium, which in this type is small, but in other Trilobites sometimes of considerable dimensions. As with their modern edible cousins, the crabs and lobsters, the dorsal surface of the body is protected by a strong calcareous crust, whilst the ventral surface, with the legs and gills, is relatively soft.

It is remarkable that apparently all Cambrian Trilobites were blind, whereas in the next formation, the Silurian, species are found that have highly developed facetted eyes. This phenomenon may be explained in two ways. The Cambrian Trilobites were either denizens of the deep sea, living in depths which no ray of light can reach, or, what is still more probable, the atmosphere in those early days of the earth-history contained as yet so much vapour that there was a permanent twilight which the sunrays could not penetrate.

Of other animals found in

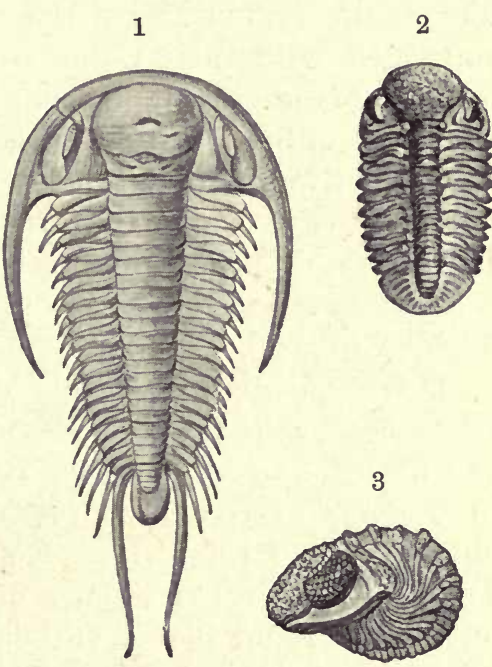

FIG. 25.-TRILOBITES.

(1) Paradoxides bohemicus (Cambrian) ;

(2) Phacops schlotheimi (Devonian);

(3) The same, coiled up. the Cambrian system we must notice the Brachiopods, several species of mussels and snails, and finally some low forms of Echinoderms, the Cystoidea. Higher animals are completely absent. The Brachiopoda are only represented by some of the lower forms. They flourish in the subsequent systems-there are many species in the Devonian, Carboniferous, and Permian systems - and then become gradually extinct. To-day they form an unimportant class with but a few species which live at enormous depths of the sea and are apparently becoming extinct. The Brachiopoda are distinguished from the mussels by having dorsal and ventral, instead of right 
and left shell-valves. Further, most species have in the interior of the dorsal valve a limy ribbon of very varied shape, which forms the supporting organ of the fleshy mouth-arms.

A similar poverty and primitive character is exhibited by the Cambrian flora, which so far as we know consists exclusively of simple marine Algæ.

In the second stratum, the Silurian system, there is a far yreater variety and a higher development of organisms. But here again Trilobites are the principal species, forming, when contrasted with their Cambrian progenitors, a veritable classic example of progressing development and adaptation to changed conditions of life. We saw already that Trilobites of the Silurian Period had well-developed eyes, whilst the Cambrian species were blind. But it is more surprising that they have now acquired the faculty of curling up, precisely as is done by one of the little terrestrial crustaceans of the family of wood-lice (Armadillidium vulgare) (fig. 25, 2 and ${ }_{3}$ ).

This acquisition is capable of a simple explanation. As Trilobites were in the Cambrian system the only large animals there was no need to fear hostile attacks, and consequently no need of special protective measures. But it is different in the Silurian and Devonian strata. Here we find other large animals, mighty Cephalopoda, near relations of the modern Nautilus and the cuttle-fishes, and like them dangerous and voracious robbers. There is no longer peace and safety. An active defence is impossible against these animals which are often more than two metres long, for the soft-skinned ventral surface of the crabs offers a favourable and dangerous point of attack. The faculty of rolling themselves up now becomes an effective protection. When a rapacious enemy came near in search of a toothsome meal the Trilobites simply folded together the cephalic shield and pygidium (fig. 26), and were thus enclosed in a solid armour which offered effective resistance to their enemy's teeth.

Besides the Trilobites we find here higher crustaceans, enormous Eurypterides, often more than one metre long. But most important of all, we find here and in subsequent systems the Cephalopoda which show in the structure of their shells a gradually increasing complexity.

Of special interest are the first representatives of the verte- 
brates met with in the Silurian Period, a low species of fishes related to the sharks. This class assumes greater importance in the Devonian Period. They are mostly fantastic forms, widely differing from present species, called Placodermata on account, of the powerful osseous armour which covers the anterior half of their body. In the Devonian formation are also found transition-forms from the fishes to the amphibians, the so-called lung-fishes or Dipnoi. Species of this remarkable Order still exist, dispersed over the whole world. Thus we find on the
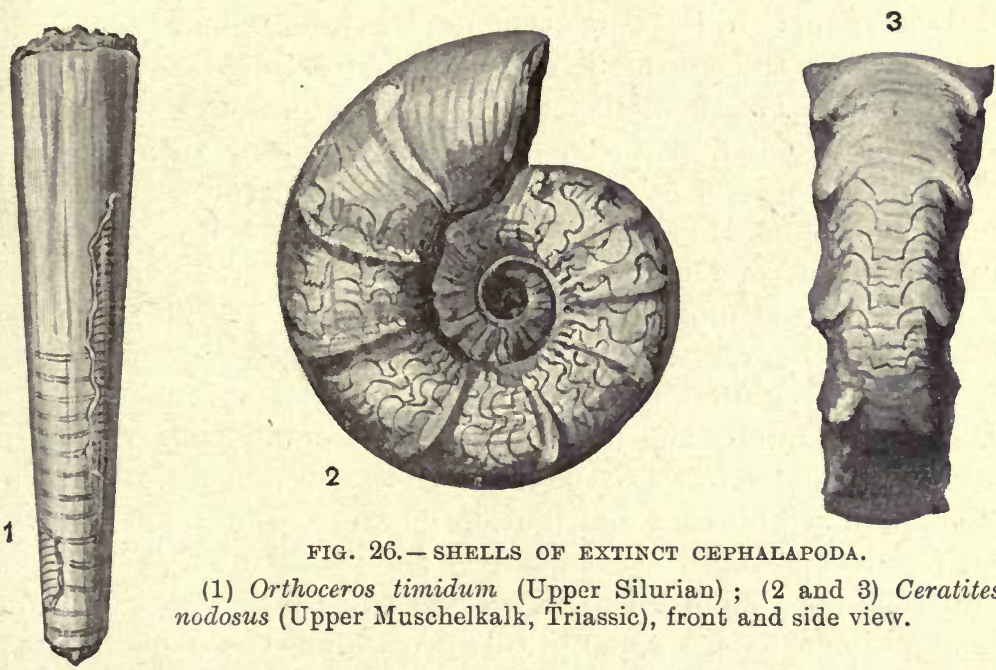

Fig. 26. - SHELlS OF EXTINCT CePHALAPODA.

(1) Orthoceros timidum (Upper Silurian); (2 and 3) Ceratites nodosus (Upper Muschelkalk, Triassic), front and side vier.

river courses of the Australian continent the well-known Ceratodus forsteri, in Africa the Protopterus annectens, and in South America a third species, Lepidosiren paradoxa.

The most important distinctive feature of the Dipnoi is that, unlike fishes, they are not restricted to breathing through gills. For if the waters which they inhabit should dry up the gills cease to be active and the swim-bladder becomes a respiratory organ, a lung. As we must probably trace the amphibians phylogenetically from similar forms, it is important to find that they are preceded by them in the geological formations. Whether the fossil-ancestors of the Dipnoi already possessed lung-respiration must be regarded as doubtful. Their distribu- 
tion contradicts this assumption, for they are largely inhabitants of extensive basins for which the danger of a sudden drying-up did not exist. Lung-respiration would therefore have been useless to them.

The Carboniferous system is characterized by a much higher degree of organization. There are land-plants, ferns, lycopodia that grow to the size of big trees, giant 'horse-tails' and palms ; in the forests, spiders, scorpions, myriapoda and numerous species of insects which appear here for the first time in considerable numbers. In the swamps we see the first amphibians, the forerunners of the Stegocephala, an Order which develops and flourishes in the Permian, and becomes extinct in the Triassic formation. To them belong the most powerful amphibians that ever existed, as for instance the ungainly Anthracosaurus, an animal of a large salamander-like structure, or the still more enormous Mastodon, whose skull alone exceeded one metre in length. Wonderfully preserved skeleton-parts and skulls of this prehistoric monster have been found in the alum slates of Oedendorf, in Würtemberg.

The Carboniferous is followed by the Permian system. Here the amphibians flourish and forerunners of the reptiles appear, to reach afterwards in the Triassic and Jurassic formations their world-wide distribution and highest development. Of all fossils the reptiles attract the particular interest of laymen and scientists alike on account of their weird forms and enormous dimensions. Among them we find the true giants of prehistoric times, who conquered land, air, and water. The reptiles of the Permian system are still unimportant forms, belonging to the two Orders of Rhynchocephalians and Theromorphs. Of the former only one genus has survived, the famous Tuatara of New Zealand (Hatteria punctata), but owing to the persecution by Maoris and the hog it is fast becoming extinct. The Theromorphs ceased to exist towards the end of the Triassic formation.

The so-called Mesozoic formations, the Triassic, Jurassic, and Cretaceous, are the typical periods of the reptiles. The seas are inhabited by the Ichthyosaurus, Plesiosaurus, and many other weird forms. In its appearance the Ichthyosaurus, which probably reached a length of 12 metres, resembled a dolphin. 


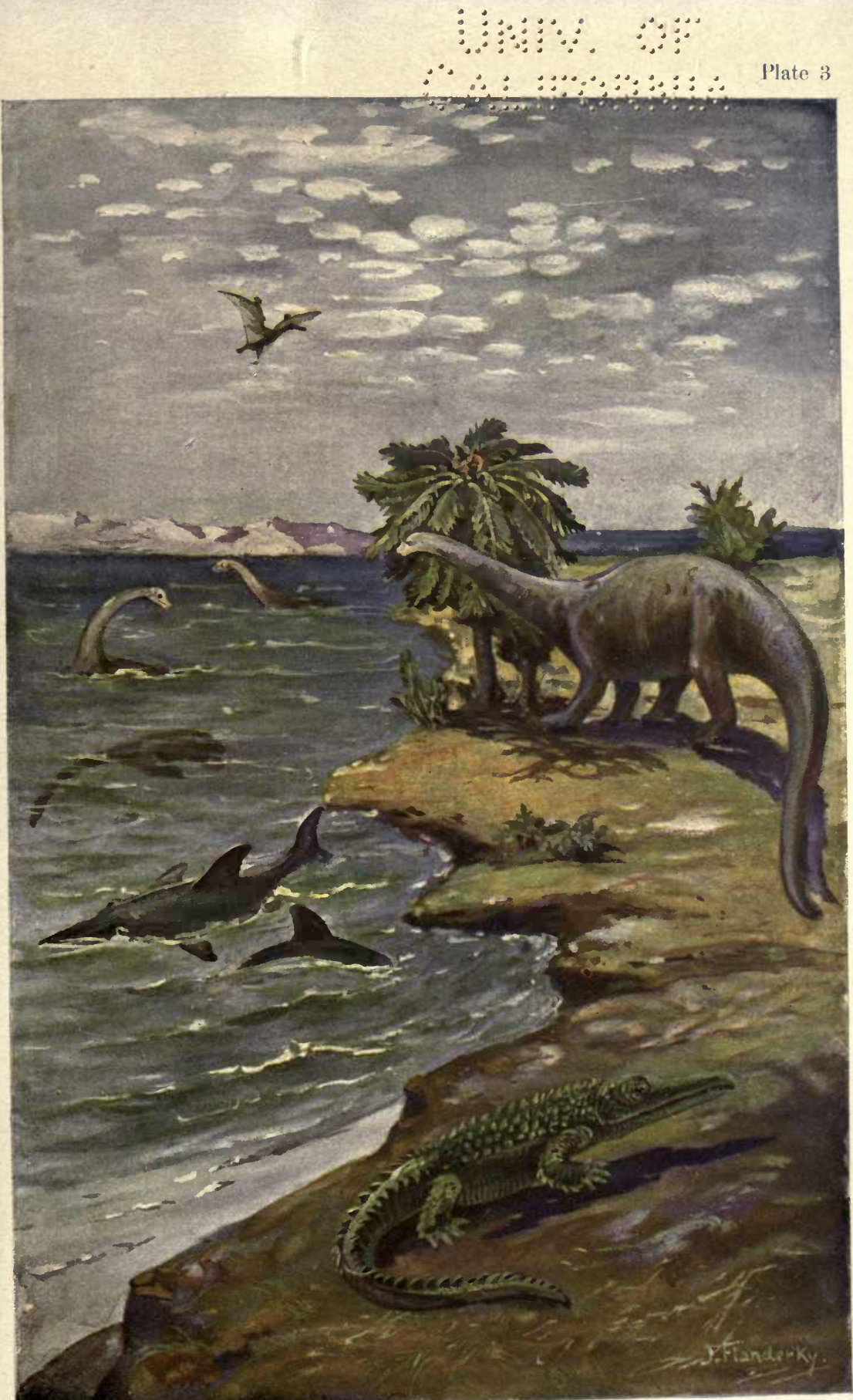

Reptiles of the Triassic and Jurassic Period.

In the foreground: Belodon; in the background, on the land: Brontosaurus. In the water, in the foreground: Ichthyosaurus; in the background, Plesiosauri. In the air: Pterodactylus. 


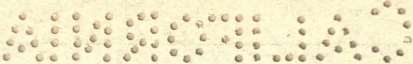


Its entire body was adapted to a life in the water; its extremities, consisting of an enormous number of single bones, were transformed into an ideal rowing-apparatus. The long tail ended in a large perpendicular fin, whilst the back carried another powerful fin. Like the Plesiosaurus, the Ichthyosaurus was a voracious animal of prey whose food consisted chiefly of fishes and molluses. As was proved by some interesting discoveries of female individuals, the Ichthyosauri were viviparous. The Plesiosauridæ are remarkable for their long swanlike neck which carries a relatively small head.

When we leave the sea and turn to the coast and the river courses we meet large crocodile-like reptiles of which the Teliosaurus and Belodon may be mentioned. On the land lived the members of the giant Atlantosaurus family, of which the enormous Brontosaurus is the best-known representative.

If previous exaggerated statements which gave the length of these animals as about 36 metres and their height as 8 to 10 metres have been reduced by modern researches to 22 and 5 metres, these giants must, nevertheless, have created the impression of walking houses, and even our largest elephants would have been completely dwarfed by them (see coloured plate). Nevertheless, there is no ground for believing that prehistoric animals were much larger than living forms. The Greenland whale (Balcena mysticetus) equals in size the largest Brontosaurus ; our modern land mammals, the elephant, giraffe, rhinoceros and hippopotamus are as large as any Saurian, and there are few animals in prehistoric time which equalled, let alone exceeded, our Cachalot (Physeter macrocephalus), with its length of 18 to 20 metres. That fossil reptiles, nevertheless, appear to have been possessed of enormous dimensions is due to a subjective reason.

A horse $3 \mathrm{ft}$. high looks small, and a dog of the same height would look gigantic, because we are accustomed to seeing larger horses and smaller dogs. Prehistoric animals do not in fact exceed the present forms in size, but we find that individuals of certain fossil classes possess far larger dimensions than their modern congeners. This is especially true as regards reptiles. Because to-day lizards about a foot in length, and snakes $10 \mathrm{ft}$. long seem large to us, it is not surprising that the relatively 
gigantic forms of extinct Saurians never fail to impress us. But whilst reptiles reached the zenith of their development during the Mesozoic and particularly the Jurassic Period, mammals are flourishing and developing gigantic forms in our time.

In spite of its terrifying appearance the Brontosaurus must have been very harmless. It was herbivorous. Remarkable is the head, the smallness of which is ludicrously disproportionate to the mighty body. It was probably a slow, awkward animal, of a low mental development. We may also mention among the land animals the Stegosaurus, distinguished by a dorsal series of large erect bone-plates, the gigantic Iguanodon, and individuals of the Ceratopsidæ whose skull was crowned with horns of an enormous size.

Not only land and water but also the air has been subjugated by the Saurians of the Mesozoic Period. Most famous among the Pterosaurians are the Pterodactyls. Their size varies between that of a sparrow and an eagle. Their bones are hollow, like those of birds, the structure being generally adapted to a life in the air. As in the bat, the flying organ is formed by the anterior extremities, the outer of the four digits being enormously elongated. Its object was to extend the flying membrane proceeding from the trunk and posterior extremities (see Lecture I.). A gigantic flying-saurian, the Pteranodon, has been found in North America. It measured 8 metres from tip to tip of the extended wings.

In the Jurassic Period we encounter for the first time a birdlike organism, the Archæopteryx. It was discovered nearly fifty years ago by workmen in the lithographic stones near Solenhofen, the scene of many other important finds. Though only a few fragments had been preserved of this strange feathered animal, it was purchased by the British Museum in London for the large sum of $£ 600$. Owing to the incompleteness of the skeleton, opinions were long divided concerning the nature of this unique being; some declared it to be a bird, others a reptile. Several years afterwards another much better preserved specimen was found not far from the scene of the first discovery and deposited in the Berlin Museum of Natural History (fig. 27), forming one of its most valuable possessions. With this discovery the position of the Archæopteryx in the system was definitely recognized. 


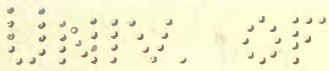

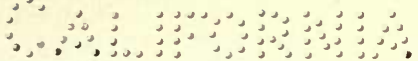

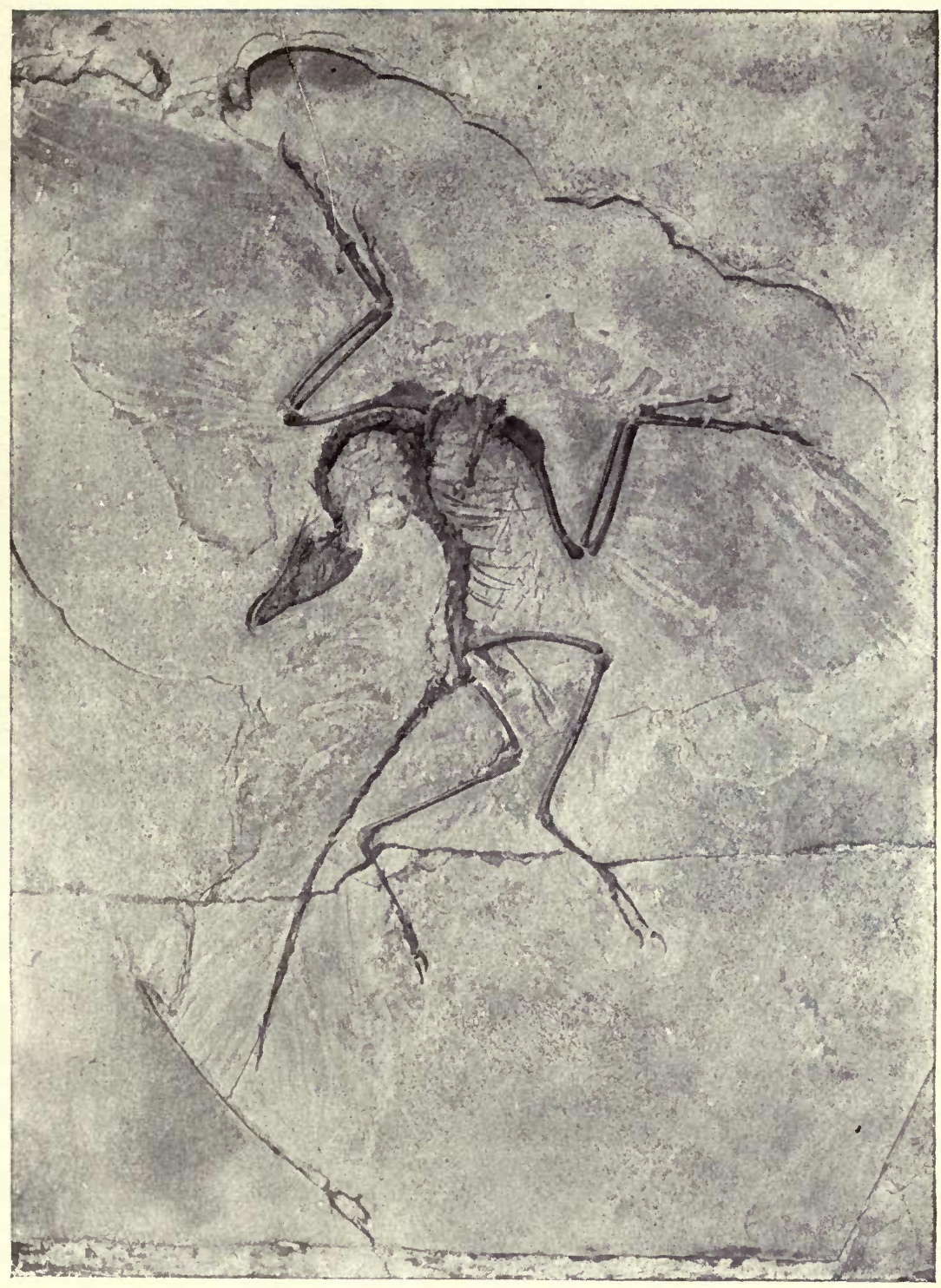

FIG. 27.-ARCHæOPTERYX.

Photograph of the specimen in the Natural History MIuseum at Berlin. 
$\because \because \vdots \quad \because \because \vdots \because \vdots \vdots$

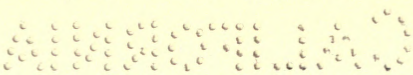


When we observe some of the living forms of reptiles and birds they appear so widely differentiated that no one would suspect them of being closely related. In Archæopteryx, however, we have an animal which is neither bird nor reptile, but a transition form, uniting in its body the characteristics of both classes. It was probably as large as a rook. The plumage, which covers the whole body and develops in the wings into long flying-feathers, the merry-thought (furculum), and the structure of the bones

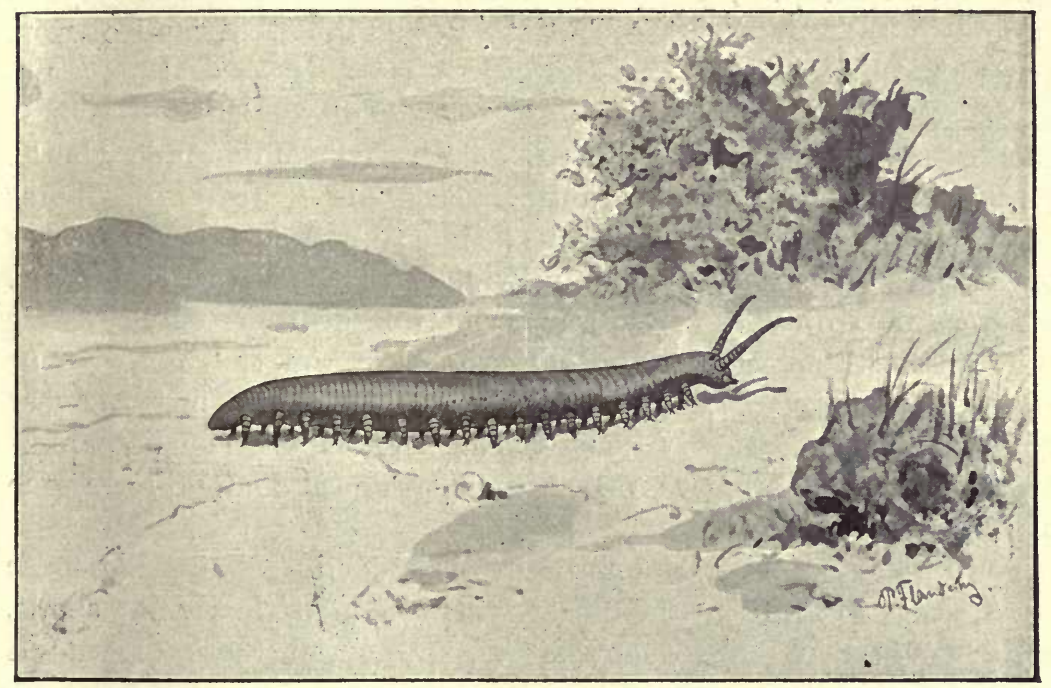

FIG. 28.-PERIPATUS CAPENSIS.

prove beyond doubt that the Archæopteryx belongs to the birds. On the other hand, the shape of the vertebræ, the presence of teeth, the three-fingered reptile-hand armed with claws, the long lizard-like tail containing twenty vertebræ unmistakably indicate that it is closely related to the reptiles.

Such transition forms exist among the living animals. The Peripatus, a little animal measuring about $10 \mathrm{~cm}$. and living in South Africa and New Zealand, resembles in appearance a myriapod (fig. 28). Its discovery gave rise to fierce controversies, for the Peripatus unites in its body a remarkable mixture 
of characteristics of annelids and arthropods. Like the annelids, it possesses typical segmented organs, but like the arthropods, in particular the insects, it has trachæa-like respiratory organs, and simple yet well-defined articulated extremities, resembling in their structure the parapodia of the marine chætopods. We must, therefore, assume that the ancestors of the Peripatus were evolved from the annelids, and that we have to regard its family as the progenitors of the myriapods and insects.

To mention a palæontological proof, Paludina, a snail with an almost complete series of forms showing its phylogeny, is found in the strata of the Tertiary Period on the Island of Kos, and also in Slavonia, Croatia, South Hungary, and Roumania. They are distinguished by a great variability. In the earliest deposits we find specimens with smooth shells and simple whorls. But the higher we ascend in the succession of strata, the higher is the development of the snails; their ornamentation increases in richness, differentiating them widely from the ancestral forms. If we knew only the first and last link of their phylogenetic chain, the stem-form, Paludina neumayri, and the most recent discovery, $P$. hoernesi, we should certainly take them to be very distant species. It is only by discovering the intermediate links that it was possible to prove their gradual change from one species into another.

Similar instances are offered by other snails. Thus Planorbis nultiformis begins, in the oldest strata, with perfectly flat shells, but evolves, in subsequent strata, more and more drawn-out tower-like structures.

The horse, rhinoceros, and tapir constitute the Sub-order of Perissodactyla. Whilst the tapirs possess in their anterior extremities four, in the posterior, three well-developed toes, the rhinoceros has anteriorly and posteriorly three toes. In the horse the number has become limited to one, for it walks exclusively on the strongly developed and elongated middle-finger, while all other fingers or toes of hand and foot have degenerated, only the thin so-called 'splint-bones' having remained to prove the existence of the second and fourth digit, or, if we wish to compare them with our hand, the index and ring finger. It is chiefly these great differences in the formation of the extremities which compel us to-day to regard the horse, rhinoceros, and tapir as members of three distinct families. 
As proved by many fortunate finds made in the Tertiary strata of Europe, supplemented afterwards by more complete discoveries made in North America, the horse has descended from ancestral forms which possessed a much more complete hand and foot skeleton and closely resembled the tapir. The oldest ancestors of our horse may be traced to the deepest Eocene strata. Here we find the genus Hyracotherium, little animals about the size of a fox. They probably lived together in large herds. The anterior extremities of Hyracotherium had
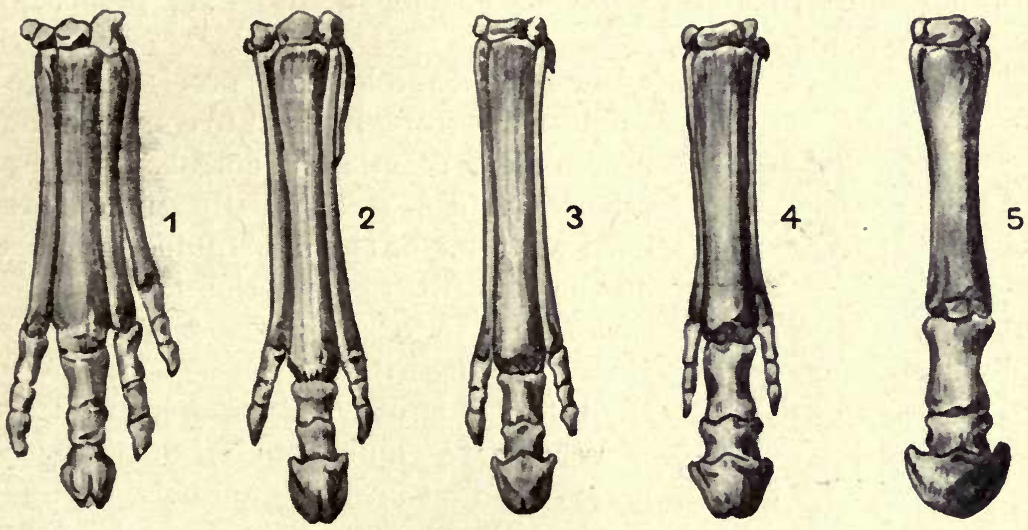

FIG. 29.-DEVELOPMENT OF THE FOOT OF THE HORSE.

(1) Anterior foot of Hyracotherium (Eocene) ; (2) of Mesohippus (Lower Miocene); (3) of Anchitherium (Middle and Upper Miocene); (4) of Hipparion (Pliocene); (5) of Horse (Equus) (modern). (After v. Zittel and Kayser.)

still four, the posterior three well-developed toes. In the later strata this form is replaced by the three-toed Palacotherium, an animal partly tapir, partly rhinoceros, about the size of a pony. In the Miocene strata we find at the bottom the so-called Mesohippus of the genus Palcotherium, and in the higher strata the Anchitherium. These animals are still three-toed, but the middle digit is already much larger than the other two and almost exclusively supports the weight of the body.

The retrogressive process becomes still more complete in the Hipparion in the Pliocene strata, the youngest of the Tertiary Period. In these animals the equine type is complete, the only 
difference being their more delicate and graceful structure, their smaller size, which is much less than that of the zebra, and finally the vestiges of the lateral digits which do not now touch the ground. Living together in large herds, these animals were widely distributed, remains having been found in the Tertiary strata of Europe, Asia, Africa, and even the New World (North America).

The more we approach the present day, the more rudimentary the toes become, finally to disappear completely in the modern horse (fig. 29). But not only the legs of the Equidæ have been modified; the teeth, too, have undergone a great change, the original short root teeth having developed into long prismatic teeth (fig. 30).

3

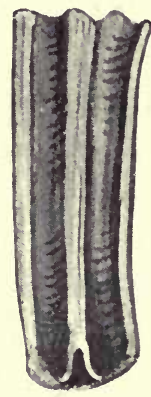

FIG 30. 一TOOTH-DEVELOPMENT OF THE HORSE.

(1) Tooth of Anchitherium;

(2) of Hipparion; (3) of Equus (half natural size). (After Kayser.)

The palæontological proof, though sufficiently strong in itself to convince the profoundest sceptic, is corroborated by other evidence. Occasionally animals are born with one or two supernumerary toes on the anterior or posterior feet. Such reversions to a previous phylogenetic 2 stage are described as atavism. We shall hear of similar instances later on.

While we found in the Jurassic period the first bird-like animals, we find in the Cretaceous strata typical birds, as, for instance, the Hesperornis, a bird of the size of a stork and the shape of a penguin. Mammals, too, begin to play an important part and to resemble in their development the present forms.

If we now draw our conclusions, it is above all remarkable that the very first animals observed in the oldest stratum in which life existed, the Cambrian Period, are comparatively highly organized Trilobites and Brachiopods. But, on the other hand, we perceive a gradual continuous development from the simple to highly complex forms which is quite incontestable. We are, therefore, forced to assume that the Cambrian is not the first period during which life existed, but that low forms of life must have existed in preceding periods. Indeed, some of the most eminent palæontologists say that the preceding period of more 
primitive life far exceeded in length the time from the Cambrian to the present day.

That no certain traces of life from these earliest strata are known to us need no longer surprise us. The longer the periods elapsed, the greater the probability that these documents of Nature perished, especially as we have to conceive the lowest forms of life as 'lumps of slime' without any skeleton parts, like the existing microscopically minute Amœbæ.

The best instance of the inaccuracy of the older leaves of the earth's chronicle is supplied by a comparison of the wealth of forms found in the Silurian with that of the Cambrian Period. From the latter we know only about six hundred or seven hundred species, whilst from the Silurian strata over ten thousand have been described.

But if the earth's history does not elucidate the mystery of the origin of life, it furnishes incontrovertible evidence of the gradual development of the higher and highest organisms from simple forms and for the transition of one species into another. We need only once more recall the Archæopteryx, the evolution of the horse, and finally the whole tendency expressed in the evolution of the organic world.

An equally convincing proof of the truth of the Evolution Theory is supplied by Ontogeny, the history of the evolution of the individual. Indeed, the development of most multicellular animals proceeds during the earliest embryonic stages in such remarkably uniform manner that we are only able to comprehend it on the hypothesis of a descent from a common ancestor. For every animal passes in its development essentially through all the stages which we observe permanently preserved in the lower representatives of the same stem. Haeckel formulated this fundamental law thus: "The evolution history of each animal, its ontogeny, is a short recapitulation of its phylogeny; i.e., the principal stages of organization through which its ancestors passed in remote ages are reproduced, though in a somewhat changed form, in the development of each individual."

But however clearly this law operates in numerous cases, there are instances in which its application seems vague and indistinct. The reason is that not only the adult individuals exhibit new characters but that also all other stages are able to 
acquire such new adaptations to special conditions of life. It behoves us, therefore, to proceed with the utmost caution in drawing phylogenetic conclusions on the basis of embryological evidence. It would, for instance, be erroneous to assume, because in the larva of the Libellulæ the second pair of maxillæ (labium) is modified into a pair of long nippers for deftly seizing the prey, that the dragon-flies had descended from a similarly constructed ancestor.

All multicellular organisms consist at the starting point of their development of a single cell, the ovum, or, more accurately, the fertilized egg-cell. For with the exception of a few cases it is necessary that two cells, the male spermatozoon and the female ovum, unite in order to make the origin of a
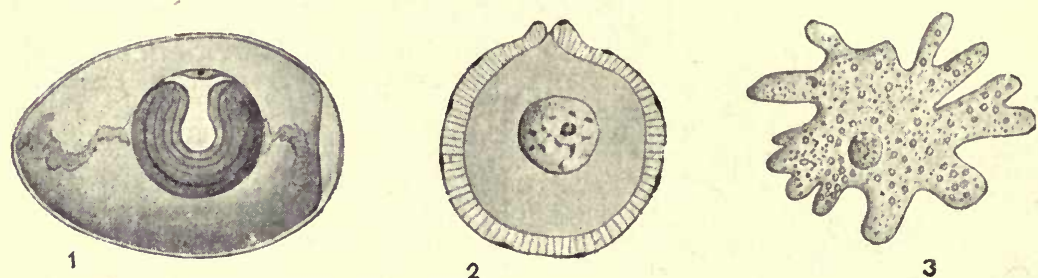

2

3

FIG. 31. -OVA OF DIFFERENT ANIMALS.

(1) Egg of a fowl; (2) egg of a sea-cucumber (Holothuria tubulosa); (3) egg of fresh-water polyp Hydra. (1, Less than natural size; 2 and 3 , greatly magnified.)

new multicellular organism possible. The process during which unification takes place is called fertilization; the result is the fertilized egg-cell. We shall have an opportunity later on to deal with this subject in greater detail.

The similarity, in their minute structure, of ova of even the most distant species is remarkably great. Indeed, the resemblance is often so complete that in many cases even an expert finds it difficult to distinguish between them. This difference in appearance, however, is due to secondary factors conditioned apparently by specific conditions of life ; nevertheless the general structure is always essentially alike. The ovum of whichever animal we may examine, we shall always find it to be a simple normal cell, consisting of the cell-body-protoplasm-and the cell- 
nucleus (fig. 31). That the egg of a mammal, which develops in the shelter of the maternal body and is fed directly by it, must differ from a bird's egg, which is laid at an early stage and exposed to unfavourable external influences, needs no specific mention.

The first important feature of the egg of a fowl is its enormous size compared with the egg-cells of most other animals of the size of a fowl. The ovum of Man measures but the fraction of a millimetre, and other animal ova are still smaller. But when we examine the structure of a bird's egg we see that its size is due to a secondary circumstance, the enormous accumulation of dead food material, the yellow and white yolk and the albumen. As the growing bird-embryo is dependent entirely upon itself and cannot be fed by its mother, it becomes necessary that it is supplied with a sufficient quantity of food. That this is the real cause of the difference in size is further proved by the fact that the only mammals which are not viviparous, the Duckmole (Ornithorhynchus) and the Porcupine Ant-eater (Echidna), quaint inhabitants of the Australian Archipelago, betraying in the organization of their bodies their descent from the reptiles, lay large eggs rich in yolk.

The shell of the bird-egg is not a part of the germ-cell but an organ of protection secreted by the maternal oviduct. The real cell is the minute light spot which observation reveals in the yolk. This consists, like the egg-cells of other animals, of protoplasm and the nucleus.

This remarkable uniformity does not only apply to the structure of the ova, but extends also to the developmental stages, though there are of course certain individual differences due to different conditions of existence. The type, however, always remains.

Before fertilization can take place, ova and spermatozoa must pass a maturing process which will be described on another occasion. When fertilization is complete the ovum always divides first into two, then into four, eight, \&c., cells, forming the morula or cell-heap. By further cell-multiplication is formed the blastula, a minute hollow sphere the walls of which consist of one layer of firmly united embryonic cells. Whether we have so far observed a sponge, an echinoderm, a tunicate, or even 
the archetypal fish Branchiostoma, the process is in every case exactly similar.

The one-layer germ forms the two-layer germ, the gastrula, by folding one wall of the cell-vesicle against the other. It must be understood that we are considering here only the most frequent form of development, as observed in the most distantly related species. In numerous other cases the process of gastrulation shows considerable differences, and very frequently the gastrula stage can only be demonstrated by accurate comparative examination. It seems obvious that this should be so, for an egg with a large accumulation of yolk cannot divide in the same manner as an egg which, having no yolk, offers less resistance to the process of division.
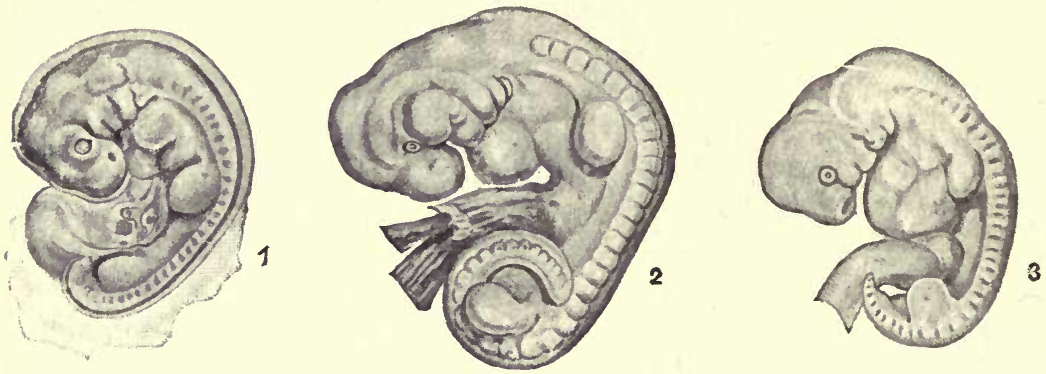

Fig. 32.-EMBRyos OF VERTEBRATES.

(1) Budgerigar (Melopsittacus undulatus) (after Parker); (2) Cercopithecus cynomolgus (after Lalenka); (3) Man (after His).

The gastrula stage is of particular importance to the Evolution Theory, for not only do we meet with it in the embryonic stages of the most widely differentiated stems, but there even exists a fully developed animal which permanently remains at this stage, the Protohydra, belonging to the Colenterates. Its whole organization consists of a stomach cavity surrounded by a double cell-mantle, having an orifice at the thinner end which serves both as mouth and anus.

Similar resemblances are observed in the higher stages of the embryonic development, thus impelling us to the hypothesis of a common ancestor. Even superficial comparison of the embryos of different classes of the vertebrates prove this striking 
uniformity of structure (fig. 32). It is, however, not so great that an embryologist would be unable, as was formerly thought, to differentiate between embryos, for there are always more or less prominent distinctions present. But on examining the different organs accurately we cannot fail to notice the uniformity.

All vertebrates, for instance, form the central nervous system as a dorsal gutter-like depression of the ectoderm, extending from the anterior to the posterior end of the young embryo. In the course of the development this gutter becomes deeper and deeper, finally separating completely from the ectoderm and forming the neural canal or spinal cord. In the lowest vertebrate, the archetypal fish Branchiostoma the nervous system retains this form permanently. Moreover, the lumen of the neural canal is here uniform in thickness, except at the anterior end where we can perceive in a slight vesicular enlargement the first stage of the brain.

In the other vertebrates the nervous system does not stand still on this primitive stage, but makes further progress in the formation of the anterior part of the brain. The neural canal continues to distend, the enlargement forming three separate parts, the primary cerebral vesicles. By a further division we obtain the five parts of the brain, which are to-day found in all vertebrates from the fishes upwards. That the brain of the different classes is, nevertheless, widely different in appearance is explained by the different size and formation of the five cerebral vesicles. Together with the growth of the mental faculties we observe in the cerebrum and cerebellum a growth as well as a differentiation; both gradually assume in birds, but especially in mammals and man, a size far exceeding all other parts of the brain.

The common origin may further be perceived in the development of the vascular system and respiratory organs. As it is one of the principal functions of the blood to distribute the oxygen received from the respiratory organs throughout the whole body and to remove the carbon dioxide resulting from the vital processes these two systems are strictly correlated. If, therefore, on an animal leaving the water, lung-breathing replaces breathing through gills the circulatory system must 
similarly adapt itself to the altered conditions and undergo suitable modifications.

Fishes breathe through gills; hence we find in them a specific circulatory system, the branchial arches, which carry the blood to and from the gills. In the majority of fishes four pairs of such arches are developed. In the amphibians, at any rate in those that live in the water and are therefore dependent on breathing through gills, the gill-arteries and gill-veins are formed in a similar manner. But many amphibians - for instance, frogs -leave the water at an adult stage and become air-breathing landanimals. The gills, now of no further use, become degenerate and are replaced by the lungs.

When the gills disappear the blood-vessels which fed them similarly degenerate, and thus we observe a far-reaching modification. One pair of the arches is completely lost, another moves to the lungs, forming the pulmonary circulation, \&c. The details do not concern us here, but it is important to note that even in the higher and highest vertebrates - the reptiles, birds, and mammals, which at no stage of their development live in the water-the branchial circulation is present in the embryonic stage exactly as in fishes and amphibians. Moreover, if we examine a human embryo of an early stage we do not only find rudimentary branchial arches, but also externally visible typical gill-clefts (fig. $32,{ }_{3}$ ). We are even able to distinguish in the human heart successively the fish-heart with single ventricle, auricle, and venous sinus; and the stage of the amphibian heart in which the single ventricle has been divided into two sections. Later a median wall is formed representing the stage which is permanently present in the reptiles. Finally, by a complete separation of both ventricles and other modifications, the type of the mammalian heart is reached.

We have seen that amphibians at an early stage live in the water and have gills, but at an adult stage take to a terrestrial life and develop lungs. In the mountainous districts of Europe the little black salamander (Salamandra atra) is very common. It is distinguished from related species by the fact that its young are born as air-breathing animals. Nevertheless, its embryos possess well-developed gills which, however, do not normally fulfil any functions. But if we kill a pregnant female, remove 
the embryos at this stage from the oviduct, and place them into water we shall observe that in spite of the abnormal conditions the gills are still able to discharge their proper functions. Here it is clear that the black salamander descended from ancestors whose larvæ were aquatic and breathed through gills, and that the habit to bear the young up to the complete development can only be a recently acquired character.

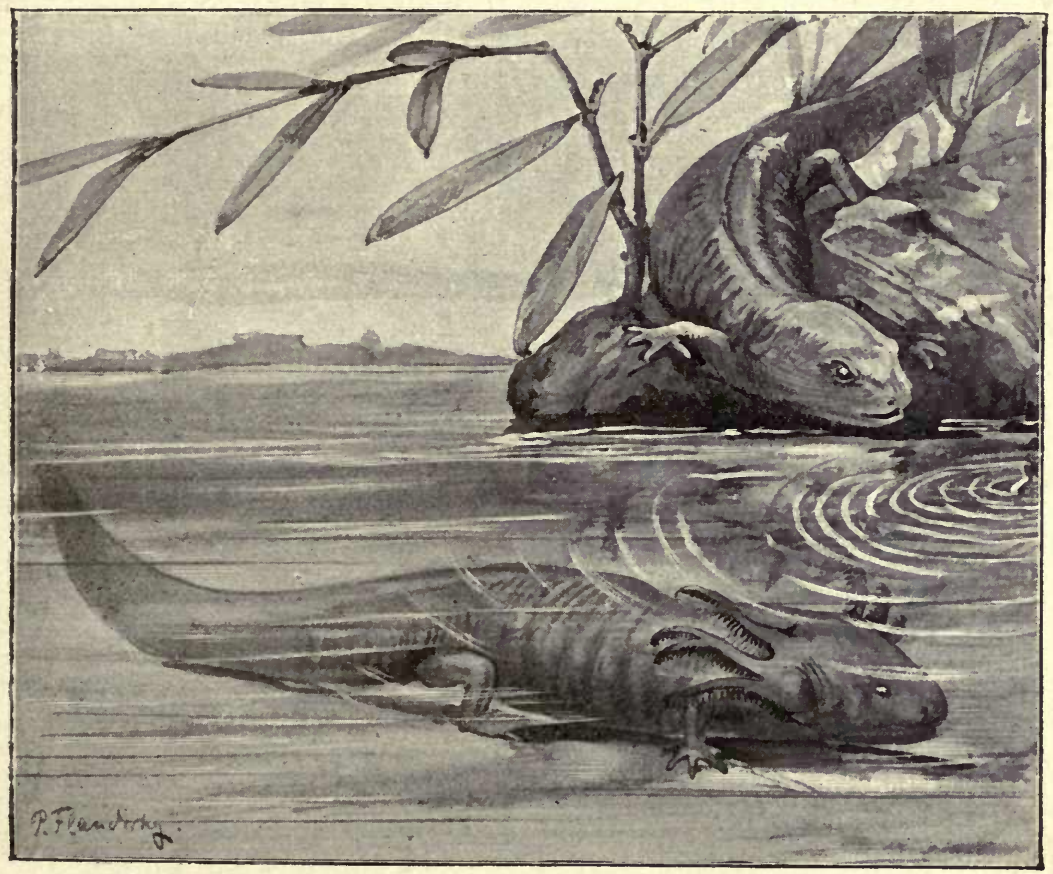

FIG. 33.-Amblystoma tigrinum.

On the land, the adult form ; in the water, the larval form, Axolotl, formerly called Siredon axolotl or S. pisciformis.

An opposite instance is furnished by the well-known Mexican Axolotl, for it is able, under ordinary circumstances, to pass its entire life and to reach maturity and power of reproduction in the gill-breathing larval stage. Formerly it was even thought that the larval form was its permanent form, and it was conse- 
quently long thought that they belonged to a type with persistent gills. But great was the surprise when a few individuals, born in the aquarium of the Botanical Gardens at Paris, were observed to lose their gills, leave the water, and become typical terrestrial salamanders.

There are, however, two explanations possible: it may be that we have here either a tenacious clinging to a low state of development, or a reverting to an earlier stage, consequent upon changed conditions of life. This latter view is upheld by Weismann who thinks that ancestors of the Axolotl which inhabits to-day the Mexican lakes were already in the diluvial period fully developed salamanders. As a result of deforestation and consequent decrease of moisture of the air the animals would have been doomed to extinction if they had not been able to live once more in the water by reverting to the gill-stage. However that may be, they offer in any case a proof of the variability of organic forms.

It is a rule almost without exception that the vertebrates possess a shape which is strictly bilateral-symmetrical, i.e., we can divide their bodies longitudinally into two equal parts. This applies to fishes as well as to Man. If we know one side of the body we shall be able to reconstruct the other. In particular, the extremities and the most important sense organs-eyes and ears-are distinguished by their uniform distribution upon the right and left half of the body.

A remarkable exception is furnished by the flat-fishes-plaice, flounders, turbot, and soles-which form one of our staple foods and are therefore universally known. Their structure seems to controvert all our conceptions concerning the construction of the vertebrates, but this deviation from the normal state is due to an unusually strong lateral flattening of the whole body. As a result of this process the distance between the dorsal and ventral surface becomes enlarged while that between the sides is shortened. Because the formation of the right and left half is widely different in appearance, and because the flat-fishes, moreover, swim laterally-due to the strong lateral compression of the body-most observers would unhesitatingly describe one side as the back and the other as the abdomen.

The underside of the flat-fishes, corresponding to the right or: 


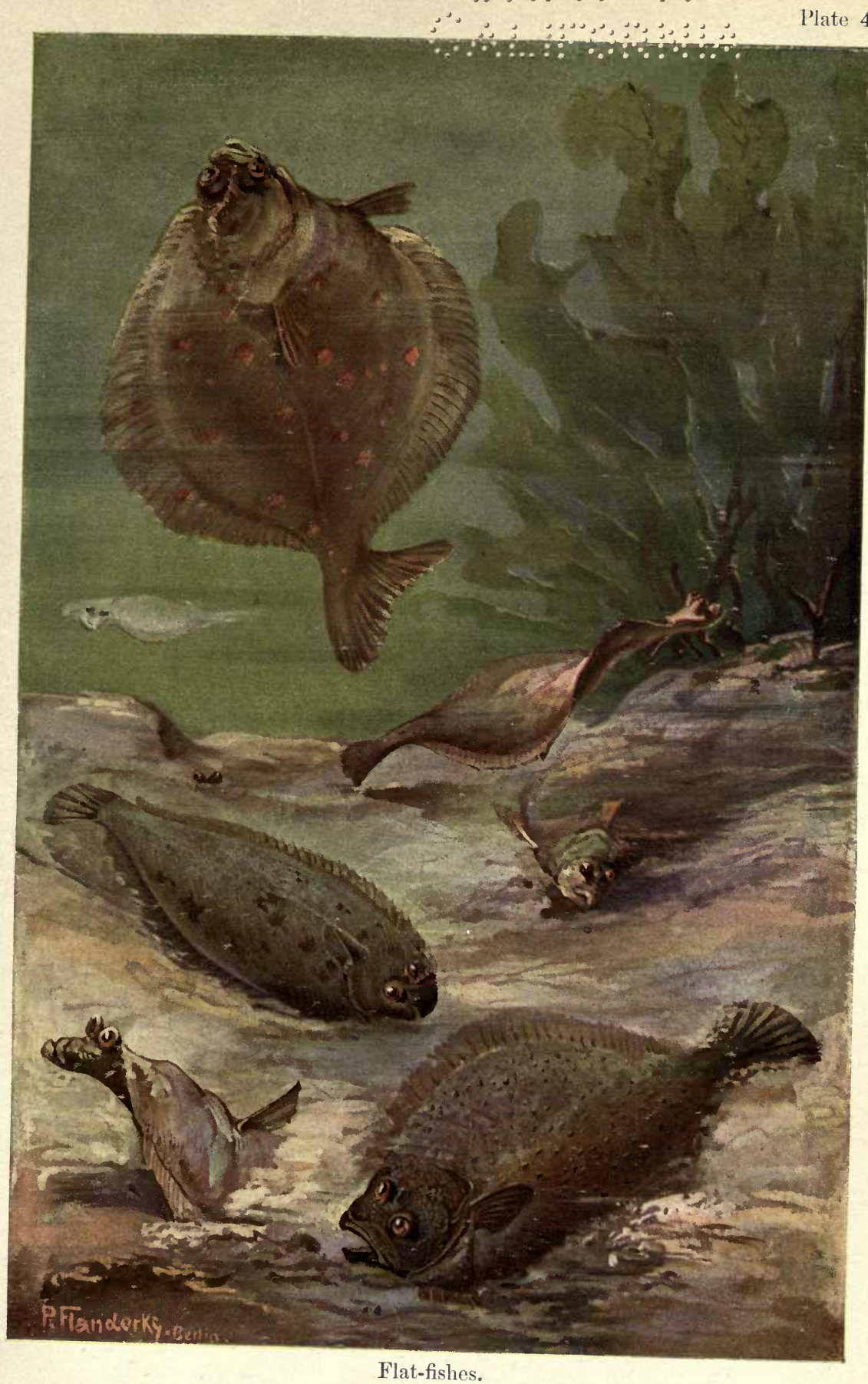

Plaice (Pleuronecta platessa), Sole (Solea vulgaris), Turbot (Rhombus maximus). 
$\because \vdots: \quad \vdots \because \vdots: \because \vdots \vdots \vdots$

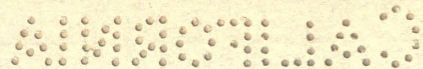


left half, according to the species, is distinguished by a colour ranging from light to white, and by the absence of the eye. Both eyes are fixed close together on the upper side which is distinguished by varied design, and frequently by bright colours. Yet in spite of the pronounced asymmetry the existing flatfishes have doubtless descended from symmetrical ancestors, for each individual must to-day pass in its own body through all the stages of its phylogeny.

The little flat-fish is hatched, having a lateral-symmetrical structure, being in nowise distinguished from the embryos of other fishes, excepting its destiny. But with increasing growth it exhibits increasing differences. Of the eyes, which were originally fixed one on each side, one leaves its normal position and wanders to the other side. Simultaneously the flattening of the body proceeds until at last the final stage of the adult animal is reached (fig. 34).

To their structure corresponds their mode of life. Their domicile is the sea-floor. Here they lie with the light underside on the sand, often buried in the sand. They are not easily detected, for the resemblance of the upper side, which is alone visible on the oceanbed, equally well protects them
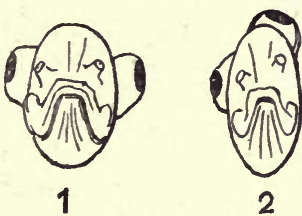

2

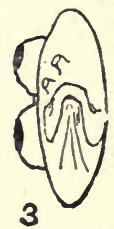

FIG. 34. - SHIFTING OF THE EXES DURING THE DEVELOPMENT OF A YOUNG FLAT-FISH.

(1) Original position; (2) second stage; (3) final position (after Leunis-Ludwig). against their numerous enemies and conceals them from their unsuspecting prey.

One of the best instances of adaptation to special conditions of life is furnished by the Baleen whales, the giants of modern times. Only the ocean with its inexhaustible wealth of life is able to produce and maintain such monsters. It is impossible to conceive the volume of food which must be taken every day by an animal weighing more than 50,000 kilogrammes in order to exist. The problem becomes all the more difficult when we learn that owing to the construction of the pharynx they are dependent for food on small animals, minute transparent snails, cuttle-fishes, shrimps and prawns, and small fishes not larger than a herring. If these giants had to capture their prey 
singly they would soon die from starvation, but Nature has furnished them with a most ingenious straining-apparatus. The mouth-cavity is of an enormous size; from each side of the upper jaw a double series of more than 200 horny plates hangs down into the mouth. "Each plate is shaped like a sword or scythe, reaching often a length of 5 metres. Both apex and

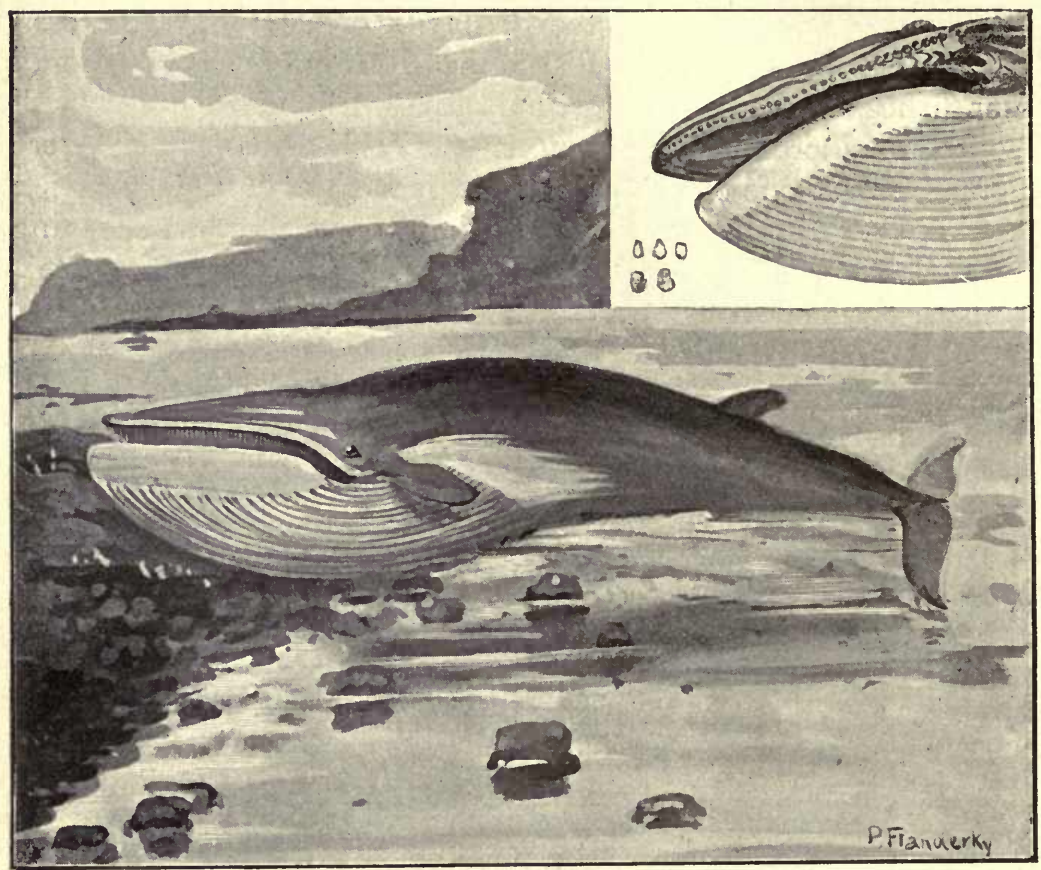

FIG. 35.-THE COMmon RoRQUAL (Balanoptera musculus).

In the corner, head of embryo of Rorqual, with teeth of the upper jaw exposed, also five single teeth.

inner edge are frayed into hairy shreds. The mouth wide open, the whale swims through shoals of pelagic animals. Having secured a good mouthful, it closes its jaw, raises its tongue, allows the water to strain out at the sides through the baleen plates on the edge of which the fcod animals are caught; thence they are swallowed." 
It would be difficult to imagine an organization better adapted to their mode of life than this enormous sieve. Yet embryology tells us that the whales were not always furnished with baleen, but that they developed by gradual adaptation from dolphin-like ancestors possessing teeth. This fact was already known to St.-Hilaire, one of the pioneers of the Evolution Theory. Recently the development of the baleen whales has been thoroughly studied by Kükenthal, upon whose drawings our illustration is based. According to him the embryos develop early both in the upper and under jaw complete rows of teeth, but these teeth become degenerate before birth without having functionated (fig. 35).

We may even affirm that the ancestors of the mammals had a regular change of teeth; for behind this first row of teeth, the milk teeth, stands a second which also remains rudimentary. Similar conditions are observed in the tortoises, whose toothless jaws are armed with sharp horn-plates similar to the bill of a bird ; their embryos, however, possess degenerate teeth.

It is these rudimentary organs which no longer reach the functional stage that are of utmost importance to the Evolution Theory. Or is there any other logical explanation of the presence of rudimentary organs than that these now useless formations once discharged certain useful functions in the ancestors? Is there a stronger argument against a divine creative act in the Biblical sense? Is it not an impossible conception that an omnipotent God had created his creatures thus imperfectly? But the Evolution Theory solves this problem without difficulty. We know that climatic conditions on this planet, air pressure, and the moisture in the atmosphere, have in the course of the earth-periods undergone many changes. Where to-day the land stands there the oceans roared in ages long ago; vast stretches of water have been replaced by continents. As the gills of the amphibians and the swim-bladders of the fishes lose or change their functions when the aquatic life is exchanged for a life on land, so all other organs change with a change in the conditions to which they were adapted. We have seen that all organs which fall into disuse become degenerate until at last they disappear altogether. As a result of the conservative element which is present in each organism and finds 
its most eloquent expression in heredity, such parts of the body reappear more or less distinctly during the embryonic stage, long after they have been lost in the adult animal. We have already considered the evolution of the human circulatory system; further instances are that the human embryo, like that of an anthropoid Ape, possesses thirteen pairs of ribs, whilst adult man has only twelve; that at an early stage the coccyx is comparatively large and protrudes beyond the lower extremities; and that in the carpus of the embryo an Os centrale is rudimentary, just as in amphibians and reptiles. In view of these and many other facts that can be adduced every unbiassed student will admit that the Evolution Theory is proved by abundant evidence, and applies to the animal kingdom as well as to the human species.

In adult man we are able to demonstrate the presence of numerous organs and parts of organs which are either quite rudimentary and useless, or in an obvious state of degeneration. Like the males of all mammals, Man possesses rudimentary teats. There are even certain cases known in which milk was secreted by the male mammary gland. On the eyes of birds, and in many fishes, amphibians, and reptiles is found a thin skin, the so-called nictitating membrane or third eyelid. In the lower mammals this membrane is still fully developed, but in the higher mammals and in man it has been reduced to a tiny rudiment, a crescent-shaped fold which lies in the inner angle close to the lachrymal gland.

The muscles of the ear are apparently in a similar state of retrogressive development. True, there are still the same muscles as in mammals, the attollens, attrahens, and retrahens aurem, but they are only faintly developed and generally without functions. This is so much true that in a person who is still able to move his auricle this atavistic ability is regarded as an amusing freak.

Other rudimentary organs are the wisdom tooth, which in the European is sometimes entirely absent; the coracoid process of the scapula, a bone which is strongly developed in reptiles, birds, and the lowest mammals, the Ornithorhynchus, or duck-mole, but rudimentary in man; and, finally, the greatly degenerate tailmuscles.

The best known of all rudimentary organs is doubtless the 


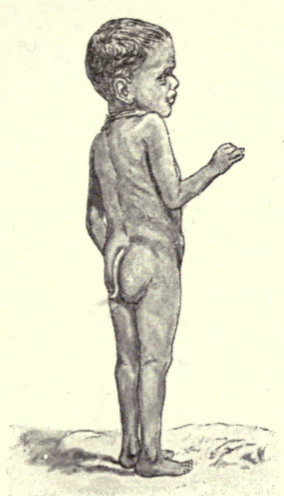

1

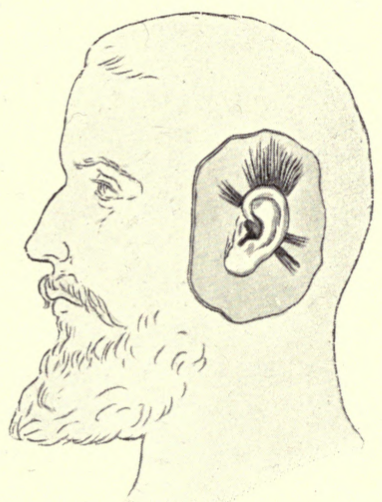

3

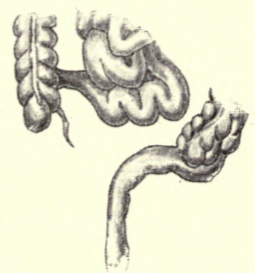

5

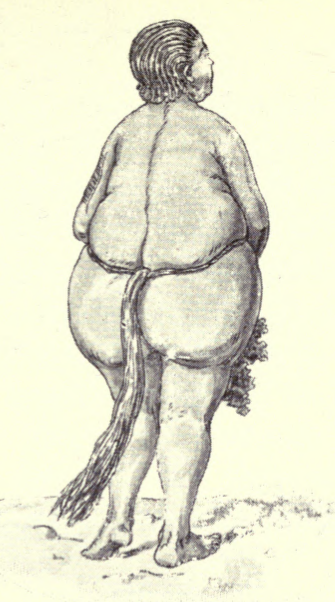

2

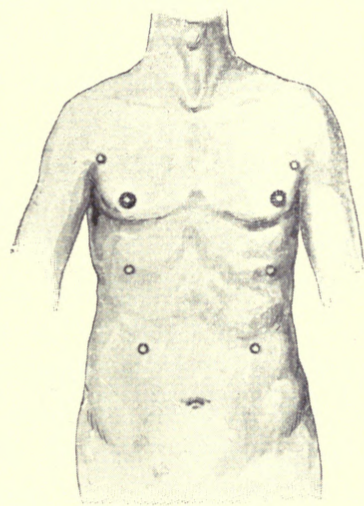

4

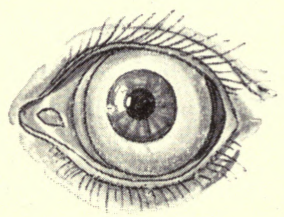

$6 a$

FIG. 36.-RUDIMENTARY ORGANS.

(1) Indian child with tail. (2) "Tailed" Bongo woman (after Ranke). (3) Rudimentary ear muscles. (4) Polymasty in a young man (after Ammon). (5) Cæcum, with vermiform appendix. (6) Eye of an owl with nictitating membrane. (6a) Human eye with crescent-shaped skin-fold (after Romanes). 

cæcum, with the vermiform appendix. In herbivorous mammals a structure of considerable size, and of great importance in the assimilative act, it is much smaller, and often absent, in carnivorous animals. In man the cæcum is small and insignificant, playing probably a small part in the absorption of the digested food. But its appendix, the notorious Processus vermiformis, has no function or value whatever, its object being rather, apparently, to create suffering. Its extremely variable length, ranging, in an adult, from $25 \mathrm{~cm}$. to a mere vestige, seems to support this conception, which is further proved by the fact that it may be completely removed by a surgical operation without any subsequent injury to the body.

Many travellers in Africa and Australia have reported the existence of human beings with long hairy tails, but further investigations have always proved these reports to be due to errors or deception. Many savage tribes, the Njam-Njam, the Bongas, $\& c .$, are accustomed to wear as girdles the skins and tails of wild animals, and this habit may have given rise to such fables which should have been discredited at the first report if it had been remembered that even the highest apes have only rudimentary tails. Nevertheless, these reports are not entirely without foundation. We heard before that each human embryo possesses a rudimentary tail, consisting of a few vertebræ. In most cases this vestigial tail soon becomes degenerate, nor is it even discernible in adult man. Yet now and then we hear of the formation of a typical tail-stump, as shown in the picture of a small Indian child (fig. 36). There are even cases known in which the tail attained a length of about 10 centimetres.

Among the invertebrates we find numerous facts supporting the Doctrine of Descent. Everyone knows the extremely varying structure of the different classes of the Echinodermata, the seaurchins and starfishes, the elegant ophiuroids, and the ungainly holothurians. Who would think that all these forms are closely related? Yet in spite of the numerous external differences their organization is surprisingly uniform. This is best shown by their remarkable organs of locomotion which distinguish them from all other animals.

Those who have seen Echinoderms in an aquarium must have been impressed by their beautiful radially-symmetrical 
shape. This structure is probably an echo of ages long ago when they were fixed animals, as the beautiful feather-stars Pentacrinus and Rhizocrinus are to-day. For it is a phenomenon universally observed in the animal kingdom that a sedentary mode of life usually leads to a modification into, or at any rate an approach to, the radial type. I need only mention corals, Chætopod worms (Serpulidæ) and the Bryozoa.

In any large aquarium we may see lying on the sand awkward looking sea-cucumbers; sea-urchins menacingly project their spines, whilst a star-fish is about to force its proboscis-like stomach between the valves of a mussel and slowly devour the living contents (fig. 37). The superficial observer cannot understand how these awkward, cumbersome animals, clad in their calcareous armour, can reach the highest point and crag of the artificial rocks, and even ascend, slowly but surely, the smooth glass wall. But observation will supply the solution. The starfish has finished its repast which seems to have stimulated its energy. Slowly it pushes itself along the bottom until it reaches the glass wall. "As it erects its arms, preparatory to ascending the side, we see that scores of soft tube-feet are protruded from the central groove of each arm. These become long and tense and their sucker-like terminal discs are pressed against the glass. These are fixed, and towards the attachment the starfish gently lifts itself. By repeating this process it gradually ascends the glass. The protrusion is effected by the internal injection of fluid into the tube-feet; the fixing is due to the fact that the contained fluid, flowing back again from the tube-feet to the internal reservoirs, produces a vacuum between the end of the tube-feet and the surface of the glass.

"On the dorsal surface, between the bases of the arms, there is a complex calcareous sieve through which the sea-water is taken in. Its pores converge into a fine tube, the 'stone-canal' which, like a complex calcareous filter, extends vertically through the body, and leads into a ring round the mouth. This circumoral ring gives off nine transparent vesicles and five radial tubes, one for each arm. Each radial vessel lies in the ventral groove of an arm, roofed by the rafter-like vesicles, and gives off internally reservoir-like bladders or ampullæ, and externally the tube-feet. The fluid in the system seems to pass from the radial vessels into the tube-feet, and back again into the ampullæ. 


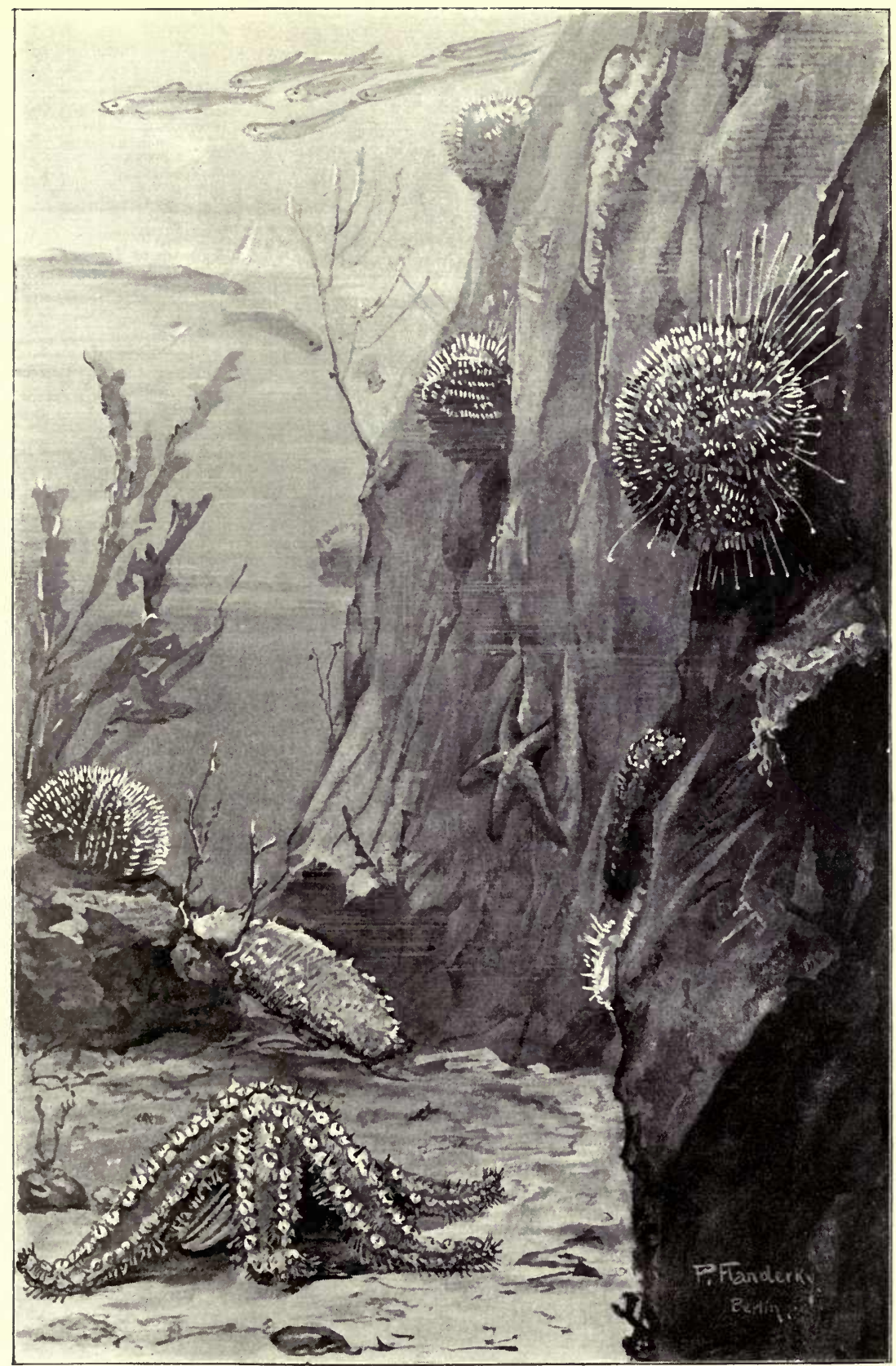

FIG. 37.-ECHINODERMATA.

In the foreground, Starfish (Asterias glacialis) sucking a mussel; on the rock, Sea-irchins (Spherechinus gramularis); in the background, Sea-cucumber (Holothuria tubulosa). 

"In the other classes of the Echinodermata the water-vascular system is similarly formed, though with interesting deviations. That of the sea-urchin does not differ greatly from that of the starfish, but in the Holothurians we observe greater divergencies. Of the five radial tubes (ambulacralia) only three are developed into organs of locomotion and furnished with suctional discs, while the tube-feet of the other two have become modified into pointed tentaclelike formations. The 'stonecanal' does not extend to the exterior, but opens into the body-cavity. In the Ophiuroidea and Crinoidea degeneration has gone still further; for being well capable of locomotion, owing to the greater mobility of their arms, all the ambulacralia have become modified into ampulla-less organs of

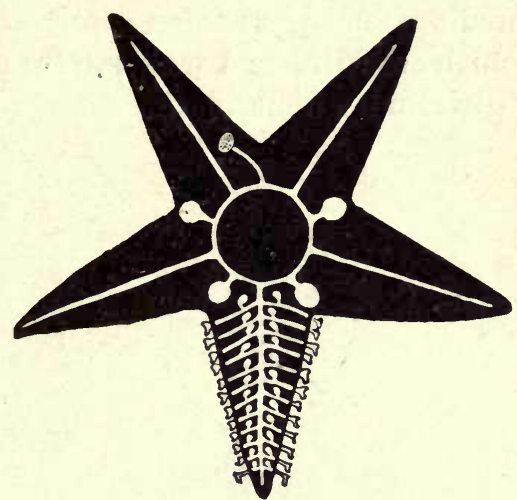

FIG. 38. -WATER-VASCULAR SYSTEM OF A STARFISH. touch."

The other organ-systems show a similar uniformity of structure, but the larva-form, finally, furnishes the most convincing proof of the phylogenetic relation of all Echinodermata. They differ from the adult animals by their pronounced bilateral symmetry as well as by their soft gelatinous body. In the seaurchins and Ophiuroids we find the Pluteus-larva form, in the Holothurians the Auricularia form, and in the Crinoids the Bipinnaria forms. All these diverse larvæ may be traced to a common ancestral form which had a trigeminous intestine and a simple circumoral cilia-wreath (fig. 39).

These various developmental stages of the Echinodermata are of particular interest to the Evolution Theory, because they form the connecting link with another stem, the Vermes. A more highly organized marine form, the famous Balanoglossus, passes through a larval stage which, owing to its extraordinary similarity, was once held to be an evolution form of an Echinoderm. The adult worm possesses in its 'proboscis' an organ similar to 
the water-vascular system of the Echinodermata. Above all the mode of formation of these two organs is strikingly similar, for they develop as protusions of the larval intestinal canal (fig. 40).

One class of the Echinoderms, the Crinoidea, differs greatly from the rest in the course of its development. Let us choose for illustration a small form which frequently occurs in the Mediterranean, Antedon rosacea. By means of their thin 'arms,' which are furnished with lateral pinnules and processes, they skilfully climb about in the seaweed. They possess great power of
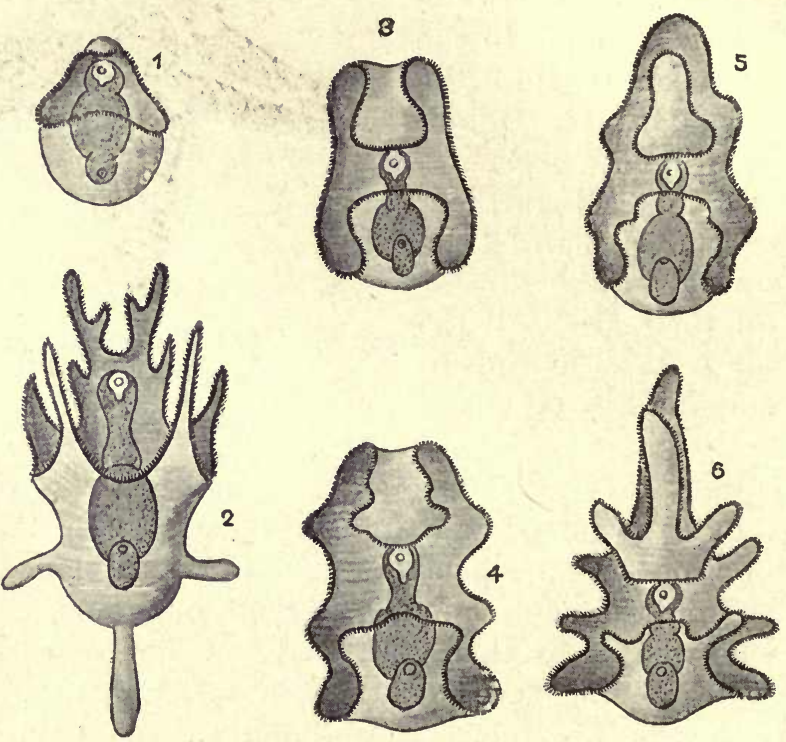

FIG. 39. - LARVA OF ECHINODERMATA.

(1) Common ancestral form; (2) Pluteus-larva of Sea-urchin; (3 and 4) Bipinnaria-larva of Starfish; (5 and 6) Auricularia-larva of Sea-cucumber. (After J. Müller.)

resistance, are easily 'kept' in an aquarium, and often proceed to reproduction. The enormous tenacity of Antedon is proved by its insensibility to injuries; one may break off all their 'arms' without causing them any serious injury; under favourable circumstances they will repair the damage in a short time by regenerating them. 
In their development the Crinoids pass two distinct larval stages. First the ovum produces a minute, free-swimming form, resembling a barrel bound with five ciliated hoops. These and a wisp of cilia at the most anterior end effect locomotion. But soon the larvæ give up their free life, anchor themselves by means of a ventral groove to Algæ or a stone, and change into a stalked larval form, entering the so-called Pentacrinus stage. From this proceeds finally the adult Echinoderm which once more returns to a free life (fig. 41). The appearance of a typical fixed stage in the evolution of a free-living animal is remarkable. Does not perhaps the biogenetic law apply here, and is not the free mode of life in Antedon a recent requisition? Turning back the leaves of the earth's history we find that the Crinoids are a very ancient and widely distributed group, and that the species existing to-day are evidently only the remainder of a vast class which is rapidly approaching extinction. The Palæozoic period represents the zenith of their development, and though the various species of Crinoids occurred in narrowly defined regions, they are found in such masses that frequently deposits of a thickness of several metres almost exclusively consist of their limy armour. If we examine these extinct forms accurately, we see that they were in fact stalked, fixed forms. Such forms still exist to-day on the ocean bed, where conditions

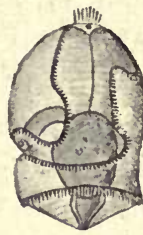

FIG. 40.

FORNARIA-LARVA OF A MARINE-WORM, Balanoglossus. (After E. Metchnikoff.)

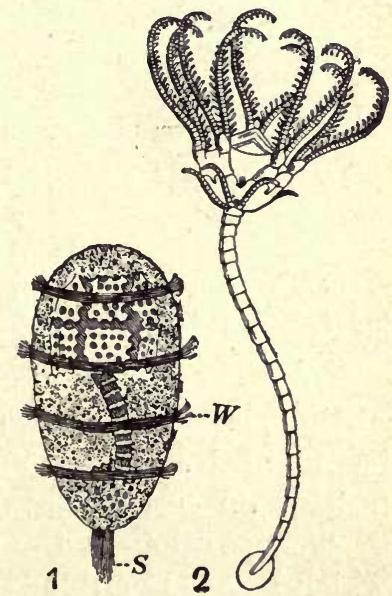

FIG. 41. - LARVAL FORM OF A CRINOID.

(1) Free-swimming larva, with skeleton of adult forming in. side; (2) fixed stalked young Pentacrinus stage. (After Clauss.) remain eternally alike-the Rhizocrinus and Pentacrinus, which I have already mentioned.

Larval forms similar to those with which we met in the 
star-fishes, holothurians, sea-urchins, ophiuroids, and finally in the Balanoglossus, are found in other vermes and also in many molluscs. Interesting conditions are observed in the annelids. Among the marine forms of this class we find a free-swimming pelagic larval form, the celebrated Trochophora. By gradual metamorphoses, growing longitudinally, this larva is transformed into an adult worm. In distinction to the pelagic annelids the fresh water forms have no intermediate larval stage ; the ovum produces the fully developed worm. Nevertheless, there is no doubt that the freshwater annelids formerly passed through a larval stage, for in the growing embryo we find indubitable characteristics of Trochophora.

Finally let us consider an instance taken from the crustaceans. Who has not heard of the duck-mussel (Lepas anatifera), which

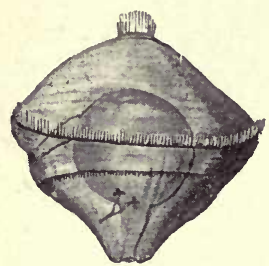

FIG. 42. -TROCHOPHORA LARVA OF POLYGORDIUS, A MARINE ANNELID. in the old German legend was the young stage of the barnacle (or barnicle) goose. According to old ideas, the distinctive feature between the animal and vegetable kingdom was the ability of locomotion. Hence, corals and sea-anemones, sponges and tunicates were even until recent times counted among the flora. Duck-mussels, being fixed, were regarded in mythical zoology as plants, and the monks in mediæval times were not slow in arguing that as duck-mussels were plants, so the geese and ducks that developed from them must also be 'plants,' and were not therefore included in the rule which forbade on certain days the eating of flesh.

The position in the system of zoology of the Cirripedes, of which I have mentioned the duck-mussel as the best known type, was long obscure. Almost universally these animals were regarded as mussels. The calcareous plates which encase their body and greatly resemble mussel-shells not unnaturally gave rise to this error. But now we know that the Cirripedes are crustaceans, though when we fish a piece of driftwood or pumice-stone from the sea and observe on the underside 'mussels' anchored by a strong leather-stalk, and projecting from the partly open valves numerous cirral threads, we see a picture widely differing from our usual conception of crustaceans. But a knowledge of the phylogeny of Cirripedes leaves no room for doubt. 
In the evolution of all lower crustaceans, the so-called Entomostraca, we meet invariably (however differentiated the adult animals may be) with a peculiar larva, the Nauplius. It is a lively little animal which swims gaily about by means of its three pairs of appendages, of which the first is unforked, the other pairs doubly-branched. The median eye is also a distinctive feature in the Nauplius larva. By a more or less complicated metamorphosis the Nauplius changes into an extremely great variety of crustacean forms. And as 'duckmussels' also originate from Nauplius larvæ their position in the system becomes clearly defined.

It is here necessary to modify to some extent the preceding statement that all crustaceans pass through a Nauplius stage, for an exception is made by the water-flea (Daphnia), the favourite food of aquarium fishes. This little crustacean passes

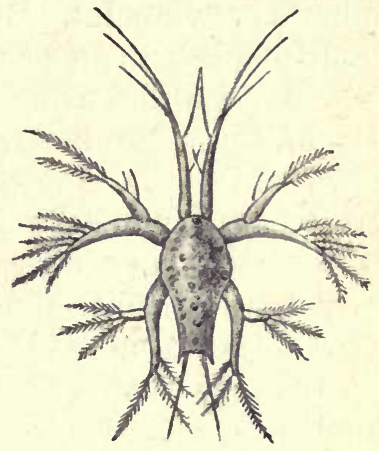

FIG. 43. - NAUPLIUS STAGE OF Pencus potimirum. the stage of the free-swimming Nauplius in the ovum and emerges as an adult Daphnia.

It is a well-known fact that the growing larvæ and young crustaceans moult several times. The object of the moulting is chiefly to enable the animal to grow, for the rigid chitinous cuticle would make development impossible. Before the moulting the old shell becomes virtually dead, a new shell begins to form within the old, and finally the shell is cast with considerable effort. Almost at the moment of casting the animal, hitherto in a compressed state, increases in size. The new shell is at first soft and requires several hours to acquire firmness. When it has become rigid the growth of the crustacean is once more postponed till the next moult.

However strange it may sound, the Nauplius in the ovum performs a similar act of moulting, a process which is all the more illusory as the rigid egg-shell effectually precludes every increase in size. Is not the only explanation this, that the Daphnia, like other crustaceans, had once a free-swimming 
Nauplius stage? Can this aimless moulting in the ovum indicate anything else but a tenacious retention of a once vitally important process?

The following instance will convince even the greatest sceptic. If we take from any lake in Europe or North America a tumblerful of water and pour it through a fine sieve we see a number of minute transparent animals, each formed round a minute brown point. By means of a magnifying glass we are able to distinguish them as crustaceans, about 1 centimetre in length, whose scientific name is Leptodora hyalina, a species of the Daphnidæ. No better case of adaptation of an animal to its environment is known. The transparent body makes the crustacean practically invisible in the water and thus enables it to escape its enemies, but approach its prey undetected. The tiny brown point, the only part which is visible of this remarkable creature, is the food in the stomach.

Like the related forms, the Leptodora produces two different kinds of female reproductive cells, described as summer and winter ova. Whilst from the former the growing animals emerge under normal conditions fully developed, having passed the larval stage in the ovum, the winter ovum produces a freeswimming Nauplius. It seems difficult to find a more convincing proof. The cause of this differentiation is probably to be found in the fact that the supply of food furnished to the winter ova, which leave the maternal body prematurely, is insufficient for the complete course of their development. Unless it is therefore to die in the egg from hunger, the young crustacean is compelled to seek its own livelihood.

The higher crustaceans, the so-called Malacostraca, begin their free life with the more advanced Zoæa stage (fig. 44). Formations of a Nauplius larva occur now only rarely; our common crayfish, indeed, emerges from the egg fully developed, differing from the adult in size but having all organs properly formed. In contrast to it, some of its nearest relations, for instance the beautiful Brazilian Penæus (P. potimirum) has a very complete ontogeny (fig. 43). It comes into existence as a dainty little Nauplius. Gradually the larva increases in size, the body becomes segmented and the anterior half protected by a shell. Thus cephalothorax and abdomen are formed. Simultaneously 
other changes take place, transforming the Nauplius into a Zoæa. The median eye is replaced by a pair of eyes, and the three pairs of appendages become six.

Continued growth and moulting produces the second Zoæa stage, which approximates more and more that of the adult animal. The number of appendages is again increased, but whilst formerly all served the purpose of locomotion, they now gradually assume separate definite functions. The two first appendages become antennæ, the next develop into jaws, whilst the other become rowing-legs. The abdomen is better developed and the eyes become typical lateral

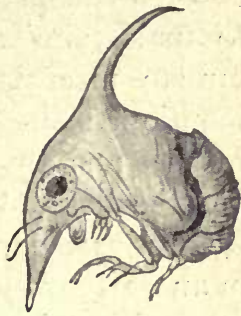

FIG. 44.-ZOZAA STAGE OF A CRAB. outgrowths of the head.

Another moult brings the Zoæa to the Mysis stage. It has now thirteen pairs of appendages, of which the third, fourth, and fifth are used as masticatory organs. The legs are assisted in locomotion by the abdomen, the most posterior segment of which has become transformed into a frond. This larval form is especially interesting because we find in the order Schizopoda a family of the Mysidæ the members of which permanently remain at the Mysis stage. A last moult concludes the complicated metamorphosis, giving the Penæus its final shape.

Though the opinion is no longer held by modern naturalists that adult animals of the Nauplius type existed among the oldest ancestors of the crustaceans, and though it is now doubted for several reasons whether a mature Nauplius ever existed, their regular appearance in the evolution of all crustaceans can only be explained in the sense that the Nauplius is the primary larval form from which the living crustaceans have descended.

There is no better test for the accuracy of a theory than that it enables us to make certain predictions which are subsequently corroborated by observation. One of the most brilliant triumphs of science is the discovery of the planet Neptune. As early as 1828 Bessel contended, on the basis of certain slight irregularities in the path of Uranus, that they were probably caused by some as yet far-distant planet. Independently of each other, yet almost simultaneously, the famous English astronomer Adams, and 
Leverrier, the Director of the Paris Observatory, determined the place in which this planet would have to be looked for; and when Galle in 1846 directed his telescope to this spot he actually discovered the planet Neptune. The Evolution Theory enables us to make similar prophecies. The discovery by Goethe of the human intermaxillary bone is a case in point. I have already mentioned the ues centrale of the carpus which is present in reptiles and amphibians but absent in man. If our view concerning the descent of man from lower animal ancestors is correct we are justified in assuming that a rudimentary ues centrale exists in an early evolution stage of man. In point of fact it was discovered in a human embryo by Rosenberger.

Investigations made into various species of Hawk-moth caterpillars (Sphingida) led Weismann to believe that the simple longitudinal stripes in the caterpillars of the Humming-bird hawk-moth (Macroglossa stellatorum) are phylogenetically older than the more general spots or oblique stripes, because caterpillars thus marked developed from earlier forms with longitudinal stripes. If this assumption was correct it was equally applicable to other Sphingidæ caterpillars with oblique stripes, and Weismann predicted that the then still unknown earlier forms of the Privet Hawk-moth (S. ligustri) possessed longitudinal stripes. A decade afterwards the English zoologist Poulton succeeded in demonstrating that the young caterpillars actually possessed the postulated longitudinal stripes.

Recently the advances made in biochemistry have supplied valuable corroborative evidence of the theory of phylogenetic relations. It is a remarkable fact concerning the blood of two different animals that the red blood corpuscles of one individual are destroyed by the blood plasm of the other. Decomposition becomes more difficult in proportion as the relation of the species becomes more distant, whilst in closely related animals or in individuals of the same species no injurious effects are observed. After numerous experiments Friedenthal proved that the bloodserum of man destroys the red corpuscles of the baboons and mandrills, but not those of the anthropoid apes. Conversely, the red corpuscles of man were in most cases decomposed by the serum of the lower monkeys, but remained entirely unaffected by the blood of the higher apes. 
We have already become acquainted with the valuable faculty of the living organisms to generate for each toxin introduced an antitoxin which combats the dangerous effects of the former. It is owing to this faculty that the organism is able, by a gradual increase in the doses, to become immune against the most dangerous poisons. When we inject the blood of a distant species certain elements are formed in the body, called 'precipitins,' which under a continued systematic treatment with a certain kind of blood are capable of accumulating in the blood of the animal under treatment. These 'precipitins' possess the faculty of causing in the blood.serum of the species from which the blood for the injection was taken remarkable precipitates, whilst leaving unaffected the blood of all other animals.

If, for instance, we inject at regular intervals of two to six days ten ccm. of blood from a fowl-the dose may be increased after the rabbit has become accustomed to the foreign blood-we shall obtain at last a rabbit serum (rabbit-fowlantiserum) which mixed with fowl's blood causes in it strong turbid precipitates. But the fact chiefly of interest to us is that the rabbit serum has this action not only upon fowl's blood, but also, though in a lesser degree, upon the blood of related species.

This faculty has been made by Nuttall and others the startingpoint of a series of comprehensive biochemical experiments, in order to ascertain the degree of relationship of various different species. These tests generally corroborate the results which have been obtained by a study of comparative anatomy and phylogeny. It must, however, be understood that it is in no case possible to say how closely the examined animals are related; it is only possible to ascertain from the strength of the precipitate that an animal $\mathrm{A}$ is more nearly related to an animal $\mathrm{B}$ than to an animal $\mathrm{C}$.

By an ingenious method Nuttall was able to compare the degree of relationship simply by measuring the volume of the precipitates. Thus an anti-sheep serum, obtained from a rabbit by systematic injections of sheep's blood, when mixed with sheep's blood yielded a strong precipitate the volume of which was assumed to equal 100 per cent. Mixed with bullock's blood, the precipitates now equalled only 80 per cent., with that of the antelope 50 per cent., reindeer 30 per cent., pig 20 per cent., 
horse 16 per cent., cow 12 per cent., dog 7 per cent., and kangaroo only 5 per cent. Correspondingly, anti-pig serum indicated in the pig 100 per cent., in the para 14 per cent., cat 14 per cent., dog 13 per cent., sheep 13 per cent, and kangaroo 5 per cent. An anti-cattle serum produced reactions in other species of cattle and, to a lesser degree, in sheep, goats, antelopes, and gnus. We are, therefore, probably justified in assuming that the phylogenetic degree of relationship of these animals corresponds to the volume of the precipitates.

In like manner Nuttall endeavoured to shed light upon man's position in the zoological system, and it is remarkable that these experiments not only led to the same result as those of Friedenthal, but also agreed with Haeckel's genealogical tree of the princates. For it was shown, as was indeed expected, that an anti-man serum produced the greatest reaction in individuals of different races, weaker results in the anthropoid apes, still less results in guenons and baboons, and least of all in the monkeys of the New World, the Platyrhini. Finally, in the lemurs a very faint turbidity occurred only very rarely and under employment of very strong serum. These experiments seem to indicate that the biochemical differences between man and the chimpanzees and gorillas are less than those between these anthropoid apes and their lower relatives. Though the blood-reaction alone does not supply an incontestable proof of the phylogenetic relation of the various animal species, it forms a most valuable link in the chain of evidence.

The biochemical method, it may be mentioned in passing, is of the utmost practical value in the detection of crime, for it is often necessary to prove whether blood-stains on a floor or the clothes of an accused person are those of a human being or animal, a question upon the answer to which often depends life and death. To-day such proof is easily furnished, for all that is necessary is to dissolve the blood-stain in water and add a small quantity of anti-man serum. If the blood is that of man, a turbid, flaky precipitate appears after a few minutes, if that of an animal, no reaction takes place. So accurate, indeed, is the effect of the serum that it is even possible to demonstrate with it the origin of blood which is already in a state of putrefaction, or has been in a state of desiccation even for a period of several years. This 
method was therefore adopted many years ago in forensic medicine in Germany and most other civilized countries. As it is further possible to detect in sausages the presence of horse and dog flesh, biochemistry is a powerful adjunct in the prevention of adulteration of this kind of food.

Instead of blood other albumens may be used. Thus Uhlenhut showed that the blood-serum of a rabbit which had received at regular intervals in the abdominal cavity injections of solutions of albumen from a fowl's egg caused a strong precipitate if mixed with a solution of such albumen, but no precipitate if mixed with a solution of any other albumen. Thus it is now possible to distinguish between the albumen of the various species of birds. These precipitates may still be distinctly observed in dilutions of 1 gramme of albumen to 100 litres of water. Ascoli states that he has observed reaction in dilutions of 1 in 1,000,000. An interesting fact in this connection is that von Hansemann succeeded by the biochemical method in determining the origin of mummies more than five thousand years old.

I have now completed my task of giving in large outlines the facts that prove the gradual evolution of the organic world. We have seen that palæontology, comparative anatomy, the history of evolution, and finally, the investigations of biochemistry, all form a chain of evidence for the truth of the Evolution Theory in which every link is firmly forged. 


\section{CHAPTER VII.}

\section{THE FACTORS OF EVOLUTION.}

We may now take the Evolution Theory as proved. Our opinions may alter in detail concerning the phylogenetic relationship of the organic world and suffer modifications, but the hypothesis that the simpler preceded the more complicated, the lower the higher, chronologically and causally, must now be regarded as an established fact of scientific research.

It is, however, a different question when we ask what causes have effected these modifications and development of the species. The most comprehensive and thorough attempt at explanation is made by the so-called Darwinian Theory. In many circles, in particular in those who are hostile to the evolution theory - 'the monkey hypothesis,' as it is sarcastically called-the Darwinian theory and the doctrine of evolution are regarded as identical, and it is assumed that if the ingenious hypothesis of the great British naturalist, the fundamental principle of which is the theory of natural selection and the survival of the fittest, can be refuted such refutation would at the same time dispose finally of the theory of descent.

We cannot protest too strongly against the confusion of the teachings of Darwin with the doctrine of evolution. They are strictly separate, for the hypothesis of natural selection takes the evolution of organic life as proved, and merely claims to give an explanation of the forces which were active in the changes of the organic world, and of the methods by which the origin of the higher organisms from simpler ancestors may have taken place. Even if the doctrine of this great naturalist should be proved to be erroneous, such proof would in no way affect the accuracy of the evolution theory. All that would be attained in that event would be the admission that science has so far been unable to 
give a satisfactory uniform explanation of the manner and method by which the changes and development in the organic world have taken place. But the doctrine of Darwin in its main points still holds the field unrefuted, and honest criticism has found itself restricted to pointing out the many weak parts of the hypothesis of natural selection and to indicate that Darwin, and in particular his successors, greatly over-estimated the importance of natural selection, and that there are other causes which have played a significant part in the development of the organic world. But whatever may be the verdict of coming generations concerning the doctrine of this great man, it cannot detract from his merits; no one can rob him of the fame that it was he who by his great and comprehensive work carried the Theory of Descent to universal recognition and final victory.

What are animal species? Are they really immutable, final, natural units, as Cuvier states, or are they more or less arbitrary definitions made by man in order to facilitate the study of nature. Just as easy as it is strictly to define any species so long as only a few specimens of it are known, so difficult and yet even impossible becomes the task of an accurate definition when we have to deal with numerous individuals, especially if they belong to different geographical districts. It will always happen that some will fit easily into the system whilst others will diverge on many points.

We see everywhere in Nature that the descendants, the children, are more or less like their parents, and exhibit generally the same specific features as the latter. On the other hand, there is no doubt that no child is entirely and in all details like its parents; it will always differ from either to a greater or lesser degree. In addition to the character of the species, it bears its own individual character. This seems natural enough when we remember that every higher organism owes its existence to two different individuals and inherits characteristics both from its father and mother.

These individual fluctuations and deviations are called variations. Speaking generally, they move within very narrow limits, revolving, as it were, round a fixed centre, the type of the species. But under certain circumstances, when by accident or owing to external unknown influences such variations accumulate 
through various generations towards a certain direction, there may arise individuals which differ from the rest of the species and their parents in so many points and so widely that we may no longer regard them as sub-species or variations, but must give them the rank of a separate species. If this assumption is correct, variations must claim our utmost interest as the starting point of the genesis of new species, and it would mean an enormous progress towards the solution of the mystery of speciesformation if we succeeded in discovering the causes that lead to it.

Nowhere in the whole of Nature do we find such obvious inclination to variations and race-formation as in domesticated animals and plants. Long neglected by science, because to deal with these 'unnatural' products of human self-interest or fancy was almost regarded as a desecration of pure science, they were chosen by Darwin as the basis of his epoch-making investigations.

The cause of the contempt felt by older investigators was of a very different nature. Dogmatic supporters of the theory of the immutability of the species did not know what to do with these 'degenerate' creatures which would in nowise fit into their system. As happens very frequently, their mask of contempt concealed a very real fear. No one denies to-day that domesticated animals and plants are equally with their freeliving relatives entitled to our fullest interest, for the history of domestication is the record of one of the most marvellous, though unintentional, scientific experiments ever conducted. Where is there another experiment undertaken with such a wealth of material, and carried on during thousands of years ?

There is no doubt that the first individuals of the human species had no domesticated animals. The animal kingdom was to the primitive man of interest only in so far as he had to defend himself against the attacks of the larger carnivorous animals, or as some supplied him with food and warm coverings. Even throughout the Stone Age domestic animals appear to have been unknown in Europe, for the most ancient and lowest form of the descriptive arts, that of the cave-dwellers, shows us only pictures of beasts of the chase scratched upon bones with the point of a flint. Domestication is therefore obviously 
$\because \because \circ \quad \because \because \vdots \because \because \vdots \vdots$

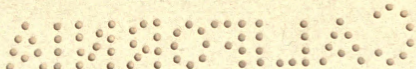




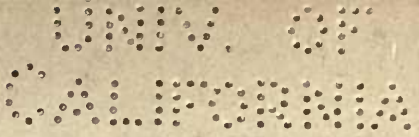

THE FACTORS OF EVOLUTION

preceded by the chase and capture of animals in the wild state. At first they were probably captured without any idea of domesticating them for the purpose of deriving certain advantages, and only gradually primitive man began to perceive the uses to which animals might be put. Thus there developed out of an originally hostile relationship in the course of time an alliance from which both parts derived advantages. Man gave to certain animals shelter and food and derived in return certain services. In true perception of the high value of domestic animals to civilization, their treatment, with a few deplorable exceptions, has always been humane; in many countries they have even been regarded with feelings of veneration and worship.

The majority of the species of our domestic animals are very old, many thousand years having elapsed since they began to 'live with man.' We are, therefore, unable to judge of the process of domestication by direct observation and shall be in most cases referred to tradition, hypotheses, and experiments in order to obtain a clear view of their history. A familiar exception is the African ostrich, which has recently been thoroughly domesticated, whilst gradually becoming extinct as a free-living bird. It is, therefore, no matter of surprise that of a few domesticated animals we know only their wild prototypes. Nevertheless, it would be a mistake to assume that as a result of a long period of domestication the wild ancestors have either become extinct or have been gradually gathered up into man's stock of domesticated animals, for research has been able to prove the existence of wild ancestors in many cases where they were thought to have become extinct, and it was also shown that the different races of many domesticated animals, as for instance dogs, do not descend from only one wild ancestor but from several. The exact number of such ancestors investigation has not been able to ascertain. In other cases the numerous breeds of domestic animals have been traced back to one wild ancestor.

Darwin has proved that, for instance, our domesticated pigeons have all descended from the rock-pigeon (Columbia livia). If we glance at the coloured plate (Plate V.) and notice the sharply differentiated birds, we find it difficult to agree with this statement. Nevertheless, it has been clearly proved by the fact that in the crossing of widely differentiated races of pigeons, 
each of which is again widely differentiated from the rock-dove, some of the descendants revert to the wild stem-form, exhibiting distinct characteristics of the species Columbia livia.

The rock-dove is found throughout the greater part of Europe, North Africa, and wide stretches of Asia. Its colour resembles that of the ordinary bluish-grey field pigeon, but is distinguished from it by the bright metallic sheen on the feathers of the neck and breast, and a more delicate and elegant shape. It lives socially in large communities, like all other animals suitable for domestication, builds its simple nest in inaccessible crevices of rocks out of dry twigs, straw, and fibres, and, like its domesticated descendants, lays regularly two eggs, and has a strong inclination against settling on trees. It shows the same peculiar nodding of the head and clapping of the wings, and delights in large swarms to circle round and round high up in the air. By what magic has man been able to produce these widely divergent birds? We need only think of a carrier, fantail, pouter and turbit to admit that the differences between these various breeds are extraordinary, more striking than the differences of many natural species-for instance, hare and rabbit, the common nightingale (Daulias luscinia) and "sprosser" (Daulias philomela), \&c. The distinctive features are indeed so great that if he met them in the free state no systematist would hesitate to describe each of the mentioned breeds as well-defined, distinct species If, nevertheless, we continue to describe the different forms of our domestic animals only as varieties and not as species it is merely due to force of habit, for there is no valid reason why they should not be regarded as distinct species. If by nothing else, they prove their right to the rank of species by the fact that as long as the protective conditions remain under which they came into existence they will continue to breed straight like any other natural species. The magic which has effected this apparent miracle is called artificial selection. (Compare Plate V.)

The variability and plasticity of the pigeon is most remarkable. A skilled and persistent breeder may in the course of a few generations produce almost any desired variation, and there is hardly a part of the body which cannot be altered at will. In the carrier-pigeon the bill is very long and straight, and 
covered by a thick red growth of the cere; in the bagadottes it is crooked, like an awl. The beak of the turbit becomes, in extreme cases, so short that the birds are no longer able to feed themselves, but must be fed artificially. The pouter carries its body upright. Its throat is of an enormous size, and the bird is able to blow it out with air. The fantails possess, instead of the normal number of twelve tail-feathers, thirty to forty, which are carried upright spread out like a fan. Some pigeons have smooth plumage, others rough; some have a feathermantle or a cap, others a 'white beard' or a 'shirt-collar.' Further, the size of their body, the number and size of ribs and tail-vertebræ, the formation of internal organs, differ widely in the different breeds. In the home of pigeon culture, England, many breeders have attained such a state of skill that they are able to inbreed to order, in a very short time, any desired feature. It is even possible by breeding to alter mental qualities, i.e., the delicate structure of the brain, as is proved, to mention only one instance out of many, by the well-known tumblers. Fanciers have succeeded to breed into this pigeon the habit of ascending to a considerable height and then turning a complete somersault or several somersaults in the course of their descent. A similar phenomenon is observed in the Japanese dancing mice, which will sometimes turn round for several minutes exactly like a live spinning top.

Let us now consider the question of the methods to be adopted by a breeder in order to obtain a certain feature. Let us suppose that he intends to breed a carrier-pigeon, that is, a bird with an extreme growth of wattle round the bill and eyes. A prize monstrosity such as this is pictured on the coloured plate. First of all, the breeder will look around his stock of pigeons, pick out those birds which either possess these characteristics, or at least one of them, in a more pronounced form than their companions and breed from them. As inborn features are inherited, as the descendants are in a sense the 'sum of both parents,' there will in most cases be found among the young pigeons some birds which possess more strongly developed wattles than their parents. These birds will now be selected for further operations, and by carrying on this process of selection for several generations the breeder will frequently 10 
succeed in a comparatively short time in producing, more or less exactly, the desired results.

Suppose, now, that the breeder desires to impart to his carrier-pigeons a certain colour. He will, therefore, proceed in precisely the same manner, selecting among his carriers, for breeding purposes, only such as exhibit the desired colour in the most pronounced manner. Continuing along this line, a skilful breeder will gradually produce pigeons which are widely differentiated from their parents on almost every point. The production of new races is, therefore, not, as is generally assumed, the result of the crossing of different animal species, though crossing may lead to the formation of new races, but by the patient, determined accumulation through numerous generations of slight variations.

What is said here of pigeons applies to all other domestic species. We need only mention the breeds of dogs, sheep bred for wool or flesh, rabbits with long lop-ears or short erect ears, domestic cattle and pigs, and many other products of domestication.

It must, of course, be understood that only those parts and characteristics can be subject to conscious variation that may be controlled from outside. It is, therefore, frequently found that domestic species exhibit, together with widely divergent external characteristics, a surprising similarity of internal structure. It is obvious that by artificial selection generally only thuse parts are transformed the transformation of which is desired, whilst the rest of the body retains its original qualities. For instance, in the various breeds of strawberries and gooseberries flowers and leaves are alike, but the fruits differ both in appearance and taste. In the numerous species of cabbage, the flowers, which are of no account to man, are uniform, but the edible leaves show a great variety. In tulips and other garden flowers the process is reversed; flowers are widely differentiated in form, size, and colour, whilst there is no difference between the leaves. Finally, in the various breeds of silk-worms, caterpillar, pupa, and imago are surprisingly alike, but the cocoonthat is, the part which is of value to man-has been greatly transformed by breeding.

How enormously artificial selection may increase certain 
features may be illustrated by a few instances. The tail-feathers of a Japanese "phoenix" attain a length of 4 metres; good laying breeds like Wyandottes and Hamburgs may reach an annual production of 200 eggs. Toulouse fattening-geese frequently reach a weight of 15 kilogrammes; and finally the merino sheep, in particular the so-called electorals, produce wool at the rate of 6,000 hairs per square centimetre, whilst ordinary breeds have only about 1,000 .

In most cases the breeder will be unable to modify, by means of artificial selection, any one organ without affecting, even though it be undesirable, other parts of the body. If, for instance, it were desired to breed goats with such enormous horns as are carried by the Alpine Steinbock (Capra ibex) the process would inevitably lead to a modification of the entire organization of the affected animals. The skull would become thicker and stronger to be able to carry the heavy burden of the horns; similarly the muscles of the neck and back would increase in strength, and the neck tendon would become thicker; the spinous processes of the cervical and dorsal vertebræ would, therefore, become longer and stronger in order to meet the greater demands made upon the muscles of the neck. Further, the skeleton parts as well as the muscles of the anterior legs would adapt themselves to the greater burden, and this, again, would react upon the nervous and vascular systems. We see, therefore, that even the transformation of a comparatively unimportant part of the body, the horn, necessitates a corresponding transformation of the rest of the body.

Every organism is, as it were, in a state of fluctuating equilibrium. Its single parts are mutually dependent, so that each modification of one organ disturbs the harmony of the whole, and produces compensating modifications in other parts. This remarkable interdependence of different systems and parts is called the correlation of the organs, an important factor in the formation of new species and breeds.

A remarkable case, in which the correlation of the various parts may be clearly perceived, was recently observed in a deer park. Shortly after a large red deer had thrown his antlers he fractured his left anterior leg. It was set with every possible precaution, and the healing progressed favourably. But whilst 
a normally formed antler developed on the right, the sound side, no formation whatever took place on the left, the side of the fractured leg. It was plain that the organism had used the material originally destined for the left horn for the more necessary object of repairing the injury to the leg. In the following year the deer grew once more two well-formed antlers.

In many other cases the correlation of the different parts is easily understood. Thus we find that a strong elongation of the vertebral column is accompanied by a shortening of the extremities, whilst, on the other hand, in animals with well-developed extremities we observe a shortening of the vertebral column. It is only necessary to mention here newts and frogs, lizards and blind-worms or snakes, and carp or tench and eels. A strong formation of the anterior extremities, as it is observed in the frog, ostrich, kangaroo, jerboa, and man is accompanied by a weaker development of the anterior extremities. In all these cases use and disuse can be held responsible for the compensation.

Of the remarkable correlation of the sexual organs and the so-called secondary sexual characters no explanation has so far been forthcoming. The best known instance is that of the famous papal singers whose marvellously pure and powerful voices attract numberless strangers to Rome; indeed, the impression caused by these wonderful sounds is unforgetable. These singers are men whose generative glands were in their infancy removed by a surgical operation. As a result the throat retains its small boyish formation; there is no breaking of voice, and the eunuchs retain into their ripe age the clear, high timbre of a boy's voice, which excels in power and beauty of tone every woman's voice. Though the castration of boys for this purpose was forbidden by more than one papal bull it has been practised until quite recent times. The destruction of the sex-organs does not only affect the formation of the voice but also of the entire body. The body of the eunuchs has a feminine form, they incline to be corpulent, do not grow a beard, but have very pronounced mammals. More striking still is the effect of castration upon the mind, for eunuchs are generally indolent, stupid, and treacherous. Castration is frequently practised in domesticated animals, in horses, to take the 'fire' out of them, and in rams, bulls, boars, and cocks, to prepare them for fattening. 
Other strange phenomena in this problem of the correlation of the parts are that dogs and cats with white coats and blue eyes are always deaf, and cats with yellow, black, and white stripes are always females. It is a subject in which there is much room for investigation.

But let us return to artificial selection. We have already seen that three factors must co-operate in the production of a new breed: (1) Variability; (2) conscious selection by the breeder of such variations towards a certain direction, and (3) the ability of the parental organisms to transmit their physical and mental qualities in a more or less perfect degree to their descendants. These three factors are the sine qua non of artificial selection: if only one of these conditions is absent the formation of a new race is not possible.

Darwin's daring doctrine which he formulated on the basis of his experiments in artificial selection was this: Exactly the same causes which we see at work in the formation of new species and breeds of domestic animals effect in free Nature, too, the transformation of the organic world and the formation of new species. But instead of the artificial breeder there is another, natural, mode of selection, the battle of the organisms for the means of livelihood, the struggle for existence. But whilst in artificial selection animals are frequently bred possessing characteristics which are of advantage to man in one way or another, but of injury to the animals themselves, sometimes to such an extent that many domestic animals are to-day unable to live in a free state without the protection of man, the struggle for existence tends to select those individuals which are best fitted for the conditions of their existence; the gradual development, adaptation, and perfection of the organic world must, therefore, be a necessary consequence of natural selection.

That heredity is as highly developed in animals living in a free state as in domesticated animals requires no proof, for it is notorious that the various animal parents produce offspring which, with the exception of slight individual variations, are their very images.

Less obvious is the second essential condition, variability, though accurate investigation will always succeed in demon- 
strating its presence. Whilst we are able to observe at the first glance the individual characteristics of those belonging to our own race, and even recognize after a lapse of years persons whom we met perhaps only once before, all persons who go to a country peopled with a different race find it very difficult to distinguish between the natives. At first it seems to them as if all people look exactly alike, at any rate those of the same age and sex, or those that are not accidentally marked by some distinguishing feature. Only long habit and practice enable the eye to discern the personal distinctions of these foreign races, and we become gradually accustomed to discriminate as easily between those individuals as between our own countrymen. Still more difficult it is of course to discern individual distinctions in animals which are so much more differentiated from us in their organization. Here the individual disappears, as it were, entirely behind the type, and only a trained eye is able to perceive individual variations, especially in the lower animals. If, for instance, we observe with an untrained eye a large flock of sheep we shall only be able, at the best, to distinguish the bucks, the ewes, and the lambs, but all the other sheep would seem exactly alike. But a good shepherd knows each single individual of his flock, though it may often number thousands. The large sheepbreeders of Australia possess this skill to a remarkable degree, and the rapidity and certainty with which they pick out a certain animal, though it does not appear to be distinguished by any special mark, is almost incredible. In the same manner many gamekeepers are able to recognize every head of game in their preserves.

Thanks to the careful investigations and laborious measurements which are now undertaken on our biological stations we possess conclusive proof that even important organs may be subject to great modifications in different individuals living under identical conditions. Professor Heincke, of the biological station in Heligoland, made such investigations with the herring and was able to demonstrate a most extraordinary deviation in the structure of fishes inhabiting the same district. To mention only one instance, he showed that the number of vertebræ fluctuated in different fishes between fifty-three and fifty-eight. That certain parts in man are subject to similar fluctuations we 
have already heard on a previous occasion. I will here only recall the great differences in the formation of the cæcum with its vermiform appendix. Whilst the appendix possesses in many persons a length of 10 to $20 \mathrm{~cm}$., it is in others entirely absent.

Let us now consider the third factor, the natural breeder, the struggle for existence. It is a rule without exception in Nature that both animals and vegetables produce more germs than grow to maturity or become capable of reproduction. If all the germs of only one species of animal remained alive and reached maturity, the world would soon be too small, and the quantity of food insufficient for supporting this one species, for organisms multiply in geometrical progression and thus would soon reach countless numbers. The well-known illustration of the chess-board will best explain this rapid mode of multiplication. If we place upon the sixty-four squares of the chess-board grains of corn in the manner that we put one grain on the first, 2 on the second, 4 on the third, 8 on the fourth, and so on, we shall have to place 1,024 on the eleventh square, and on the twenty-first more than a million. The thirty-ninth would require one billion grains, and the last square a number of such length that is impossible to pronounce it. It has been calculated that its volume would be sufficient to cover the entire earth surface with a thin layer of corn. If all the germs produced attained maturity and the power of reproduction the multiplication of organisms would proceed in the same terrifying manner. The elephant is the best known example of an animal with a low ratio of increase. According to Darwin, its power of reproduction begins with the thirtieth year and continues to the ninetieth. As the elephant-parents have to care for their young a considerable time before these reach the state of independence, they produce in this long period only about six young. If we assume the average life of an elephant to be a hundred years we should have, if all the young elephants grew up and reached the power of reproduction, after 740 to 750 years about nineteen million elephants as descendants of the first pair.

Among the minute organisms, the bacteria, the comma bacillus, the dreaded cause of the Asiatic cholera, multiplies under the most favourable conditions about every twenty minutes by fission; this would at the end of one day give the enormous 
figure of 1,600 trillion descendants of one bacillus. According to Fischer, this mass of bacilli would, in spite of the extreme minuteness of the individuals, yield in the dry state a weight of 100,000 kilogrammes. It would therefore require a gigantic experiment to let only one of these minute bacilli grow and multiply during twenty-four hours to the fullest of its ability.

But long experience has shown that the number of the individuals of a species within a certain definite area maintains itself during the course of great periods usually on the same level, however great may be the temporary fluctuations. The supposition is, of course, that the conditions of life remain the same. Devastating epidemics, famine, great floods, long periods of frost or drought may, of course, reduce the species in a short time to partial or actual extinction. On the other hand, we know from numerous instances that animals as well as plants which are suddenly introduced into new and favourable conditions multiply often in a most extraordinary manner. No one imagined when the first rabbits were brought from Europe to Australia what a terrible scourge they would some day become to that country. Threatened by no natural enemy, and finding food in superabundance, the animals increased at such enormous ratio that they soon became a veritable pest, for the extermination of which the Government in vain promises large premiums.

Cattle and horses belong to the animals with a low ratio of reproduction. If it had not been proved beyond doubt we should not believe it possible that the enormous herds that to-day inhabit the wide pampas of South America are the descendants of European races. The vegetable kingdom offers many other similar instances. The plains of La Plata are for miles covered with artichokes and another large species of thistle, yet it is not so long ago that the first plants were brought from Europe.

As with the increase in the numbers of the species there is observed a corresponding increase in the desire for reproduction, it might be thought that multiplication can proceed without limitation. That is, however, not so; for we find that very soon an average number is reached which constitutes the maximum even for the changed favourable conditions; increase beyond that point is rigidly prohibited by the conditions of life. If now this normal number of a species is not to be exceeded there must not 
remain alive more than two descendants of each pair of parents. The oak or yew, the age of which is said to reach a thousand years, need even produce only one germ in order to maintain their species. As the rate of fertility of a species is generally a fixed factor, it is easy to conclude from these two data how many germs of life must be doomed to destruction if the normal number is to be maintained.

Of the six young of a pair of elephants it is therefore necessary that four should die before they have reached maturity. Considerably higher is the destruction in a pair of crows, for supposing that crows hatch each year on an average twice, each time five young, and continue to do so for twenty years, then of these 200 descendants it is necessary that 198 die a premature death. An even more terrible destruction we see in organisms with high fertility. A carp, for instance, produces every year about 250,000 eggs, and remains capable of reproduction for at least fifty years. Of the $12,500,000$ descendants, therefore, $12,499,998$ perish as eggs, or embryos, or immature fish, for only two must reach maturity to reproduce their species. If out of the 100 million eggs produced by a sturgeon only one million developed into mature females, and if this increase proceeded in a similar manner through four generations, the fourth generation would produce an amount of caviare greater than the entire volume of the earth. But this wonderful event will, unfortunately, never take place, for it is possible only for a very limited number of individuals to exist; all others are doomed to perish.

Still more remarkable is the waste of life-germs in many parasitic worms, such as tape-worms, liver-flukes, \&c., which produce at one time up to 100 million eggs. In view of this fact it seems almost inconceivable why parasites with such tremendous fertility do not molest man and animals whom they infest to a far higher degree, and why it is possible that such innumerable germs should be destroyed almost as soon as they are born. But if we consider the perilous life-cycle with its hundreds of dangers that beset these parasites from the egg to the mature worm we shall understand why among the many millions only a few favoured ones are able to escape unscathed. The liver-fluke, Fasciola hepatica (fig. 45), lives in the bile-ducts of sheep, cattle, pigs, \&c., and occurs sometimes in man. By stopping up the bile-ducts and 
preventing the flow of bile these parasites cause a disease, called distomiasis, which gradually brings about the death of the host. In order that the eggs of the liver fluke may develop they must first of all reach the intestinal canal of their host, whence they are liberated with the fæces. But only those
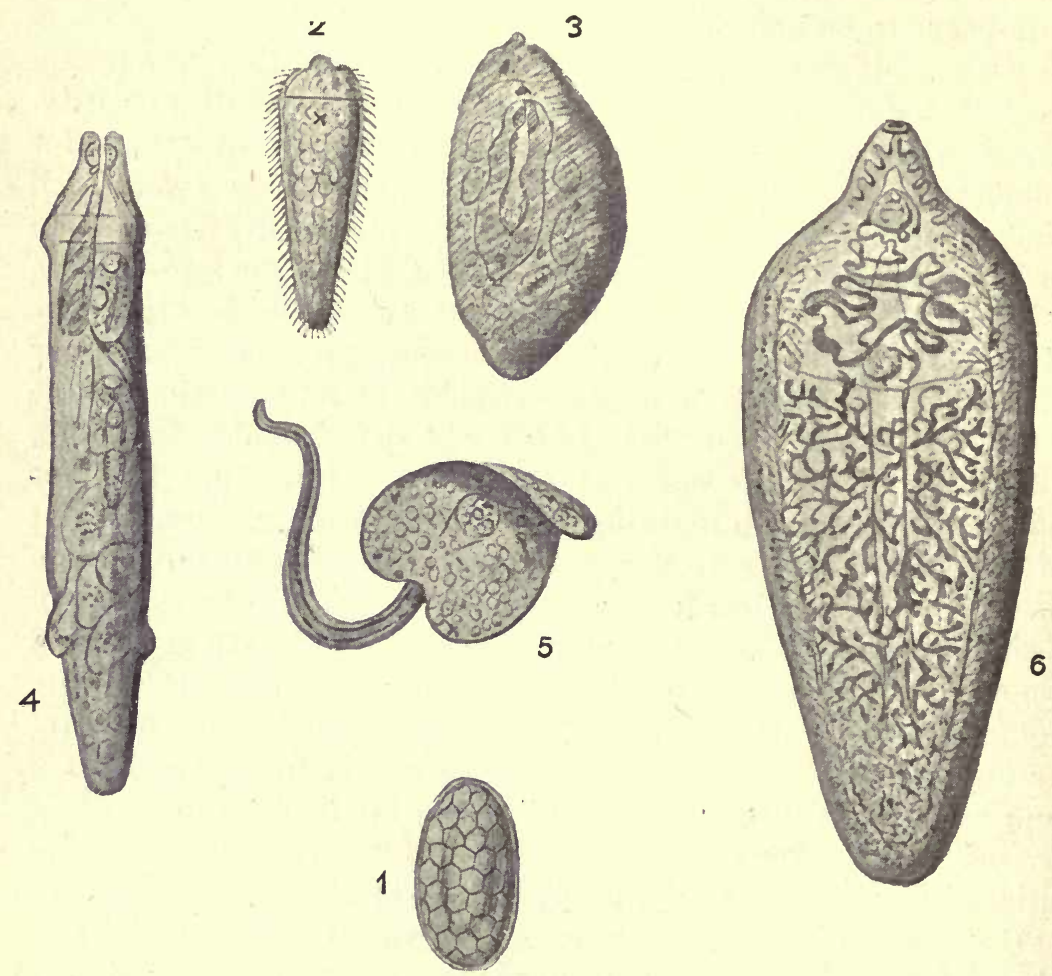

FIG. 45. - LIFE-HISTORY OF THE LIVER-FLUKE (Fasciola (Distomum) hepatica.)

(1) Ovum; (2) free-swimming ciliated larva; (3) sporocyst with young rediæ (second larval form); (4) redia with cercariæ (third larval form); (5) adult freeswimming cercaria; (6) adult sexual fluke.

which chance carries to a ditch or pool will reach maturity. For having arrived in the water there emerges from the egg a larva which by means of its cilia swims about until it happens to meet a certain water-snail. Forthwith it bores its way into the snail, sheds its cilia-dress, and changes in the interior of 
the mollusc into a so-called sporocyst. By budding, the sporocyst produces a second larval form, the redia, and this again a third, the cercaria, a little trematode furnished with a strong paddle-tail.

The task now before the cercaria is to pass from the snail into the open. Having succeeded in this, it swims about in the water searching for a new intermediate host, adopting as such usually small crustaceans or insect larvæ. If chance should carry the cercaria into the body of a suitable animal it throws off the tail which has now become useless, surrounds itself with a firm shell, and changes in the cyst into the young, but as yet sexless, liver-fluke. Finally, it is necessary that the second intermediate host containing the parasite is eaten by the final host, a vertebrate. This happens if sheep and cattle graze on wet meadows. The arthropod is digested by the juices of the stomach, the cyst is dissolved, and the young liver-fluke is liberated from its prison. All that now remains to complete its metamorphosis into a mature trematode is to invade the bileducts: with that it has reached the end of its journey and can proceed to the reproduction of its species. We can now readily understand that the fertility of species must stand in strict proportion to the dangers to which the development of its individuals is exposed.

In addition to the vicissitudes of the life-cycle, the question of food and of natural enemies play an important part. For instance, the butterflies and caterpillars of a district are chiefly kept down by the number of insectivorous birds, in particular the tits, by ichneumon flies, and numerous other parasites which prey upon them and their brood. A severe winter and want of food, causing destruction among their natural enemies, is usually followed by an enormous increase in the caterpillar pest. Thus a plague of one of the most noxious insects of our forests, the 'nun' (Psilura monacha), is usually due to a previous reduction in the number of its natural enemies. What enormous dimensions this pest may under favourable conditions assume was shown in 1890-1891 when, in the kingdom of Bavaria alone, about 12,000 hectares of State forests were destroyed, and over $\$ 125,000$ spent on exterminating this pest. Fortunately, an increase in the pest of caterpillars always brings about, by the super- 
abundance of food, a more rapid increase in the number of their natural enemies. Then the reverse process begins. The caterpillars and butterflies, threatened by numerous enemies, are rapidly reduced in number; their enemies, consequently, suffer want of food, and their increase becomes in turn restricted; thus the pendulum swings to and fro.

But it is not always easy to determine the factors that maintain the balance, as is proved by Darwin's classic instance, which showed that the fertility of the daisy and red clover in any district is determined by the number of cats in that district. It is well known that insects play an important part in the fertilization of many flowers as carriers of pollen. Indeed, many flowers have so much adapted themselves to certain species of insects and their visits that only these can effect fertilization. Without fertilization there can be no seed. According to Darwin the pollination of red clover and daisies is exclusively effected by the humble-bee, because only these insects are able, thanks to their long proboscis, to reach the object of their desire, the nectar. Thus a hundred clover plants yielded under normal conditions two thousand seven hundred seeds, whilst a like number, which had been protected against the visits of the humble-bee, did not yield a single seed. The number of the humble-bees of a district depends chiefly upon the number of field-mice which on their subterranean wanderings rob and destroy many nests. Finally, cats are probably the most zealous persecutors of field-mice, and their number is, therefore, the determining factor in the number of field-mice. There are, of course, other enemies, the mouse-buzzards, owls, storks, \&c., who play a not unimportant part, but in this way the fertility of clover can, nevertheless, be traced directly to the number of cats.

Though these instances show that the various species of animals exercise a controlling effect upon each other, this form of the struggle for existence is not that to which Darwin ascribes the rôle of the natural breeder. Natural selection can only take place if among the numerous descendants of one species generally those individuals survive, reach maturity, and transmit their individual characteristics to their offspring, which in the structure of their body are best fitted to the conditions of life, 
i.e., if always those are selected which have proved most successful in the fight for existence. The result of such natural selection must be a constant improvement of the organic world. That this survival of the fittest is actually the rule in Nature Darwin endeavoured to prove by an enormous mass of evidence.

Those who are accustomed to look around with open eyes will always be surprised anew at the high degree of fitness observable in every organism. Most distinctly does this farreaching adaptation and fitness of organisms appear in the many cases of protective coloration and mimicry which have become known during recent years.

Formerly it was thought that such adaptation could only be understood on the basis of a teleological principle. Like an engineer about to construct an engine, who first calculates and draws on paper the single parts and their proportions to each other, and then proceeds to transform the theory into reality, thus the world-creating spirit, according to teleology, first designed the plan of his mighty work and then created the world. But there is no doubt whatever, nor need of specific proof, that the means employed by Nature in the evolution and, speaking figuratively, in the construction of its organisms, when compared with human planning, can only be described as the result of blind chance. Wherever we may look, we shall find in Nature an extraordinary waste of life. Thousands, even millions, of descendants are produced; thousands and millions must prematurely perish, and only a few reach full maturity. Indeed, the destruction of life-germs, the failure is the rule, and the attainment of the aim, the natural development, the rare exception. "If," says Friedrich Albert Lange, "a man standing on a large heath were to fire millions of barrels in all directions in order to shoot one hare; if in order to enter a locked room he were to buy ten thousand different keys and try them all one after the other; if in order to procure shelter for himself he were to build a town, choose one house, and leave the rest to become the play of wind and weather, no one would call his action rational; still less must we look in his procedure for hidden reasons and a superior wisdom."

There is another point: the different species of animals and 
vegetables when observed individually exhibit undoubtedly a surprising fitness, but we see a different picture when we regard them as a whole. The large majority of animals are herbivorous; day after day they destroy enormous quantities of flourishing plant life in order to exist. To the plant kingdom, therefore, the existence of herbivorous animals represents the very extreme of unfitness. The vegetarian animals again serve as food for the great number of carnivorous animals, and from their point of view the existence of the flesh-eaters is most undesirable. Even if we take up a purely anthropocentric position and regard man as the measure of all things and the final aim of creation, and assume that everything has been created for his purposes we cannot, even in that case, escape from contradictions. For what fitness is there in the fact that intestinal parasites, trichinæ, fleas, bugs, and mites, as well as the enormous armies of bacteria and parasitic protozoa, are so perfectly adapted for their parasitic mode of life that they scorn all medical art, torment the 'lord of creation,' and exact each year a toll of millions of human lives? Is it not rather blasphemy to assume that an all-loving, all-powerful Creator had designed the animal and vegetable plant world so perfectly only to let them loose against each other in a fierce relentless struggle?

Finally, whilst, generally speaking, the structure of organisms is well adapted to the conditions of life, it is far from perfect, for we have already met in man organs which actually endanger his life.

It is Darwin's great merit that he for the first time directed the attention of the scientific world to the enormous waste of life and discovered in this apparently blind play of chance a deeper reason. The theory of the struggle for existence and the doctrine of a natural selection of the fittest in this struggle enables us to explain the origin of numerous adaptations in nature mechanically, that is, naturally, without being driven to the assumption of a supernatural Creator. Whether Darwin's hypothesis suffices in all cases is another question which we shall have to examine later. But whatever the decision may be, it must be clear that the validity of the theory of selection can only affect a relatively unimportant problem of organic life, for to the first and foremost question, the riddle 
of life, it supplies no answer. Indeed, it naïvely takes the lifeprocess as granted. But must not even the most primitive animal, the simplest plant, be already organized, and able to react suitably to external stimuli in order to be capable of existence and reproduction? Of this fundamental fitness of all life this doctrine supplies no explanation.

Those who have ever tried when shooting without a dog to stir a hare know how difficult it is unless lucky chance guides our steps. We may time after time pass within a few steps of a hare, cowering down in his nest and trusting for safety to the colour of his fur, which with its brown, black, yellow and white hairs harmonizes so completely with the colour of the soil or dried leaves as to be almost indistinguishable. Thanks to this protective coloration the hare has been able to preserve his species in spite of the most merciless persecution both by man and animals. But it is only in the summer that he enjoys this protection. When in the winter the land is thickly covered with snow there begins for the hare a hard time, for only too frequently is he seen by his enemies even at great distances. But suppose that the temperature in Europe should sink from year to year and that the snow which now covers the earth not longer than two months should remain three, five, or six months. It is obvious that in that event the conditions of life for hares would be completely changed and rendered unfavourable. According to the laws of probability, under this doctrine only those animals would in that event have the best chances of escape from their enemies which had the largest mixture of white in their fur and were therefore less easily distinguished from the snow-landscape than other hares. Of course even these animals would sometimes fall victims to their enemies, but their average prospects of life would be more favourable. Thus the light-coloured hares would survive, reach maturity, and transmit their distinctive feature to their offspring. Continuing this natural selection through many generations, all dark-coloured hares would eventually become extinct, and there would remain only the light-coloured variety. But natural selection would again make a choice among these whitecoloured hares, for the best chances of escape would be to those most nearly like the colour of the snow. Thus we. should 
gradually reach a time when there would be only snow-white hares. That this is no mere imagination is proved by experience, for we actually find in the Arctic regions and high mountains that our common hare is there represented by a white variety.

The soft, white fur of the Polar fox has in recent years become fashionable with ladies. How can the origin of white foxes be explained? Apart from man the fox has not so many enemies that he should stand in need of protective coloration. Here the theory of selection provides an easy explanation. Dark foxes may be distinguished on the white snow at great distances, and their colour thus becomes a warning to their prey to escape to safety. A red fox would therefore be severely handicapped in searching for food, an all-important reason for putting into motion the forces of natural selection. From century to century increasingly less numbers of red foxes would be able to reproduce their kind, whilst the light-coloured foxes would steadily increase in number and transmit their useful characteristics to subsequent generations; thus the process would go on until natural selection had left only pure white foxes.

Whilst the human breeder must usually content himself with being able to breed or change one definite feature, natural selection begins at the most different points. To resume our illustration, Nature would not be satisfied with selecting only light-coloured animals, but among these again the best runners, the most intelligent, the strongest, and those who possess any other useful quality in a higher degree. Natural selection employs the same methods as man, but in its effects leaves man's work far behind.

But there are other animals in the Arctic regions which are distinguished by a white colour. The brown bear would on the vast snowfields of the Far North be doomed to die from hunger, whilst the Polar bear is easily able to stalk his prey, the seals, and obtain abundant food. All our owls are brown, grey, or spotted, but their Polar relative, the great snowy owl, has white plumage. The sable of the Far North forms the only exception, for it has dark fur. A look at its life-habits will explain this seeming inconsistency. It lives and seeks its prey on trees. A white colour would therefore not only be no ad- 
vantage to it but a distinct disadvantage. A great white lump cowering on the dark branches would be at once detected, while its dark fur is but with difficulty distinguished from the trunk and branches.

Remarkable instances of colour-adaptation are offered by many animals of the temperate zones, whose covering assumes an appearance which differs with the different seasons of the year. We need only recall the case of the ermine, whose winter fur is much sought after ; the mountain hare, and the ptarmigan. Even the Arctic fox and the great white snowy owl assume in summer a darker hue. Our common weasel, in the summer of a simple brown colour, changes its fur in the autumn and becomes gradually snow-white. It is remarkable that in the southern parts of Europe, where there is little snow, the weasel retains its reddish-brown summer fur throughout the winter.

Just as in the Arctic regions and on the mountain tops the white colour predominates among animals, so inhabitants of deserts and jungles have chiefly a yellow or brownish-yellow colour. The king of the animals is yellow, like the little desert fox or its prey, the jerboa. The ground-colour of the tiger is a yellow-brown, and the black stripes make it still more difficult for him to be perceived in the jungle. This colourarrangement of dark stripes or spots on a yellow ground is found in numerous animals of the Tropics, for instance, the zebra, giraffe, okapi, leopard, panther, and gepard. In all these cases we are confronted, according to the opinion of most investigators, with an effective protective colouring.

Numerous instances are found among the lower animals, among others, the sand-coloured vipers, the cobras, the geckos, lizards and numerous species of insects, in particular the many locusts to be found in desert regions. It might be objected that the locust cannot be regarded as a well chosen instance because of its scarlet under-wings, as there could scarcely be anything more unsuitable or unsafe than these red wings which actually attract the eyes of birds afar to the welcome food. Nevertheless this arrangement grants to the locust ample protection. It is true that the birds are attracted by the striking colour and at once give chase, but no sooner do they approach the locust than the insect folds its wings and disappears as if the earth had swallowed 
it up. The bird which is looking for a fiery-red insect is all the more apt to overlook the insignificant sand-coloured animal which cowers motionless on the ground. For when the locust is in a resting attitude the underwings are completely covered by the upperwings. It seems, therefore, that the striking colour is only one more protective measure for these insects. It might be possible to explain similarly the striking colour of the underwings of the death's-head moth, some 'owls,' 'red underwings,' and many other butterflies.

It is further known that the inhabitants of grass and leaves, such as grass-locusts, many caterpillars and larvæ, frogs, lizards, etc., are green. Only birds appear to supply the exception to this rule. There are no green species of birds in Europe, with the exception of the green woodpecker, greenfinch, siskin, serin, some tomtits, the golden-crested wren, and a few others. But if we consider that in our climate trees and shrubs are without leaves during a great part of the year, we shall understand that here a green colour gives to birds only a very doubtful advantage. On the other hand, in the Tropics, or in countries with evergreen forests, we meet very frequently with green birds.

As regards the denizens of the water, we became acquainted in the last lecture with the dainty Leptodora hyalina, a little freshwater crustacean, whose transparent body is almost invisible. But the phenomenon observed in Leptodora is not an isolated one. Numerous other inhabitants of fresh water and the sea have acquired a similar transparency. Fixed to the ocean-floor live the "glass-rope sponges." Who would regard these beautiful forms as animals? Do they not rather seem like artistically executed Venetian crystal ornaments woven from the finest glass threads? Floating about the ocean are immense numbers of salpæ, medusæ, jelly-fishes, snails and crustaceans, swimming in close formation through the water, yet being hardly visible. Even the eggs and free-swimming larvæ of many of the lower marine forms are distinguished by perfect transparency (see fig. 46).

A remarkable phenomenon of adaptation must be briefly mentioned. It is well known that light can only penetrate to relatively shallow depths of the sea, perhaps 400 to 600 fathoms; 


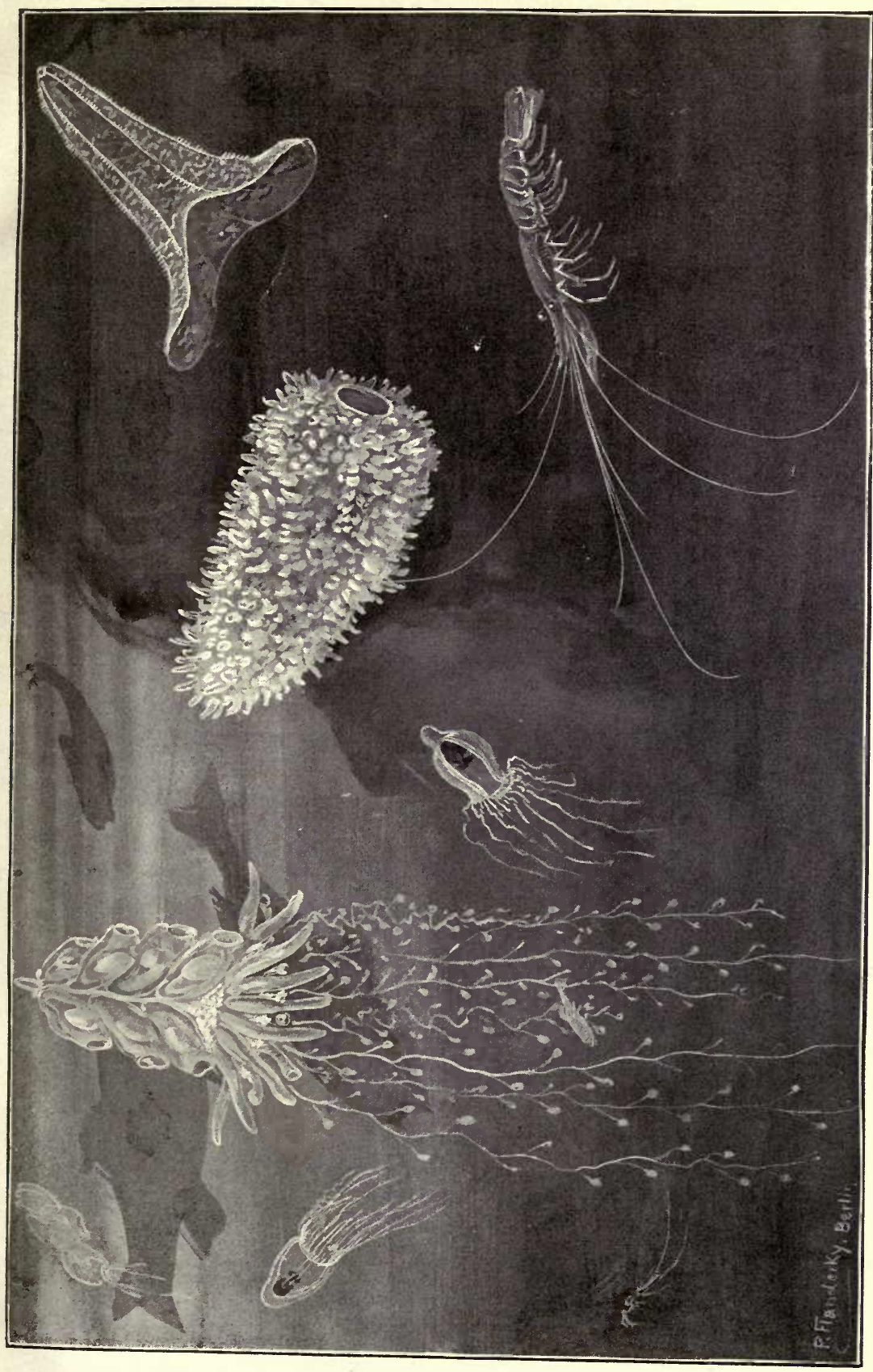



deeper regions of the ocean are hidden in eternal night. It is, therefore, remarkable that in spite of this fact the greatest depths, abysses of 7,000 to 8,000 metres, are inhabited by fishes, cephalopods, crustaceans, etc., which have well-developed, highly organized eyes. This seems to contradict all previous experience, which shows that organs which have ceased to fulfil their functions become degenerate. The Proteus is blind, the mole has diminutive eyes. How is it possible that in the absolute darkness of the ocean-bed there exist animals with well-developed eyes? The reason is, however, simple: though it is true that deep down in the ocean there was originally darkness, the denizens of the deep sea have entirely changed these uncomfortable conditions by creating an artificial illumination, for the large majority of the animals which are known to us as inhabiting the ocean-bed are furnished with luminous organs.

The ability to produce light is widely distributed among organisms, but we are still in the dark concerning its biological importance. Among the vegetable organisms it is in particular certain bacteria and fungi which show this remarkable property. Among animals we know phosphorescent species among fishes, tunicates, insects, crustaceans, vermes, molluscs, echinoderms, cœlenterates and protozoans.

Among the terrestrial arthropods it is above all the glowworm, Lampyris noctiluca, which attracts our attention. It is distributed throughout the whole of Europe. During warm June nights we may frequently observe the males in swarms of hundreds flying about like floating drops of fire, searching for the wingless females who sit on the ground in the grass of meadows or under shrubs, pointing the way by means of their natural lanterns. One may keep glow-worms easily in a terrarium or large preserve-glasses planted with grass, and observe night after night their scintillating movements, provided that they are always well supplied with moisture. But these 'beauties of the night' look most disappointing when seen in the daylight. The female is an ugly 'worm,' 2 centimetres long; nor can the male, which is about half as long, lay claim to good looks. The luminous organs of these insects lie on the ventral surface of two of the last abdominal segments, which even during the day may be distinguished by their yellow colour. The larger American relatives of 
our glow-worm are frequently worn by ladies as living ornaments in the hair, or enclosed in little medallions, as brooches, for their brilliant sparkle vies with the costliest diamonds.

Glow-worms possess phosphorescence for purposes of reproduction, for it helps the sexes to find each other. In other animals it may serve to attract the prey or to deter enemies; but there are also numerous other organisms to which it gives no demonstrable advantage.

The most magnificent instance of organic light-production is observed on the ocean. Never shall I forget the wonderful impression which I received when noticing for the first time this wonderful spectacle on the Algerian coast. A mild spring evening had kept us on the sea till darkness. When at last we were making for the shore there rose every now and again, here and there, sparks giving a bluish light. Gradually the phosphorescence became more and more frequent and intensive, each wave bursting into a rain of fire. On our bow silver drops glittered and glistened, and each stroke of the oars called forth myriads of lights. It was a veritable fairyland of light and splendour. The magicians which performed this miracle were little unicellular organisms belonging to the Infusorians. Their names are Noctiluca and Leptodiscus. They are barely 1 millimetre in diameter, and their organization can cnly be observed with a microscope. If we examine them we see that specific luminous organs are absent, and that it is the whole cell-body which lights up at the slightest stimulus of a mechanical or chemical nature. Of their mode of life only very little can be said : they float on the surface of the water, drifting with the current; if storms, rain, or cold approach they sink down to a depth where there is eternal calm. Only during favourable weather they rise to the surface, often in such vast swarms that during the day the sea for long distances appears to be covered as with a reddish film. The rising and sinking of the Infusorians in the water is probably effected by taking in and ejecting sea water, a process by means of which they alter their specific gravity. The little creatures do not appear to derive any advantage from their phosphorescence.

If different instances of colour-adaptation showed us many strange things, the phenomena of mimicry cause still greater 
surprise. We can here distinguish two forms of imitation. Some animals possess an astonishing likeness to dead objectsdried twigs, leaves, etc.; others again assume the exact shape and appearance of a distantly related species. Phyllopteryx eques, a fish of the Australian seas, strikingly resembles, with its bizarre, ragged, ribbon-like body-appendices, the seaweed in which it lives and with which its colour harmonizes. Many looper-caterpillars (Geometrida) look like dry twigs, several little beetles and loopers like the dejecta of birds. Xylina vetusta in a resting position looks like a piece of dried wood. Striking instances of protective mimicry are found among the Phasmids. Every one knows the so-called Walking-leaf (Phyllium siccifolium), which, in its colour as well as the form of its body, legs and wings, looks exactly like a green leaf. We frequently find in butterflies-for instance, in the Death'shead moth, the 'red underwings,' etc.-that in a resting position they mimic the dry bark or leaves of trees, while during flight they exhibit brilliant colours. Because the day butterflies fold both pairs of wings over the back, but the 'owls' place the upper wings over the underwings, in the former the whole lower side, in the others only the upper side of the wings is furnished with protective colours and designs. Probably the most beautiful instance is the famous Kallima, a tropical butterfly, which in a resting position looks exactly like a dried leaf.

Equally general is mimicry proper, that is, the mimicking of one species of animal by another species. In these cases the mimicked species is usually one which has little to fear from natural enemies by reason of its venom, its objectionable taste, etc., while the mimicker is unarmed and exposed to numerous attacks. Thus the hornet with its dreaded poison dart is mimicked by the harmless hornet-moth; humble-bees and honey-bees serve as a 'model' for various species of flies; wasps are mimicked by beetles, and ants by spiders. In the forests of Guatemala lives the coral-snake (Elaps corallinus), dreaded on account of its fatal venom, a strikingly beautiful animal whose brilliant red body with black transverse bands is conspicuous afar. In social union with it lives a harmless snake of another genus, Erythrolampsus, which resembles the coral-snake in all details so much that only an expert is able to 
distinguish between them. In other districts Elaps corallinus is represented by a related species which has black transverse bands bordered with yellow seams. This characteristic is again faithfully repeated by the non-venomous mimicker.

Such cases of mimicry appear more remarkable still when the animals concerned belong to widely distant classes. In New Pomerania was recently found a sea-snake, Platurus colubrinus, a venomous, strikingly coloured animal of 2 to 3 metres. This is mimicked by a fish, Ophichthys colubrinus.

Let us conclude with an instance in the life of butterflies. On the banks of the Amazon one may frequently observe gaily coloured butterflies (Heliconiidæ), which lazily flutter about in large swarms. Though these butterflies are visible at great distances and even appear to exhibit a desire to be noticed, they are almost never molested by enemies; it may sometimes happen that a young, inexperienced bird attacks one of them, but it will never repeat the mistake, for these butterflies possess such an objectionable smell and taste that they are avoided by all animals. Many years ago Bates observed that these swarms of Heliconiidæ were regularly invaded by other butterflies which belong to a widely different genus, the Pieridæ or "Whites," and furnish tasty food. But as the Pieridæ copy the Heliconiidæ, not only in shape and colour, but also in their awkward manner of flight, and live in their society they, too, escape persecution. Who would, after hearing of such instances, of which many more could be adduced, doubt the great importance of protective colouring and mimicry? Nevertheless, we are confronted, on accurate examination of the facts, by many objections, and will be driven to admit that in the consideration of cases of mimicry many gross mistakes have been made. Because an animal has the colour of sand or looks like a leaf it does not follow that it derives advantage from this characteristic. Because one species of butterfly-for instance, the Yellow Underwing-mimics in colour and design dark, lichen-covered parts of a wall, this is considered a splendid case of adaptation, causing much astonishment in every Natural History Museum. But unfortunately for the theory this butterfly settles in nature by preference on welllighted places, where it is easily distinguished from its surroundings. 
We have already heard that the large feline carnivores of the Tropics - the tiger, lion, jaguar, leopard, etc.-possess a 'sympathetic coloration' which is thought to facilitate their approach to their prey, the gazelle, antelope, giraffe, zebra, etc., which on their part appear to be protected by means of a similar colouradaptation. This sounds very plausible, but it may be objected that all cats hunt their prey chiefly in the dark, during the night when not only cats but all other animals are grey, and even the most perfect protective coloration becomes useless both to them and to their prey. Moreover, it is generally the sense of hearing which is better developed in cats than the sense of sight, and they rely, therefore, in the search for prey, chiefly upon their acute hearing. Other carnivores make still less use of their eyes, and track their prey by the scent. Here, too, protective colouring is of no advantage.

As regards the protective resemblance of insects, it cannot be denied that there is a 'purpose' in their coloration, but here, as elsewhere, we must be on our guard against an exaggeration of its biological importance. If, as is generally believed, the adaptation really granted such enormous advantage over the species not so furnished, how is it that the latter have not been exterminated in the struggle for existence? We should at least expect to see the 'protected' species far exceeding in distribution and number of individuals the 'unprotected' species, an assumption which is flatly contradicted by everyday facts. We need only think of the Pieridæ and Vanessidæ at home. Further, everyone who has collected caterpillars, butterflies, and beetles knows how soon the eye becomes accustomed to discover even the most perfectly adapted insects in their protective surroundings, and we may be sure that their animal enemies, whose senses are usually much keener than ours, cannot be deceived by a superficial resemblance. Moreover, how can we explain these cases in which one species mimics a species living in a far-distant land? A convincing instance is related by Aigner-Abafian concerning the Brazilian butterfly Semnia auritalis, which is a perfect copy of Caryatis viridis, which lives in the Cameroons, and is only very distantly related. It is plain that we have here to do with an accidental similarity; not by any means an improbable explanation, considering the 
enormous number of different species. Animals must have some kind of colour and marking-why should there not be some who closely resemble other insects or dead objects?

Even proofs apparently so convincing as the mimicry between venomous and non-venomous snakes, or the mimicking of the sea-snake (Platurus) by a fish (Ophichthys) create considerable doubt. As regards the snake and the fish, the latter has in its powerful teeth such an excellent weapon that most enemies would be chary of attacking it. It does not, therefore, stand in need of specific protection, and it seems rather that the inconvenient similarity would render it more difficult for it to gain a livelihood. Probably we find here, as in many other cases, 'the phenomenon of convergence,' of the cause of which we know very little, but of the existence of which there are many proofs. Numerous fishes of the Southern Seas, in particular the inhabitants of the coral reefs, have a uniformly striking appearance. Cats, goats, sheep, cattle and dogs which inhabit Angora and Thibet are distinguished by long, silky hair. We might even regard the light colour of the Polar animals as a case of convergence, for there exists no fundamental difficulty in understanding that similar external influences may produce similarity of appearance. That the white colour of many animals is actually subject to influences of temperature is proved by the lemmings. In their Northern home these animals assume, at the approach of autumn, a white coat, but when in captivity if they are kept in a warm room they retain their grey fur throughout the winter. No sooner, however, are they exposed to cold than they will again grow a white fur.

As regards the venomous snakes and their non-venomous mimickers, there is first of all, as far as is known, no snake-eating animal which distinguishes between venomous and harmless snakes. The common hedgehog devours with equal gusto the harmless ringed snake and the poisonous adder, the digestion of the poison glands causing it apparently not the least discomfort; even to the bite of the viper the hedgehog appears to be quite insusceptible: as we have already seen, this is due to the fact that there are immunizing substances in the blood of the hedgehog which neutralize the effect of the poison. The guinea-pig dies quickly from the bite of the adder, but an injection of blood-serum 


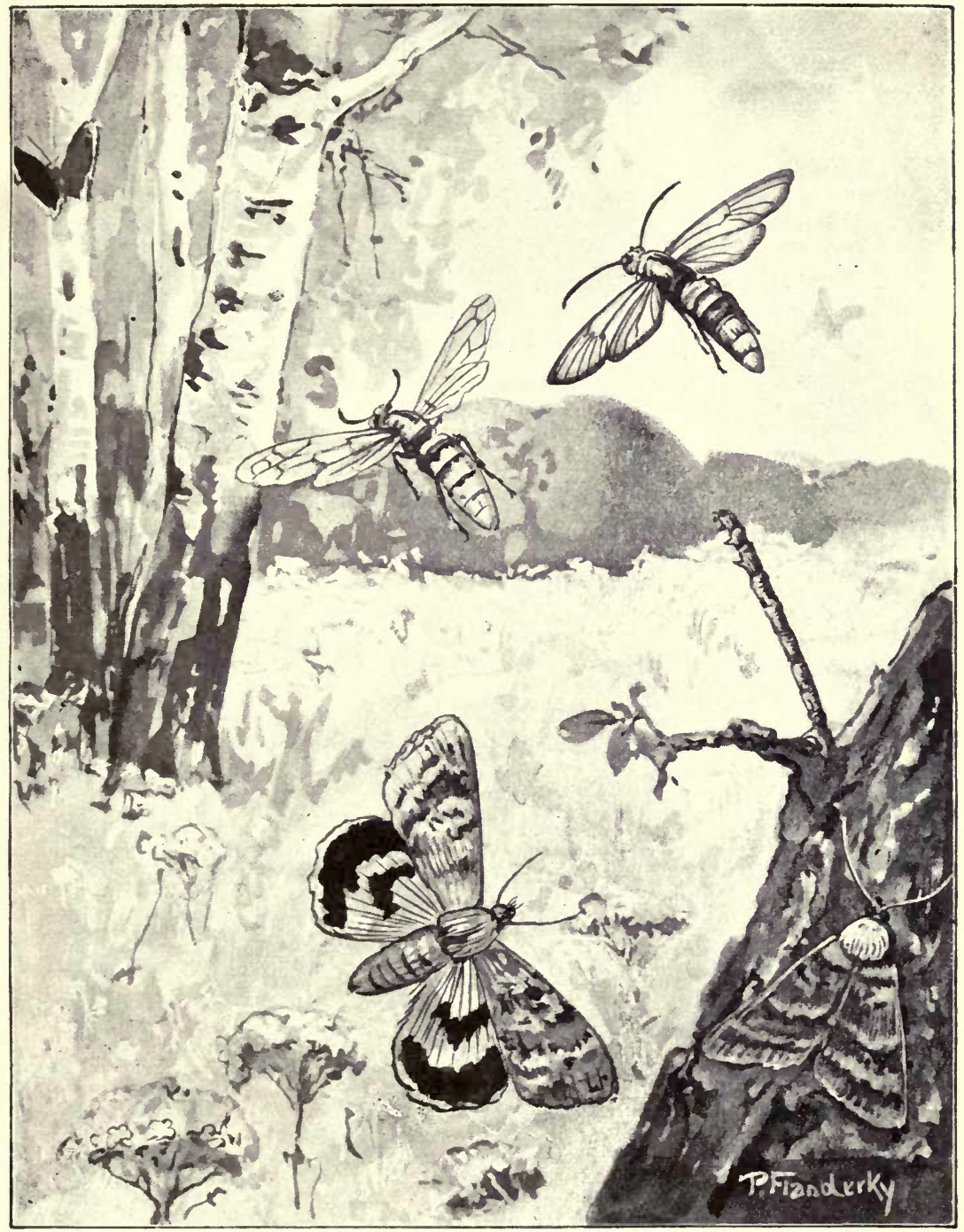

FIG. 47.-COLOUR-ADAPTATION AND MIMICRY.

In the foreground, Catocala fraxini, flying and resting. Above, a looper-caterpillar. In the centre, flying, below, a hornet (Vespa crabro); above, on the right, a hawk-moth (Trochilium). 

from the hedgehog imparts to it temporary immunity. What is true of the hedgehog is true of all other snake-hunters, so that mimicry fails so far as these enemies of snakes are concerned.

The only remaining enemy, man, makes no difference whatever in the destruction of venomous and harmless snakes, except perhaps that the destruction of the former is carried on more energetically. Probably snakes possessed their coloration long before the species man appeared on earth.

As a last interesting instance let us examine the little trees frog, which is said to adapt itself voluntarily and consciously to its surroundings. Like many other amphibians, the tree frog possesses to a high degree the faculty of changing its colour. In its skin there are found two kinds of contractile pigment-cells, or chromatophores, of which one contains granules of a yellowishgreen, the other a bluish-black pigment. In proportion as the light or dark chromatophores contract or expand, the colour of the frog changes from a light green to a deep bluish-grey. It was at one time generally believed that the frog was able to effect this striking change as the result of an eye impression, and adapt itself accordingly to its surroundings. But this statement if incorrect, quite apart from the fact that it ascribes to the animal an exalted degree of intelligence. This change of colour is nothing but an unconscious reflex-action resulting not from an eye impression but from the reaction to the stimulus of touch. For, as Biedermann has shown, if we place the frog on a smooth surface, whether light or dark, yellow or grey, it will invariably assume a greenish hue, whilst on a rough surface it assumes a dark colour. Whenever the animal, therefore, harmonizes with its surroundings, it is merely due to an accident which must very frequently happen in Nature, because numerous leaves have a smooth surface, whilst the earth's surface is rough. In many cases, however, the tree frogs are completely deserted by this characteristic. After Biedermann's experiments we can therefore no longer speak of conscious adaptation.

What, after these observations, is now our position towards the bypothesis of protective colouring and mimicry? Though we do not agree with Eimer and other investigators, who flatly deny the usefulness of such characteristics, there is no doubt that the biological importance of colour-adaptation and mimicry has 
hitherto been greatly exaggerated. But this conviction does not detract from the fact that the organic world is infinitely rich in adaptive arrangements. Almost inexhaustible seem the means with which Nature furnishes her children, in order to make them better fitted for the struggle for existence; but since to mention such organs of adaptation by name only would require volumes, we must be content with a few of the most characteristic instances.

We read frequently in the newspapers reports of a conscript having cut off a finger or a toe in order to escape military service. Few people know that similar cases of self-mutilation or autotomy are common in the animal kingdom. It is not easy to give a strict definition of this remarkable process, because autotomy represents in one direction a transition into another biological process-asexual reproduction by fission, or budding; on the other hand, it is questionable whether, for instance, the disintegration of many protozoa, in consequence of certain stimuli, may be regarded as self-mutilation, because in this process the whole animal is destroyed. The best definition is probably that autotomy is a physiological process due to the effects of stimuli of varying kinds, whereby one part of the body is sacrificed in order to save the whole. It is an adaptation of the organism to definite demands of the conditions of life.

I well remember the painful disappointment which I felt as a boy when, after a tiring hunt for lizards, I had at last been successful in catching one by the tail, only to be left in possession of the tail, whilst the lizard itself had long disappeared in the grass. It is remarkable with what rapidity the dismemberment of the tail takes place: a few vigorous striking and twisting movements of the lizard, and the operation is over. The amputation does not take place, as one would be inclined to assume, between two vertebræ, but right in the middle of one of the caudal vertebræ. From the seventh caudal vertebra, counting from the base, the vertebræ are enlarged to double their normal size and formed in the shape of an hour-glass. At the thinnest point there is a small non-osseous partition-wall, and it is here where the fracture takes place.

A simple experiment will show that the separation of the tail takes place quite independently of the animal's volition, 
being purely a reflex-action. This independence is so complete that lizards which have been beheaded or cut up, throw off the tail on receiving a stimulus at the tail-end, exactly like healthy animals. Investigations further proved that the reflex centre lies in the spine between the posterior extremities in the so-called lumbar region, for if we cut a lizard in two below the tail-extremities self-amputation does not take place.

Mutilation is chiefly performed by the tail-muscles, and it requires a vigorous effort on the part of the animal to rid itself of its tail. Thus it is that only healthy and strong lizards are capable of self-mutilation, while those that are exhausted by hunger or frost have not the power to do so. It is interesting to note that after death it is as difficult to break off the tail as it is to break off one of the legs, and it is further remarkable that in that case the tail usually breaks in any other but the normal place.

Immediately upon self-mutilation the muscles of the stump contract to prevent hæmorrhage. After a few days the wound is healed, a new tail-end begins to grow, and in a few months the damage has been repaired. Sometimes during the healing process peculiar malformations occur, and in the place of one tail two or three are formed. Aldrovandus even recorded a case of a four-tailed lizard. Though a mutilated lizard is no doubt at first harassed in its movements, the advantage which it derives from this faculty of autotomy is obvious, since it is probably in most cases the tail by which the lizard-hunter succeeds in grasping the agile animal.

In crustaceans and other arthropods self-mutilation is equally general, but here it is chiefly legs and claws which are freely sacrificed. The females of termites and ants at the end of their nuptial flight break off their wings which in their future domestic life would only be a hindrance to them. It has frequently been observed how these intelligent animals help one another in performing this operation.

The most peculiar behaviour is shown by many species of locusts, of which it is exceedingly difficult to obtain uninjured specimens. No sooner are they caught than they push the captured leg or wing between their powerful jaws and bite it off. Though ineffective with man, this self-mutilation probably 
frequently helps them to escape from their natural enemies. Locusts in captivity will slowly and with the utmost indifference chew off legs, the ovipositor, and even the abdomen. One might be inclined to think that the locusts are cleaning and polishing their legs, whilst in truth they are busily engaged in eating them up. What induces the insects to perform this incomprehensible operation we do not know, but it has been observed that if they have once tasted their own flesh it is impossible to induce them to take any other food.

Another kind of self-mutilation observed in locusts and some beetles is the ejection of blood, a process which is chiefly employed by them as a means of defence against enemies. By the violent contraction of the abdominal muscles the blood-pressure in the body is increased to such an extent that the epidermis ruptures in certain places and permits a thin stream of blood to be ejected against the attacker. The most perfect instance of this is supplied by the Algerian locust (Eugaster) which is able to eject its blood with wonderful accuracy up to a distance of 50 centimetres. As the blood contains substances with a pungent smell, their enemies, usually lizards, as a rule refrain from making a second attack.

If we finally recall the fact that many worms fall into pieces, each of which may once more grow into a fully developed individual, that starfishes can sever their arms by constriction, and sea-cucumbers on receiving a stimulus expectorate their intestines without apparently receiving any fatal injury from this horrible mutilation, no one will doubt the great biological importance of this adaptation.

We have already seen in what manner Darwin's theory of selection attempted to explain the origin of useful adaptations and the formation of new organic species. It now only remains for us to examine whether this theory is able to fulfil all that it promises. Received first with astonishment, then with boundless enthusiasm, the doctrine of this great naturalist made in a short time a veritable triumphal journey round the world, and there was a time when the great majority of prominent zoologists were all convinced Darwinists. The doctrine of natural selection seems, indeed, exceedingly clear, nor is there any other theory which vouchsafes such uniformity of observation. It is 
only quite recently that we have arrived at a just and critical appreciation of the theory of selection, and naturalists, while recognizing its strong points, point out to-day its weaknesses to an increasing degree.

The theory of natural selection is the doctrine of chance. According to it the individual possesses no formative power in the development of its body. By chance it receives at birth, through an accidental variation in one or another part of its organism, some useful character which the other innividuals of its species do not receive. But however useful this new acquisition may be to the animal, it is not able to develop it. Only by pairing with another individual which by chance possesses the same useful modification, may this new character be improved in the next generation. The only participation of the living body in the development of its useful characters lies, therefore, in reproduction. Of the causes which lead to the origin of such variations this theory does not supply any explanation. It takes variability as granted; and since chance is the determining factor it is obvious that there will arise equally numerous cases of useful, indifferent and harmful variations. We can therefore already see that selection, in order to be at all effective, must work with an immense number of variations which form the material from which the struggle for existence makes its selection on the ground of usefulness.

That variability is universal in Nature is well known, but the necessarily large number is said to be due to the excess of births, because each species produces far more descendants than will reach maturity. If we consider that many fishes annually produce hundreds of thousands of young, and that parasitic worms produce millions of germs, this demand made by natural selection seems justified, for with such a wealth of descendants it is perfectly intelligible that chance would be able to produce a sufficient number of variations to give rise to all the useful characters found in the organisms. But we also know animals-for instance, the elephant, and, in fact, most mammals, as well as numerous species of birds-which possess a very low ratio of increase. Nor must it be forgotten that in the animals with an immense progeny most germs are destroyed as ova or immature individuals, and thus the material for the stage at which the fiercest competition 
for fitness must take place, i.e., that of the adult animal, becomes in consequence very limited. In addition to the immense number, the accidental play of natural selection requires equally immense periods of time. The question arises therefore whether the geological periods are actually long enough to make the genesis of all the useful characteristics within that time conceivable. It is true that at the first glance the geological period appears enormously great. Some geologists estimate that since the Cambrian period up to modern times 200 millions of years have elapsed; yet what an enormous labour is Nature expected to have performed since then! Mayer-Eymar estimates the Tertiary period to have lasted 325,000 years, while others estimate it at $2,350,000$ years. But when we consider that within this time all the higher mammals and all their numerous adaptations are said to have been originated, even this immense period seems much too short for a pure play of accident.

While natural selection excels artificial selection in that it is able to commence in many points at the same time, it is decidedly inferior to it in one important respect. If in an enormous number of domesticated animals there appears only in two or three individuals a variation which seems useful to man, he is able to select those animals among thousands, cross them, and thus maintain and increase that particular variation. But let us suppose that something similar happens in Nature. Let us assume that of the hares in a certain district two are by the colour of their fur better adapted to their surroundings than the rest. Is it safe to assume, or is it even probable, that because of this little advantage these two, and only these two, animals escape the persecution of their enemies? Even supposing a lucky accident so to ordain it that they do remain alive, would it not be in the nature of an extraordinary miracle if these two animals with the useful variations found each other and paired with each other? Must we not rather assume that the pairing would take place with one of the other hares, and that thus the distinctive feature would after a few generations disappear again? Assuredly we cannot assume that all the hares not thus distinguished would be suddenly exterminated. For if the hares were previously able to maintain their species without this protective character, it is unintelligible why it should be difficult now, so long as conditions 
of life remain the same, merely because in some individuals of the species there has appeared a new favourable characteristic. It seems clear that as long as useful variations appear as isolated phenomena they undoubtedly disappear again at a later stage, and are in consequence without importance to natural selection.

Wagner's theory of migration, or the theory of the formation of species by geographical isolation, attempts in a certain sense to master these difficulties. The most important condition of the phenomenon that isolated variations are not again lost by repeated crossing with individuals which do not possess them is found in the isolation of the relevant animals from the rest of the species. If, therefore, some individuals of a species are separated from the rest by emigration or geological causes and placed among new conditions of life, this fact may give rise to a new species. An interesting instance is supplied by the rabbits which were liberated in the beginning of the sixteenth century by Portuguese sailors on a small island near Madeira, Porto Santo. They soon became acclimatized and have assumed a number of quite distinct characteristics : they have grown much smaller, are distinctly 'vicious,' have a reddish fur, and are indeed so widely differentiated from their European parents that it is impossible to pair them.

It is easily conceived that changed external influences which affect in like manner all individuals of one species produce simultaneously in a large number of animals corresponding useful variations. If a large number of variations exist, tending in the same direction, natural selection would, in fact, be able to accelerate the change. Only with this supposition is it, in my opinion, intelligible that in a comparatively short time there can be formed so many adaptations and new characters that natural selection is able to act at all. Chance, of course, beeomes thereby limited, and part of the formative power is transferred to the organism. It is the admission that the organism is capable of suitably reacting from inner causes to external influences, or, as Pauly expresses it, ' the awakened need itself produces the means for its satisfaction.' Selection in that case would only occupy the position of a secondary factor in species-formation. The mechanistic school may call this mysticism, but it is far less mystic than the attempt to ascribe every rational performance to 
the blind play of chance; it is, moreover, the only way to comprehend the wonder of organic formation. The assumption of inner factors of evolution could only then be justly described as mysticism if we represented these inner forces as something absolutely incomprehensible; but there is not the least cause to do this. To these inner forces - the psychic energy - there applies the same demand, as to all other forms of energy, that they must be capable of being determined quantitatively. That it is still beyond the powers of science to do so is no proof to the contrary. One must agree with Pauly when he raises the objection against the theory of selection that logically it turns matters upside down by making reproduction the causa causans of the acquisition of fitness ; as a matter of fact the organism must first have acquired fitness by fulfilling certain conditions of its existence before it can proceed to reproduction.

That species will remain unchanged for unlimited periods if the conditions of their life remain unchanged is conclusively proved by the inhabitants of the deep seas. At vast depths in which no change has taken place since times immemorial, we still find the same forms which we also know as petrefacts from the oldest geological formations. A brachiopod, Lingula, has to-day the same appearance as its ancestors in the Silurian strata. The crinoids, or 'feather-stars,' which live in shallow water near the surface, differ from their geological ancestor Pentacrinus, or sea-lily, in numerous points; above all, they are free-moving, whilst sea-lilies are fixed on the ocean bed. But the history of their evolution proves their origin beyond doubt, for the crinoids have a fixed Pentacrinus stage. The venerable sea-lilies were long thought to be extinct. The surprise was, therefore, all the greater when recently there were found on the ocean bed crinoids which exactly resembled their ancient ancestors. (Compare coloured plate II.)

Another difficulty of the theory of selection is that generally the variations are far too slight and of far too little advantage to the animals which exhibit them to be regarded as being of real value in breeding. To mention again the instance of the hare, snow-white varieties do not appear among the brown animals all at once, but according to the theory of selection we are to assume that first there appear a few individuals 
with a fur of a somewhat lighter colour. It seems, however, very doubtful whether this slight difference in coloration would grant a sufficient advantage to enable just these animals to survive. The same observation applies to numerous cases of protective resemblance and mimicry, of which it is equally difficult to understand at the first faint stage why they could be of use to their possessor. But if they were without importance at their first appearance, how was natural selection able to increase them?

Owing to these objections an attempt has been made, with very little success, to refer the origin of colour-adaptation and protective marking to the direct influence of light and surroundings. It was thought that, as in colour-photography certain substances present in photographic plates undergo under the influence of coloured light a corresponding change, so we have to regard in the numerous insects this phenomenon as being due to a 'photographic sensitiveness of the skin.' But the colour of the butterfly originates while it is still hidden in the pupa-case. Further, how could the leaf-designs of the Kallima be produced by colour-photography, for, as Plate has pointed out, it would be necessary in that case for each butterfly to assume for that purpose a certain definite attitude and retain it until the design had been photographed upon its wings?

More difficult still is it to explain by the doctrine of selection the appearance of large and comprehensive organs, such as the lungs or wings of the flying saurians and bats. In many cases these are not new formations - that is my reason for quoting them -but represent a change of functions which the organs have undergone. The lung appears first as a swim-bladder in the fishes, then undertakes in the lung-fishes temporarily, and as it were as an additional office, the duties of a respiratory organ, and finally serves exclusively in that capacity from the amphibians upwards. The origin of the wings of the bat and pterodactylus may perhaps be explained in this manner that at first there appeared in some animals lateral skin-folds which in jumping acted as a parachute. A similar state we find in the flying squirrels (Pteromys alborufus), the taguan ( $P$. petaurista) the assapan $(P$. volucella) and in a lesser degree in the common squirrel (Sciurus vulgaris). But if such a parachute was already in existence, 
and natural selection may very likely have gradually increased its usefulness until it acquired the value of a wing (fig 48).

In other cases an attempt at explaining certain phenomena in the terms of the doctrine of natural selection fails completely. How, for instance, shall we explain by natural selection the origin of such complete and highly differentiated formations as the electric organs in the tail of the Ray, which are apparently

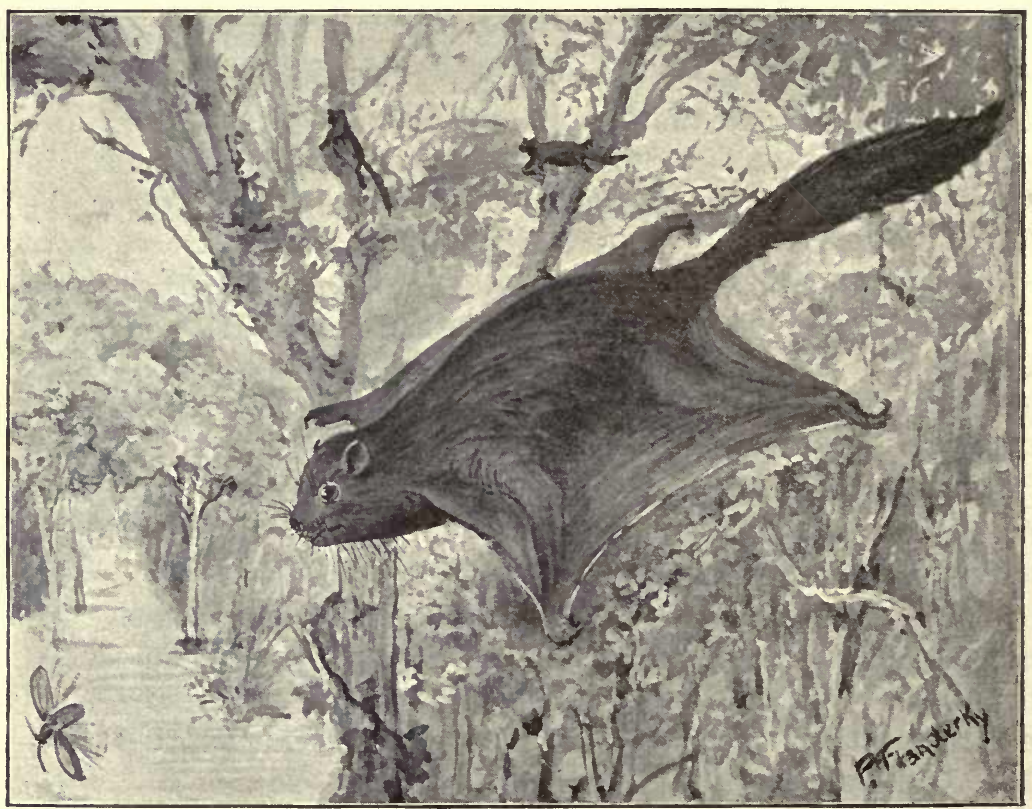

FIG. 48. - THE TAGUAN (Pteromys petaurista).

of no advantage whatever to its owner in spite of their perfect development The electric current is so weak that we are only able to demonstrate it by means of an apparatus. Efficiency as a weapon of defence, like the electric organ of the Electric Eel, it does not appear to possess. The assumption that it is a rudimentary organ is clearly contradicted by its phylogenetic history.

The long-winged seeds of the Dipterocarpaceans (or Diptera- 


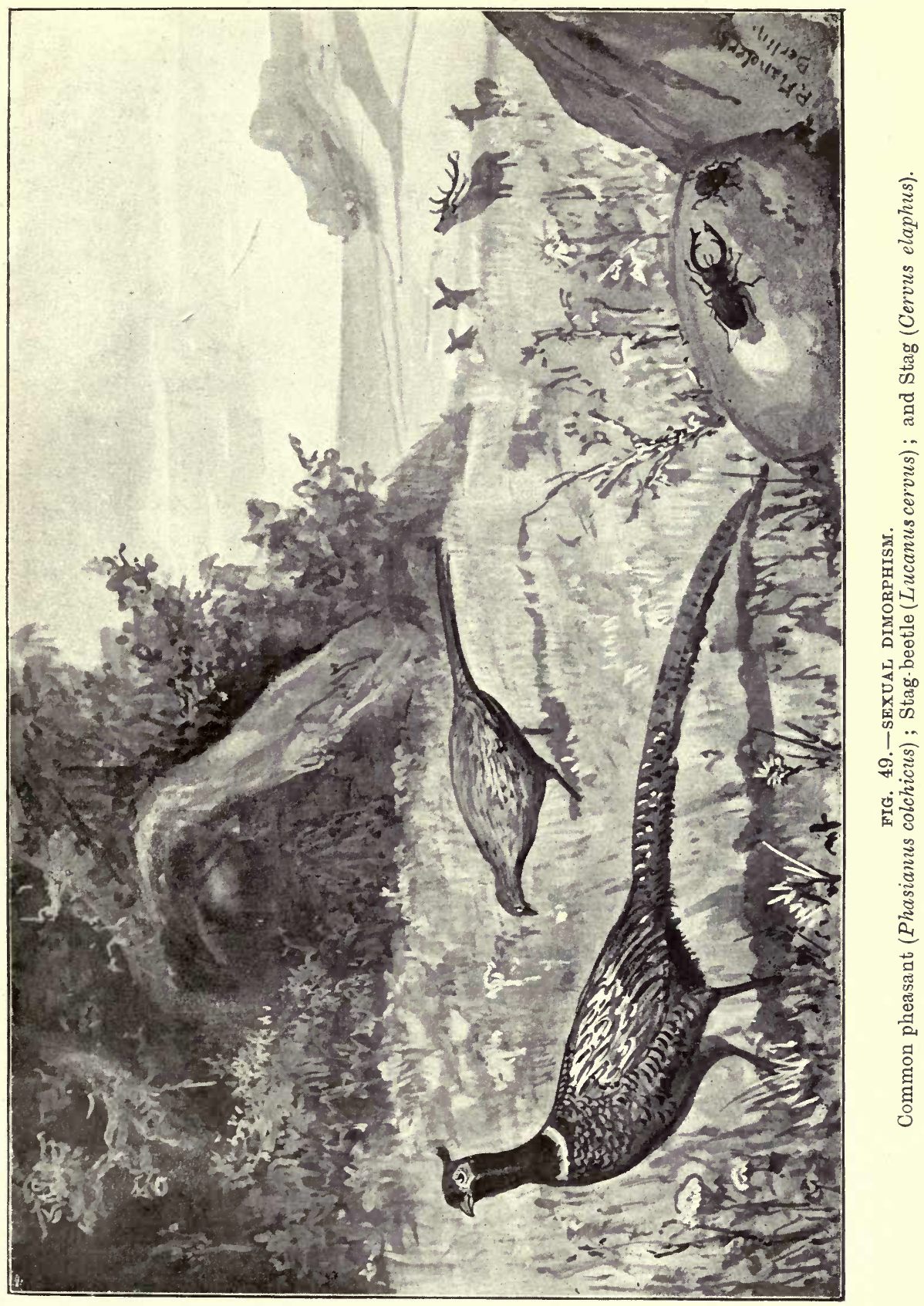



ceans), trees that grow in Asia and Africa, important to man as the producers of dammar-resin, Gurjun balsam, copal, camphor, etc., were always admired as a case of perfect adaptation for the distribution of the fruits. But according to Ridley's observations the use of these long wings is of very problematic value. If this arrangement in its modern perfect form does not grant any noticeable advantage how can it have originated by natural selection? It is a fact, unfortunately not to be denied, that there occur in organic nature many purposeless and even entirely unsuitable arrangements, a phenomenon which testifies as much against an intelligent Creator as against the validity of the theory of selection.

The weakest position of the Darwinian doctrine, a redoubt which has now been abandoned by numerous supporters, is the hypothesis of sexual selection. It is a familiar phenomenon that the male and female individuals of a species are greatly differentiated in colour as well as structure. We have had several opportunities to refer to these remarkable secondary sex-characters. In many cases the males are furnished with powerful weapons, while the females have none, or possess them in a less developed form. It is only necessary to mention the horns of the roebuck and of cattle, the mighty antlers of the stag, the spurs of the cock, etc. We find, further, that in numerous animals the male is distinguished by a greater beauty, magnificent colour, or striking seent. Who has not, for instance, admired the plumage of the bird-of-paradise, pheasant, and peacock; the delicate colours and markings on the wings of butterflies ; the remarkable ornamentation on the armour of the rhinoceros-beetle; the mandibles of the stag-beetle; the song of the birds and the formation of scent scales in numerous insects? (See fig. 49.)

As many animals, such as the stag, roedeer, and bull, fight fierce battles for the possession of the females, it might be possible to explain by natural selection, the origin of specific weapons in the male, for they are undoubtedly an advantage and help them to acquire a mate. We may therefore assume that generally the strongest and best-armed males have the best chance to reach maturity and transmit their characters to their progeny. But we are helpless in the face of such phenomena as, for instance, ornamental coloration, which so 
far from bestowing any advantage on their possessors actually constitutes a distinct impediment in the struggle for existence. Origination by natural selection appears in such cases precluded. Darwin thought that selection was here affected by an intelligent factor: that the females would always select the best and strongest males. This assumption seemed intelligible because in many instances occurring among fishes, amphibians, reptiles, etc., these ornamental colours, the so-called nuptial dress, appear only at pairing time.

It is also well known that numerous birds, among them bustards capercaillie, grouse, and pheasants, perform during courtship before the hens a regular dance, during which they seek to display their beauty as much as possible. But if we look at the wonderful symmetry and design of the wings of a butterfly or of the peacock's tail, would it not be a gross exaggeration of the intelligence of these animals were we to ascribe the origin of such works of art to their critical selection? Moreover, we have no right to assume that that which we regard as beautiful is equally so regarded by animals. The fact is that so far observation has supplied no proofs that the more beautiful males are really on that ground selected by the females. As with so many phenomena in Nature, we must here again admit that no satisfactory explanation of this phenomenon exists.

What happens to every eminent man who comes forward with new, fruitful ideas happened to Darwin: he gained enthusiastic supporters who extended his doctrine but also frequently misunderstood him and fell into gross exaggerations. His method was thought to be the Philosopher's Stone which would reveal all the mysteries of life. The struggle for existence became a phrase; the deep meaning which Darwir had given to it became gradually obscured; competition became a real sanguinary battle; Hobbes' 'bellum omnium contra omnes ' was accepted as the 'leitmotiv' of the whole of organic Nature : and in this sanguinary strife was to be found the driving force of all development and progress. Even Huxley said in an article on the struggle for existence and its importance to man that from the standpoint of the moralist the animal world presented a picture resembling that of a battle among gladiators-the fighters were first well fed and then incited to merciless slaughter 
in which the strongest, quickest, and most cunning survived, only to be compelled to fight again on the morrow. No need for the spectators to 'turn down the thumb,' for in this battle no pardon was given.

Kessler, and recently Kropotkin in his work on 'Mutual Aid in Evolution,' have shown that a brutal fight for existence is not the only factor in evolution, for in addition to strife and rivalry we find numerous cases of alliance and mutual support. This friendly living together has undoubtedly had a far-reaching influence upon the development of physical characteristics as well as upon the improvement of the mental qualities. Time forbids my dealing in detail with animal colonies and communities, but I will mention a few instances of symbiosis, because they produce sometimes almost the same kind of change which we saw as having taken place in consequence of the domestication of animals. When several years ago I was at the zoological station at Naples I derived much pleasure from spending a considerable part of my leisure time in the magnificent aquarium. The inhabitants of one of the tanks consisted of several individuals of the well-known hermit-crab (Pagurus calidus), and of some Actiniæ, the beautiful 'sea-roses' or 'sea-anemones.' They are children of warm climes, and are found in large swarms on the ocean-bed, attached to rocks or empty shells, waiting with spreading tentacles for their prey. Near Capri one may see with each wave many thousands of brilliant-red ' sea-anemones' which surround the entire coast of the island as with a girdle of fire. But their magnificent and alluring exterior is protected by a large number of offensive elements from which fine lassoes, bathed in poison, are thrown out on the least provocation, numbing or killing both prey and enemies, and causing a violent burning pain. Other tentacles are concealed in the body of the seaanemone, which, in case of need, are thrown forward through the mouth aperture. On account of these poison-lassoes the Actiniæ are greatly feared by all animals, while there are hardly any of which they themselves need be afraid.

The hermit-crab is a near relative of our crayfish and of about the same size. It owes its name to its mode of life, for it has assumed the peculiar habit of making its domicile in the shell of snails, the legal owner of which it effectively disposed of 
by eating it up. Only the head with the powerful claws protrude from the shell, the rest of the body is concealed inside. As result of this mode of life the abdomen of the hermit-crab has los its natural armour which has been rendered unnecessary by th shell of the snail, and has become soft, offering a favourable poin of attack to the crab's numerous enemies. But the animal is we aware of its weak side, and does not abandon its artificial armou except for the most urgent reasons. Only when it has outgrow the dimensions of its house it leaves it, to exchange it imme diately for a bigger domicile. Thus the hermit-crab, clad i armour, moves along on the ocean-bed in search of its prey.

Attached to the shell are always found one or more sea anemones (Adamsia rondeletii), which are thus carried throug life by the hermit-crab. It is not difficult to see the advantag which the Actiniæ derive from this remarkable arrangemen They use the legs of the crab as a means of locomotion for thei own voyages in search of prey, and take at the same time moderate toll of the repasts of their hosts. It is more difficul to understand the advantage which the sea-anemones grant $t$ their host in return for these services, for unless the hermit crab derived some advantage for itself from this alliance it woul probably leave its house with the anemones on it and see another domicile. But I was soon to be shown this side of th ' contract.'

One day, by the mistake of an attendant, a large octopu (Octopus vulgaris), one of the most dangerous enemies of th hermit-crab, had been put into the tank, and at once commence to attack the crab, seizing it with its strong tentacles covere with powerful suckers, and endeavouring to pull it out of th snail-shell. Resistance seemed quite hopeless, but the octopu had reckoned without the 'sea-anemone,' for no sooner had i seen the danger which threatened its host than it threw it numerous poison-lassoes on the naked arms of the attacker The octopus at once let go its prey and took to flight with ever. sign of pain and terror.

How well the hermit-crab understands the security granter by the presence of its friend is easily demonstrated. If w forcibly remove the crab from its house, a process during which we are exposed to a painful cannonade from the batteries of th 


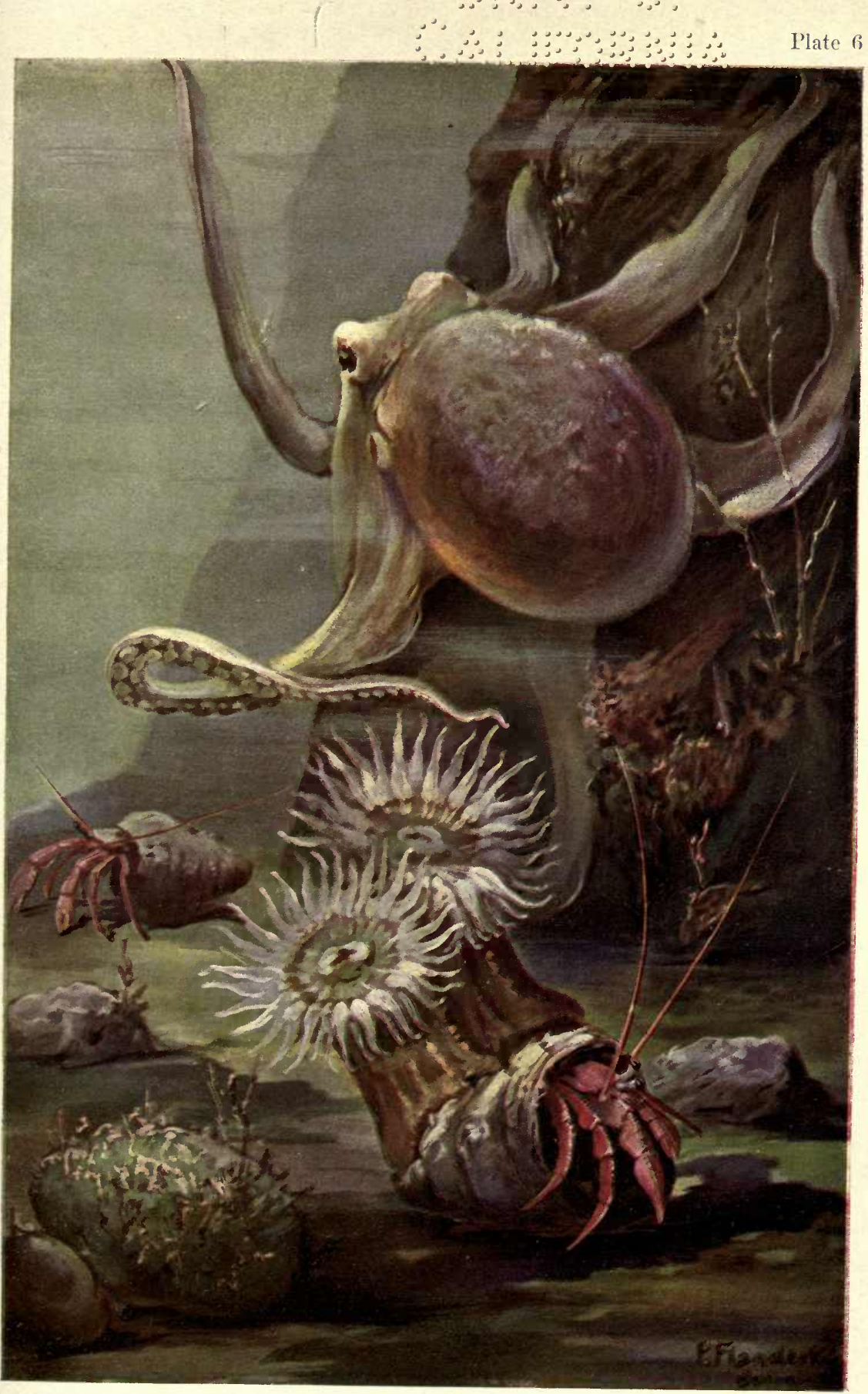

Symbiosis.

Hermit-crab (Eupagurus Bernhardus) with Actinia (Adamsia Rondeletii). On the rock, Octopus vulgaris. 
$\therefore$ 
sea-anemones, and close up the entrance to the shell, the crab will make the most desperate efforts to remove the obstacle. Only when it is convinced of the futility of its endeavours it will go in search of another domicile. Having found a suitable shell, it examines it carefully with its claws in order to find out whether any enemy may be hidden within. When the examination has proved satisfactory the hermit-crab settles down within its new armour with every possible speed. Then begins a most attractive spectacle. Quickly it returns to its old domicile and attempts by means of its claws gently and carefully to remove the sea-anemone from the shell and induce it to settle down on the new house. Very soon its endeavours are crowned with success. Sometimes it happens that for some reason the new home does not please the sea-anemone. In such case it has been observed that the crustacean will untiringly change its domicile until it meets at last with a shell which pleases its friend the sea-anemone.

With many hermit-crabs the settling on their houses of seaanemones has become a perfect mania. I have myself seen hermit-crabs which carried about with them three and even four Actiniæ, all of them of the same size as the crustacean itself, and their combined weight so heavy as to make it almost impossible for the crab to drag its dwelling along (see coloured plate 6$)$.

A similar alliance was observed by Sluiter between a 'seaanemone' and a fish. On the coral-reefs near Batavia are found numerous large yellow Actiniæ with long tentacles thickly covered with stinging-cells. Between these weapons, which are carefully avoided by other animals, there swims calmly a little defenceless fish which is thus completely protected against all attacks. In return for the protection the fish faithfully shares its food with its friend by placing pieces into the mouth of the Actinia. The 'sea-anemones,' which as a rule reply to even the slightest stimulus from outside with a fierce attack, quietly submit even to being hustled and pushed by these little fishes.

The symbiosis between Algæ and Actiniæ I have already mentioned. We saw that in that case adaptation had advanced to such a degree that the animals had lost their ability to feed themselves. 
Among ants we find instances comparable to the domestication by man of animals and vegetables. Familiar among these are the fungus-gardens of the notorious leaf-cutting ants of South America, which raid plantations in armies of thousands, cut the leaves into pieces, and carry them to their nests. There the leaves are chewed to a dough which is built up in a looselypacked heap. In the interior of this the ants form numerous chambers in which they place their young. Soon after this peculiar nest has been formed we are able to observe the appearance in the heap of threads of a certain kind of fungus, which form in places little 'heads,' the so-called 'kohlrabi.' These remarkable formations are undoubtedly a cultivation-product of the ants, for if the fungus is withdrawn from the care of the ants the formation of these ' heads' does not take place. They form the staple food of the ants and are cultivated by them for this purpose.

The numerous animals which live in the nests of ants and termites have further, as a result of that mode of life, undergone remarkable changes. In the 'hills' of termites in the East Indies, South Africa, and the Soudan is found a small species of fly (Termitoxenia), from 1 to 2 millimetres long. If accurate investigation had not proved beyond doubt that these little animals are really flies, no one would judge from their appearance that they belong to the Muscidæ. In place of the two wings these flies carry small club or hook-like formations which owing to their horny structure are totally unsuitable for flying, and are, in fact, used for very different functions. According to Wasmann, they serve as balancing poles to keep the body in equilibrium. They act further as breathing-tubes, organs of touch, and of exudation which secrete from the blood a volatile substance greatly liked by their hosts. Finally, these transformed wings serve as organs of transport by which they are lifted up by the termites and carried about. These little flies are, in fact, walking contradictions. They are not only diptera without wings, but flies without a larva or pupa stage, and insects without males and females. They are hermaphrodites, both sexes being united in one body. Apart from these flies we know numerous other beetles, etc., which are kept by ants or termites as domesticated animals, fed by their hosts, and have greatly changed in consequence of this altered mode of life. 
But let us return to Darwin's theory of selection. We have seen that natural selection alone can supply no satisfactory explanation of the evolution of the organic world, that its value in the first heat of enthusiasm has been greatly exaggerated, and that it is in no case possible to prove that the struggle for existence does perform the rôle of the breeder. Hence many naturalists have now arrived at the conclusion that the part played by the struggle for existence is not so much one of selection, but rather tends to exterminate inferior individuals, and to exclude them from the reproductive function. But here, again, we must be careful not to exaggerate the value of elimination, for numerous cases are known of cripples with serious pathological defects who have been able to live many years in spite of this supposed fierce struggle. For instance, Pauly describes a pike, about $50 \mathrm{~cm}$. long, with a malformation of the upper jaw, giving the appearance as if this had been cut off 2 or $3 \mathrm{~cm}$. from the point. But though the fish was greatly hampered in its chase after prey, it was yet well able to maintain itself until chance brought it into the fisher's net. Hofer mentions a case of a two-year-old carp whose mouth-aperture was grown together in such a manner that the fish was forced to take its food through the gill-clefts.

But if the theory of selection does not offer a satisfactory explanation, how are we to conceive the process of the origin of species? We have already heard how Lamarck attempted to overcome these difficulties. His explanation seems clear, even if it does not suffice for all phenomena, in particular for the acquisition of passive adaptations. It is, however, based to some extent upon a factor which has not yet been proved,- - the heredity of acquired characters.

If we consult the scientific literature upon this point we find widely divergent views. While some writers flatly deny the possibility of acquired characters, others equally emphatically support it. Let us, therefore, consider the facts so that we may form our own conclusions.

In order to demonstrate the impossibility of such transmission some people cut off the tails of mice, repeating this process during several succceeding generations; and as the descendants of these tailless mice were nevertheless always born with fully 
developed tails, this experiment was thought to have furnished a conclusive proof against the transmission of acquired characters. It is, however, hardly possible to imagine a more naïve experiment, for there can scarcely anyone be found to believe that the loss of an organ takes place in Nature in such a rough and ready manner. That external injuries of parents are not transmitted to the children should be accepted a prior $i$ without any such experiments. Moreover, we can on this point refer for a proof to a far greater experiment. 'Though circumcision has been practised among the Jews on an enormous scale.for several thousand years, nothing has ever been heard of the foreskin having, as a result of the operation, begun to atrophy or become degenerate. In another case, however, it seemed as if under certain circumstances injuries, or at least their consequences, are transmissible. Thus Brown-Sequard contended that epilepsy caused in guinea-pigs by severing the Nervus sciaticus had actually been transmitted to the descendants. Later experiments made by Sommer have, however, cast some doubt upon BrownSequard's observations, so that in the absence of corroborative evidence we are compelled to disregard them.

The classic instance of the transmission of acquired character are the important experiments made by Weismann, Fischer, Standfusz, and others, with butterflies. Fischer selected the Tiger moth (Arctica caja), and fed a large number of young caterpillars on white dead-nettle and dandelion, their ordinary foodplants. One hundred and two caterpillars reached the pupa stage. For purposes of control, some of these pupæ were kept under normal conditions and produced normal butterflies; the rest, were exposed intermittently to a temperature of $-8^{\circ} \mathrm{C}$. The result of these unusual conditions, which were well sustained by the pupæ, was most remarkable. The emerging butterflies, forty-one in all, were considerably darker than their normal relatives; in particular the brown or black spots or stripes on the anterior and posterior wings were much larger. It seems plain that these changes were the direct consequence of the effects of the cold to which they were exposed during the pupa stage.

Fischer now selected among these butterflies a male possessing this variation in a strongly pronounced form, and paired it with a female exhibiting the characteristic in a similarly pronounced 
manner. Their progeny were kept at the ordinary room temperature of about $20^{\circ} \mathrm{C}$. Of the resulting 173 butterflies most had the normal appearance, that is, they had reverted to their original form; but seventeen of those that had emerged last exhibited the characteristics of their parents. Other experiments undertaken later with various species of Vanessidæ produced similar results (fig. 50).

Here we have a clear proof that changed conditions of life can produce changes that may be transmitted to subsequent generations. If Weismann objects that we are here not dealing with a transinission of acquired characters, because the cold did not only change the bodycells, but simultaneously also the germplasm, we cannot admit this objection as relevant. The question is not whether changes affecting the bodycells are transmissible, but whether it is possible for a change in the conditions of life to cause reactions and changes in the organism that can be
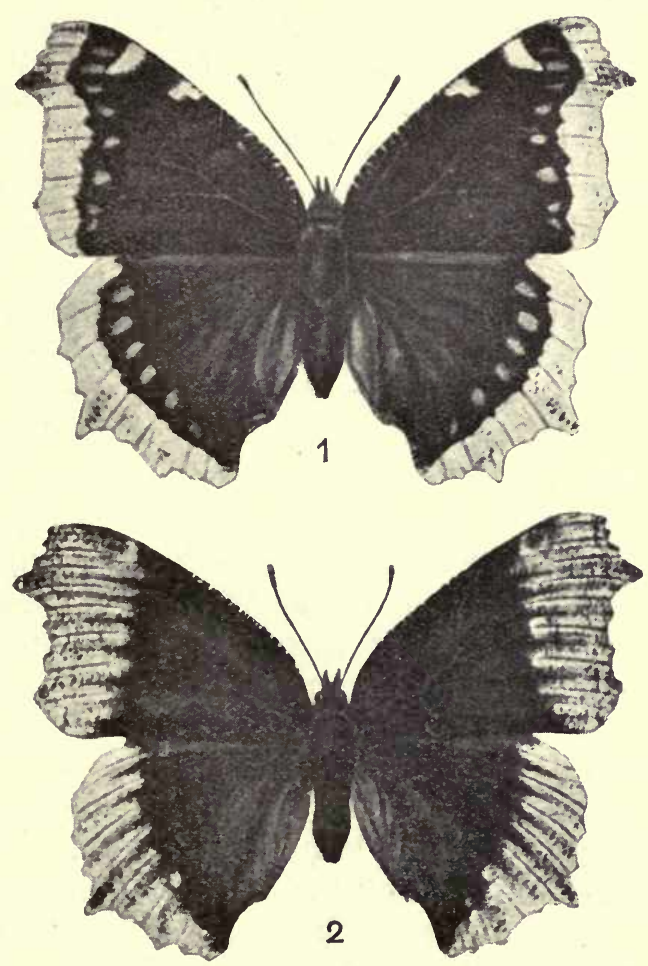

FiG. 50. - INFLUENCE OF THIMPERATURE DURING THE PUPA STAGE UPON COLOUR AND DESIGN OF BUTTERFLIES.

(1) Camberwell beauty (Vanessa antiopa L.). (2) V. antiopa L. v. hygicea Hdrch., obtained after exposing pupa two hours twice a day for four days to a temperature of $-10^{\circ} \mathrm{C}$. (after Lampert). transmitted to the descendants. It is obvious that nothing can be transmitted which is not deposited in the hereditary substance of the body. But if the individual is able to 
acquire changes in its germ-plasm, and if these changes appear afterwards in the body of the descendants, it is none the less a transmission of acquired characteristics. It is only essential that the acquired change is permanent, and is not lost with the disappearance of the cause. Hertwig justly says that ' a possession is what one has acquired; an inheritance, that which passes to the descendants. How the possession was acquired can in nowise affect the question whether inheritance shall be called apparent or real.' Hertwig further says that the quoted 'instance of the temperature-experiments with butterflies leaves no doubt whatever that the acquired characters of the parents were transmitted to the descendants.' The possibility of a transformation of the species in the sense of Lamarck receives strong support from these experiments. Selection plays, of course, a certain part, because among the numerous normally coloured butterflies he selected those that exhibited modifications.

Engelmann has further shown that it is possible to alter the natural colour of certain Algæ (Oscillatoria) by exposing them some time to coloured light. Very soon the little plant assumes a complementary colour. If, for instance, we expose an Alga for several weeks to green light it becomes red, and retains this colour even when it is kept once more in ordinary light. As during this process cell-division, i.e., reproduction, continues, and as the daughter-cells similarly retain the red colour, it is clear that in this case, too, the change has become hereditary.

It is known that firs and larches on mountains grow more slowly and form thinner rings than those that grow on the plains. If we sow the seed of Alpine forms in districts slightly above the level of the sea, it will be found that they retain their acquired characters, that is to say, they will differ from the plant, the seed of which was ripened in the plain, by slower growth and thinner rings.

For the origination of new species by external influence it is not even necessary that the newly-acquired characters are really transmitted. It is sufficient for the purpose that a change in the conditions of life is able to cause changes which remain constant so long as the changed conditions remain. If we, for instance, assume that our climate had become colder, 
and that the pupæ of the butterflies would be exposed during their development to such a cold temperature as that to which they were subjected in Fischer's experiments, then the same causes would, according to our knowledge, produce the same results in nature. We should see species of butterflies exhibiting modification in their colour towards the dark shade. As the descendants of these modified butterflies would again be exposed to the same conditions, they would possess the same characteristics as their parents, no matter whether these newlyacquired characteristics had been transmitted by their parents or not.

It is clear that the change in the conditions of life exercises an influence not only upon colour, but also upon size, scale formation, etc. In course of time, therefore, animals would come into existence so widely differentiated from their ancestors that we should regard them as new species. The original species, however, would in the meantime have become extinct. Whether the characters of these new species would be really constant and able to maintain themselves in the event of the reconstruction of the original conditions does not affect the question which could, indeed, only arise if some one would be able artificially to reproduce the old conditions. If it were possible to sow seeds of different plants of our earth on any suitable star in the Universe, the plants that grew from those seeds. would probably be so changed that we should be unable to recognize them.

How radical the changes can be which are produced in an organism by an artificial modification of the normal conditions of life will require further attention. It is not saying too much when we describe animals and plants as compulsory forms dependent in appearance and structure upon the stimuli which have influenced them during their life. There exists, as it were, a fluctuating balance between the organisms and the external conditions of life : a change in the stimuli calls forth corresponding changes in the organization. The simpler an organism, the less resistance it seems generally able to offer to changes. From numerous facts one gains further the impression that the length of the action of a stimulus has a considerable influence upon the constancy or inconstancy of a certain modification. 
On starch-containing substrata-moist bread, potatoes, etc.appear sometimes little red spots which look like drops of blood. This strange phenomenon gave rise to the legend of the 'bleeding host,' and was frequently employed for the purposes of the Church. The cause of the 'bleeding' of the bread is a minute organism, the so-called miracle-monad (Micrococcus prodigiosus), whose colonies are distinguished by a bright bloodred colour. But if we take this little bacterium from its ordinary nutrient medium and place it in an alkaline agar-agar solution its red colour becomes less and less distinct and finally disappears altogether. The vitality, however, of the micrococcus is by this experiment in nowise injured, for if we return it after a short time to its normal condition the red colour reappears. But if we cultivate it on agar-agar for a considerable time it grows afterwards white on bread and potatoes, and will regain its normal colour only after many generations. We see here quite clearly that changed conditions do produce a change in the organisms, and that these are more permanent the longer the new conditions have been in operation.

We have already seen that irritability is one of the fundamental properties of the protoplasm. We saw, for instance, that the little Amoba limax may be influenced both in its vital functions and in its shape by mere changes of temperature. If the temperature was reduced the animalcule became rigid and assumed the shape of a sphere; if the temperature was increased it revived, unrolled itself, and crawled about, only at a further increase in the temperature, once more to lapse into heat coma and contract into a sphere. Still more interesting and important are those changes which we are able to produce in the same animalcule by chemical influences. It is known that the form of the pseudopodia in the various species of Amœbæ is the principal means of distinguishing between the different species. Thus Amoba limax forms usually only one long pseudopodium. A. proteus is distinguished by numerous shapeless pseudopodia, and in $A$. radiosa, finally, the pseudopodia radiate from the body in all directions in the form of long spines. The last mentioned species, in particular, with its peculiar con. struction, could not be mistaken for any other Amoba. But let us now observe A. limax under the microscope. At first the 
animalcule lies quietly, rolled up into a ball, but soon it protrudes in all directions short amorphous pseudopodia, and we see before us a form which reminds us of a young $A$. proteus. Then the whole protoplasmic body expands longitudinally, and the typical $A$. limax crawls about beneath our eye. If we now leave the animalcules undisturbed they will permanently retain this form, but if we make the water slightly alkaline by adding a trace of liquor potassæ the Amœbæ suddenly roll themselves up as if frightened, but gradually become accustomed to these changed conditions and project once more their pseudopodia. But remarkable to relate, these are now no longer broad and shapeless, but pointed and spiny : the Amaba limax has become a typical radiosa. This form remains permanent as long as the water remains slightly alkaline; but when they are once more placed in ordinary water the compulsory form disappears and the normal Amoba limax reappears.

Among higher animals and vegetables numerous instances are known which form an eloquent proof of the dependence of the organisms upon their environment. We have already seen that the temperature exercises a far-reaching influence upon the colour of the butterflies. Phenomena such as have been obtained artificially in the Tiger-moth and other butterflies may be also observed in Nature and are then described as seasonal dimorphism.

A little butterfly (Vanessa levana) occurs with us in two forms which differ so greatly from each other that for a long time they were regarded as two distinct species. As soon as the sun sends down its first warm rays the little spring-form emerges from the pupa and begins its flight. Each collector knows the pretty brown-coloured butterfly with the coloured design on its wings. From the eggs of the spring-form develops about July the summer-form, which is not only considerably larger but possesses a black ground colour with light spots and stripes. As the pupæ of the spring-form must pass through the cold of winter, but as the summer form is never exposed to cold the attempt was made to seek an explanation of the difference in appearance in the temperature. Experiments confirmed the hypothesis: we may at any time produce the spring-form from pupæ which under normal conditions would have been developed in the summer-form simply by exposing them to cold. Con- 
versely, in warmth the eggs of the summer-form will duly produce once more a summer-form. Analogous results were produced by experiments made with other butterflies in which seasonal dimorphism occurs. We have, therefore, good grounds for believing that the different races of the various species of butterflies which live in the Northern zones were produced by climatic influences. This is in particular proved by a case mentioned by Eimer. 'The common Lycæniad, Polyommatus phlaas, which occurs from Lapland to Sicily, has in Lapland one generation, in Germany two. But only in South Germany are these two generations distinct; in North Germany they are still identical.'

'Another Blue, Lycana agestis, exhibits a double seasonal dimorphism, for it occurs in three forms. A and B in Germany alternate as winter and summer forms. $\mathrm{B}$ and $\mathrm{C}$ in Italy occur successively as winter and summer forms. Form B, therefore, occurs in both climates, but in Germany as a summer form, in Italy as a winter form. The German winter form A is entirely absent in Italy, whilst the Italian summer form does not occur in Germany. We have here a distinct if small chain of changes, obviously caused by climatic conditions.'

As in the higher animals, so in the butterflies the sexes frequently differ widely in appearance. The male 'lemonbutterfly' (Rhodocera rhamni) is distinguished by a brilliant yellow colour, but the wings of the insignificant female are pale yellow, almost of a whitish hue. If we keep the pupæ at room temperature the seasonal dimorphism disappears, and the female butterflies, too, rejoice in the decorative colours of the male. Standfusz has further succeeded with the magnificent Parnassius apollo to give by warmth to the female the colour of the male, by cold, to the male the colour of the female. When we see this correlation of temperature and colour and design in animals is it a wonder that doubts should arise whether socalled protective coloration and colour-adaptation can be regarded as a result of natural selection? Is it not rather more likely that the colouring, etc., is the effect of different stimuli which so far we have been unable to analyse?

Like heat and cold, light has a far-reaching influence upon the shape and colour of the organisms. Everyone knows that the 
inhabitants of dark caverns are disposed to lose the pigment of their body surface. The famous denizen of the Adelsberg grotto, Proteus, is quite colourless. But if it is kept for some time in a well-lighted aquarium the skin begins to form pigment and its colour becomes darker.

Light may further have considerable influence upon the course of the processes of regeneration. On this subject Loeb, whose valuable labours have elucidated many difficult points, has made a series of remarkable experiments. In every marine aquarium is found a pretty polyp-stock, Eudendrium ramosum, a relative of our fresh-water polyp Cordylophora lacustris. These organisms are highly sensitive, and after the first few days of their captivity, in consequence of having been handled, throw off all 'heads,' only the bare trunk remaining. If the aquarium has plenty of daylight the damage is quickly repaired, for in a few days the trunk has regenerated numerous polyps. In the dark, however, not a single head appears even after many weeks. A similar result is obtained if we expose them to different-coloured light; blue rays favour regeneration, while red rays have the same effect as complete darkness. Finally, if we expose to red light the polyps that were formed in blue light they inevitably perish.

Plants are to a still higher degree affected by light. Light is not only an essential condition of the nutrition of all green plants, but controls also in a high measure their growth, formation of organs, and generally the whole external appearance. What an enormous difference is there for instance between the Black and the Lombardy Poplar. The cause of this dissimilarity is the light. In the Black Poplar generally the upper side of the branches is exposed to the daylight, and it is only here that the leaf-buds are able to develop. Exactly the reverse is the case with the high-rising branches of the Lombardy Poplar, which are mainly illuminated on the under side and therefore develop the leaves below.

Most striking is the correlation of form and the effects of light in the organs of plants which carry the chlorophyll and carry on assimilation. In the normal state the stems of the Prickly Pear (Opuntia), which is very common in the countries of the Mediterraneau, are greatly flattened and therefore often 
regarded as the leaves of the cactus. However, the leaves proper of Opuntia have degenerated into-spines. If we keep this plant for some time in a cellar or in a darkened room the stems continue their growth cylindrically, i.e., in the original form, and of a flattening there is no longer a trace. Again, in many orchids it is the roots which carry the chlorophyll and perform the functions of leaves. As long as the roots remain hidden in the moss-cushions of the branches of the trees on which these orchids are parasitic they retain their cylinảrical form. Only when they come forth into the light, i.e., when they can take up their new functions of assimilating carbon dioxide, they proceed to flatten.

A still better proof is supplied by one of the liverworts, Marchantia, which flourishes in many districts in large colonies in moist sandpits, on stones, or in flower-pots. This little plant possesses a rather large dorso-ventrally flattened thallus, the upper side of which is strikingly differentiated in structure from the under side. Nevertheless it is uncertain, in the spores as well as in the germ-discs originating from the spores, which of the parts will afterwards develop into the upper side and which into the under side. But if we expose the germ to daylight only for two or three days it becomes definitely settled, though neither a flattening nor differentiation is visible, that the illuminated side is to be the upper side. Whatever we may now do with the young plants will not alter this fact: a stimulus extending only over a short time was sufficient permanently to fix its structure.

Different is the behaviour of the prothallus of the ferns. In his the non-illuminated underside which lies on the ground carries the rhizomes and the male and female sex-organs. But if we make a newly-formed prothallus pass its development swimming on a nutrient medium we may, at will, change the upper into the under side, and back again into the upper side, merely by altering the lights. In order to fix the structure definitely it is in this case necessary to let the stimulus remain active throughout the entire period of development.

If I now mention that the ivy forms its aerial roots invariably on the shady side, that the anatomical structure of the leaves of foliage trees differs in proportion as they are well or indifferently 
illuminated or grow in the dark, I hope to have adduced a sufficient number of facts to prove the formative power of the light.

In botany an apparatus is frequently used in which a horizontal axis is made to rotate slowly by clockwork. This clinostat, as it is called, enables us to withdraw objects fastened to the rotating drum from the influences of the law of gravitation. The results obtained are in many cases very wonderful. For instance, if we place climbing plants on the clinostat, the turning movements of their stem cease, the younger growing parts unravel, and the entire plant extends longitudinally.

A still better instance of the influence of gravitation is given in experiments by Massart, recently published by Lotsy. In the manner mentioned Massart withdrew a tropical plant; Alloplectus sanguinea, which is distinguished by its asymmetrical leaves, from the influence of gravitation, without bringing about any particular change ; even newly-formed leaves exhibited a similar asymmetrical form. But if the seed was permitted to germinate on the clinostat, Massart obtained plants with symmetrical leaves.

Interesting observations concerning the effects of altered gravitation on the development of the eggs of a water-beetle, Hydrophilus aterimus, were recently made by Megusar. Like its better known relative the Great Water-beetle, $H$. piceus, this insect builds peculiar boat-like cocoons which float on the surface of the water. In the interior of the firmly closed fabric the eggs stand in close vertical formation. The lower part of the eggs becomes afterwards the anterior side of the embryo. This position remains unaltered during the normal course of development, but when Megusar turned the whole cocoon upside down and fixed it in this unusual position, thereby changing at the same time the poles of the eggs themselves, he first of all retarded their development, for the first larvæ appeared several days later than those which had come from a cocoon which had been left in its normal condition. Furthermore, the size of these larvæ was much less than that of normal larvæ; they possessed plumper bodies; their movements in the water were awkward and clumsy ; they endeavoured in vain to seize their prey, and after a few days were found dead.

There are in nature only very few cases in which the formative 
influence of environment is so distinct as in Polygonum amphibium, a relative of the well-known knot-grass, which was recently made the subject of important experiments by Massart. This one instance alone would suffice to refute the doctrine of the constancy of organic species and to show that organisms remain alike only under like conditions and change with a change in circumstances. This little plant is exceedingly modest in its demands; it flourishes equally well on marshy land and in the water, and is even found on the hot sand of dunes. But it changes its appearance according to its habitation. At a first glance we are only able to distinguish between the land-form and the water-form, and between this and the dune-form. On the land Polygonum amphibium is distinguished by an erect stem covered with knots. The small lancet-shaped leaves are, particularly on the under side, furnished with cilia and attached to the stem by very short foot-stalks. In the water-form, however, the stems are much longer, float on the water surface, and grow horizontally. The number of the leaves is increased, they have lost their cilia, changed their form, developed longer foot-stalks, and formed in addition below each knot large rudimentary roots. The difference does not only extend to external appearance but is seen also in the internal structure, for while the stem of the land-form is solid that of the water-form is hollow. In the dune-form, finally, the branches crawl on the sand, the knots are greatly enlarged, the foot-stalks short, the leaves small, thickly covered with cilia, and of a viscid nature. As Massart showed, all these radical differences are the direct result of the influence of environment, for if we lead the branches of the land-form into water the newly-formed leaves and stems assume at once the shape of the typical water-form; if we transplant the waterform on wet land the stems become erect and form ciliated leaves with short foot-stalks. Finally, if we place the dune-form into water all existing leaves rapidly perish, the stems become longer, and the new leaves are the typical long-stalked leaves of the water-form.

Let us now consider for a moment the effects of chemical stimuli. It is generally known that the salts and other substances contained in the soil are able to affect the growth of the plants and the production of fruits favourably or unfavourably. 
On this knowledge is based the system of artificial manuring and cultivation of the soil, which through the exhaustive investigations and experiments of the last two decades has been raised to a science to which agriculture principally owes its increased productivity.

In order to obtain information concerning the nutritive value and effects of a substance, water-cultures are employed, i.e., the seeds are made to grow in vessels containing distilled water to which the salts under examination are added in a chemically pure form and in definite quantities. In a solution which contains all the necessary salts land-plants flourish as well as under natural conditions, but if we omit one or another of the substances we observe immediately a retarding of the growth and other changes. If, for instance, we omit to add iron the young leaves become pale, assume a yellowish colour, and are no longer able to decompose carbon dioxide. The plant is therefore doomed to die, but so long as there are signs of life we may again restore the green in the leaves by adding soluble iron salts. Other substances are able to produce in the plants entirely new characteristics. If, for instance, we grow maize in a water-culture containing hypo-sulphuric magnesium the plant produces flowers which differ so much from the normal that we are unable to regard them any longer as maize-flowers.

Chemical stimuli may greatly affect the life and development of animals. For obvious reasons such experiments are mostly conducted with aquatic animals. Several years ago Loeb discovered the interesting fact that slight traces of potash when added to the water accelerate development, while the adding of a small quantity of an acid has a retarding effect. If we transfer, during their developmental stage, the fertile eggs of echinoderms into sea-water completely free from lime, the embryo-cells continue to live, but they gradually fall asunder, and in place of an organism we see ultimately a chaotic heap of individual cells. If we decrease the amount of lime in the sea-water by only onetenth the process is likely to produce remarkable disturbances in many animals. The Pluteus-larvæ of the sea-urchin are normally distinguished by the possession of long tentacle-like processes which are supported by a special lime-skeleton, but in water with a diminished amount of lime the formation of a lime-skeleton 
is suspended, the arms become rudimentary, the larvæ assume the shape of a hemisphere, and recall only distantly the normal Pluteus.

Considerable sensation was caused not long ago by an observation made by Schmankewitsch in some of the lower crustaceans. In the brine-pools on the coast of Istria is found a small crustacean, the Brine-shrimp (Artemia salina). It is distinguished from its northern relative Branchipus, which occurs in many districts of Germany in ponds and ditches, chiefly by the smaller number of abdominal segments and certain other characteristics. Schmankewitsch contended that by a gradual sweetening of the water it is possible to transform Artemia into a typical Branchipus, and further, that gradual increase in the salinity transforms Artemia salina into a different species, Artemia milhauseni, which is distinguished by a very short, thick, spineless tail-lobe. Recently the statements made by Schrnankewitsch have been contradicted, at any rate in this form, by the investigations of Samter and Heymons. Nevertheless, it is certain-and this is the essential point-that the change in the salinity of the water undoubtedly brings about a radical change in Artemia salina, even if it cannot transform it into a typical Branchipus or Artemia milhauseni.

Numerous observations of apiculturists and observers of ants have made it clear that the variety of form in ants, bees, and termites is mainly the result of an external factor, fcod. Thus, if the queen of a bee-colony is dead and there is no royal brood, the bees are able to transform ordinary worker-larvæ into queens by giving them suitable food. In bees we also seem to obtain a deeper insight into the causes which determine the future sex of the animals, for it is believed that the drones, i.e., male bees, always develop from the unfertilized eggs of the queen, while queens and workers always develop from the fertilized eggs.

Numerous instances are known of the influence of food upon higher animals. In tadpoles which are fed on vegetable matter the intestines reach a length which exceeds that of the body about seven times; but if we feed the larvæ exclusively on flesh food the intestines become only half as long. Canaries fed with cayenne pepper assume a reddish colour; a course of hemp-seed diet gives to bullfinches a black colour. The natives of the 
region of the Amazon River feed the common green parrot with the fat of certain cat-fishes and thus produce birds with brilliant red and yellow feathers. Finally, it is well known that horsedealers frequently dose horses before a sale with small quantities of arsenic, as a result of which the body fills out and the hair assumes a smooth and silky appearance.

I must not omit to mention here that a change of external conditions does by no means affect all organisms in the same manner, but that rather many stimuli which effect radical changes in one animal species frequently pass by others for considerable periods without producing the slightest effect. An instance will make this clear. Towards the middle of last century the delicate, branched trees of a polyp, Cordylophora lacustris, were only known on the European and North American coastlands. Suddenly, however, the little polyp began to wander up the river into the interior, and now we find them in many parts of Germany inhabiting rivers and inland lakes. In many towns Cordylophora makes itself most unpleasantly noticeable by invading the waterpipes, where it proceeds to grow luxuriantly, and thereby finally stops them up. The life-history of this polyp forms one of the few instructive cases of a typical marine species changing within a short time and almost under our very eyes into a freshwateranimal. But in spite of the greatly changed conditions of life the organism of the animal has hitherto been in nowise modified.

If we observe the cycle of evolution of an animal or plant as a whole we see how numerous different stages follow upon one another in law-governed succession. As the hand of a clock must traverse one hour after another, and can only indicate the twelfth hour after having previously indicated the eleventh, so in the organic world the succession of stages appears to be unalterable. The embryo develops into a child, the child becomes a boy, the boy a man, and only he may reproduce a similar offspring which in his turn must travel the same cycle. 'This regularity is manifest throughout the whole of Nature, and it does not, therefore, cause surprise that the mind of man conceives it as an iron necessity. According to a famous botanist ' each stage of development generates the next in succession; it operates continuously; there is no single stage which may be omitted. Each differentiation is the condition of the next. 
With a machine-like precision and inevitable necessity one phase follows another until the inherited form has become complete.'

If there were no progress on earth, if the conditions remained always alike, this statement would be correct, but under present circumstances it is impossible to agree with it in this rigid form. The organism is more than a machine, for it is able to adapt itself. The course of development, too, is, to a certain degree, subject to external influences : certain stages may, under certain circumstances, be suppressed, not only for a short tine, but also permanently; even the succession of developmental stages may be altered. A few observations will prove that this statement is incontrovertible.

We distinguish among the mosses two generations : an asexual, which reproduces by means of unicellular spores; and a sexual, which originates from the spores and produces male and female germs. From the fertilized egg-cell develops then once more the asexual generation which is represented by the stalked capsules. These two generations alternate in a regular cycle. In the ferns we observe a little deviation from this scheme, in that there proceeds from the spore at first the so-called protonema from which the moss-plant proper grows with its sex-organs. But, as Klebs has shown in the minute Funaria hygrometrica, it is possible by withdrawing the light to suppress the sexual generation. While normally the life of the protonema was but brief, and was extinguished soon after the development of the mossplant, it grew in the dark almost continuously for two years without producing germ-cells. The early form remained therefore alive far beyond its 'destined span.'

Like the mosses, the ferns have an alternation of generations. Normally the spore is followed by the prothallus which carries the sex-organs, then impregnation takes place, and from the impregnated egg develops the asexual generation, the fern proper, which later proceeds to spore-formation. This succession is as definite and regular as the course of development in the higher animals and in man. But under special conditions we may succeed in shortening the development, and in omitting not only the most comprehensive and important stage, the fernplant itself, but in suppressing at the same time the development 
of the sex-products. It is true that the spore produces the prothallus as before, but this does no longer produce sex-organs, but proceeds, contrary to all rules, at once to the formation of spores.

It seems now clear that the evolution of the organism is strictly dependent upon numerous external factors. We have seen that organisms are not unalterable quantities, but that there exists correlation between them and surrounding nature. Alterations of the conditions of life immediately call forth more or less radical alteration in the characters of the species.

It is a question of another kind whether the change thus produced may be regarded as an adaptation, or, in other words, whether the organism responds to each stimulus by a suitable modification. If we recall the different changes that took place in Polygonum amphibium in water, on wet land, and on the dunes it would seem as if we had here to deal with conscious reactions. Many other facts may be interpreted in this sense. But if, for instance, a bullfinch assumes a black colour on a diet of hemp-seed, or an oyster, transplanted from the North Sea into the Mediterranean, forms on its shell rich ornaments and long spines; or if, finally, the egg of the Sea-urchin, forced to develop in water poor in lime, produces a Pluteus which has no supporting skeleton or arms, we are unable to perceive the purpose in such changes. Indeed, many changes are obviously injurious and weaken the vitality of the organism concerned. We see therefore that direct influence produces useful as well as indifferent and injurious alterations.

Each organism maintains, as we have already seen, an everchanging balance with its environment. If the equilibrium is disturbed by a change in the external conditions in life, the organism either perishes or continues to modify until a new state of equilibrium has been created. But this new state need not necessarily be an advance upon the former, but only a more or less successful 'squaring' with the changed conditions of life. It is exactly upon this that the constancy of the new form depends. If the acquired modifications are useless or indifferent, the individual concerned may be able to maintain itself; but if they are injurious we are justified in assuming that natural selection steps in and extinguishes the useless organism. 
It might be asked here whether new species may not also be produced by crossing different species. This question is justified, but as I shall have to refer later on, when dealing with the theory of heredity, to the famous crossing-experiments of Mendel, I need here allude to it only very briefly.

As long as the dogma of the constancy of the species was omnipotent the possibility of a crossing of species was flatly denied. This denial is all the less comprehensible as the bastards of the ass and the horse were known in Egypt, Persia and India thousands of years ago. It is, however, possible that as both mule and hinny are sterile this instance was not regarded as possessing any value. But to-day we know a large number of results of crossing not only different species, but even different genera. I need only mention the bastards of sheep and goat, dog and wolf, hare and rabbit, canary and different finches, salmon and trout. It is true that in most cases the bastards possess degenerate sex-organs and are sterile, but we know, nevertheless, already quite a large number of crosses which are capable of reproduction. The bastards of rabbits and hares have remained fertile through many generations, and bastards of the domestic goat and the steinbok, of different species of butterfly, etc., have produced several generations of descendants.

It is remarkable that it is very easy to cross the male of one species with the female of another, but not vice versâ. Thus the egg of salmon may be fertilized with the seed of trout and developed, but every attempt to cause the development of troutova with the spermatozoa of salmon has ended in failure.

Many interesting results were derived from experiments which Standfusz made with butterflies. Here it appeared that the products of crossing generally followed in appearance the phylogenetically earlier form. If, for instance, we cross the female of the Poplar Hawk-moth (Smerintinus populi) with a male of the Eyed Hawk-moth (Smerinthus ocellatus), the descendants of the two species resemble more the phylogenetically older $S$. populi than $S$. ocellatus. The same result was obtained in crossing a male Dilina tilice with S. ocellatus. In this case, too, the characters of the phylogenetically earlier kind predominated in the descendants.

It seems not open to any doubt that by crossing we can obtain 
animals with new characters. But as animals generally only pair with like and entertain a distinct antipathy to unlike, we cannot ascribe to this factor an important rôle in the origin of species. The race feeling is in most animals so strongly developed that very highly differentiated individuals are frequently avoided by their own species and even persecuted.

It only remains to examine one more point. We heard that variability is one of the fundamental conditions of natural selection, but we have not yet examined the question whether the selection of such variations really can produce new species, and whether such selection is not quickly obstructed by natural impediments. 'I'his objection might to many seem irrelevant, because the facts of artificial selection and the history of domesticated plants and animals have already decided this question affirmatively. Nevertheless, the doubt is fully justified. Many naturalists even go so far as to regard the results of artificial selection as strong evidence against the possibility of selection in Darwin's sense. In an important (though one-sided) paper ${ }^{1}$ G. Wolff sums up his doubts thus: 'It is true that the theory of selection proceeded from an empirical fact, the results of an artificial breeding of plants and animals, but from these facts it could never deduce an empirical justification of the evolution theory. The facts of artificial breeding are rather to be interpreted as an empirical proof of the constancy of the species, because a change in form can only be produced by it within certain well-defined limits that may not be transgressed. The very fact that in many cases we are able by artificial selection to produce comparatively considerable modifications, often within a few generations, is an empirical argument not for, but against Darwin's doctrine of natural selection, for the manifest limitation of the sphere of effectiveness of artificial selection speaks against one of the first suppositions of the theory of selection, which demands such a plasticity of the living material as to make a constant unlimited alteration of organisms in every possible direction possible by the process of selection. It is precisely because artificial selection performs so much that it proves so little. It would be so much more advantageous for the tactical position of the theory of selection

1 'Die Begrundung der Abstammungslehre.' 
if artificial selection could not point to any successes, i.e., if their supporters could employ here, too, their only strategic method of defending themselves behind the fortifications of the impossibility of controlling their hypotheses. But in no case can the facts of artificial selection be employed for proving empirically the doctrine of natural selection, for all that they can do is to render possible the idea of natural selection and its explanation.'

'Never was there a theory so completely without proofs taken from experience. All hypotheses of the doctrine are put forward as self-evident, and are thus so much without an empirical foundation that even the first hypothesis of the theory, the survival of the fittest in the struggle for existence, is an assumption which is supported by no observation and the justification of which is confuted by everything that experience may ascertain.'

These are grave accusations made by a serious thinker who certainly cannot be suspected of dogmatic prejudice. Let us now consider what are the grounds upon which Wolff takes up his hostile attitude.

If we recall the many results of artificial selection, if we think of the various races of pigeon, or of the pheasant in which Japanese breeders have produced tail-feathers 4 metres long, it would seem as if a natural limit did not exist; as if, in fact, the organism were 'like clay in the hands of the potter,' to which selection can impart any desired form. But if we examine without prejudice the various factors we shall observe everywhere lines of demarcation beyond which selection is not able to pass.

When, in 1850 , the systematic cultivation of the sugar-beet was taken up in this country, the sugar in the beet-root (Beta vulgaris) from which the sugar-beet had been produced by artificial selection was at that time not more than 7 to 8 per cent. To-day it is 14 to 16 per cent. Beyond this it has been found impossible to increase the percentage of sugar, even in spite of determined efforts and the most careful selection.

The weight of a gooseberry was towards the end of the eighteenth century about 15 grammes. In the course of seventy years this was increased to 60 grammes, but since then the weight has remained at that point, though theoretically there is no reason why gooseberries should not reach the size of apples or pears. A similar limitation is apparent in other cases, but are 
we thereby justified in exploiting this fact as a proof of the ineffectiveness of selection? In my opinion this would prove an entirely wrong conclusion.

By artificial selection we are generally able to increase at any rate one defined characteristic. In consequence there arises in the organism a discord, a disturbance of the equilibrium of the correlated parts. The more extreme the development of a characteristic, the greater the disturbance, until finally Nature imposes a strict halt to any further advance. Man has no regard for the well-being of the affected animals, but solely seeks to increase those qualities which are of advantage to him. It is, therefore, entirely wrong if someone-as for instance, H. St. Chamberlain-regards our thoroughbreds as specific samples of perfection, and seeks to derive from their genesis hints for the improvement (Veredlung) of the human race. But we should rather regard the animals with a one-sided development as cripples which are barely capable of independent life. Would it not sound ridiculous to speak, for instance, of a dachshund as 'improved' (Veredelt)? It is only the uniform, harmonious development of all characters which we regard generally, and in particular with regard to man, as improved (edel).

But let us return to our example. If it should be possible to increase and improve, for instance, in the gooseberry, simultaneously with the size of the fruit, the strength of the branches, the formation of the sieve vessels, tracheæ, roots, circulatory system, etc., selection would in all probability be able to obtain still further success, and would thus remain for ever dissatisfied.

Many accurate investigations into the variability and the power of increasing it have been made, in particular by botanists. But, as is the case in the experiments with sugar-beet and gooseberries, they have not hitherto led to incontrovertible results; the conclusions, therefore, which have been drawn from these experiments by the different investigators are widely divergent.

If we examine a number of peas or beans, or the leaves of a shrub, with reference to size we observe a remarkable law: all the sizes vary around a mean. Most numerous are the leaves of a medium size, and the variations become rarer in proportion as they are larger or smaller than the medium size. 
This universal rule-called, after its discoverer, Quetelet's lawdoes not only apply to differences in size but apparently also to all other variations. We have already heard of the case of the vertebræ of the herring, which also follow Quetelet's law.

While the variability remains generally unchanged as long as circumstances remain unchanged, it is possible to alter the average by a selection of greatly differing variations. But the longer the selection operates the less progress is made, until finally a point is reached which apparently cannot be passed by selection. Let us consider in this light the breeding experiments made by Müller with maize. His attention was directed to the number of rows in the cobs of Zea mays, which in the beginning of the experiment varied between eight and eighteen. Twelve occurred most frequently. If he sowed corns taken from a cob with sixteen rows he obtained descendants having from ten to twentytwo rows; the average, therefore, had been shifted to fourteen. In proportion as the experiment was continued the average was gradually shifted to eighteen. At this point it came to a standstill. Strict selection was able to maintain this average but unable to increase it, while in the absence of selection the descendants returned to the original average of twelve. The characteristics remained, therefore, constant only so long as selection was maintained, and could only be increased up to a certain point, beyond which selection was powerless. Whether, in the event of the experiments being continued for very long periods, a fixing of the characters obtained by selection and a further shifting of the average is possible must at present be regarded as an open question.

In addition to the fluctuating or individual variability we may occasionally observe a jump in variations, described as 'mutation.' The most important difference between these two forms is that the qualities produced by mutation are strictly hereditary. But mutation frequently affects not only one or another character; it changes also more or less suddenly the entire character of the affected organism. While in former years mutations were not thought to be of any importance to the origin of new species, De Vries made them the foundation of a new theory of evolution. The classic object with which this great investigator conducted his experiments was Enothera 
lamarckiana. As long as one does not know the conditions under which new species are produced it will always remain difficult, according to De Vries, to find suitable material for an experiment of this kind, and here chance must help to smooth the way.

In the 'eighties De Vries commenced to investigate the flora in the environments of Amsterdam with the object of discovering, if possible, a plant in the mutation stage. He was fortunate enough to find what he wanted in O. lamarckiana, on a fallow potato-field near Hilversum. This plant had in the course of ten years taken possession of more than half the field in question. Among the many hundreds of individual plants he observed in particular two forms which differed in so many characters that they had to be regarded as new species. They were afterwards described as O. brevistylis and O. lavifolia, and proved constant in cultivation.

In order to obtain more accurate information concerning its mutability, De Vries transplanted in 1886 a certain number of roots and seeds from the potato-field into his experimental garden at Ainsterdam. In the course of several generations the seeds of these first individuals produced, in addition to normal plants, suddenly, by mutation, seven new species, which were described as $O$. lata, rubrinervis, gigas, albida, oblonga, nanella and scintillans. With the exception of lata and scintillans all proved to be constant under self-fertilization. The other forms do not interest us, as they either produced no seed or could not be sharply differentiated, but the history of one of these new species is most instructive.

In 1895, the fourth generation of the O. lamarckiana, 14,000 seeds had been sown, of which the 'mutating' individuals were cultivated, but all others recognized as lamarckiana pulled up to make room. In August about a thousand of these plants were in bloom, but many had remained rosettes. Of these, thirtytwo of the most vigorous individuals were planted in a special bed. In the following year they commenced to flower, and one specimen at once attracted attention by its thicker stem, closer inflorescence, and considerably larger flowers. Enclosed in a parchment bag, it was artificially fertilized with its own pollen. It produced a wealth of seed and formed the origin of a new 
species, $O$. gigas. It is absolutely certain that its ancestors, at least in the last three generations, were the ordinary $O$. lamarckiana. The self-fertilized seeds of this Urpflanze were in the following year sown separately and produced more than 450 plants, which all exhibited the pure type of $O$. gigas, there being not one reversion to lamarckiana. Even in later generations O. gigas remained constant. It seems therefore proved that a new elementary species can appear suddenly in a single individual and be constant from the beginning.

While $O$. gigas remained constant in its characters, there were other mutations in which this fact was not observed. Such an instance is $O$. scintillans, from the seed of which, in spite of self-fertilization, originated always three forms, $O$. scintillans, $O$. oblonga, and finally the original $O$. lamarckiana. In addition the seed frequently produced elementary species of a second order which united in themselves the characters of two species. Thus an intermediate form, for instance, between $O$. scintillans and $O$. nanella, has not unfrequently been observed.

Concerning the causes which effect the mutation, we can only make guesses. We gain, however, the impression from the many facts before us that mutability occurs periodically and is replaced by periods of apparent constancy. As a rule the new 'elementary species ' appear at once in a large number of individuals, an exception being formed by $O$. gigas, of which only one individual was observed. Like all organisms, O. lamarckiana and its mutations are subject to fluctuating variability, and one is able to produce among them new races by rational selection. But they always remain forms which are in 'need of selection'; they differ very little from the type, probably only in one essential, and must not be mistaken for the 'elementary species.' Of mutations, too, it is therefore true that they can be either useful, or indifferent, or injurious. Numerous mutations, like the sterile O. lata, the weakly nanella and albida, and the fragile rubrinervis, would hardly be able to maintain themselves in nature. On the other hand, O. lavifolia appears to be at least equal to O. lamarckiana, whilst $O$. gigas certainly excels it. From these experiments De Vries concludes that ' the mutations have no tendency; some of the new types perish without progeny. Among the rest of the newly formed and fully developed species natural selection must later make its decision.' 
Since naturalists have begun during recent years to observe more accurately the occurrence of jumps in variations many instances have been made known both from the plant and animal kingdom. The occurrence of 'single variations' had even been noticed by Darwin himself, though in view of the individual or fluctuating variations he did not ascribe to them any particular importance in the formation of species. Nevertheless we are indebted to him for a record of several significant instances.

In 1791, in Massachusetts, a sheep was born in an ordinary flock having a long back and short bow-legs like a dachshund. Because of its strange, unnatural appearance the animal was bred from in the hope of obtaining a race unable to jump over the hedges and fences which separate the homesteads. As only one individual of this variety existed it was necessary to cross it with an ordinary sheep. The first generation consisted of both bowlegged and straight-legged individuals. When two bow-legged sheep were crossed the character proved constant in the descendants. Thus originated the Ancon race. Afterwards the Ancon sheep were replaced by the more profitable Merinos, and are probably extinct to-day. It is interesting to note that the crossing of an Ancon with another sheep did not produce a mixed race, but that the lambs were either bow-legged or straight-legged. There are even cases on record of twins, of which one exhibited the Ancon type while the other was normal.

It is probable that our dachshunds originated by mutation from greyhounds, but as the race of dachshunds is very oldthey were kept as long as two thousand years ago in the Nile delta-it is impossible to obtain accurate information concerning their origin.

According to the investigation of Keller and others, it may be taken as proved that the absence of horns in different races of cattle, sheep, and goats, the races of goats with four horns, the three-toed pigs of the Crimea, the famous tailless Manx cats, black panthers, black-shouldered peacocks, the 'telescope' and multiple-tailed gold-fishes and many other animal forms owe their existence to mutation. Most of the species mentioned are distinguished by the fact that in in-breeding all their characters remain constant.

It seems now proved that non-continuous variability can lead̄ 14 
to the formation of new 'elementary species.' Nevertheless, the theory of mutation cannot satisfy us as being the sole factor of development, for it leaves unexplained above all the origin of numberless adaptations. As mutations do not tend in any direction it would mean confiding too much in chance if we were to regard it as the creator of organic fitness.

If, in conclusion, we review the results at which we have slowly arrived we shall be compelled to confess that research and speculation has hitherto not been able to formulate a universal law of evolution. We are still at the beginning of a long, tedious journey. The deeper we seek to penetrate into the mysteries of life the greater becorme the difficulties. All theories that have been promulgated are only able to explain a strictly limited part of phenomena, leaving by far the greater number unexplained. Darwinism yields no information concerning the causes of variability; the theory of Lamarck fails in front of passive adaptations; the theory of mutation plays with chance even more than selection; and vitalism finally brings forces into play, of the nature of which we are not even able to form an idea.

It is not pleasing to admit this insecurity, but a hypothesis is nevertheless much to be preferred to wearing dogmatic blinkers and resting in delusive security. It is true that there are many investigators who regard all questions as solved, and with the aid of a few well-sounding phrases furnish an explanation of every phenomenon; but truth is not found with the dogmatist.

We have, however, attained one result: no longer will it be possible to shout: "Hie theory of selection, hie Lamarckism, hie hypothesis of mutation!" The forces which these different theories regarded as the foundation of organic genesis do not exclude each other, but we must rather assume, on the grounds of our experience, that selection and mutation, direct influence of environment, and interual forces of the organism, as yet unknown but for all that not unknowable, all participate in the evolution of organic life. 


\section{CHAPTER VIII.}

\section{THE CONSERVATION OF LIFE.}

THE veil which covers the genesis of the first germs of life on earth seems impenetrable. Wherever we may search we find no answer to the question of the origin of life. On this subject exists no accurate knowledge, and we must be content with hypotheses and probabilities. Nor are we able to obtain information about the nature and appearance of the first primitive organisms. The runes of the earth's history engraven in geological formations have mostly perished. The book of Nature is defective and illegible, and the further we attempt to go back the less clear, the more confused and strange the writings become, the more pages are missing. Though palæontologists have achieved wonders in deciphering many of these mysterious signs they have failed to answer the most important question of all.

If we now, in spite of the knowledge that we move on unstable, hypothetical ground, were to accept as true the doctrine of spontaneous generation, how are we to conceive the first representatives of the organic world? Organisms generated from inorganic matter could manifestly be but extremely primitive. Whether they were little structureless lumps of albumin, as Haeckel thinks, or vast masses of protoplasm that were as yet unindividualized and covered large tracts of the primordial oceanbed we are unable to say, and all speculating after details will be futile. However low and simple we may imagine the ancestors of the present animal and plant world to have been they must have held in common with the present species two fundamental properties: metabolism, and the faculty of maintaining the species by means of reproduction. That this latter ability must be ascribed also to the problematic primordial organism is proved by the different plant and animal species and by our own 
existence. But as the children are never an exact replica of the parents but differ from them in one or another characteristic, there must already have been inherent in the 'primordial slime' the possibility of variation. If that were not the case evolution of the organic world could not have taken place, and it would bear to-day the same primitive appearance as in the ages in which it came into existence.

Most zoological text-books divide the animal kingdom into two great divisions. On one side are the higher multicellular animals, among which we find all animal organisms, from the little polyp whose body consists merely of a cavity surrounded by a double cell-layer, up to man with his body complex with numerous tissues and organs. On the other side are the unicellular protozoa.

The name protozoon always seems to create in the lay mind erroneous ideas. It came into use at a time when our knowledge of the structure of the protozoa was of rather primitive nature, and when serious men still believed that the Amœbæ and Infusorians owed their existence to spontaneous generation, developing everywhere in decaying substances. To-day we know that the unicellular organisms are no more original forms than are mammals or insects. Like the latter they bear unmistakable signs proving that their species have undergone a development extending over vast periods. But all vital functions go on in the protozoa in a much clearer and simpler manner than in the multicellular animals, and a study of their reproduction throws a clearer light upon the conditions obtaining in the higher animals. It is one of the greatest joys of biological research to penetrate with the aid of the microscope into this rich world of invisible life and to discover its secrets.

In a drop of water taken from any ditch or pond we are able to observe with the naked eye a minute white spot. This little insignificant thing holds within itself all the wonders of life. All the numerous functions of respiration, nutrition, locomotion, and reproduction which are performed in man by highly complex organ-systems, are going on in this minute drop of transparent slime in a different yet none the less perfect manner.

The little organism before us is a member of the so-called Rhizopods, an Amoeba. It owes its name 'change' to the fact 
that it does not retain the same shape for long. Now it rolls itself up into a ball, the next moment extends the body longitudinally, or thrusts out sac-like processes. Only sudden stimuli or unfavourable external conditions render the animalcule temporarily motionless (fig 51).

Like all other typical cells, the Amœba consists of protoplasm and a nucleus. Specific organs have not yet been evolved, but the protoplasm has become separated into a granulated endoplasm and a more transparent hyaline ectoplasm which surrounds the whole body of the animalcule as with a thin mantle. In the endoplasm take place the digestive functions, while the light-coloured protoplasm - mantle serves the purposes of locomotion. Apart from this the cell-body appears uniform, except that in the interior we observe a little vesicle, filled with a clear liquid, which expands at rhyth-

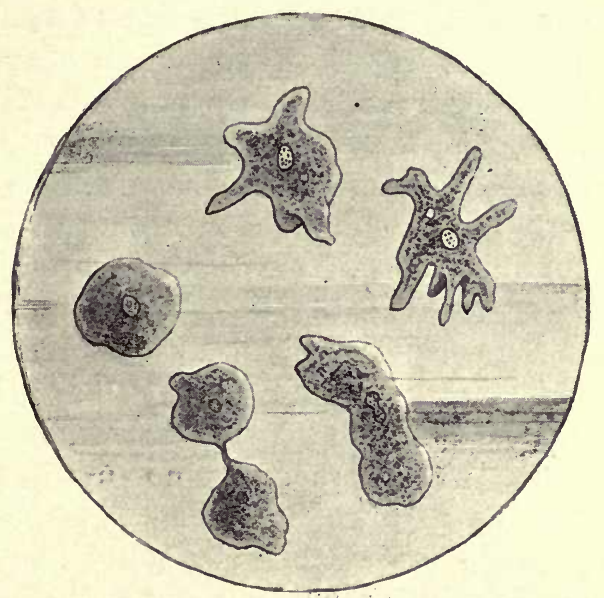

FIG. 51.-Amoba proteus IN VARIOUS STAGES OF MOTION. BELOW, DIVISION OF THE PARENT-AMEBA INTO TWO DAUGHTER-AMOEBE. mic intervals, then col-

lapses suddenly, and ejects its contents into the surrounding water, when the process commences anew. This is the 'pulsating vacuole.' Its task is the removal of the water which has been taken in and used up in respiration, and the ejection of liquid excreta.

If we let the Amœba remain undisturbed we shall see that the ectoplasm begins to protrude in a certain spot, and forms a pseudopodion. The rest of the body-substance flows lazily after the protrusion, and by repeating this process the Amœba floats slowly along the surface of the rock or plant. If any particle of food, such as a bacterium or alga or any other similar protozoon, is encountered by the Amœba it is engulfed by the pseudopodia. 
The digestible parts are decomposed and assimilated, and the refuse expelled in the same manner in which it was taken. Thus the Amœba floats along with an awkward movement, eats, and grows. But the growth is not unlimited. When a certain size has been reached the nucleus of the Amœba begins to constrict in the middle and changes from the globular form into the shape of dumb-bells. Gradually the constriction becomes more distinct and deeper, and finally we get two cellnuclei which wander to the two opposite cell-poles. Now the protoplasm of the cell-body also begins to draw itself out until finally the two cell-halves of which each contains one of the two nuclei remain connected only by a thin bridge of protoplasm (compare fig. 51). In the end, this last connecting link breaks and instead of the parent-Amœba we have two daughter-Amœbæ which are exactly like the mother excepting in size. Like her they crawl about in search of prey, quickly grow, and divide in their turn, after some time, into two little Amœbæ. How simple and yet how wonderful! This primitive process of reproduction, which is not inaptly called a 'growth beyond the individual measure,' is repeated through innumerable generations, for so far as our experience goes there is no natural limit. In these lowest organisms that which we call development is as yet absent, for the young are at 'birth' exactly like the mother, excepting in volume. But growth without a change in the organism cannot be described as development. Nor do these primitive organisms know death. They possess, as Weismann expresses it, potential immortality, because, as we have seen, the mother divides into two daughter-individuals and continues to live in them. But the Amœbæ are not immortal for all that, for like other organisms they can be destroyed by poison, heat, or serious mechanical disturbances. Potential immortality only expresses the idea that a physiological death-the normal decay, which is a fundamental necessity of the organism-does not take place in the Amoba and many of its relatives among the protozoans.

It is a difficult idea to grasp, for that death follows life and must of necessity follow it is an idea so deeply rooted in the human mind which is reminded of it daily and hourly that it will not accept any exception of this law. The doctrine of potential immortality of the unicellular organism was therefore 
fiercely contested and declared to be false. But if we examine the question itself on the basis of the facts we shall see that the assumption of, as it were, an eternal life for numerous protozoa is neither sophism nor playing with words, but a logical necessity, unless indeed we wish to rob the conception of 'death' of its natural meaning.

Let us first of all define the problem and agree upon the meaning of the words. 'Death' is distinguished from 'life' by two factors, one a physiological, the other a morphological. Death is indicated by the cessation of the individual life-phenomena and by the appearance of a corpse : only when these conditions are fulfilled we are able to speak of death having taken place. Let us apply this to the Amœba. That there is no appearance of a corpse or of anything that can be regarded as equal to it we have already seen, for the mother divides into two daughter-individuals without leaving a residue. Thus it would seem that the question is already decided in our favour, but the opponents of this doctrine of immortality cling in this specific case to the physiological factors and contend that in reproduction by fission the mother ceases to exist as an individual, and that the individual life-phenomena are thereby discontinued. To a certain degree and with many modifications this conception might be defended, but if we examine the question more thoroughly it seems to me that we shall reach a different result.

Like many higher animals and most protozoa, our Amoba possesses the important faculty of replacing lost parts of the body by regeneration. If I cut from the body of the Amœba a particle of protoplasm it does not perish from this injury. On the contrary, the wound closes up, the Amoba takes in food as before, and the damage is soon completely repaired. How does this affect the individuality of the Amœba? Are we still dealingr with the same individual? I took away a part of its body, a part of its individuality, which afterwards was replaced by regeneration. No one will contend, because part of the whole body was cut off, that we have no longer before us the same animalcule, that because of the operation we now have to regard the old Amoeba as dead, and that the Rhizopod which now crawls about under the microscope is an individual other than the first. With the same right it might be contended that the 
man whose arm or legs have been amputated is no longer himself: that the healthy man is dead, and that the cripple is a new individual which did not exist before. No one would seriously maintain such an absurdity, and the patient himself would most energetically protest against such suggestions.

How large the part of the body is which I cut away from the Amoeba or any other organism cannot in any way affect this consideration. It does not matter whether I take away a minute particle or half of the Amceba cell-body, so long as the animalcule is able to survive the operation. Equally so it is without importance which part of the body is lost, whether it consists only of protoplasm or of nuclear substance, or whether it was an eye, or an arm, or leg that was destroyed.

Let us now assume that I divide an Amœba in such a manner that both halves are equally large and that both contain protoplasm as well as a share of the nucleus. Let us call these two pieces $A$ and $B$, and trace their future fate. $A$ closes its wound in a short time, rolls itself up, and begins to act like a healthy animalcule. It crawls about, eats, and grows. Before long the damage has been repaired and everything is exactly as it was before. As regards $A$, therefore, we stand towards it in the same position as we stood towards the wounded Amœba, i.e., $A$ is no newly-generated creature, but the old Amœba cut in two, which has not died but continues to live in spite of the terrible mutilation, and continues its individuality uninterrupted in $A$. We cannot, therefore, speak here of death and dying.

But what has in the meantime abecome of the other piece? Has it perished like the smaller particles of protoplasm which we cut off before? Here, too, we find that it has developed precisely like $A$, and become a complete Amœba. But because $B$ also remained alive can we conclude post festum that $A$ is dead, in spite of all observation to the contrary? No, the only conclusion which we are justified in drawing is that the original Amœba is not only not dead but has doubled its individuality and continues to exist undiminished in $A$ and $B$.

What I have done here by an artificial operation does not differ fundamentally from the natural manner of reproduction by fission. We must therefore acknowledge that the natural act of reproduction is not bound up with a process of dying, but only 
leads to a doubling of the individuality. We must also admit that the unicellular organisms - or at any rate the Amœbæ which have been the subject of this examination-have this advantage before us and all multicellar organisms that they possess potential immortality.

As we shall see later, many protozoa divide during reproduction not only into two, but three, four, and even more parts which are all able to develop into complete individuals. But does that justify us to speak of death? Assuredly not, for the sole difference which we are able to observe is that in these the mother-individual has not only doubled, but trebled, or quadrupled, or multiplied $x$ times. The facts are so clear and incontestable that one cannot see why anyone should find it difficult to accept them.

Reproduction in such a simple manner can take place only in very few protozoans, because only very few have such low organization. In the closely related Foraminifera it requires already rather elaborate preparations before the mother may proceed to fission. The Foraminifera differ from the Amœbæ only by the possession of a shell. We may describe them as Amœbæ which have made for themselves a solid shell as a protection against enemies (see fig. 52). As great as are the differences in shape and appearance of the shells of the individual species, as different is the material which has been used in their construction. Sometimes the shell is merely a delicate membrane, a secretion of the outer protoplasm. Sometimes the animalcules absorb little particles of sand, or of diatom-shells, which they afterwards deposit on the surface of the body and join into a firm armour by means of a chitinous glue. In others the shell consists of numberless minute silica-plates, while the vast numbers of marine Foraminifera make their shells by preference of carbonate of lime which they take from the sea water and secrete, often in the form of most delicately shaped shells. These marine species are of particular importance to man and the history of the earth because in many parts of the earth they have been the origin of enormous mountains and rocks. Just as the Foraminifera are to-day found swimming in the ocean in vast masses, driven by current and wind hither and thither, so they must have peopled the ocean in remote ages. 
In spite of their potential immortality numberless individuals continually sank to the bottom, their bodies decaying, but their tiny shells accumulating. Generation followed generation, and higher and higher rose these mountains of corpses until they almost reached the surface. Now follows a period of enormous revolutions of the earth's interior or contractions of the rigid crust : the sea floor rises and from the floods ascend the mountains of dead Foraminifera, an enormous continent of chalk. But what Nature builds to-day she destroys to-morrow, for nothing in this world is eternally constant except alone change.

Keines verbleibt in der gleichen Gestalt, denn Veränderung liebend,

Schafft die Natur stets neu aus anderen andere Formen,

Doch in der Weite der Welt geht nichts-das glaubt mir-verloren.

Wechsel und Tausch ist nur in der Form, Entstehen und Werden,

Heisst nur anders als sonst anfangen zu sein, und Vergehen,

Nicht mehr sein wie zuvor.-Goethe.

Rain and wind beat incessantly against these rocky masses, and cut deep valleys into the land; the sea follows, completing the work of destruction, but what it tears away in one place it deposits in another. Such alternations of destruction and construction created the island of Rügen in its rugged shape as we know it to-day. But still the waves thunder against the chalk cliffs, and rain and storm continually carry away to the sea earth and fragments of stone. Many thousands of years may yet have to pass, but the day will come when Rügen will be no more, just as there was once a time when it was not yet. But the 'becoming' is eternal. Billions of Foraminifera still people the ocean-the descendants of those whose shells built the island of Rügen-and they will make new lands and new islands arise. But it takes longer than the short life of man to observe Nature in its giant task. The enormous numbers of lives which must be born and die before one single chalk-rock can be built will be understood when we hear that one gramme of chalk contains more than fifty thousand shells of Foraminifera.

Foraminifera played an important rôle in other parts of the earth's history. In the Carboniferous Formations we know in many districts extended strata which consist almost exclusively of shells of Fusulina and Schwagerina. In the Tertiary Period we encounter, especially in Southern Europe, in the Carpathians 
and Pyrenees, deposits of the familiar nummulites. These are probably the largest unicellular organisms which ever lived, for we know shells of the size of a florin.

But let us return to our subject: it is not the protozoans as such but the natural phenomena of reproduction which are of interest to us here. Some Foraminifera, with a comparatively soft shell, are, like Amœbæ, able to reproduce by a simple drawing-out process (constriction), whereupon each of the daughter-animalcules completes the inherited shell-half by regeneration. Others leave their house when the time of reproduction comes and divide, whereupon each half builds for itself a new house. Other species exhibit more remarkable deviations. Let us examine these in the little Euglypha alveolata which lives in fresh water. This pretty animalcule possesses a shell shaped like a pear or egg, artistically built of minute silica-plates. At the pointed end is a round opening through which Euglypha protudes its protoplasmic pseudopodia and takes in food. When it is about to

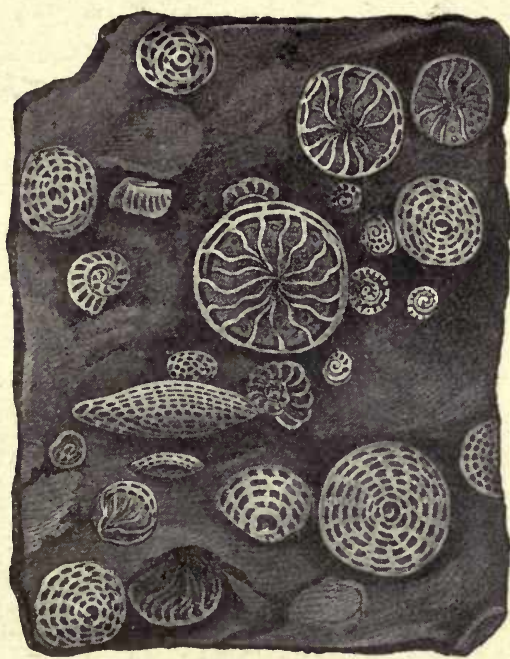

FIG. 52.-NUMMULITES. divide it secretes first of all in the cell-body, in immediate proximity of the nucleus, numerous minute silica-plates. 'Then all pseudopodia are retracted, and in their place appears a thick, round lump of protoplasm, representing about half of the entire body substance. Now the nucleus begins to change: in a highly complicated manner it divides into two parts which are exactly alike. While one half remains in the shell the other wanders into the protruded protoplasm. In the meantime the silica-plates have also passed on to the protruded protoplasm and formed themselves into a connected shell which is an exact replica of the old house. A chitinous glue joins the 
single plates firmly together, thus giving to the whole the necessary solidity. For some time the two animalcules remain in the position of shell-opening pressed against shell-opening, connected only by a bridge of protoplasm, but suddenly the connecting cord breaks, the two animalcules crawl apart, and the division is complete. Very soon afterwards the living contents of the two shells have by growth regained the normal size.

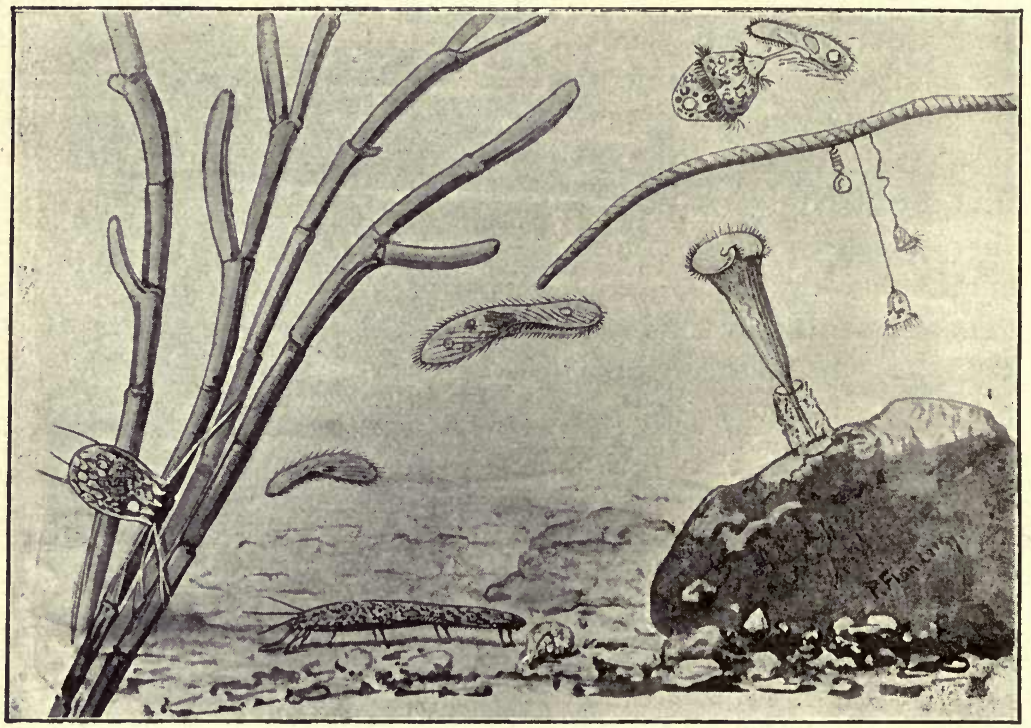

FIG. 53.-A MICRO-AQUARIUM. FORAMINIFERA AND CILIATES (MAGNIFIED).

On the left, below, on the branches of an Alga, a Foraminiferon (Euglypha alveolata); crawling on the bottom a shell-animalcule (Stylonychia mytilus); above, swimming, two slipper-animalcules (Paramacium caudatum); a third attacked by a ciliate infusorian (Didinium nasutum). Below, hanging from the branch of an Alga, three bell-animalcules (Vorticella nebulifera); on the stone, a trumpet-animalcule (Stentor roeselii).

Among all protozoans the Ciliates occupy undoubtedly the highest position. Indeed it seems no exaggeration to say that there is as great a distance between an Amœba and a Ciliate, as between the sponge or polyp and a mammal. We are continually filled with wonder when we observe the differentiations of which a simple cell is capable. In the Ciliate we find as perfect a 
division of labour of the single parts of the cell-body as we would only expect to find in the highest multicellular organisms. Indeed many of these Infusorians-I will only mention the trumpet-animalcule Stentor, the dainty bell-animalcules Vorticella and Epistalis, the so-called shell-animacule Stylonychia-appear to be so highly organized that no unprejudiced observer will wonder at the founder of scientific protozoology, Ehrenberg, contending that these animalcules possessed, like the multicellular animals, an intestinal canal, nervous system, sexual glands, muscles, kidneys, etc., and it is only quite recently that the opinions of Dujardin and von Siebold, which perceived the protozoa to be simple cells, were universally accepted (fig. 53).

If we fill a glass with water and decaying leaves we shall find after a few days a magnificent culture of Infusorians. This will in most cases contain the slipper-animalcule (Paramacıum), one of the most widely distributed species. Under favourable conditions of temperature and food the water becomes in a short time filled with innumerable little white points.

The Paramacium reaches a length of about 0.2 to $0.3 \mathrm{~mm}$.; we are therefore just able to see it with the naked eye. Its shape is an asymmetrical oval, slightly flattened dorso-ventrally, in which we can distinguish an anterior and posterior end. While the former appears somewhat rounded the posterior end is more or less pointed. The whole body-surface of Paramacium is covered with an enormous number of delicate cilia arranged in longitudinal rows, which during life almost incessantly carry out lashing movements and enable the animals to dart skilfully through the water. We can best compare the movements of the cilia to the uniform waving of a cornfield, gently stroked by the wind, rising following falling; but just as the ears are not always bent by the wind in the same direction so the play of the cilia changes from time to time in order to drive the animalcule in another direction.

The ciliation of the body is not quite regular in Paramacium, though more uniform than in many other Infusorians. Thus we observe in the anterior end a flat groove, the so-called 'peristomical area,' on which we find stronger cilia of somewhat different shape. The posterior end is distinguished by somewhat longer cilia. 
In the other orders of the Infusorians the differentiation inciliation has made very considerable progress. We see that the cilia are here used for the most diverse functions-swimming, crawling, jumping, wafting-in food, etc., and are transformed according to their work. Perhaps the most remarkable transformation which the cilia have undergone is observed in the shell-animalcule (Stylonychia mytilus) which I have already mentioned. Here some of the cilia of the ventral surface-i.e., the surface which during locomotion is opposite the object on which they crawl, and where is found the mouth-aperture-have assumed a strong, rigid 'slate pencil' form, while others have become cirrhous. 'These simple 'legs' are skilfully used by Stylonychia for running along the ground when in search of prey.

But let us return to the Paramacium. At the bottom of the peristome-field we observe a small round orifice, the 'mouth' of the cell. Food, which chiefly consists of bacteria and similar minute organisms, is wafted into this mouth by means of the cilia, and reaches through the orifice the pharynx of the animalcule, a short canal bent in the shape of an $\mathrm{S}$, which leads direct into the body-plasm. The indigestible parts are passed out through a special aperture. The very complex contractile vacuoles serve as organs of excretion. They are no longer the primitive vesicles of the Amueba, for we can here distinguish between an inner vesicle and a canal-system, extending from it to the protoplasm. The canals collect the used-up fluid from the entire body, conduct it to the central vesicle which, in consequence, swells gradually until it reaches a considerable size. Suddenly it collapses by passing its contents to the outside through a minute pore. This process is repeated at regular intervals.

If the organella mentioned before demonstrated already an enormous progress in the development as cornpared with the Rhizopods this distance will be still further increased when we consider the other differentiations of the protoplasmic body. In Paramacium we are able to distinguish an ectoplasm from the endoplasm. The first, again, is divided into a more solid cover, the pellicle, under which we can distinctly perceive a thin layer of a honeycombed structure. Below this lies the so-called ' cortical plasm,' a fine hyaline mantle which is sharply separated from the endoplasm and can, moreover, be distinguished from it 
by the fact that it never takes in particles of food. The cortical layer is specially marked as the seat of the 'trichocysts,' minute organs of defence which may be compared to the familiar poisoncells of the corals, sea-anemones, and jelly-fishes.

The trichocysts are small, spindle-shaped formations, filled with a watery fluid. Touch or other stimuli of a mechanical or chemical nature void them. When brought in contact with water the contents congeal into a thin, hard thread which eventually bores into the body of the attacker or prey, and there probably causes a burning pain or paralysis. I say, probably, because no satisfactory observation has so far been recorded.

The alveolate layer, which I mentioned before, is partly transformed into contractile fibrils, a kind of primitive muscle surrounding the body longitudinally, thus imparting to it great motility.

As regards the nuclear apparatus of the Ciliates, we find in this class two different kinds of nucleus, the socalled macro-nucleus, which is often distinguished by a very considerable size, and the micronucleus. While the macro-nucleus controls and regu-

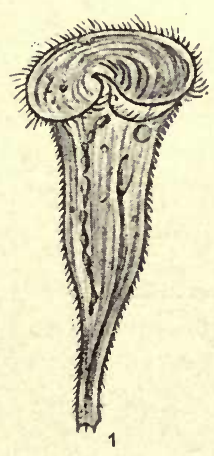

FIG. 54.-TRUMPET-ANIMALCULE (Stentor ccruleus) IN TKREE SUCCESSIVE STAGES OF DIVISION.
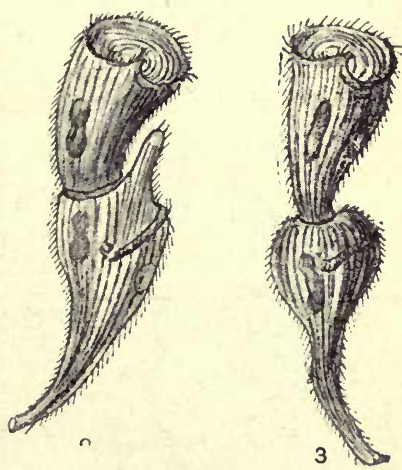

lates all 'vegetal

functions' of cell-life - digestion, respiration, locomotion, etc., the micro-nucleus becomes active only at times of sexual reproduction. The changes which it then undergoes are so striking that it has been described as the sex-nucleus.

Like Amœbæ, the Ciliates reproduce by simple fission, but while in the Amøbæ the two daughter-individuals are at once equivalent it is not so here, owing to the great differentiation of the body. Let us observe, as an example, a trumpet-animalcule (fig. 54).

The anterior end, which has been enlarged like a trumpet, 
bears the mouth-aperture to which leads a long ciliated wreath, the 'adoral cilia-zone'; the pointed posterior end is furnished with a suctorial disc.

Let us now suppose that Stentor begins to draw itself out. What would happen? We should have two halves, of which one would be without a mouth-aperture and the 'adoral ciliated spiral,' whilst the other would be without the suctorial foot. But Nature could not be so unjust as to endow both individuals with unequal proportion. When a Ciliate therefore feels that it has become too large for one animalcule it begins to lay down its most important organella in duplicate. It is no longer content to double only its nucleus but forms, as, for instance, in Stentor, a second ciliated wreath and a new mouth-aperture below the old. Division only takes place after this has been done, and now the two young Stentors resemble the mother in everything except in size and unimportant details.

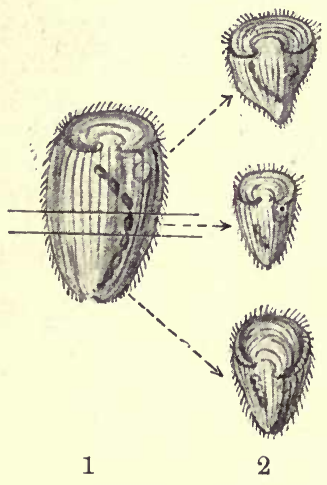

FIG. 55.-Stentor coruleus. (1) Cut into three nucleated parts ; (2) Three Stentores produced by regeneration.

It is possible to multiply the Ciliates artificially by dissection. As long as these individual sections have obtained their share of nuclear substance they are always able to survive the operation, and shortly to regenerate the absent organella. Thus a Stentor may easily be cut into two, three, four, or more parts, and each section will grow again into an adult animalcule if the conditions are at all favourable (see fig. 55).

The fertility of most unicellular organisms is astonishing. After a few months we would find in our Paramacium-culture a succession of hundreds of generations. If we discontinued our observations at that period we should gather the impression that reproduction by fission proceeds here until all eternity, apparently as undisturbed and uniform as in the Amœba. But further observation teaches us that this does not apply to the Ciliates without considerable modifications.

After multiplication has proceeded for some time normally 
we observe all at once a remarkable change. All the animalcules which we may take out and observe under the microscope will be found to be in pairs, joined ' mouth to mouth.' It seems as if the entire culture suffered from a kind of conjugation mania. When this intimate union has continued for some time the pairs separate and the individuals live as heretofore, swim hither and thither, and divide, until after a number of generations they enter into a fresh union of pairs.

What is the meaning of this mysterious process? It is doubtless one of great importance to the destiny of the Infusorians, for if it were otherwise how would it have become so universally established? A light is shed upon the mystery by the classic experiments made by Maupas. As conjugation usually takes place simultaneously in a very large number of individuals it seemed probable that its cause was to be found in the influence of external conditions, an assumption which to a certain extent proved accurate. It appeared that this conjugation-epidemic always took place when food became scarce, but that abundance of food always postponed it. It is no doubt necessary that other internal conditions have to be fulfilled before conjugation can take place, but we will disregard details.

The results of preventing such conjugation are curious. At first no injurious changes of any kind are perceptible and reproduction takes place undiminished : the mother-animalcules divide into children, these into grandchildren, and thus generation follows generation. But very soon the descendants do not seem to possess any longer the same vigour as their ancestors: the cilia-covering becomes incomplete: the size decreases; all signs of 'senile degeneration' appear; and in a short time the entire colony has become extinct. If, however, the Paramacia are permitted to proceed to conjugation at the right moment all signs of degeneration are absent, and the power of fission is inherited undiminished from one generation to another.

It seems, therefore, that Infusorians already die a natural death, though a death which does not take place as an inexorable necessity, as in the higher animals, but may be 'switched off' by the mysterious process of conjugation. Maupas and other investigators, on the basis of these observations, conceived therefore conjugation to be a life-renewing process, a means of unlocking 
new sources of energy without which the existing life-machine would inevitably perish.

But though this explanation sounds clear we must not forget that in test-tubes we offer to the Paramacium very different conditions from those that obtain in free nature. Moreover, in the last-mentioned case we deliberately continually overfed the animalcules in order to prevent the union. It is, therefore, at least as probable that the gradual degeneration and the final extinction of the colony can be referred to these factors, as that the cause is to be found in our having prevented conjugation. I am rather inclined to agree with Weismann, who says that the importance of conjugation lies in the amphimixis, in the exchange of the characters of two different individuals, and the increase in variability and adaptability conditioned by it.

Let us now endeavour to find out with the aid of the microscope what conjugation really is, and what happens during this process (fig. 56). Soon after the animals have taken up a 'mouth to mouth' position their nuclear apparatus shows characteristic changes. The macronucleus which, as we have already seen, controls the 'vegetal' functions of cell-life is not in any way affected, but in the micronucleus we notice far-reaching alterations. At first it divides indirectly into two daughter-nuclei which immediately divide again. It must be remembered that all these processes take part in both conjugated animalcules in the same manner. We see therefore in each in place of one uniform micronucleus four daughternuclei, but very soon three of these once more perish and are disintegrated in the protoplasm, while the fourth once more divides into two nuclei. But though identical in appearance, their destiny is very different. We distinguish them by calling one the 'female,' the other the 'male' nucleus.

Though our observation has already taken up several hours we must not lose patience, because the most important process is yet to come. In the region of the mouth-aperture a small plasm-bridge has formed between the two Paramacia, and now we see that the male nucleus of $A$ wanders into the protoplasm of $B$, and vice versa. The two united individuals therefore exchange their nuclear substance. When that has been done the Paramacia once more separate and each travels its own road, in 
appearance still the same, yet differing from what it was before. The whole process of conjugation, which mostly begins in the early hours of the morning, lasted about twelve hours.

But the process is still incomplete, and is continued in the separated animalcules until a complete renovation of the entire nuclear apparatus has taken place. The first step towards this
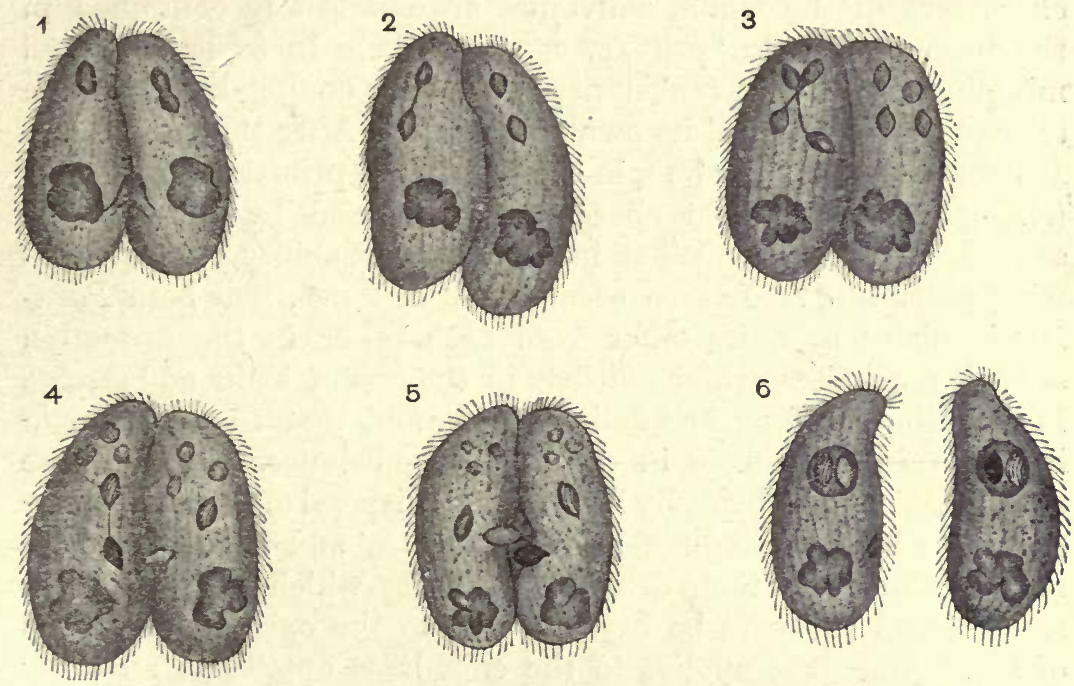

Fig. 56. - CONJUGation of Paramacium in six Stages.

(1) Two slipper animalcules, 'mouth to mouth': the micro-nucleus of the individual on the right begins to divide; (2) division of the micro-nuclei in both individuals is complete, and the parts are about to divide again ; (3) in each of the conjugating individuals four daughter-nuclei have been formed; (4) three of these in each individual perish, the fourth divides again into two nuclei, which are described as 'male' (shown as black or white) and 'female' (striped) nuclei ; (5) exchange of the two 'male' nuclei; (6) separated, male and female nuclei have become fused into one conjugation-nucleus, from which a new macro-nucleus and micro-nucleus originates, while the old macro-nucleus disintegrates.

end is that the 'male' and 'female' nucleus fuse into one. Then the old macronucleus disintegrates with every sign of degeneration; we may see its remains lie for some time in the cell-body until they have gradually been eaten up. But from the conjugation-nucleus a new macronucleus and a new micronucleus originate by fission, and thus the animalcules are ready 
once more for a new period of reproduction. The opinion which I expressed briefly in the beginning that in the mingling of the characters of two different individuals we have to look for the most important meaning of conjugation is hereby corroborated.

We have already heard (in the fourth lecture) that cogent proofs force us to regard the nucleus as the carrier of heritable characters-i.e., as that organ or that part in which all heritable characters of the whole individual are potentially contained in the form of minute 'primary constituents.' In exchanging and mingling their nuclear substance each of the conjugating infusoria transmits to its 'pair' its own characters. After the fusion both Paramacia have, therefore, in their body the primary constituents (Anlagen) of their old characters augmented by those of the second animalcule. What increase of variability, or, at least what possibility? Let us assume, for instance, that both Paramacia about to unite differ from each other in the formation of their cilia-dress, which consists in the one of short and strong, in the other of long and delicate cilia, and that the corresponding Anlagen were fixed in the nuclear substance. In that case each ' pair ' would obviously have at their disposal after the nucleusexchange both these different 'dispositions,' and we can conceive that in them and their descendants those which reach development would prove to be best adapted to the existing conditions of life. And what applies to the cilia-dress applies to all other organella and divergencies, so that the two sets of characters of both animals may find in their descendants a development of the most varied combinations.

But while amphimixis increases on one side the extent of variation it limits on the other side the danger that might threaten from one-sided variation. If, for instance, one part of an animal 'varies' in the descendants, the variations may either become weaker or, with the same probability, it may tend to 'vary' in a forward direction and become more and more pronounced. If now such variations accumulate through several generations we can imagine that the form of the affected part may assume such extreme dimensions that it would constitute a serious danger to its owner. Such a one-sided tendency of variation is entirely prevented by conjugation, because an exchange of characters implies, generally, a simultaneous correction of too pronounced deviations. 
That this is, in fact, the meaning of amphimixis is shown by the observation that only those animals proceed to conjugation which are most distantly related. Further, a large number of accurate investigations made with different species of infusorians have shown that individuals descended from the same mother-animalcule did not conjugate even when all other conditions of union have been fulfilled. In fact, conjugation between closely related individuals greatly resembling each other would lose its greatest object; in many cases it would even do greater harm than good by accumulating like characters. It is the same cause which forbids inbreeding of higher animals and matrimony between bloodrelatives. Just as Nature generally prevents self-fertilization and inbreeding, so the human race, in true perception of the dangers, created in early times laws and manners which limit or entirely forbid marriage between parents and children, between brothers and sisters, and even between cousins.

The great resemblance of the conjugation-process of the unicellular organisms to the fertilizing act of the higher animals is remarkable. Fundamentally they are processes of the same kind, and we are probably entitled to assume that conjugation is the early phylogenetic stage from which the process of fecundation was, in the course of phylogenetic development, gradually evolved. We shall see later on that there are in the organic world of to-day almost imperceptible transitions from the ' union' of Paramacium to the phenomena of sexual reproduction of the multi-cellular animals. We shall also learn when first the phenomenon of death became an inexorable law, and we shall further see how with progressive differentiations its power became more and more established and extended until it appears finally as a necessary stage of organic development.

Though the conjugation-process of the infusorians and the fertilization of multi-cellular organisms are of equal importance they differ greatly in their external appearance. While in Paramacium and its class the entire animalcules fuse in the 'sexual act,' to separate again after the exchange of nuclear substance, in the higher and highest organisms it is only the germ-cells, definite minute particles separated from the body, containing the heritable characters, which unite during the act of fertilization and remain in a permanently close union. From this insignificant 
rudiment (Anlage) slowly originate, by division, differentiation, and growth, the embryo, and finally the mature organism. The reason why in the multi-cellular organisms a conjugation of the entire animals can no longer take place is that only naked cells can become fused together. A further important difference is that the two copulating sex-cells, which for that reason we describe as male and female germ-cells or as spermatozoon and ovum, differ greatly in size, form, and appearance, while the Paramacia which proceed to a union are perfectly alike. On the other hand we know alreadjy among infuscrians a separation into 'male' and 'female' sexes, and the similarity in the phenomena in the highest animals is increased by the further fact that the union of conjugating individuals is permanent.

If we examine the numerous minute crustaceans which are among the most familiar inhabitants of the fresh-water aquarium we shall find their shells sometimes covered with a dense, woolly fungus which under a magnifying-glass are discovered to be colony-forming infusorians, members of the genus Vorticella. Dainty, many-branched little trees carry at the ends of their branches minute bells, the animalcules proper. In contrast to Paramacium, the cilia in Vorticella are greatly reduced in number; the entire stalk is naked, only one well-developed spiral fringe leading to the mouth-opening at the anterior end. Its function is to waft, by its lashing movement, the food to the mouth. In some species we observe, in addition, a simple circle of cilia round the body. As Vorticella generally does not change its habitat a complete cilia-dress is no longer of any use to them.

Like all other infusorians, no bell-animalcule is able to reproduce by simple fission, but as the drawing-out or constricting process is in numerous forms incomplete, and as the daughterindividuals remain connected with the mother-body by means of a thin stalk proceeding from the posterior end, this frequently gives rise to the formation of large colonies. When the time of conjugation arrives the individual citizens of the Vorticella colony exhibit remarkable differences. While one part remains unchanged, others in quick succession divide each into four individuals, without waiting for growth to make up the resulting decrease in size. After a short time these little 'male' germs separate from the mother-stem and swim freely about by means 
of a specially formed cilia-wreath. How long this free life lasts depends upon many accidents. If the little 'microgamete,' as it is called, encounters on its travels a normal individual of the same species, a so-called macrogamete, it attaches itself at once to its side and fuses with it into one uniform whole. And as the cellbody, so their two nuclei unite. Only the discarded pellicle of the microgamete, which is not included in the union, is the external sign that conjugation has taken place.

At first the fertilized Vorticella differs from an ordinary macrogamete by the formation of its nuclear apparatus, but by repeated division descendants are produced which have once more a normal appearance and are ready for a new conjugation-or we must now, perhaps, more accurately use the term fertilization.

If we cannot know with certainty what caused in the bellanimalcule this division of labour-i.e., the formation of male 'wander-spores,'-it is, nevertheless, perhaps not quite futile to make at any rate an attempt to explain the probable causes of these differentiations. I have already pointed to the great importance of the conjugating-process, and we saw that only an exchange of nuclei between non-related individuals can guarantee the intended result. The large majority of Vorticellae are fixed to the ground. Is it not then obvious that in most cases conjugation is practically impossible, or at any rate most difficult? It is true that in the colony-forming species numerous individuals are produced together in a small space, but since they are all bloodrelatives union between them cannot take place. Thus the formation of free-moving germs which separate from the motherstem and are able independently to seek another strange stem, seems the only possible means to bring about conjugation, in spite of a sedentary mode of life.

Why the 'wander-spores' are so differently shaped, why there is a differentiation into two sexes, and, in the act of fecundation, why the union of both sexes becomes permanent instead of the animalcules contenting themselves as heretofore with a mere exchange of their nuclear substance our hypothesis has so far left unexplained. Yet the reason for this new phenomenon is not difficult to perceive: it is the same circumstance which conditions the difference in the formation of ovum and spermatozoon in the higher animals. 
As the 'wander-germs' which separate from the mother. stem must often seek their partner in a comparatively enormous space it is clear that numerous individuals must perish before they reach the desired goal. It was therefore necessary to produce a very large number of free-moving germs. The best way to produce such large numbers was at the expense of the body. Here we have a natural explanation of the fact that the free-moving individuals were developed as microgametes, or, as we may also call them, male germs, while the others, the macrogametes, or females, which remained fixed to the stem and had to await the coming of the microgamete, could retain their original cellsize. And as the small quantity of protoplasm made it probably difficult for the microgametes to reproduce from themselves alone normal individuals the permanent complete fusion with a macrogamete seemed most advantageous for their further development.

If this assumption sounds at first somewhat forced it finds, nevertheless, corroboration in many facts derived from the lifehistory of the higher animals. It is known that in these the difference in size between male and female germ-cells has become still more considerable than in the unicellular organisms, for the ova belong to the largest, the spermatozoa to the smallest, animal-cells known to us. The ovum of the sea-urchin exceeds in volume the male germ by more than 200,000 times, and in animals with unusually large eggs, in particular reptiles and birds, the proportion becomes still more unfavourable to the spermatozoon. The simple reason is that ovum-cells are produced in much less numbers than the spermatozoa, consequently they are able to develop their protoplasm very strongly and load themselves, in addition, with abundant quantities of foodstuff for the maintenance of the growing embryo during the later stages of its development.

Spermatozoa on the other hand, being minute, are produced in enormous quantities. Because it is necessary that they possess the utmost motility to seek and find the ovum we observe how during growth the spermatozoa reject almost their entire protoplasm, so that a fully developed spermatozoon consists only of nuclear substance.

Although the spermatozoon contains, like the ovum, in its 
nucleus, the 'primary constituents' of a complete organism, it cannot develop one out of itself because of the absence of a sufficiency of food. If, therefore, the spermatozoon is not to perish before it has fulfilled its mission it must join with an ovum. Only in an ovum will it be possible for it to develop its individual faculties. The male germ is, therefore, of necessity dependent upon the fertilization process.

It is different with the ovum. Though we know that it has been built for fertilization, this process is far from being an absolute necessity, for there are numerous cases known of natural and artificial parthenogenesis in which eggs develop into complete individuals without preceding fertilization.

When I said before that the male spermatozoon is of necessity dependent upon the fertilization process the statement was only conditionally true, for we know a case in Nature, that of an Alga (Ectocarpus siliculosus), in which not only the female germcells are able to develop parthenogenetically, but that also the male sex-cells can, under certain circumstances, reach independent development. How is this unique behaviour to be explained? In Ectocarpus siliculosus the difference in size between the germ-cells is not considerable, for the spermatozoa possess a proportionately large amount of protoplasmic substance, and this is no doubt the reason for a certain independent development. Nevertheless, the independent formation of the separated germ-cells is only an act of necessity, and the little male plant always grows into a poorly-developed organism, corresponding to the smaller size of the male-germ.

The most important lesson to be learnt from this observation is that ovum and spermatozoon are formations fundamentally of equal value, normal cells of which each carries within itself the 'primary constituents' of a complete organism and is able, under certain circumstances, to develop them independently. Generally, however, we find that the sex-cells are dependent upon conjugation. Nature, indeed, makes all preparations, if I may use such anthropopathic expression to describe its blind work, for forcing fertilization and mixing the qualities. Thus we see that in progressing evolution the independent development is made more and more difficult and even impossible to both spermatozoon and ovum. This is effected in the male 
germ-cells chiefly by a great reduction of their protoplasm, in the egg-cells by a very ingenious means with which I will deal in the next lecture.

We see, further, that the separation of the organic world into two sexes, the existence of male and female sex-cells is no original state but a secondary acquisition which has been developed very gradually by adaptation to changed external conditions of life, and hand in hand with the differentiations in organization. Division of labour, this omnipotent factor which rules the entire organic world, is here again the motive power to which we are able to trace all phenomena.

Apart from reproduction by fission we know in many infusorians and in numerous other protozoans another kind of propagation, budding. The most important difference is that in fission the mother-animalcule divides itself completely into its two descendants, while in budding it remains complete and undivided, and merely separates from its body one or more minute nucleated particles which gradually develop into complete organisms.

The highest perfection and the most complete conformity with the phenomena of reproduction in the multicellular animals is without question exhibited by the sporozoa. Their name sounds strange even to-day, when science has succeeded in exposing them as the most dangerous enemies of the human race, for though they are microscopically minute they are capable of causing the most terrible devastations in the human body. Among these sporozoa are found the organisms which are the dreaded cause of malaria. Their presence or absence decides whether vast tracts of fertile land shall be inhabited by man or not. In addition to the malarial parasite we find among the sporozoa the cause of Texas fever, horse-sickness, and many other diseases. Though all sporozoa do not cause serious illness they all lead a parasitic life and there is hardly a class of animals on which they do not prey. But as the malaria parasite is undoubtedly the most important to man we will examine it here in detail.

It is more than a quarter of a century ago since Laveran, who was then an army surgeon in Constantine, Algeria, discovered for the first time the malaria parasite in the blood of a fever 
patient. Later, by the co-operation of English, Italian, German, and French investigators, its relation to malaria and its strange life-history were clearly ascertained.

These species of malaria parasite are distinguished: Plasmodium (Hamamœba) pracox, vivax, and malaria. Whether these three forms are really three separate species, or only varieties of the same species appears doubtful, especially as all three

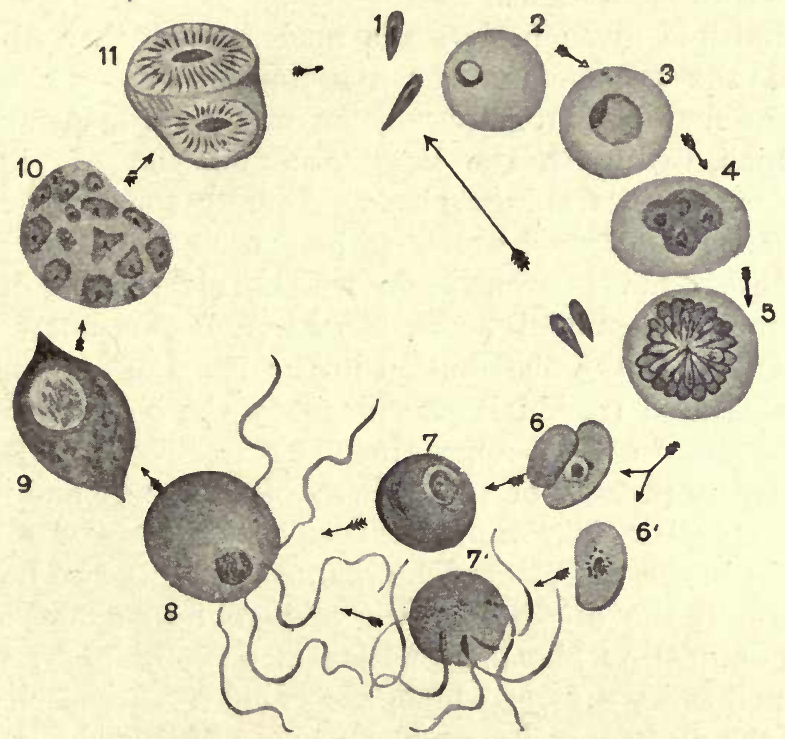

FIG. 57.-LIFE-CYCLE OF THE MALARIA PARASITE OF MAN.

(1-5) Stages of development in the human blood. (6-11) Stages of development in the Anopheles. (1) Sporozoites. (2) Sporozoite has invaded a red blood-corpuscle. (3) Sporozoite becomes a monont. (4) Nucleus multiplication. (5) Spore formation. (6) Female germ (oogony). (6') Male germ (antheridium). (7) Mature female germ. (7') Formation of microgametes. (8) Fertilization. (9) Fertilized oogony (amphiont). (11) Development of gymnospores in the interior of the amphiont.

are dependent upon the same hosts, man and a mosquito (Anopheles). These three parasites are the cause of the three kinds of human malaria which are distinguished as perniciosa, tertiana, and quartana. I shall deal here with the cause of tertiana, Plasmodium vivax. The other two closely conform in their mode of life to this species.

If we examine the blood of a fever patient we find in the 
blood-corpuscles minute amœboid germs which quickly grow by feeding upon the blood-corpuscles. The red pigment of the attacked blood-corpuscles is decomposed by the protoplasm of the parasite and deposited in the interior of the Plasmodium in the form of dark brown, almost black, pigment. The little parasite continues to grow and finally completely fills the considerably expanded blood-corpuscle which surrounds it now only as with a thin membrane.

By multiple division, first the nucleus and then the protoplasm of the Plasmodium form a number of spores, usually twenty, at first held together by an undivided central plasmic body which, owing to the large accumulation of pigment in its interior, appears almost black. Finally the blood-corpuscle disintegrates, the spores are liberated, reach the blood and soon infest another blood-corpuscle in which this process of growth into a 'monont' and of spore formation begins anew (fig. 57, 1-5). Owing to the distribution in the blood of the pigment of the disintegrated (residual) plasmic body the blood of a malaria patient assumes a dark appearance.

The entire process of the growth of the spore and its reproduction comprises in Plasmodium vivax and pracox a space of forty-eight hours, in Plasmodium malaria seventy-two hours.

Externally the division of the monont into spores and their invasion of healthy blood-corpuscles is perceptible by a rise in the temperature- a fever which, according to the species of the cause of the disease, recurs regularly every forty-eight or seventytwo hours.

From the simple reproduction by fission as we saw it in the Amœbæ, Foraminifera and Infusoria the division of the malaria parasite differs in many ways. In the first place the mothersporozoon disintegrates at once into a large number of descendants, and, secondly, its body is not used up entirely for generating the bodies of its descendants but a considerable part is doomed to decay as a residuum. Does it not seem that we have here what is called the morphologic side of the death problem, the first appearance of a corpse? Indeed, the process is so interpreted by many investigators and the residual body described by them as a corpse. But here, again, confusion arises from an inaccurate definition of terms. 
What is a corpse? The question sounds so simple and is yet full of difficulties. May we describe any rejected part of a living organism being doomed to decay as a corpse? Can this term be applied in this specific case to the residual body, and am I justified by the appearance of this residual body in saying that the Plasmodium dies a natural death? In my opinion I would be equaliy justified in contending that the act of birth in the higher mammals and man is accompanied by an act of death, because during birth a part of the material body, the placenta, is rejected and perishes. But no one thinks of describing the placenta as a corpse in this sense, as no one would think of describing an amputated arm or leg, a destroyed eye or a drop of shed blood as a corpse. Why should we then make an exception here in the unicellular organisms, limit the contents of the term, and give it another meaning? It seems clear that we can only describe as a corpse the sum-total of all parts of an organism that has perished, but not any one part of a body which did not before possess autonomous life. In the unicellular organism it is the entire cell, in the multicellular and the higher animals it is the entire organism which becomes a corpse.

While the asexual form of reproduction serves as a means of rapid distribution of the Plasmodium in the body of the host and leads to the flooding of the host with disease germs, the transmission of the parasite from man to the second host, the gnat, is effected by an act of reproduction. In speaking of these processes I shall confine myself to Plasmodium (Hæemamœba) precox, the cause of the dangerous perniciosa.

If a mosquito of the genus Anopheles sucks the blood of a fever patient it happens that with the healthy blood-corpuscles some that have been attacked by parasites reach the intestines of the gnat. While in the body of this intermediate host the disease germs which were predestined to asexual reproduction soon perish, we observe that some of the spores undergo a remarkable transformation. For a number of the parasites grow vigorously, assuming at first the shape of a half-moon, but gradually a globular form. We describe them as female germs or oogonies. Others, the male germs or the antheridia, pass at first through a similar transformation and are then only with difficulty 
distinguished from the oogonies. In these the nucleus had already in the human body commenced to divide into several particles. These little nuclei vigorously extend longitudinally and each surrounds itself with a small quantity of protoplasm which undertakes the function of flagellæ. In this manner there originate from each antheridium five to six microgametes which we may describe as male spermatozoa, but the main mass of the protoplasm of the antheridium becomes residual matter and thus ceases to play any further part.

In the intestines of the Anopheles fertilization takes place, i.e., the fusion of an oogony with a microgamete. The fertilized oogony now loses its globular form and changes into a sickleshaped motile form which begins to wander, perforates the intestinal wall, and seeks a fresh place for its further development. Immediately below the elastic intestinal membrane the little parasite settles down. Protected by the membrane which surrounds them as if they were encysted, they rapidly grow into buds which may be clearly observed with the naked eye. The oogonies are now described as amphionts.

In the meantime the originally homogeneous nucleus has directly divided by constriction into an enormous number of small nuclei which, as the result of further division, become more and more minute. Around each of these minute nuclear particles the protoplasm aggregates in the form of long, thin threads. Thus originate in the cyst the gymnospores. How enormous the multiplication of the parasites can be is shown by a calculation of Grassi, according to which one amphiont is able to produce up to ten thousand gymnospores. As on the stomach-wall of an infected Anopheles there are frequently found more than a hundred such cysts, a simple calculation shows that one gnat may harbour simultaneously more than one million spores.

When the formation and maturing of the gymnospores is complete they leave the amphiont-capsules, invade the bodycavity of the Anopheles, wander through the fat-tissue, and finally accumulate in the salivary gland of the host, probably attracted by chemotactic stimuli. Here they may be frequently observed in astounding numbers. If now a mosquito in this state seeks the blood of a healthy man, there enter the human blood, simul- 
taneously with the drop of saliva which the Anopheles lets flow into the wound which it bores with its proboscis, numerous gymnospores. Here the germs probably invade at once the red blood corpuscles-direct observations are as yet absent-develop into mononts, and these divide again into spores. With this act infection is complete and the cycle may commence anew. A fever fit announces the presence of malaria.

The reproduction-cycle of the malaria parasite represents a change of generations, that is, a change and a regular succession of sexual and asexual reproduction. We shall hear of similar cases among the metazoans in the next lecture.

Though all this sounds very simple it required an enormous amount of labour before the life-habit of the parasite had been accurately determined, for it must be clear to every one that the disentangling of the threads entailed much more than merely to observe under the microscope the blood of a malaria fever patient, the contents of his intestines, and the salivary gland of a mosquito. But man does not penetrate Nature's secrets quite so easily. Perhaps it was only chance which first indicated in the blood of a malaria patient one or another stage of the parasite. This discovery is followed up, the blood of healthy and infected persons is examined, and it is found that only the latter contains similar germs. Gradually the conclusion is arrived at that these

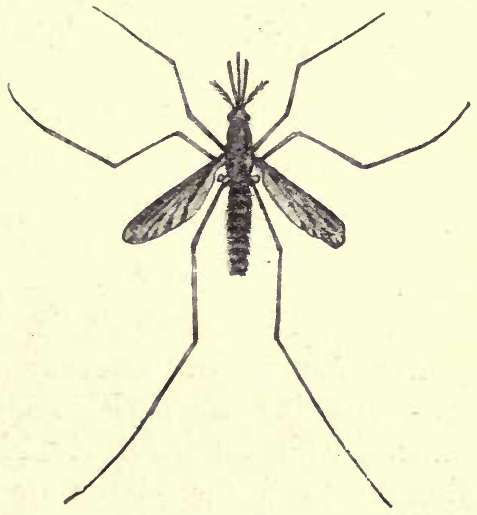

FIG. 58. - THE MALARIA MOSQUTTO (Anopheles claviger). minute organisms stand in some relation to the sickness. One searches for the way by which the parasites can have reached the human blood. There are so many possibilities. The most diverse hypotheses are constructed, examined, and rejected until finally the right way is found and the carrier discovered in bloodsucking insects : in this particular case, the Anopheles.

Again, in the interior of the Anopheles are found parasites of very different appearance, gymnospores, amphionts, oocytes, 
and male germs. Only gradually is it perceived that these many-shaped organisms are but different developmental stages of one organism; but even with that discovery little progress has been made, for these numerous stages have apparently no connection. One knows neither beginning nor end of the chain. Yet patient research never flags; what remains hidden to one is discovered by another investigator, and gradually untiring observation and combination forge link to link in right succession, until at last after long laborious work and many errors the cycle of evolution is perfect.

I have so far omitted one important fact in the process of the reproduction of the protozoa. It happens frequently that multiplication commences with a period of rest. In such cases the organs of locomotion in the protozoa usually become degenerate, the organization becomes more simple, the plasmic body assumes a globular form and secretes a protective covera cyst. They remain in this state often for a considerable time without exhibiting any perceptible signs of life. Protected by the cyst they are almost unsusceptible to all injurious external influences, and in many cases, when the water in which they live dries up, when winter comes, or food becomes scarce, it is only this ability to enter into a stage of rest which can keep death away. Reproduction takes place usually before the encysted protozoans leave their shells.

The faculty of proceeding under certain circumstances to cyst-formation we find developed already in the lowest protozoans. The beautiful Amoba proteus is found in our ponds, clinging to water plants or floating in the water. With its life-history we are already acquainted, because it is identical with that of other aquatic amœbæ to which I referred in the beginning of this lecture. But at certain times we can observe striking changes in the body of Amoba proteus. The pseudopodia are retracted, the difference between the hyaline ectoplasm and the granulated endoplasm disappears, and the amœba assumes the shape of a ball which soon commences to rotate slowly around its axis. In the course of its movements the amœba secretes a covering; at the end of five days this has become a complete cyst, and the revolving movement ceases. In the meantime the nucleus has undergone certain changes, 
having become divided into numerous parts which still further divide into smaller particles until from 500 to 600 nuclei have been formed. Around each of these minute nuclei a part of the protoplasm becomes aggregated, and now the cyst is inhabited, instead of one mother-amœba, by many thousands of minute amœbæ of about 0.01 to 0.015 millimetres. Very soon the entire company leaves the protecting shell, enters the outer world, and grows gradually into normal amœbæ.

It will be noticed that here, as in other cases mentioned, the mother-amœba does not become entirely dissolved into her descendants, for a considerable part of the maternal protoplasmic body remains as residue in the cyst; but though doomed to rapid decay we cannot call it a 'corpse.' The entire process as described has taken about three months.

If we have not been able to become here acquainted with all the details of the evolution of the protozoans we have at any rate learned the most essential factors. It is now necessary to answer one important question: How did the higher animals develop from the unicellular organisms? Which causes brought about a combination of numerous cells into a higher organic unit, a multicellular organism? Are there any connecting links between the protozoa and the strange world of metazoa? These are questions which force themselves upon us and demand an answer.

Like protozoa and the lowest plants, all multicellular organisms consist at the starting point of their individual existence of one cell, the fertilized ovum. Like a protozoon, the egg-cell multiplies by simple fission, and thus gives existence to numberless descendants. And yet what an enormous difference in their future fate! While both daughter-individuals of a protozoon completely separate one from the other, and after fission exert no influence whatsoever upon their mutual development but develop into individuals which are equivalent to the motherorganism in every detail of organization and able to proceed after a short time to the reproduction of similar descendants, the future destiny and appearance of the young offspring of the ovum is very different.

In contrast to the daughter-cells of the protozoon, the descendants of the ovum remain, even after fission, permanently connected, and retain a far-reaching influence upon each other. 
Let us imagine the earliest developmental stage of an echinoderm: for instance, the Sea-urchin. The egg-cell, which has been liberated into the sea-water and there been impregnated, divides at first into two cells, and these again into four, eight, sixteen cells, and so forth. In this manner a large "cellheap" is produced, the morula. The individual citizens of this primitive cell-state are as yet equally well constructed, no one cell being favoured to the disadvantage of another cell, but this state does not remain long. As development progresses the embryonic cells multiply at an increasing ratio, the individual parts of the cell-heap become more closely united, and from the morula originates the germinal vesicle, the blastula, a hollow sphere the wall of which consists of a single layer of firmly compressed cells.

That the single parts of the cells are developed differently is clear from the fact that the outer side of the cells, coming into immediate contact with the surrounding sea-water, is exposed to influences very different from those which affect the inner side, which is opposite the 'groove-cavity.' So far the conditions were the same for all parts of the blastula, but now a change takes place. Some cells separate from the rest and wander into the groove-cavity. Then the little hollow sphere invaginates in the manner of an india-rubber ball the wall of which is being pressed at one point towards the other side, and the one-layer germ, the blastula, has become a two-layer germ, the gastrula.

The necessary consequence of this change is a different development of the cells, corresponding to the influences that act upon them, and to the differences of their functions. But I can only deal with it here in large outlines. The external cells undertake the task of locomotion and form cilia; the inner cells opposite the cavity, the primary archenteron, undertake the work of nutrition and are suitably transformed; finally those cells which we saw enter the groove or segmentation cavity produce by continued division and differentiation the connective tissue, the supporting matter, and muscles. In the growing organism division of labour becomes more and more perfect. The individual citizen of the cell-state does not, like the protozoon, care only for his own well-being, but places a part of his strength and work at the disposal of his comrades, the community, which in their turn undertake many of his cares. 
But we must not anticipate. Let us therefore return to the unicellular organisms. Among the Vorticellæ we saw numerous forms whose mode of reproduction in so far resembled the reproduction of the ovım, as with them division did not lead to a complete separation of the newly formed individuals. We saw that from one aniınal gradually proceeded many-headed polypstocks, the single individuals of which remained somewhat loosely connected by means of plasmic stalks. But though this connection in the Vorticellæ is slight and only the individual cells are independent of each other, it represents nevertheless the first step which leads from the protozoon to the multicellular organisms. It is true that the most important difference between them and the higher organisms, the division of labour between the single parts of the community, is as yet absent, unless we conceive the formation of two kinds of sexual cells to be its beginning. For this reason the advantage of this close association is difficult to understand, and yet a reason must exist, for how else can the habit of making only an incomplete division have been fixed by heredity?

It is interesting to observe that other species of protozoans, which generally lead a lonely life, occasionally proceed to the formation of a colony. This is another proof that such union, even without division of labour, must be useful, though we are not always able to perceive its advantage. Thus the parasitic gregarines, which have long been known as intestinal parasites of lower animals, and the Peridinia which live in enormous swarms in European ponds and waters, are frequently observed to exist as long "chains of dozens of individuals.

Most striking, however, because apparently giving proof of intelligence, is the system of commensalism, as observed in particular in the brilliant-coloured Heliozoa. If two, three, or more of these animalcules accidentally meet near a prey which a single Heliozoon would be unable to overpower we notice that their pseudopodia suddenly fuse on contact. Like hunters who surround a head of game the Heliozoa form round their prey a circle which gradually closes. The rigid central filaments which ordinarily give to the pseudopodia their firm shape become rudimentary, the pseudopodia shorter, and the circle more and more narrow until finally all the bodies have become fused intc 
one uniform mass : and in the midst of this common protoplasm the prey lies defenceless. When the meal is finished the animals separate once more, and each goes its own way until want of food may chance to bring them together in another spot. Thanks to this union, the Heliozoa are able to overpower even animalcules which are far superior to them in strength and ability.

A still higher stage of development than the Vorticella colonies has been reached by Pandorina morum, the small flagellate belonging to the family of the Volvocidæ, an organism which stands on the borderland between the plant and the animal world.

In many parts of Europe the Pandorina may be observed in any little pond. Sixteen cells have formed themselves into a ball and produced by common labour a gelatinous cover which protects their bodies. In Pandorina all parts of the body are as yet equivalent; each cell is furnished with nucleus, protoplasm, contractile vacuoles, light-sensitive pigment, chlorophyll, and two flagellæ which protrude from the gelatine-cover and serve as organs of locomotion. Equal is also the work which each cell performs for itself and the community, but in the fact that the members of the colony already do common labour, undertake the nutrition in common, and build the gelatine-cover in common, lies the great progress as compared with the union of the Vorticellæ. What binds the Pandorina-cells so firmly together that they no longer live as individuals is difficult to see, for each cell is capable of performing all essential life-functions, and would therefore undoubtedly be able to look after itself, yet they are always found united in this manner. Strictly speaking, Pandorina can no longer be regarded as a protozoon or protophyton, for it represents already a higher multicellular organism.

As in Pandorina, in contrast to the multicellular organisms, the single body-cells are as yet entirely equivalent, each individual cell possesses therefore the faculty of reproduction and of forming a new colony of sixteen cells. Moreover, reproduction proceeds exactly as in a typical protozoon. When a Pandorina colony has been floating about for a certain time in the water and the cells have become fully developed as the result 
of abundant food they commence almost simultaneously to multiply by successive fission. We have now a colony of sixteen Pandorinæ, each consisting of sixteen cells. For some time the young animalculæ are held together by the old common gelatinecover, but very soon the daughter-colonies leave the maternal home and go into the outer world.

They are delicate creatures whose existence is only too often threatened by injurious external influences. How are they to preserve their kind when the waters in which they live dry up, or severe cold freezes them to ice? Like the amœbæ and many other protozoans, the Pandorina is assisted through the hard times by a rest stage. Sometimes the body-walls of a colony divide each into eight flagellate parts, the so-called gametes. When these have reached the water, gametes of different descent proceed to pair. The products of these fusions live free only for a short time; then they encyst and their flagellæ become degenerate. Whatever may happen now, the young germ protected by the cyst is able to withstand all perils, calmly awaiting better times. As soon as conditions are once more favourable it crawls forth from its prison and by fission develops once more a young colony of sixteen heads. Thus we find in the Pandorina, in addition to asexual, a sexual reproduction, but the latter is still of a very simple character, for a differentiation of male and female sex has not yet been reached.

A near relation of Pandorina is Volvox which lives in close union with it. Every lover of Nature knows the little greenish balls, easily noticeable with the naked eye, which slowly rotate through the water. While the body of the Pandorina consists only of sixteen cells, a Volvox colony may consist of more than ten thousand cell-individuals which form the one-layer wall of a large hollow sphere filled with a thick fluid. The union of the individual citizens of this cell-state has become most intimate. Here, too, the entire colony is covered with a uniform gelatine shell, but the different individuals are in addition connected with each other by thin bridges of protoplasm. As in Pandorina, so the single cells possess here still great independence. Like every other cell, they consist of protoplasm and nucleus, but in addition we find some which are furnished with contractile vacuoles, chlorophyll, pigment, flagellæ, and a special close-fitting gelatine 
mantle. Apart from the far greater individual number of the Volvox colony, which is joined together in one organic unit, a fundamental difference does not appear to exist between them and Pandorina. But while there every single body-cell is able to reproduce independently and form a new colony of Pandorina, the cell-individuals of a Volvox colony have lost this old inborn faculty. They are still able to divide, but the parts are no longer able to grow into a young Volvox. Only a few favoured individuals of the cell-state have retained the faculty to preserve the species. We see, therefore, in Volvox a beginning of what we may describe as the essential characteristic of a higher multicellular organism: the separation of the whole organism into body-cells and germ-cells (fig. 59).

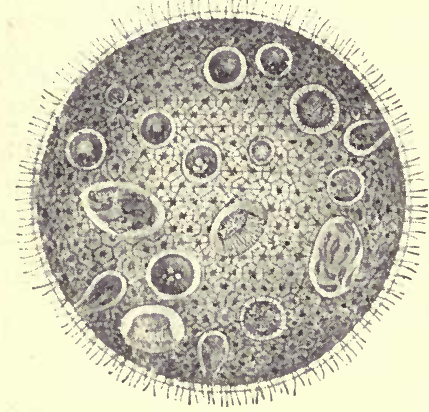

FIG. 59. - Volvox globator. SEXUAL HERMAPHRODITIC COLONY WITH OVA AND SPERMATOZOA IN PROCESS OF FORMATION.

If we observe a Volvox colony, slightly magnified we distinguish at once among the numerous cells a few which are differentiated from their neighbours in shape and size, and among these differently constructed cells we discern again two different kinds. They are the rudiments of male and female sexcells. The microgametes or spermatozoa develop first. The semenforming cells grow rapidly, producing by continual fission within the colony a large heap of a hundred or more spermatozoa about 0.005 millimetres long. Two long flagelliform processes serve as organs of locomotion. In the meantime the female germ-rudiments (Anlagen) have become more distinct. The absence of flagellæ differentiates them from all other members of the colony. Without fission having taken place every female germ, of which the colony contains about twenty to thirty, develops into a large cell of a round shape and rich in plasm, the macrogamete or ovum. When the female and the male sex-cells are mature they separate from the rest of the cells and fertilization takes place in the water. From the fertilized ovum a new Volvox is then gradually developed. 
But what becomes of the old maternal organism? When all germ-cells have seceded it continues to exist for some time but is unable to form new germ-cells, for body-cells can only produce body-cells. Soon symptoms of old age become perceptible; one function after the other ceases, and finally the colony reaches the inevitable end and dies. For the first time in the organic world we see here that death appears as a physiological necessity, as the inexorable fate which is henceforward in store for all organisms after a shorter or longer existence. Of what benefit would continued life be to the unfertile Volvox? It would be useless for the preservation of the species, and at the best handicap the course of life for the young colonies. But Nature, as we have seen on various occasions, has no regard whatever for the individual and will waste billions of life germs, to achieve its only object: the preservation of the species.

But why must the Volvox die? Why was it necessary for death to come into the organic world?

We are confronted here for the first time with a new difficulty. How is it possible for the germ-cells to develop into a complete Volvox colony? Owing to which qualities are they able to reproduce not only their like, but also body-cells which are widely differentiated in structure? It is the great problem of heredity which here unrolls itself before us. That both parts of the amœba develop into organisms which are like the mother we seem to understand without any difficulty, for here no development is required, only simple growth, because progeny and progenitor are morphologically equivalent from 'birth.' But it is already different in the Infusorians. Here both descendants must by new-formation generate the organella of which they were deprived during fission. It is therefore clear that the infusorium must have inherited from the mother the faculty to develop all the individual parts of its body out of itself. But I must leave the problem of heredity for a later occasion when we come to consider the various theories of heredity.

If a colonist, a second Robinson Crusoe, should reach a strange, uninhabited land, fertile as the Garden of Eden, and find everywhere identical favourable conditions of existence he will not be long in doubt where to choose his future homestead. Wherever he happens to be he will erect his hut. As Nature 
offers to his body and mind everywhere the same wealth and beauty there is no cause for cautious hesitation and careful selection. His life in the midst of abundance might seem to us an enviable lot, and yet it will be but a poor life spent in laborious work. Being alone, all labour rests on his two shoulders, for there is no one to lend a hand to help him lift the burden. In spite of the generosity of Nature his days will be spent in labouring for the satisfaction of the simplest needs of life. He must cook and bake, he must be his own tailor and shoemaker, he must keep house, tend the field, and harvest the fruit; almost defenceless he is exposed to attacks by beasts of prey, nor will the night bring him complete rest, for there is no one who will keep watch over him while he is asleep. He will drag along a miserable existence, and in the end his mental faculties, wanting almost every stimulus, will atrophy.

But if perchance a second colonist should reach by the same island the position of his domicile is predetermined. Where else would he erect his hut but in the neighbourhood of the first? If their mutual condition be still far from being splendid they are now able to make more of their lives than if each were dependent only upon himself. They can exchange their ideas and take counsel with each other and, above all, they will proceed to a division of labour. The burden which was far too heavy for one is easily carried by two pairs of shoulders. While one cultivates the garden, tends the field, and carries wood and water, the other undertakes the care of the household and prepares the food; when one rests the other keeps guard, and their united forces grant an increased security against hostile attacks. The more persons immigrate as time goes on, the more favourable the conditions of existence become for all; for in proportion as the division of labour becomes more complete, more time and leisure is gained by each individual for play, pleasure, and the culture of the mind and body. But not only is the burden of labour decreased: the output of labour is increased. Who must do something in all branches of work will never do something really great in any. The waste of energy resulting from the splitting of his force, from which the first colonist suffered severely, does no longer exist with the citizens of this colony. The agriculturist is only an agriculturist and need not trouble 
about anything else; the shoemaker makes only foot-wear, the tailor only clothes, and in return their other needs of life are satisfied by the community. But such union and civilization holds many perils. Whilst the individual does splendid work in his own narrow sphere, he becomes far too highly specialized. Left to himself he would be unable to exist; in a certain sense he ceases, and must cease, to be an individual and becomes a part of the state.

The development of the higher organisms from the protozoa is an exact parallel to this example. The individual cell, however highly it may be organized, will always remain on a very low stage. Its forces are split in the satisfaction of all the many necessities of life, for it must be intestine, lung, kidney, muscles, and sexual organ, all at the same time, and therefore remain amateurish in all its performances. But by way of compensation it is free, dependent upon no one and, as it were, immortalyet it lives but a life barren of the possibilities of development to which Nature for ever tends. Several cells join together in a higher union for purposes of common labour, without as yet bringing about a real division of labour. As a result all conserve their original characteristics and faculties, no one-sided differentiation of the individual taking place. Thus we obtain an organism such as the Pandorina.

The formation of the cell-state makes it possible that not all the members need breathe and eat in order to exist. It is sufficient that some of them render this service. Thus in order to carry out these vegetal life-functions better and more intensively the affected cells devote themselves exclusively to this different activity and participate no longer in the preservation of the species. That care is now left exclusively to other citizens which are maintained and nourished by a community. The separation of the vegetal functions from reproduction, the division of the organism into body-cells and germ-cells is the first result of the division of labour. On this stage of development stands the Volvox.

But Nature knows no standstill. The Volvox stage is overtaken, the division of labour becomes more and more perfect, and the labour of the organism correspondingly increased. In a higher animal, a sponge, worm, insect, or even vertebrate, the 
body is not only divided into body-cells and germ-cells, but the body-cells again have become differentiated and changed, according to the functions which they perform, into muscle-, nerve-, blood-, intestinal, kidney-, connective tissue-. and bone-cells. Indeed, the degree of division of labour is a measure of the degree of development of an organism : the higher the organism the more completely does the individual cell give up its independence and individuality and become a serving link of the whole without any self-purposes. In many cases the cell must even die in order to fulfil its task in the organism. The epidermis cells of man, at first living cells full of plasm, become harder and harder and finally die, thus forming the cover under which the connective tissue and other delicate organs are protected against injuries and other noxious external influences. The boneforming cells become osseous, and as dead bone-corpuscles help to build up the skeleton.

Is it not now clear why the Volvox body and the body of all higher multicellular organisms must die, and why only the germ-cells are able to reproduce a species? Having through division of labour undergone a one-sided transformation, the bodycells are only able to perform certain definite functions that have been given to them. But as the parts of every engine deteriorate by wear and tear and finally disintegrate, so life uses up the body-cells, and, being deprived of the faculty to regenerate by reproduction, they are doomed to early decay. The continuity of life rests now only on the germ-cells. With the production of germ-cells the most important mission of each organism is fulfilled, for its death no longer imperils the preservation of the species, and thus we see that death and reproduction frequently synchronize. 


\section{CHAPTER IX.}

\section{REPRODUCTION AND HEREDITY.}

THE last chapter gave us an insight into the marvels of reproduction of the lowest forms of animal life. Though the conditions were simpler the questions were essentially the same that confronted us in the reproduction of the higher and highest animals. Death, which only makes a shy attempt to establish its dominion over the lowest forms, now never ceases to hold its victim in a firm grasp. Individuals come and go; only the germ-cells guarantee the continuity of life and make the characters of the parents reappear in their descendants. If sexual union played a comparatively inferior rôle in the unicellular organisms it now rules the entire life. Love now becomes an omnipotent factor which brings together the two sexes with elemental force. In addition we observe a new factor : the care of the parent for the offspring. There are, of course, many multicellular animals which, having deposited the ova, do not take any further interest in them, but the higher we ascend in the animal world, the greater the solicitude demanded by the young brood, the longer are the parents compelled to look after the young, jointly or separately, until they have at last acquired the necessary strength and skill to join in the struggle for existence. In many of the higher animals and man, this union of parent and offspring may even become so complete that it will end only with the death of the progenitor.

The jump from the protozoa to the higher animals is not so great as would at a first glance appear, for the two great kingdoms are connected by gradual transitions: organisms of more than one cell. Further, the lowest multicellular animals as yet occupy in their whole organization a very low stage, enormous though the progress they represent, compared with the organisms 
consisting of one and more cells. Of a division of their bodies into sharply-defined sections-head, thorax, abdomen, and extremities-so characteristic of insects and vertebrates, there is as yet no vestige. The single body-parts are similar to each other, the whole being not so much sub-ordinate as co-ordinate. In addition, the differentiation and specialization of the individual cells has not made much progress: they have rather retained their embryonic character. Thus it is that injuries or mutilations are easily sustained by these animals, while more highly differentiated forms would perish from them. A Gothic dome, a Doric temple, partially destroyed, is a useless ruin, no longer capable of serving its purpose; but a simple beam we may, without disadvantage, cut up into several parts, and each section, though smaller than the whole, will still retain the qualities of the beam. The same holds true in the case of the higher, differentiated animals, as compared with the lower, more homogeneous forms. A vertebrate or an insect that has been cut into two parts is no longer able to live. Both halves are too closely correlated: the life-functions of one half are conditioned and supplemented by those of the other, and they can only fulfil their numerous tasks when joined in a close union, but are doomed to perish when separated. But an animal whose body has not yet reached such a high state of differentiation and whose structure is as yet more uniform retains its power to live even after mutilation, and is even able quickly to replace the lost parts by regeneration. Hence numerous lower multicellular species still retain the asexual form of reproduction by fission or budding, in addition to reproduction by germ-cells, while representatives of the highest classes of the animal kingdom are exclusively dependent upon sexual preservation of their species.

Fission, as well as bud-formation, is closely. associated with the power of regeneration, for in order to retain life the animals that have been cut into parts must of course be able to replace the lost parts. For this reason it is clear that this faculty is far greater in the lower organisms.

The celebrated experiments made in 1740 by Trembley with the green freshwater polyp Hydra viridis proved that even the smallest particle of the body of the polyp is able to develop into a complete organism. Jäger was further able to observe in Hydra 
grisea that all body-cells became completely severed, lived independently for several months, and crawled about like amœbæ. Jäger suspected that the individual cells hibernate in this state and develop into complete polypes in the following spring.

In the other relatives of Hydra, the sea-anemones and corals, this regenerative faculty is still equally well developed. In numerous species of higher multicellular organisms, most of the worms, echinoderms and tunicates, the power of regeneration is frequently very strong. One may often observe, for instance, how an earth-worm, attacked by a myriapod, separates in the middle, thus saving its life by sacrificing part of its body. The anterior end is in that case able to reproduce a new posterior end, while the latter can reproduce a new anterior part.

The enormous tenacity of many Turbellarians is astounding. For example, we may cut up a Planarian into longitudinal and transverse sections and yet see how each part once more develops under favourable conditions into a complete organism. In this almost indestructible creature one may easily reproduce the strangest malformations, for the slightest injuries are sufficient to stimulate the body-cells into regeneration. If, for instance, we make several incisions into the body of a Planarian new anterior or posterior parts will be formed in these spots, according to the direction of the incision.

We heard on a previous occasion that the starfishes are able, by constriction, to shed their arms, and that each arm is able to re-grow a complete star. The sea-cucumbers are able at touch, or after prolonged captivity, to eject, by means of powerful contraction of all the muscles of the body, their intestines through mouth and anus, without suffering any vital injuries from this horrible mutilation. In the molluses and arthropods the regenerative faculty has considerably decreased, being restricted to the re-growing of tentacles and syphons, or to the supplementing of lost legs, antennæ, or claws. In a few rare cases more important organs may be repaired : for instance, eyes in crabs. I must not omit here to point out a remarkable experiment made by Herbst. If he removed the eye of one of the higher crustaceans, together with the eye ganglion, an antenna was developed in place of an eye; if, however, only an eye was removed and the nerve-centre left intact regeneration of an eye took place with perfect regularity. 
Among the vertebrates the tailed amphibians possess the most highly developed regenerative power. Axolotls and Tritons are not only able to regenerate their tails but also their legs. That lizards are able to regenerate a new tail we have already heard, but they are not able to regenerate the legs. Among fishes, birds, and mammals it is no longer possible to speak of regeneration, for with them re-growth is restricted to restoring the skin and healing slight wounds. We perceive, therefore, that the faculty of regeneration decreases in proportion as the differentiation of the animal body increases. 'The fact that embryos, including those of the highest vertebrates possess, generally speaking, a considerable regenerating power well accords, therefore, with our hypothesis concerning the causes of regeneration.

We have so far seen that regeneration of different body-parts appears usually as the result of pathological changes. But it may also be observed in the normal course of life of numerous species of animals, when it is closely associated, as I have already mentioned, with asexual reproduction. As among the protozoans individuals sometimes ' grow beyond their individual measure,' and then divide into two or more individuals, a similar process may be observed in the higher organisms. But as the sections are naturally deficient in certain parts and organs, these must be supplemented either before or after constriction. The more frequent and more practical course, however, is when divisionas in Infusorians-is preceded by regeneration, and the most important organs are at a certain time 'laid down' in several sets. Only when that has been done separation takes place. The young in that case are like their mother in every detail, excepting alone in size.

This method of reproduction may be very distinctly observed in a little Turbellarian, the Microstoma. When it has reached a certain size a little circular sulcus becomes visible in the centre of its body. Below this dividing line there appear a new mouth-aperture, primary optic spots, and other important organs of the region of the head. The animal is now ready to divide into two individuals. In Microstoma the asexual reproduction frequently proceeds so rapidly that new dividing lines may be observed in both halves long before the constriction has become complete, and this generation of grandchildren sometimes bears 
the rudiments (Anlagen) of the organs of the great-grandchildren.

This division with preceding re-growth of the organs occurs, in addition to the Turbellarians, among quite a large number of the individuals of other classes ; for instance, various tunicates, numerous jelly-fishes and sponges reproduce in a similar manner, when fission may take place either transversely or longitudinally. But as in these organisms division is frequently incomplete the result is the formation of larger and smaller stocks. Sponges, in particular, are as a rule composed of a large number of individuals whose relations are very frequently so close that they appear to us as one individual. A division followed by regeneration is also observed in several worms and also many starfishes.

Very remarkable are those cases in which the young do not await their full development, but proceed to sexual reproduction even at an early embryonic stage. Kleinberg states that the embryos of Lumbricus trapezoides, a relative of our earthworm, divide shortly after the gastrula stage. In this manner two individuals regularly originate from each ovum. In exceptional cases a longitudinal division will take place in embryos of vertebrates. This usually gives rise to strange duplicate malformations, but leads sometimes to the formation of normal, healthy twins.

These conditions are most striking in the case of Encystus, one of the Ichneumonidæ. This little robber searches usually for butterfly-eggs into which it lays one egg by means of its ovipositor. Before this proceeds to develop it first divides into a considerable number of cells from each of which, if conditions be favourable, there arises a larva and later a young ichneumonid.

While during reproduction by fission the mother-individual is completely divided into the two young, and therefore ceases to exist as an independent individual, it continues in the budding process to exist as an independent individual even after the separation of the bud. Generally speaking, fission generates equivalent products, budding non-equivalent products. But this inust not be taken too literally, for as Nature is always an enemy of sharp contrasts so a gradual transition exists between these two forms of asexual reproduction, and in numerous cases it is left to our choice to describe the process either as budding or as fission. 
In sponges and jelly-fishes bud-formation can proceed from any part of the body, but the higher animal-forms which are still able to produce by budding, above all numerous tunicates and the moss-animalcules, possess a special generative gland, the Stolo prolifer, from which the formation of the young proceeds.

A beautiful illustration of

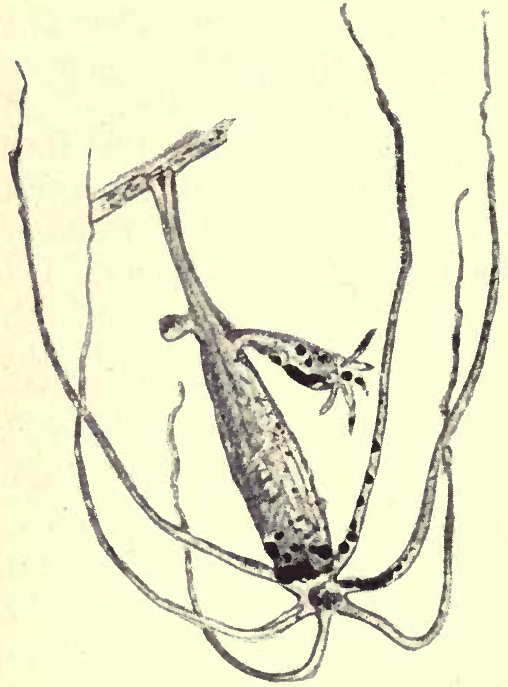

FIG. 60.-GREEN FRESH-WATER POLYP (Hydra viridis). the first method of budding is offered by the green fresh-water polyp, Hydra viridis. The structure of this delicate animal is still exceedingly simple and corresponds in its essentials to the organization of a gastrula. The mouth aperture, situated at the distal extremity of the body, and surrounded by filiform tentacles, leads directly into the body-cavity, which is covered on all sides by a double celllayer, endoderm and ectoderm. Here the mouth has still a double task to fulfil : to take in the food-particles and to eject the digested food. It serves, therefore, at the same time as mouth and anus. The proximal end of the Hydra is closed by an adhesive disc, whereby the animal is commonly attached to some water-weed.

If the polyps are kept in an aquarium and are liberally supplied with their favourite food, minute crustaceans, which they seize skilfully with their tentacles, one is soon able to observe remarkable changes in most of the individuals. While the body was at first slender and uniform, small prominences now appear on the body-wall, increasing rapidly in size. The microscope shows that both endoderm and ectoderm jointly participate in this new formation and that the maternal bodycavity is continued into the bud. Gradually these prominences assume the form of a polyp, with mouth and tentacles being formed at its distal extremity. The hydra has become a polyp- 
stock which, however, mostly consists of only two or three individuals. Only very rarely have I succeeded in breeding large stocks of four and sometimes five individuals. This state, however, does not last long, for the buds soon. separate from the maternal body and commence an independent existence.

Numerous species of marine jelly fishes form, by gemmation, enormous animal states which frequently consist of hundreds of thousands of individuals remaining permanently united. But as stocks of such immense size and with such enormous power of reproduction could not exist long without the necessary mechanical support, these animalcules jointly construct a firm skeleton of carbonate of lime, or, in some species, of a hornlike substance.

The most magnificent instance of such animal colonies is doubtless that of the corals whose restless labour makes new islands and reefs rise from the ocean-bed and played a most important part in the early life of the earth.

It seems that asexual reproduction cannot proceed uninterruptedly in any of the higher species, for after a series of generations it is always once more replaced by sexual reproduction. We are probably right in assuming that the faculty of gemmation and fission was only a very late acquisition of the higher multicellular animals, and that it is an adaptation to the special conditions of their life. The original method however is reproduction by germ-cells. In the metazoans, therefore, conditions would on this assumption be opposite to those in the protozoans, in whom we saw asexual reproduction to be the original method, while sexual union was doubtless only evolved at a much later period of their phylogeny. That with an assumption of this kind we are only dealing with probabilities and guesses and that we are completely deserted by experience needs no particular mention.

The inclination to asexual reproduction is usually increased by favourable conditions of life and abundant food; want of food, on the other side, and other influences which threaten their existence induce organisms to proceed to sexual reproduction. It is only necessary to restrict the amount of food of the Hydra in order to observe soon afterwards the formation of sexproducts.

Whether exclusive asexual reproduction is not possible in 
higher multicellular organisms, but must in a short time lead to degeneration; on that point opinions are greatly divided. But if we consider that the pyramid-poplar and numerous other ancient domesticated plants, such as the vine, fig-tree, date-palm, bananatree and many other useful plants, have propagated their species since times immemorial by an exclusively asexual method, (i.e., by layers), without having suffered the least decrease in strength or the quality of their fruits, it would seem that a natural limit does not exist and that the asexual propagation can in many cases replace sexual reproduction. But the pyramid-poplar is frequently mentioned as a case against this hypothesis, because it has lately everywhere commenced to sicken and die out. The cause of this phenomenon is, however, probably not so much to be found in their mode of reproduction as in an undue increase in parasites and other unfavourable external conditions, against which the seed would be equally defenceless.

As a kind of inner gemmation we may describe a method of reproduction which has hitherto been observed with certainty only in fresh-water sponges. At the beginning of the inclement season there are formed in the interior of the sponge-body globular accumulations of cells which all originate from the central germinal layer. The external cells form themselves into a mantle consisting of one cell-layer, and secrete a solid cover which is supported by numerous silica-needles, the amphidiscs. When severe frost sets in the sponge-body perishes, but these gemmulæ are, thanks to their power of resistance, able to live through the winter. They sink to the bottom of the water and remain there apparently lifeless, but when spring returns the encysted spongeparticles leave their protecting membrane, commence to grow, and proceed to reproduction.

In the moss animalcules found in fresh water we observe similar multicellular interior buds, called statoblasts, which after a long period of rest may develop into a new colony of Bryozoa. The principal task of these buds is to help the animalcules through the perilous times of drought and frost, and later, when the warmer weather has returned, to bring about rapid multiplication of the species. In order to be able to discharge these functions the statoblasts are enclosed in a hard chitinous shell which effectually protects the young germ against all the dangers 
1

/ 


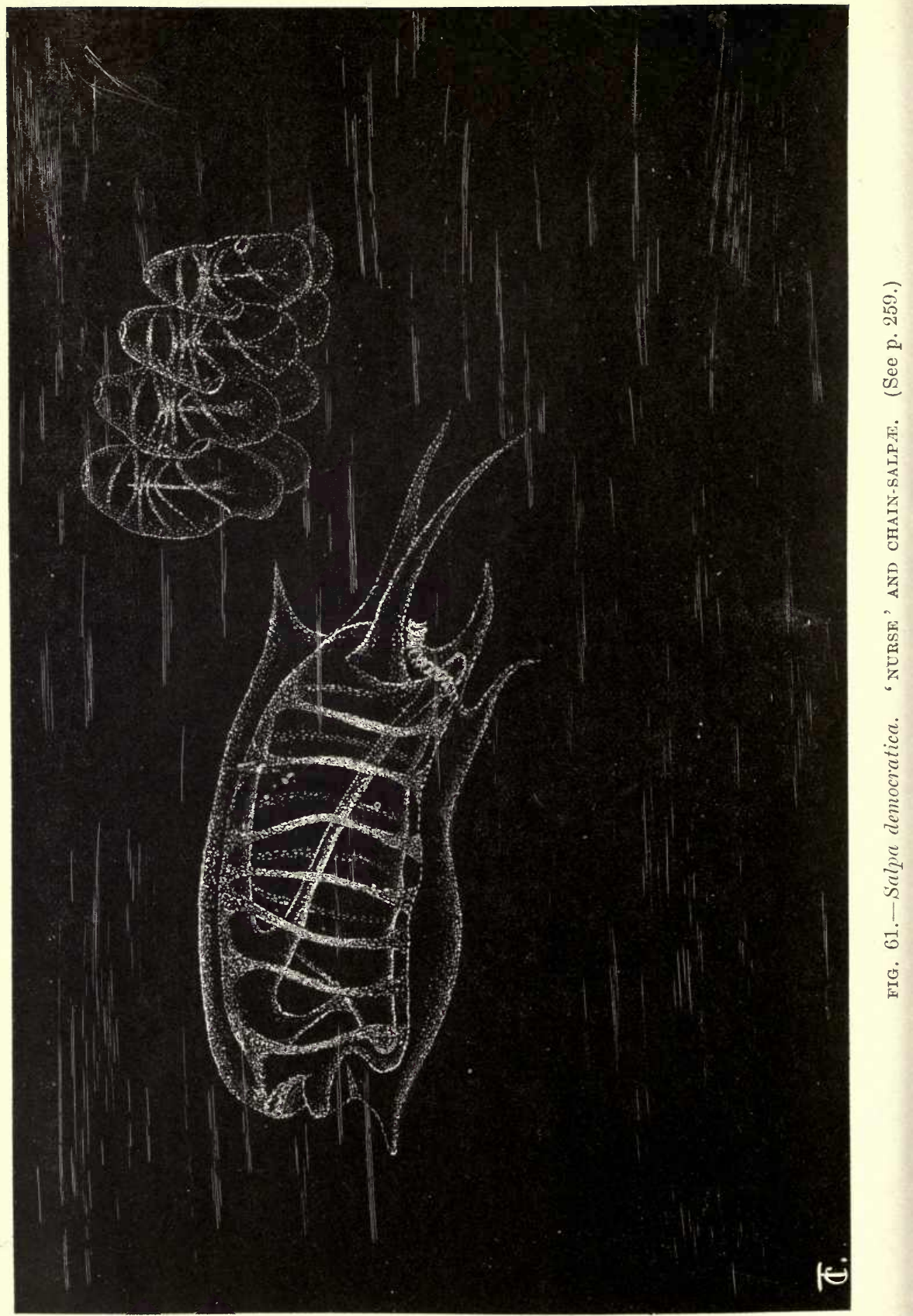


of life. In the flattened margin of the shell are numerous small cavities which during the dry period are filled with air and act like swim-bladders, keeping the buds suspended on the surface, when they once more reach the water. Winds and currents then drive the statoblasts over vast stretches of water and finally each produces a young Bryozoon.

One may frequently see that asexual reproduction regularly alternates with sexual, so that one asexual generation, or a limited number of asexual generations, is always succeeded by a sexual generation. In that case we speak of an alternation of generations. As long ago as 1815 this phenomenon was discovered in one of the locomotor tunicates, the Salpa, by the poetnaturalist Chamisso. Fig. 61 shows in the foreground a large specimen of the asexual generation of Salpa democratica, the 'nurse,' which always leads a hermit life. At the posterior end we see the Stolo prolifer from which sprout successively several colonies of Salpæ. As soon as these buds have reached a certain size they separate from the body of the 'nurse' and float about, joined together in long chains. These chain-Salpæ are sex-animalcules which possess sexual organs, but no stolon. Soon after its separation from the stolon each individual of this chain produces an ovum, and afterwards male spermotozoa. They are therefore hermaphrodites. Fertilization and embryonic development take place in the interior of the maternal body, and from each ovum there develops finally a solitary Salpa, the 'nurse,' which once more proceeds to the formation of chain-Salpæ. This completes the cycle of development. As the body of most Salpæ possesses a high degree of phosphorescence, it is a wonderful sight to see, from a seat in a boat, these long glowing chains move like fiery serpents below the surface of the water.

The alternation of generations is most interesting in numerous members of the jelly-fishes. Here it is frequently connected with a strict division of labour and a resulting great diversity of forms. While the fresh-water polyp Hydra is a sexual animalcule and an asexual generation in one individual, numbers of its near and distant relatives have abandoned the faculty of producing reproductive cells, and proceed to the formation of special sexual individuals, the Medusæ.

During prolonged north winds the ports of the Baltic Sea 
are often littered with the brilliant blue-tinted jelly-fish, Aurelia aurita. From the ovum of these animals originates a little ciliated free-swimming larva, the Planula. After a short life of freedom it attaches itself to the sea-floor and changes into a polyp, the sixteen-armed Scyphostoma. On the body of this polyp soon appear numerous circular grooves which gradually increase in depth, resembling a pile of tea-cups. This is the beginning of

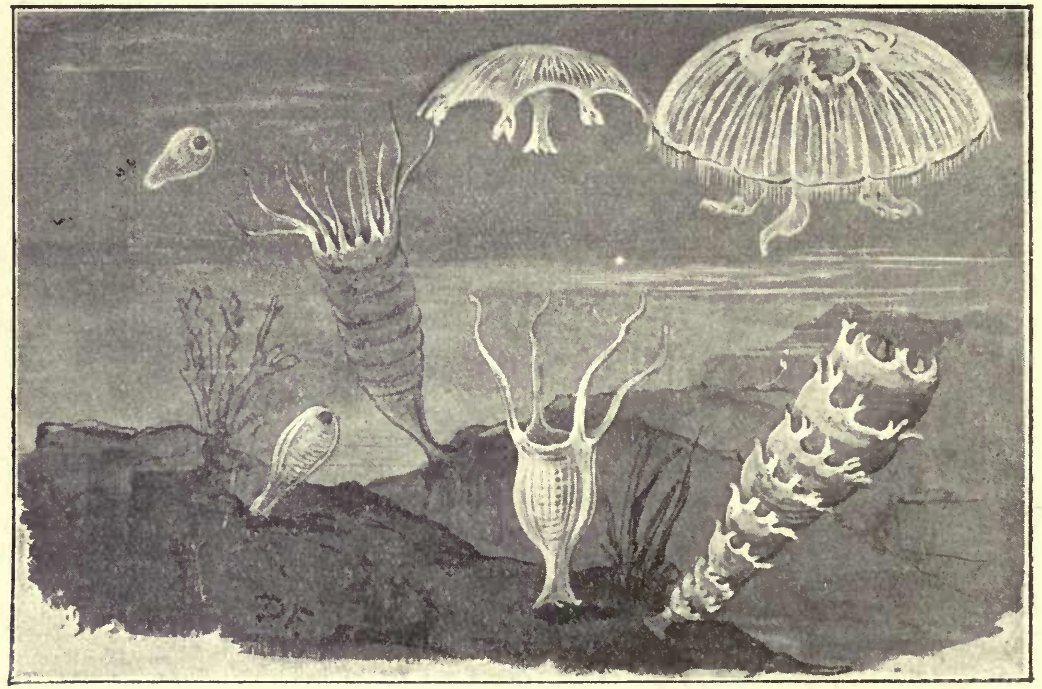

Fig. 62.-DEVELOPMENT of Aurelia aurita.

On the left, above, the free-swimming larva form a Planula; below, on the the rock, a Planula about to become a Scyphostoma. Three other fixed forms show the process of strobilation and the formation of the Ephyra-form; on the left, swimming, an Ephyra soon after separation from the Strobila; on the right, an adult Aurelia aurita.

sexual reproduction by means of terminal gemmation. The Scyphostoma has thereby become a Strobila. Now the polyptentacle in the most extreme bud begins to degenerate, and the bud separates. The others quickly follow, and in a short time numerous so called Ephyræ are swimming about. But there is still a long road to travel. Only a slow and complicated metamorphosis, during which the larvæ must pass many different 
stages, transforms the Ephyra into the sexually mature Aurelia. (See fig. 62.)

Apart from terminal gemmation, the scyphostomæ are able like Hydra, to reproduce by lateral sprouting, but in that case only polyps are produced. In many Medusæ, as for instance the brilliant Pelagia noctiluca, the original asexual polyp generation is often entirely suppressed. In this case the ova produce at once Ephyræ which change into Medusæ.

Somewhat different is the cycle of development in the marine types of polyps, the Hydrozoa. These animalcules usually form small, but sometimes very extensive stocks which adhere to the stones and shells by means of many-branched roots, the Hydrorhiza. From this root rises the Hydrocaulus, the stem which carries at the end of its branches the different citizens of its colony, polyps and medusæ. Hydrorhiza, as well as Hydrocaulus, possess essentially the same structure as the polyps: they consist of ectoderm and endoderm and an interposed supporting lamella. As, the stomach of the individuals is continued directly into the stem and roots, all the food which is captured by any one individual is distributed among the entire community. The union of this little colony is so intimate that it has almost become one individual of a higher order, and the single individuals have sunk to the level of organs. In a still more distinct form this is the case in the magnificent Siphonophora, which are nothing but free-swimming polyp-stocks. Very few people would believe, having fished one of these delicate structures from the sea, that they hold in their hand not one organism, but a complete animalstate. (See fig. 46.)

These hydroid-stocks derive the requisite support from a horn-like cover, a secretion of the outer cell-layer, which surrounds the entire stock. In some species this armour ends at the base of the polyps, but in others it widens here into a bell of considerable size, into which the polyp withdraws, like a snail into its shell, at the least sign of danger.

As long as the little animal-stock is growing, new buds continue to sprout laterally from stem and branches, and develop either into sexual polyps or into medusæ. The polyps remain throughout their lives fixed to the stem, but the adult medusæ separate from the stem to carry their sex-products through the 
ocean and develop new colonies far away from home. They serve, therefore, prominently as a means of distributing the species and opening up new regions for the Hydrazoa to colonize. The great importance of this fact to the preservation of the species, the advantage which they possess as a result of this arrangement in the struggle for existence over other fixed organisms which have no free-living sex-animals or similar arrangements for the distribution of their germ-cells and are therefore restricted to their narrowly defined domicile, is obvious. We are probably right in assuming that the medusæ owe their origin to this very need. Phylogenetically the polyps represent, therefore, the older and lower stage of development from which the free-moving sexual form was gradually evolved. For however much the medusa may differ in its appearance from the polyp, accurate comparison shows that it is nothing else but a more highly differentiated polyp which has become adapted to a free mode of life.

It must strike us as very remarkable that some species of Hydrozoa have again abandoned this advantage. It is true that the Plumularide and Sertularid\& still produce a medusa-generation, but the sex-animals are incomplete and no longer adapted to a free-swimming life. Like the polyps, they are fixed to the stem. The sex-animals have thus become sex-organs.

The degree of degeneration can vary greatly. In some species only the mouth-aperture, tentacles, and the strong muscular velum is lost, but the protective bell with its most important organs and the mouth-stalk remain. In others the form of the sex-organs hardly permits us even to suspect that they have originated from medusæ, and that once they were independent animals. Only the degenerate stomach and the sexual organs have remained, being surrounded by the sparse remainders of the bell as by a thin mantle.

It is necessary to mention here the alternation of generations in some of the tapeworms. While the larvæ of most tapeworms produce only one sex-animal, in the cysticerci of Trenia coenurus, the cause of the deadly "gid" of sheep, and of T.echinococcus, one of the smallest, but probably also one of the most dangerous tapeworms, there are produced by inner budding several, sometimes numerous, tapeworm-heads from which 
afterwards the proglottides begin to sprout as soon as the heads have reached a suitable animal-host. The fertility particular of $T$. echinococcus is enormous. The sex-form, the 'worm' proper, lives in the intestines of the domestic dog. Its length rarely exceeds $\frac{1}{2}$ centimetre, but it is all the more dangerous for being so easily overlooked. If many lovers of dogs knew to what dangers they expose themselves and their family by petting their dogs or even kissing them they would exercise greater caution, for if mature proglottides or ova of Echinococcus reach the intestinal canal of man they rapidly develop into embryos which penetrate the tissues and settle in the brain, lung, or other organs. What terrible pains they are able to cause will be understood when we hear that these cysticerci often reach the size of a human head and a weight of $20 \mathrm{lbs}$. On the large original cysticercus-bladder are produced by invagination many thousands of smaller bladders, and from each of these vesicles originate the minute cysts in which the tapeworm-heads are 'rudimentary.' We observe, therefore, a regular alternation between a sexual generation, the tapeworm, and an asexual, the cysticercus, which reproduces by budding. In this case it was probably the extremely favourable conditions of nutrition which gradually induced the larvæ to proceed to asexual reproduction.

Those who have kept a fresh-water-aquarium are well acquainted with the agile water-flea, Daphnia. In fine weather our ditches, ponds, and lakes are often so peopled with them that it is only necessary to draw a fine net through the water to capture numberless thousands. Many observers will have noticed that all water-fleas which are caught in the sea during summer are females. No matter how much we may search, it seems impossible to discover a male. Nevertheless, the animals are not doomed to sterility, for they are able to produce numerous young and these can proceed to reproduction in their turn, but still no male water-fleas are to be found. To take these tiny crustaceans for hermaphrodites able to produce male spermatozoa in addition to ova would be wrong, for they are typical females.

After reproduction has in this manner proceeded through numerous generations until the approach of the autumn, all at once male individuals appear, easily noticeable to the trained eye by their smaller size. The females again produce ova, and 
finally a union and fertilization of the sexes takes place. But while formerly the egg-cells passed their embryonic development in the roomy brood-chamber of the mother, situated between the chitinous armour and the dorsal surface of the body, and come into life as developed crustaceans, the fertilized ova enter the brood-chamber only for the purpose of being furnished with a solid chitin-shell, the ephippium. After that they are left to their fate: the death of the mother, which soon after intervenes, would in most cases render further care impossible.

What is the meaning of this maleless reproduction which, apart from the daphnids, we find in numerous other animals? How is it possible for eggs to develop without fertilization? The answer to the latter question must be postponed till later, but I will here recall what we have already heard on a previous occasion. No matter how well the germ-cells may be adapted for fertilization, it happens not infrequently that ova, and in one case even male sex-cells, proceed to parthenogenetic development. The value of parthenogenesis lies principally in the fact that it increases the fertility of the species and produces in a short time an enormous number of individuals. We meet, therefore, with it chiefly in animals whose conditions of life are favourable only for a brief time, and which are afterwards threatened with destruction from numerous causes. However important fertilization and the resulting mixing of qualities may be for the development and adaptation of organisms, parthenogenesis undoubtedly confers in such cases a greater advantage. It becomes, however, never so much the exclusive method of reproduction that sexual union is entirely suppressed.

A simple calculation will show the degree to which parthenogenesis is able to increase reproduction. In the first generation, when all ova develop into female individuals, the number of descendants is doubled, but with each further generation of females the number increases rapidly, because the number of the ova increases in geometrical progression. We need only think of our illustration of the chess-board to understand the extent of this extraordinary multiplication.

The strict dependence of their reproduction upon external conditions of life in the water-fleas has been proved by most careful experiments made by Weismann, and recently by Issakowitsch. 
It is clear from what I have already said that the parthenogenetic 'summer eggs' serve chiefly the purpose of rapid increase and distribution, but the fertilized 'winter eggs,' able to resist equally well drought and frost and to develop even after a rest period extending over years, serve to preserve the species in times of necessity. It appears that in the daphnids the number of the successive asexual generations is the lower the more frequently the colony of the species concerned is visited by periods of destruction. Thus the species which are threatened by severe frost only once in a year have the largest number of successive parthenogenetic generations. These are, of course, above all those daphnids which live in the large waters. On the other hand, those species of water-fleas which have their domicile in shallow, easily drying pools or ditches, have only very few, and sometimes only one, generation of parthenogenesis which is immediately followed by the appearance of males and, resulting from that, asexual generation.

According to the most recent investigation by Issakowitsch, the causes that govern the question of sex lie exclusively in the external conditions, i.e., in the changes of temperature and the conditions of nutrition. In order to decide the question, this investigator chose the method of experiment which naturally offers the greatest prospect of success if a question is rationally put. He started several cultures, one at a temperature of $+24^{\circ} \mathrm{C}$., one at room temperature, i.e., $+16^{\circ} \mathrm{C}$., and one at $+8^{\circ} \mathrm{C}$. The result of these experiments was that with decreasing warmth the tendency towards the formation of sex-animals increased, while with an increasing temperature the ova developed into an asexual generation of females.

In accordance with these results were the experiments made by Issakowitsch with a view to determining the influences of nutrition. Here, too, it was found that hunger-cultures produced only sex-animals, quite independent of the number of the asexual generations that had preceded them. Issakowitsch sums up the results of his investigations in these words: "When the nutrition of the maternal organism has become so low that it is no longer able to provide the ovum with the food sufficient for its development into a female, a less exacting male develops. 
If the nutrition becomes still lower so that it is not even able to develop from the egg a male individual a large number of primary egg-cells join together in order to form at the expense of the whole mass one fertilizable winter egg." This explains why at the beginning of the inclement weather, or before the drying up of the home-water, suddenly the male daphnids appear and ' winter eggs' are formed.

This result becomes still more clear.when we observe the process of egg-forming in the water-fleas. Let us choose for this purpose a well-known daphnid, Sida crystallina. The ovary of this animal has the form of a long tube closed at one end. At the blind end lies the germ-layer in which the young eggcells are formed, always four at a time, which are at first equivalent, stored one behind the other, and filling the entire lumen of the egg-tube.

But the fate of these four young egg-cells is very different: only one of them, no doubt the strongest, develops into a normal ovum, while the other three are used as food. As new groups of similar cells continue to proceed from the germinal layer, there is a succession in the ovary at regular intervals of one egg-cell with three food-cells. Afterwards egg-cells and foodcells surround themselves with a yolk-membrane. With that the 'summer egg' is ready and may be voided into the broodcavity. In the 'winter eggs,' which are very rich in yolk, the ovum is not satisfied with the ordinary food material, and thus we observe that as many as twelve groups, that is, forty-eight cèlls, are used for its construction.

But the daphnids possess yet another arrangement for the nutrition of their 'summer eggs.' The epithelial cover of the ovary-tube consists in the adult female Daphnia, whose ovary is filled with germ-cells, of cells so flat that they have been overlooked by investigators until quite recent days. But in the new-born females these epithelial cells are expanded so much that they fill almost the entire lumen of the tube, and make the whole ovary look like a solid chain of bladder-cells. If now the young cells begin to advance from the germinal layer they impress themselves deeply into these epithelial vesicles which under the influence of pressure give the fluid which they contain to the egg-cell and thereby resume their 
insignificant normal size. There is no doubt that we observe here a process of nutrition in which the epithelial cells only act, as it were, as intermediaries which receive food-naterial from the maternal body, store it within themselves, and transmit it, as required, to the advancing egg-cells for their support during development. When the mature eggs have left the ovary the epithelial cells once more suck themselves full with the nutrient fluid, fill once more the whole lumen, and once more give up their contents to the next advancing group of eggs. It is significant that this feeding process is only observed during the production of the 'summer eggs,' but is entirely at rest when the 'winter eggs' are formed. This makes it also clear why 'winter eggs' require such a large number of egg-groups for their development, and why their formation is only undertaken in case of necessity.

Such succession of sexual and parthenogenetic generations is described as heterogony, to distinguish it from the typical alternation of generation, the metagenesis. In numerous cases heterogony is connected with a very prominent polymorphism; indeed, the members of the various generations are often so divergently constructed that only after closely observing their cycle of development it becomes possible to recognize them as belonging to one species.

Everyone has seen on oak-leaves the pretty red-cheeked gallapples, but less known are the little gall-flies whose sting produces these growths. These gall-flies form a very numerous family (Cynipida), those that live on the oak numbering alone about a hundred species, each of which produces a different gall. From the root to the fruit there is hardly a part which is not exposed to the stings of the flies and cannot be compelled to form such diseased growths. Though the gall-flies have a special predilection for oaks, they do not on that ground despise other plants, but attack the maple, fig-tree, wild rose, blackberry, and many herbs. The bedeguar of wild roses, which is caused by the sting of Rhodites rosce, and often assumes the size of a fist, is known everywhere. But above all the Aleppo-galls of the gall-flies of Asia Minor have attained a certain celebrity, because they were formerly much employed in the preparation of very good ink. If we cut an oak-apple with a knife 
the blade becomes black, for chemical union has taken place between the iron and the tannic acid of the gall, the result being ferrous gallate or, in other words, ink. Apart from gall-flies, several beetles, leaf-wasps, plant-lice, and gall-midges also produce galls.

Galls are nothing else but the brood-chambers in which the ova pass their development. Thus "two birds are killed with one stone': the growing larvæ enjoy a perfect protection against most animals, and have at the same time in the juices of their host-plant a rich source of food. Sometimes each gall contains only one larva, sometimes several.

One of the most interesting kinds is the little oak gall-fly, Biorhiza renalis, whose strange life-cycle was first discovered by Adler. Before the beginning of spring, the first generation of small wingless creatures leave their brood-chambers. They differ so much in appearance from the gall-flies that it is hard to believe they belong to the species. All individuals are females. As soon as they enter the outer world they set about their most important and indeed only task, egg-laying. The oak-trees, like all nature, are still in their winter sleep; young and tender leaves are, therefore, not available for the brood of these wasps, and they must undertake the laborious task of sinking their eggs into the firmly closed winter buds. For this purpose the females are splendidly equipped, their strong, dagger-like ovipositor appearing expressly created for perforating the firm cover-leaves. Nevertheless it requires many hours before the wasp has penetrated to the interior of the bud, bored numerous fine tubes and deposited into each one egg. In the course of the spring these buds develop into large galls containing numerous larvæ. In July the second generation emerges, this time males and females, typical gall-flies, distinguished, apart from their wings, by their larger size, longer legs, and different formation of their ovipositor. After fertilization the females lay their eggs singly into the parenchyma of the under-side of the young oak-leaves, and around each leaf is formed a small, longish gall from which the parthenogenetic generation of females is hatched before the coming of the next spring.

How ingeniously has Nature cared here again for the preservation of the species? In the inclement season a maleless 
generation has more hope of surviving, and the task of egg-laying can be much more rapidly discharged when there is no need for the two sexes to seek each other. But rapidity is in this case an inestimable advantage, as only a few bright days are available, and the coming of the frost soon terminates their life.

Plant-lice, too, have two generations. In spring and summer we find parthenogenetic females, usually furnished with two pairs of wings. They are viviparous, and their young again develop into females.' This is repeated for several generations, until finally in autumn the winged males and the wingless generations of fertilizable females appear; these lay eggs which hibernate and produce in the next year a viviparous generation of females.

Still more complicated is the reproductive process in the notorious Phylloxera vastatrix, the destroyer of vineyards. Its economic importance alone justifies its mention.

Until the beginning of the 'sixties Phylloxera. was unknown in Europe. It was imported from America and became only too quickly acclimatized. The devastations caused by these tiny animals are enormous. In the course of eight years they destroyed in France alone 75,000 hectares of vineyards and caused a loss to the country of about $£ 300,000,000$, costing France more than the unfortunate war of 1871. In Germany, too, the damage done by Phylloxera in the districts of the Rhine and other vineyards is very considerable. For years the Government has bravely endeavoured to proceed against this pernicious pest with all the means provided by science, but has not so far succeeded in exterminating it, though it has been found possible to prevent Phylloxera from spreading further afield.

But more interesting than its economic importance is to us its mode of life. From the winter eggs that have been laid under the bark, small wingless insects emerge in spring, which ascend the stem and deposit on the leaves numerous heaps of unfertilized eggs. The eggs of this first 'nurse'-generation develop again into wingless females, and as this process is in the course of the summer repeated about seven or eight times we can imagine how enormous the multiplication of this terrible plague must be. They pierce the vines with their sharp proboscis and suck the sap. Beginning with August, there appear in addition to these females other more slender and winged females 
which fly from vine to vine, laying eggs here and there, partly large, partly small.

This generation, too, reproduces parthenogenetically, but from their eggs the sex-animals are developed, from the large eggs, the females; from the small, the males. They are most remarkable creatures, and can only be properly described as walking sex-organs. They have not only no wings, but are also without proboscis and intestinal canal. They are 'ephemeral,' unable to feed themselves, and their only object appears to be to alternate the succession of asexual generations by fertilization. Each female deposits under the bark only one egg and with that its life-task and its life is ended. These are the 'winter eggs' from which the first rays of the spring sun call forth the young parthenogenetic generation of females.

It is only in a few cases where it may be so clearly observed that fertilization and reproduction, though closely related, are yet processes of a different kind. In Phylloxera fertilization does not lead to multiplication, for as each female produces only one fertilizable egg, the appearance of a sex-generation reduces the number of individuals in fact by half. The importance of fertilization does not consist in reproduction, as was formerly believed, but in bringing about amphimixis-a mixing of the qualities. Development can, therefore, take place without previous fertilization, and, on the other hand, fertilization need not necessarily cause development or reproduction. But fertilization is of the utmost importance to organisms, as it imparts to them a far greater adaptability, and, on the other hand, suppresses, or at any rate hinders, an injurious one-sided tendency to variation. Arrangements have therefore subsequently arisen which as a rule prevent the independent development of the germ-cells. Thus the inability of sperm and ovum to proceed separately to development is an adaptation to the demands of life.

Heterogony proceeds largely in a like manner in the parasitic Trematodes of which we have heard before. As may be remembered, in the larval forms of the Liver Fluke sporocysts and rediæ produce asexually numerous larvæ which are all able to develop into sexual mature animals. This process is not to be conceived as interior gemmation, as was formerly believed, but 
the larvæ develop from unfertilized ova which originate in the interior of the sporocyst. As the ova are not generated by an adult form but by the undeveloped larval form, this process is described as pædogenesis, as distinguished from parthenogenesis.

Before we enter upon the internal phenomena of sexual reproduction, and in particular the structure and genesis of germ-cells, let us cast a brief glance at one of the most attractive and beautiful parts of zoology, the care of the parents for their offspring.

In the lowest classes of Metazoa, the sponges and jelly-fishes, a proper care of offspring does not exist. As the majority of these forms are fixed to the spot but lead in their earlier stages a free-swimming life, the parents are for this reason alone prevented from watching over the well-being of their offspring. But in sponges and most jelly-fishes the ova pass at least the first stages of their development in the maternal body, and leave it only as independent larvæ when they are nearly capable to struggle through life without assistance.

Most unfavourable among all animals is doubtless the condition of the brood of many intestinal parasites whose progenitors remain behind in the interior of their host while the descendants are ejected with the fæces as ova, and handed over defenceless to all the perils of a protracted development. Countless individuals meet with an early death, and the preservation of the species is only secured by the immense fertility of these parasites.

Many other higher animals, in particular numerous insects, are prevented by their death, which often follows upon egglaying, to watch over the fate of their young, but they endeavour to compensate them by depositing the germ-cells in safe places or surrounding them with protective covers, and at the same time providing that the young on being hatched shall find sufficient food. We saw a practical illustration of this kind in the gall-flies which deposit their eggs in the interior of plant-parts, granting at once protection and abundant food. Other insects seek out certain animals whom they compel to shelter and feed their brood. Such a case is shown in the illustration. We see here a caterpillar whose entire surface is covered with cocoons of an ichneumon-fly (fig. 63). 
The females of the Ichneumonidæ lay their eggs into the eggs, larvæ, pupæ, and adults of other insects, but by preference into caterpillars of different butterflies; from the eggs

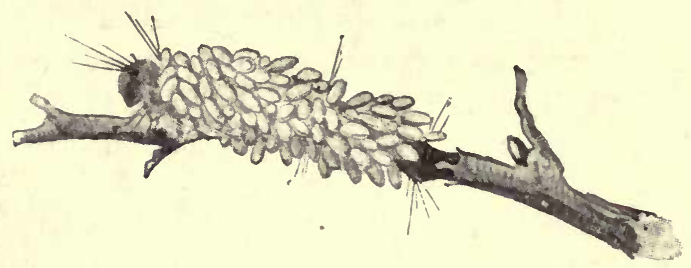

FIG. 63. - CATERPILLAR COVERED WITH COCOONS OF Microgaster glomeratus.

emerge the grublike larvæ without feet and anus, which forthwith commence to eat up their unwilling host, first devouring those parts of the body which are not of vital importance, the large accumulations of fat made by the caterpillar to serve for its own support during the long pupa rest-stage. Owing to this cunning procedure the host remains apparently quite healthy and may even proceed to the pupa stage, but then its fate is sealed, for the larvæ, having now devoured the food in the reserve store, mercilessly attack the vital organs. When all the food has been eaten up and the caterpillar is dead, the development of the parasite is usually complete. The method adopted by the ichneumon-fly in depositing her eggs shows a remarkably fine instinct, for large caterpillars receive a considerable share of eggs, while only a few are deposited into caterpillars whose small size does not guarantee a sufficiency of food. Year after year the Ichneumonidæ

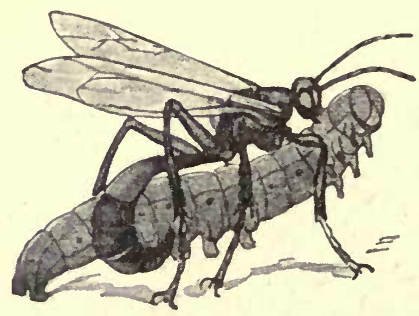

FIG. 64.-Ammophila hirsuta PARALYSING A CATERPILLAR. take immense toll in the insect world, greatly to the advantage of man, for without their help the insect plague would soon become overwhelming.

Many wasps place their broodcells in the soil or decaying wood, but before proceeding to egg-laying they fill the cavity with numerous caterpillars, insects; and spiders, which they paralyze by stinging them (fig. 64). Though alive, these unfortunate animals are unable to escape sand are later eaten up literally alive. A 
similar phenomenon is observed in the mole, in whose run, especially in winter time, large heaps of living earth-worms are found which the mole has paralyzed by a bite in the cephalic lappet. This method secures the victim as safely as if it had been killed, and has the additional advantage that the foodsupply remains always fresh.

Numerous weevils make really touching provision for their offspring. The so-called leaf-rollers cut with their proboscis deep into the leaves of the host-plant and by means of their legs skilfully roll the section up. Having bidden a few eggs in this roll, they fold the open ends down and firmly seal them with a viscid fluid secreted through the anus. Untiringly the abdomen moves up and down until the minutest hole has been closed. The inner parts of the leaf afterwards serve as food for the young larvæ (fig. 65).

Still greater precautions are taken for the safety of its offspring by the nutweevil. In default of an ovipositor it bores with its long, thin proboscis a little circular hole into the soft nutshell and pushes, also with its proboscis, into each nut one egg. By the beginning of October the larva has mostly
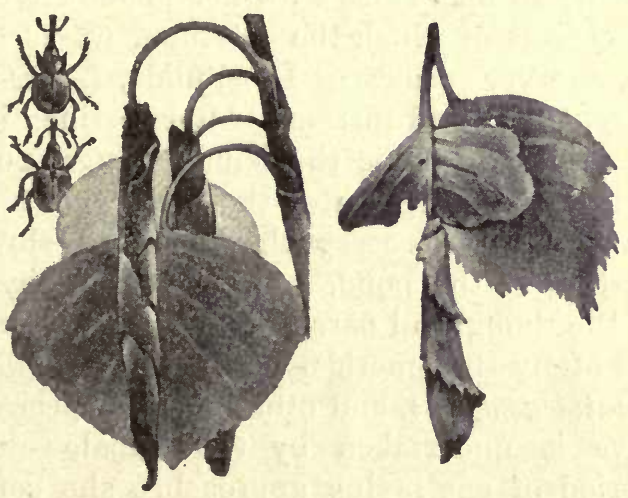

FIG. 65.-(1) Rhynchites populi, WITH LEAF-ROLL. (2) LEAF-ROLLS OF Rhynchites betula. consumed the kernel

and now cuts with its sharp mandibles a way through the nutshell, which in the meantime has become hard, in order to pass its development deep down in the earth.

Equally remarkable is the behaviour of the so-called gravediggers which are not content, like numerous other carrionbeetles, simply to deposit their eggs on the carcases, but first bury the corpse by joint labour. Most celebrated is doubtless the Sacred Pill-beetle (Sisiphus sacer), which was in ancient times 
worshipped as the emblem of a world-creating Divinity. Even to-day in many of the Southern countries a scarabæus cut in precious stone and worn on the breast is regarded as an unfailing remedy against the sterility of women. These beetles are, like their near relative the horse-dung beetle, very partial to this useful but not very appetizing material. By joint labour male and female shape the dung into large balls which they drag and roll to some hole. Here the ball is pulled to pieces and carefully cleared of all parasites; the female then lays her eggs and the ball is reformed.

In many species of the Libellulidæ both sexes participate in egg-laying and the care for the further development of the eggs. According to Tümpel, in Libellula cancellata the male seizes the fertilized female, drags her to the nearest water, and compels her, by rapidly moving his abdomen up and down towards the water, to make also with her abdomen whipping movements, as the result of which the gelatine-covered eggs fall into the water. In another species of Libellulida, Lestes sponsa, the care of the parent goes still further. After fertilization both sexes united fly to a rush; to this the female clings, pushing by means of her ovipostor one egg after the other under the surface of the stem. During this process they descend slowly downwards to the bottom of the pond, a thin layer of air, which covers the body of the thoughtful parents, protecting them against drowning.

Many Ephemeridæ proceed in a similar manner, in particular Beatis gemellus, and other related species, but here the perilous dive is undertaken by the female alone. As soon as the period of egg-laying approaches she compresses her wings and surrounded by an air-bubble as by a diving-bell, she descends to the bottom of the pond where she carefully conceals the eggs under stones. As soon as the work is done she attempts to rise once more to the surface, but only too frequently strength fails and an early death is the reward of her sacrifice and courage.

Numerous other insects, as for instance most butterflies, are content to deposit their eggs in the neighbourhood of a suitable food-supply. They are guided by an unerring instinct, so that even when during the adult stage they have passed to a widely divergent mode of life and acquired other needs they yet never make a mistake. This astonishing instinct is one of the most 
mysterious phenomena in the life of animals. To us it is simply incomprehensible why many mud-flies which themselves feed on honey but deposit their eggs in mud or even in manure-pits are able to know that the conditions of life which are necessary and pleasant for them are entirely unsuitable for their offspring (fig. 66). That the animals during the egg-laying process are reminded of their own youth we are not justified in assuming, for it would mean giving too much credit to their intelligence and to their memory. Phrases such as 'innate impulse,' ' habit bred by selection,' explain nothing and merely serve as a cloak for ignorance. But the case quoted here is only one out of innumerable instances of this mysterious phenomenon.

If there existed a degree in the incom-
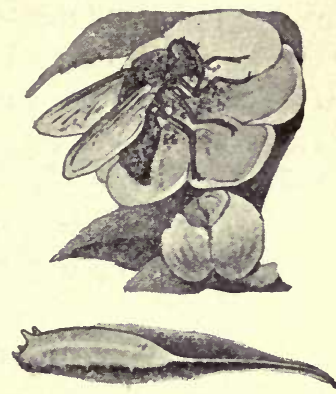

FIG. 66.-MUD-FLY (Eristalis tenax) WITH ITS LARVA WHICH LIVE IN MANURE-PITS. prehensible I might quote as still less comprehensible the fact that in preparing its cocoon a caterpillar does not make it to fit its own size and form, but to fit the form of the emerging pupa, of which it is impossible for the caterpillar to know anything from experience. Similar unsolved questions are raised by the ingenious and artistic construction of many of the nests of birds, and their migration. How do the young birds find their long way to their southern winter-quarters? Who informs them that the autumnal storms in the land of their birth announce a period of short rations and famine? Formerly it was believed that the inexperienced young simply followed the parents. That may be true for many species, but it has been demonstrated in others that the young commence their flight before the old. We must, however, not lose ourselves in such theoretical questions. All that I intended was to show how many problems are still awaiting their solution, and how unfounded is the fear that the rapid progress of science will leave to future generations nothing to investigate.

Species with a longer span of life are still better able to care for their offspring. Among the most careless parents are most of the Echinoderms which liberate their germ-cells into the sea, where afterward impregnation and development take place. 
But even among these lazy anirnals we find a great number which for a considerable time carry their brood with them. Some of the starfishes protect their growing young under their bent spines. In the Ophiuroidea the eggs pass a large part of their development in the bursa, a thin-walled air-sac; several species of starfishes form a kind of breast-pocket by bending. back their arms, and in many Holothurians the young develop either in the body-cavity or under calcareous spines which have been specially formed for that purpose on the dorsal surface.

Most highly developed among all vertebrates is the care of the offspring among the social insects, in particular, ants, bees, and termites. It is remarkable that among these animals the nursing is not done by the parents but by a specific asexual worker caste, or more accurately, a caste in which the sex-organs have become degenerate. These facts, however, are so universally known that I need not deal with them in detail. The familiar spider, which is such a notoriously bad wife that after impregnation she kills and eats the male without ceremony, exhibits a touching care for her eggs: there are, in fact, only very few classes of animals in which the care of the offspring is regarded as such an important function as among spiders. Many spiders construct for their eggs ingeniously spun bags which they attach to leaves and branches of different plants. These webs are often so constructed that they closely resemble in shape and appearance the fruit of the plants to which they have been fixed, a fact which enables them, of course, more easily to escape their natural enemies. Among other species of spiders the females are not satisfied with this passive care, but fasten the egg-sac to their abdomen and continually carry it about with them.

Crabs exhibit a similar care for their young. Most people have probably seen a female crayfish, at any rate when boiled, firmly grasping with its little abdominal feet a large number of minute round eggs.

Fishes are regarded by most men as unintelligent and stupid, but when we see the truly touching and devoted care which many species bestow upon their offspring, and if in particular we observe the common stickleback (Gasterosteus aculeatus) during spawning time, we shall not be inclined to agree with this 
opinion. In April or May the male stickleback builds out of fibres a little tube-like nest, sometimes supported by, and hidden between, the stems of water plants, but more frequently, for the sake of greater security, buried deeply in the sand at the bottom so that only one opening is visible. Marital faithfulness exists neither in male nor female; numerous females are fertilized and compelled to lay a few eggs, until at last several hundred eggs

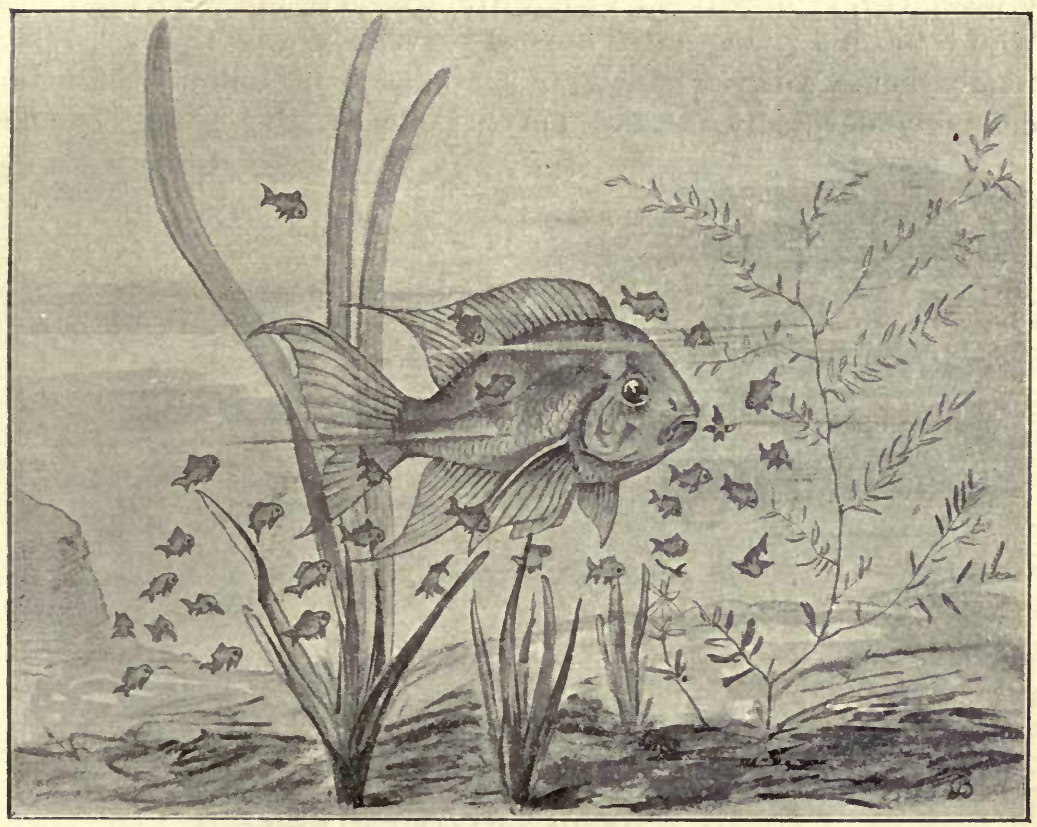

FIG. 67.-Geophagus brachyurus. MALE WITH YoUNG.

have been collected. While the work of the female ceases with the egg-laying, for the male begins now a period of much sacrifice and hard work. Untiringly he keeps guard over the safety of the nest and the well-being of the growing young. Frequently the male stands for hours over the entrance to the nest, and by gently moving his pectoral fins fans towards the young a continuous stream of fresh water rich in oxygen. The courage of this little fearless fish is astounding, and even larger 
animals will frequently withdraw before its fierce onslaught and the threateningly erected spines. The same care which the stickleback bestows upon the nest and the eggs he gives afterwards to the young brood. Only when they are no longer in need of his protection his interest decreases, and the grown-up sticklebacks will act wisely in not venturing on their father's ' beat,' for he will now attack them as fiercely as other fishes.

The care for its offspring of another fish, Geophagus brachyurus, is illustrated in fig. 67. Here, again, it is the male who leads his young, after having previously watched over their incubation. Like a hen with her chicks, he follows the little company devotedly about, but if one of the young should

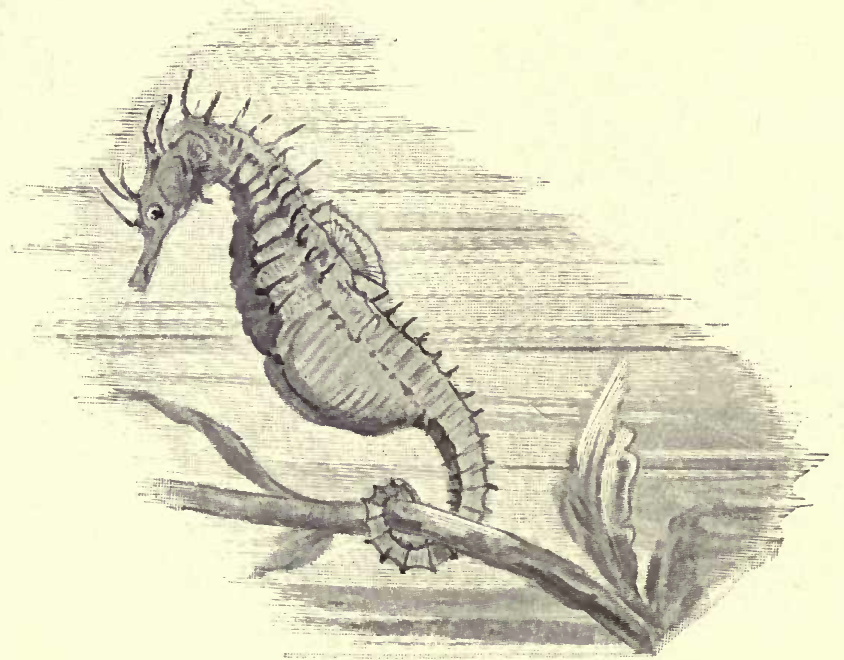

FIG. 68.-Hippocampus antiquorum. MALE WITH BREAST-POCKET.

venture too far in purposeless daring the male seizes it with the mouth and-often not very gently-flings it back among the rest of the swarms.

It is remarkable that among fishes, as well as among numerous amphibians, the male, as a rule, attends to the care of the offspring, while the female takes no interest of any kind. Only in very rare cases are females observed to care for their 
offspring after egg-laying. Such notable exception is that of Aspredo lavis, a species of shad. Here the female glues the egg to her body.

The female of Solenostoma, a fish belonging to the small group of the Lophobranchii, carries the egg in a bag which has been specially formed by the ventral skin and fins. In other Lophobranchii, however (the grotesque Hippocampus antiquorum and the Syngnathus acus) in defiance of all rules it is the male who becomes 'pregnant,' for he possesses on his ventral surface a roomy sac in which the eggs pass their embryonic development (fig. 68). With the growing of the young brood this breast-pocket enlarges enormously, and thus gives the strange appearance of 'pregnancy.' Also against all rules of the game, it is the female which puts on the 'nuptial dress.'

Some other fishes which do not possess a special arrangement for the care of the young carry the eggs in the mouth-cavity. Thus it is reported of an inhabitant of Lake Tiberias, Chromis paterfamilias, that the males at times carry up to two hundred embryos in their mouth.

The life-habits of the Brazilian frog, Pipa americana, remind us of the behaviour of Aspredo which I have already mentioned. In these animals both sexes share in the care of the offspring, the larger and heavier share being taken by the female. The male places with its anterior legs the impregnated eggs upon the back of the female. The stimulus exerted by the eggs upon the skin causes peculiar growths, and around these are formed cells, like those of a honeycomb, in which later the young frogs are found (fig. 69).

The female of Nototrema, a frog which inhabits tropical America, also carries the fertilized eggs in a pocket on her back. If I further mention that the male Alytes obstetricrans winds the long egg-chain round his posterior legs, and then lives for some time in concealment on the land, finally to bring the young frogs back into the water when they are ready to emerge, I hope to have given a sufficient number of instances to show the important part which is played by parental care and devotion even among the lower animals.

How closely the union becomes between the young of birds and mammals and their parents requires no particular mention. 
Both males and females share with extraordinary devotion in the task of hatching and obtaining food, and it seems to us quite unnatural that the cuckoo, which is a very faithless wife, giving herself to any male, leaves the hatching of her eggs to other smaller birds. More frequently it is the males who do not trouble about their young or are even hostile to them, so that the female is barely able to protect the young against the attacks of their brutal sire.

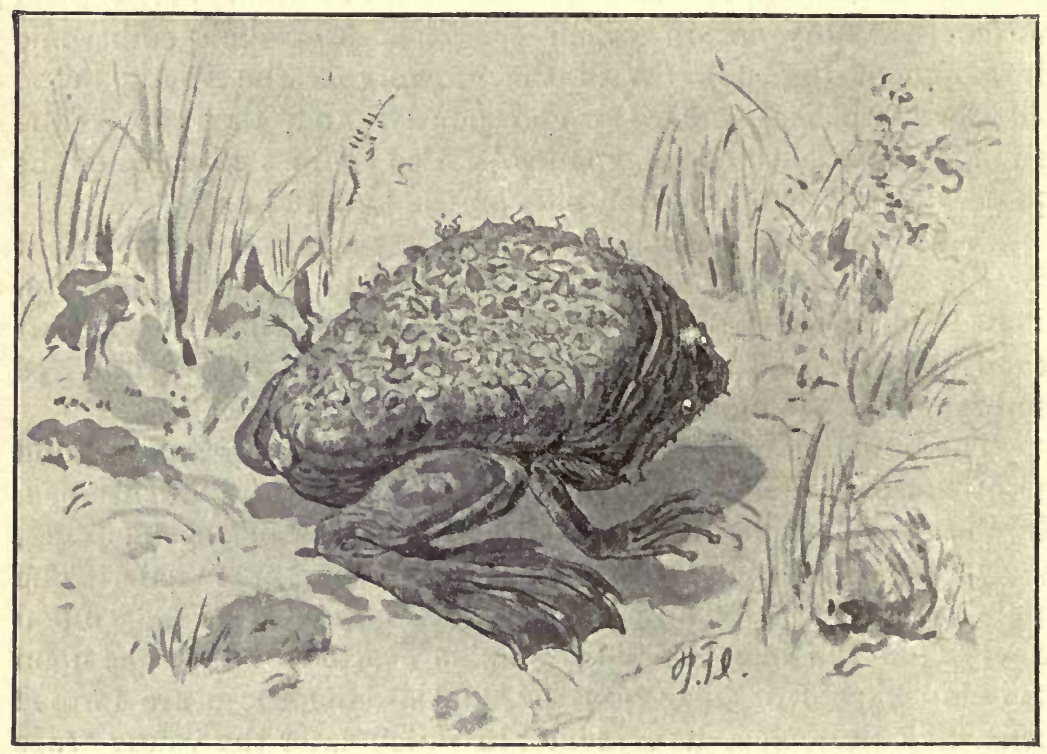

fig. 69.-Brazilian frog, Pipa americana, with young.

The female rhinoceros-bird, to mention only one instance, exhibits a particularly touching devotion to her young. It almost seems as if these birds do not trust to their own patience and endurance, and in order to prevent themselves from leaving their eggs they actually close up the nest-hole in the tree with their fæces, letting only a small aperture remain through which the female receives food from the male.

By way of contrast, other birds know how to make hatching an easy task. The Australian Talegalla (Catheturus lathame) and some related species gather heaps of leaves and decaying 
plant matter, and hatch their eggs by the heat produced in the heaps by fermentation. In order to regulate the temperature in the interior of the heap they actually build several ventilating shafts. Other birds even understand how to make use of the volcanic activity of their own countries, and bury their eggs in the warm ashes of volcanoes.

The highest stage of perfection in the care of the offspring is reached by the mammals, among whom the parental care forms such striking characteristics that the whole group has derived from it its name. In most mammals the young pass their entire embryonic development in the interior of the maternal body, and are fed immediately from the blood-circulation of the mother. They are born developed but helpless creatures, and must be suckled for a considerable time with the secretions from the maternal milk-glands until they are able to obtain their food independently. Only the Monotremata of Australia lay eggs like reptiles and birds. These eggs are either hatched in the nest, as in the case of Ornithorhynchus paradoxus, or in a pouch on the ventral surface of the mother, as in the case of Echidna aculeata.

In the marsupials the young are born in a very incomplete, helpless state. The Giant Kangaroo, for instance, bears barely forty days, and produces a naked, blind embryo, the size of a walnut, without extremities. Carefully the mother seizes it with the lips, and places it into the pouch, where it at once commences to suckle. After about seven months the embryonic development is complete, and for the first time the young looks shyly out into the world. Soon it leaves the pouch, first for a short time, but gradually for longer periods. But even fairly large young kangaroos dive, at the least sign of danger, with a bold jump into the maternal pouch until they are finally forcibly prevented in the interests of a new generation.

I could mention many more attractive features of the lifehabits of other mammals, but time forbids, and I will, therefore, now turn to the formation of germ-cells.

The problem of fertilization and reproduction has occupied the human mind for many ages. Until the discovery of the microscope this was therefore a region which the mind in vain endeavoured to invade. All that was possible was tentatively to build up hypotheses. As the act of impregnation itself was 
hidden to the eye, it can be only too easily understood that earlier investigators regarded the act of impregnation as the lifecreating element. Nevertheless, Aristotle was already on the track of truth when he assumed that the motner supplies the formative matter for the new creature, but that the father causes the development.

Owing to the difference in the size, animal ova were known to investigators long before spermatozoa were discovered. The scientists of the seventeenth and eighteenth centuries believed almost universally that each ovum contained the developed animal with all its different parts and organs, as it were, en miniature, and that impregnation stimulated this animalcule into growth and 'metamorphosis.' The celebrated Italian physiologist and physicist Spallanzani thought, on the ground of his investigations concerning the reproduction and development of the frog, that as the frog developed by metamorphosis from the tadpole, and this again directly from the ovum, the egg itself must already contain a minute frog. Moreover, as the fertilized egg is in appearance exactly like the unfertilized egg which still adheres to the maternal ovary, he thought that the embryos of frogs must be in existence in the maternal body long before impregnation had taken place. In pursuing this idea, therefore, investigators arrived at the conclusion that these germs again contained the primary constituents (Anlagen) of subsequent generations, so that according to them in the case of man the ovary of Eve contained all the human beings that ever lived and ever will be born.

Difficulties arose for the supporters of this doctrine of 'preformation,' when a disciple of the great Dutch physiologist, Leeuwenhoek succeeded, in 1667, in discovering in the sperm of a man suffering from gonorrhœa minute motile formations, resembling microscopic tadpoles. At first these 'semen-worms' were regarded as parasitic organisms, living in the seminal fluid and being of no particular importance. But very soon Leeuwenhoek himself succeeded in demonstrating the presence of exactly similar 'worms' in the semen of many other animals, mammals, amphibians, birds, fishes, molluscs, and so on. Finally, continued investigations led him at last to the conviction that these spermatozoa were not the ova but the actual germs which merely 


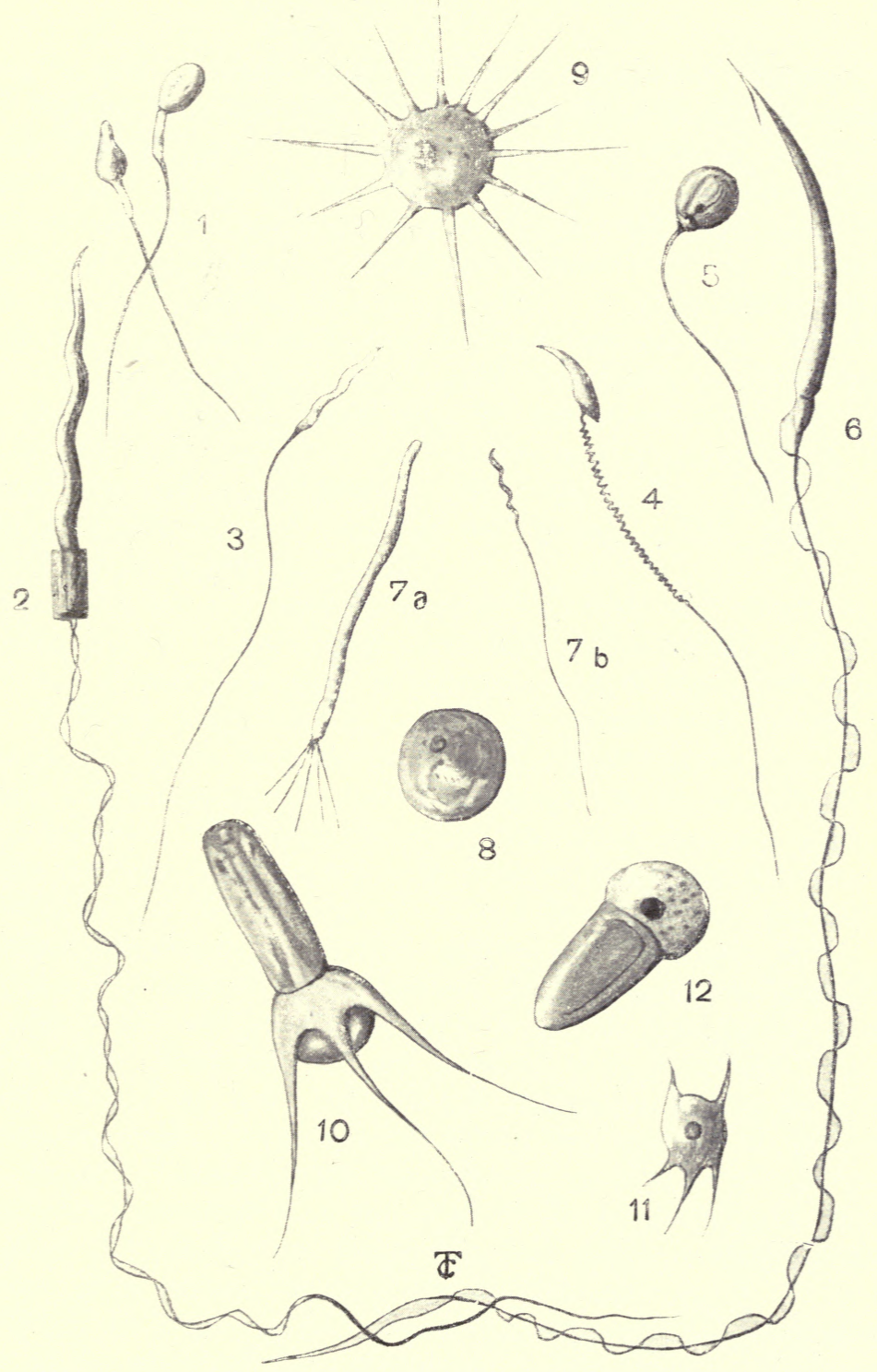

FIG. 70.--SPERMATOZOA OF DIFFERENT ANIMALS.

(1) Man. (2) Raja clavata. (3) Torpedo marmorata. (4) Mus decumanus. (5) Perca fluviatilis. (6) Molge marmorata. (7a) Vermiform; (7b) piliform spermatozoon of Paludina vivipara. (8-11) Various crustaceans. (8) Latona setifera. (9) Moina rectirostris. (10) Homarus vulgaris. (11) Polyphemus pediculus. Ascaris megalocephala. 

found in the maternal body the most suitable conditions for their further development. This hypothesis reduced the ovum to the level of mere food-material, at the expense of which the spermatozoa live and grow. Supporters of Leeuwenhoek's doctrine even went so far as to contend that they had under the microscope actually seen a minute 'homunculus' in the spermatozoon, and observed its development. Though this fantastic contention soon met with the liveliest contradiction, the real nature of the spermatozoon remained completely unknown until the nineteenth century; only with the establishment of the celltheory and with the proof that ovum and spermatozoon are simple cells, and that fertilization consists in the union of the male with the female cell, the veil began to lift from this mysterious phenomenon.

We have already become acquainted with the structure of different animal-ova and seen how their cell-form becomes quite distinct. Indeed, the eggs of sponges, and of some jelly-fishes bear in their appearance a striking resemblance to simple Amœbæ, and have by their protoplasmic pseudopodia retained a certain independence of motion (compare fig. 31, 3). In those cases, however, in which the cell-character of the ova appears hidden the differences lie either in a large accumulation of foodmaterial for the growing embryo, or in other secondary protective arrangements demanded by the conditions of their later fate.

But quite differently formed are the spermatozoa (fig. 70). No one would take these thread-like motile formations to be simple cells. However, we are here aided by evolution, which shows how these thin threads are transformed, step by step, from normal cells. We need not follow this process of development in all its highly complicated phases, but it will suffice for our purpose to remember that the head of the spermatozoon corresponds to the cell-nucleus, the,middle part to the centrosome, and the long, thin tail essentially to the protoplasm.

By far the largest part of the cell-plasm is during the development of the spermatozoon rejected as useless ballast. The spermazoon acquires thereby greater motility and is at the same time prevented from developing independently before impregnation. This is one of the methods of Nature to enforce amphimixis.

Why do ova not divide, though they are liberally supplied 
with protoplasm? What prevents them from producing an embryo independently? When we were dealing with cell-reproduction we saw that the centrosome underwent important transformations, that it appeared to control all processes, and that most investigators saw in the centrosome the real organ of cell-division. In the maturing of the egg-cells this small but important form becomes apparently degenerate and, in this circumstance, according to Boveri, whose theory is gradually gaining universal recognition, is to be sought the cause of the inability of the ova to divide. For in the act of impregnation the spermatozoon brings into the egg-plasm a new organ of division, a new centrosome, and with that the impediment which hitherto stood in the way of division is removed and development can begin. It must, however, be remembered that this is only an hypothesis with which it is very difficult to reconcile many observations; still it is the best attempt so far made at explaining this phenomenon.

In some of the lower crustaceans, in which copulation leads with a high degree of certainty to fertilization, and spermatozoa need only be produced in small numbers, these have retained their typical cell-form. The extraordinary, even unique importance of the germ-cells to the preservation of the organic world makes us understand that Nature has made the most comprehensive preparations to secure their origination and growth.

The most primitive method of germ-cells is found in the sponges, in which ova and spermatozoa, being distributed throughout the entire body, may originate in the mesodermic tissue. In this case we speak of a diffuse formation of germ-cells. But even in these primitive forms we find special preparations made for the better nutrition of the sex-cells, for each ovum is during its period of growth closely surrounded by a wreath of other cells whose one purpose appears to be to feed their protégé and guard it against external influences. In similar manner the young semen-forming cells are cared for in all animals.

In most of the higher classes of animals, and from the vermes upwards, in all classes, the formation of germ-cells goes on in specific sexual glands, the testes and ovaries. We cannot consider here all the numerous preparations that have been made for the care of the germ-cells, but the final results are in all of them the same : the formation of healthy, vigorous germ-cells. 
Two fundamentally distinct methods may be discerned in their nutrition: either the food-cells themselves serve as food and are simply eaten up by the growing sex-cells, or they draw a continual stream of food-material from the maternal body and pass it on to the ova and spermatozoa. They act therefore as intermediaries.

That the food-cells, as a rule, are nothing but degenerate germ-cells we have already heard on a previous occasion, where I also referred to the silent but fierce struggle which takes place in the sexual glands, as the result of which competition only the best and strongest germ-cells are able to develop. But even the complete germ-cells are sometimes subjected to a severe test of their fitness.

To give only one instance, the spermatozoa of the higher animals possess the peculiar habit of taking up their position in the fluid with the head opposite to the direction of the current. If we now gradually increase the strength of the current we see under the microscope that numerous spermatozoa become exhausted and are carried away by the stream, but that the strongest pluckily work their way up stream. Though this seems insignificant, it has a very important meaning. In the female uterus and oviduct there is a slight current to the outside, which indicates the direction to the invading spermatozoa and must be overcome by them before they can penetrate to the ovum and complete the union. In this simple manner once more selection takes place, by which weakly elements are generally eliminated.

In order that the germ-cells may fulfil the purpose of their existence it is above everything necessary that there should be suitable preparations for bringing ova and spermatozoa together. The first condition is a permanent, or at any rate periodical, coming together of the two sexes. Most favourably situated appear to be in this regard the hermaphrodites, those animals in which both kinds of germ-cells originate in one and the same individual. Especially in the lowest classes of multicellular animals, hermaphroditism is still fairly general, and in the numerous species which are either fixed or slow-moving it becomes the general rule. We know hermaphrodites among sponges, jelly-fishes, vermes, echinoderms, molluscs, crustaceans, 
and tunicates; and even among the highly developed vertebrates cases of hermaphroditism exist in the Myxine glutinosa and Serranus scriba.

We are therefore compelled to assume that the hermaphroditic development of animals represents the original stage from which in the course of their phylogenesis a separation of the sexes was gradually evolved. This assumption is supported in particular by the fact that even in vertebrates and insects, in which normally the sexes are always separate, hermaphroditism occurs occasionally abnormally. As these animals frequently possess a prominent sexual dimorphism, it sometimes happens that striking malformations appear. Thus we know of ants, bees, butterflies, beetles, \&c., in which the right body-half is purely male and the left purely female, or vice versa. In the Berlin Natural History Museum is preserved the skin of a bull-finch in which the dividing line of the body is strictly vertical, so that one breast half exhibits a bright red male plumage while the other half shows the insignificant grey of the female. As unfortunately only the skin was handed in, it was impossible to examine the inner organization in this bird. This is all the more regrettable as hermaphroditism frequently exists only externally, the sexual glands of animals having in spite of it retained their purely female or purely male character.

In some cases it seems clear that the bi-sexual forms have acquired their hermaphroditism only secondarily, and that separation of sexes had already taken place in their ancestors. The cause of this lies in a change of the life-habits, and rests either, as in the fly Termitoxenia and numerous other animals, on adaptation to a parasitic mode of life, or, as in the Cirripedia, in the loss of free motility.

The degree of hermaphroditism frequently varies. As a rule ovaries and testes are found in the same individual, but in different places, possessing separate outlets for the sex-products. Only in very few cases-as, for instance, in some vermes, echinoderms and mussels, as well as in numerous snails-male and female germ-cells originate generally in the same gland, which is in that case described as the hermaphroditic gland. But even in this extreme case Nature seeks to prevent selffertilization, permitting it only in cases of extreme necessity. 
Frequently self-fertilization is made impossible by the fact that both kinds of sex-cells mature at different times, so that these animals either function first as males and then as females, or first as females and then as males. The advantage of hermaphroditism is, however, evident, in spite of the avoidance of self-fertilization, especially as regards slow-moving animals, for whenever two individuals meet it is always male and female that meet. The great value placed by Nature on cross-fertilization becomes quite clear when we find that even in many hermaphrodites-as, for instance, the duck-mussels-there appear at certain times dwarf adjunct males, in the event of mutual impregnation of the hermaphrodites being for some reason or other rendered impossible.

With the numerous other arrangements which aim at a union of the sexes for the purposes of impregnation I can deal here only in very brief outlines. Only in the higher vertebrates do we observe the kind of union which may be described as a marital association, but in the lower forms the union of the sexes occupies only a short period.

Very remarkable conditions are observable in a species of vermes, Bonellia viridis, found in the Mediterranean. The female lives concealing its sac-like body among the rocks, only the cephalic lappet, which is about 20 to 30 centimetres long, being visible; the minute male, which is only about 1 millimetre long, and was only quite recently discovered, leads an unnoticed existence in the sexual organs of the female. Similar arrangements are found in some of the parasitic crustaceans.

In Diplozoon paradoxum, a trematode which is parasitic on the gills of carps, both sexes are found grown together like the celebrated Siamese twins. In another species, Schistosomum (Bilharzia) hamatobium, a parasite of man dreaded in Southern countries, the male by rolling up the lateral margins of its body forms a partly closed tube, the canalis gynacophorus, in which it carries the more slender female through life. These cases are, however, as much exceptions as the symbiosis of many barkbeetles and land crabs, for generally the sexes separate immediately after fertilization if, as in the majority of insects, they do not die shortly after having fulfilled this all-important task. 
In order to increase the sexual stimulus and make both parts more eager for copulation, various arrangements have been made which frequently condition a considerable difference in the appearance of the two sexes. As a general rule the female animals are the more passive and reserved part. In order to overcome their objection, the males possess numerous means, while conversely many characteristics of the female serve to excite the sexual instinct of the male. Among these stimuli are the scent-scales of the male butterflies, the musk-glands of alligators, beavers, and civets, the anal glands of lizards and snakes, and the strong broody odour of many mammals. Sounds, too, play an important part in attracting the sexes and conquering female shyness. The autumnal forest reverberates with the calling of the stag; at the awakening of springs the songs of the nightingale and finches sound from the bushes; from the bare tops of the firs the blackbird untiringly sounds its sibilant note; in the meadows locusts and crickets play their monotonous tune; and from the near pond comes in thousand voices the concert of the frogs, interspersed from time to time with the melancholic call of the toad.

When dealing with sexual selection, we saw that striking colours and other ornaments may serve as sexual allurements. Indeed, many males assume for the ' wedding' a special festive garb and perform in addition before the females strange dances, as if they hoped to charm them either by their beauty, skill, or strength. During copulation snails bombard one another with ' love-darts,' little daggers of carbonate of lime which are driven into the male genital passage to increase the sexual desire. The hook-like spicula at the posterior end of the male thread-worm serves the same purpose.

But just as the instinct of copulation produces love and affection between two sexes, so it causes simultaneously hatred against rivals, and many animals, from the gentle dove to the truculent stag, fight in the pairing period fierce and sanguinary battles which sometimes end only with the death or at least expulsion of the rival. The male sex is consequently furnished with special weapons which are absent in females. We remember at once the mighty mandibles of the stag-beetle, the spurs of the cock and Ornithorhynchus-in this latter species a poison 
gland opens directly into the spur-the horns of deer, the antlers of stags, manes of horses and lions, and tusks of boars. In addition we find that the males are furnished with better or even new sense-organs for seeking, and with other preparations for seizing and holding the females.

The male Leptodora, a little transparent fresh-water crustacean, which I have mentioned several times, possess greatly prolonged antennæ.

The males of numerous beetles, butterflies, etc., are also often distinguished by their strongly developed and highly differentiated antennæ. In the male of the honey-bee almost the entire head is occupied by the greatly enlarged, faceted eyes, while the queen and the workers possess considerably smaller eyes. This extraordinary development of the organs of sight is absolutely necessary for male bees if they do not wish to lose sight of the queen during the rapid nuptial flight. In some male flies of the genus Cloë and Potamanthus there are found special 'turban eyes' which are absent in the females flies. Finally, we have already seen that the faculty of producing light is of great assistance among many animals in the finding of the sexes.

Among the instruments for seizing and holding the females I need only mention the gripping-antennæ of several of the lower crustaceans, the swelling on the 'thumb' of the male frog, and the spurs of the Ornithorhynchus.

Fertilization may either be external, during which the germcells are simply voided into the water, or internal, with preceding copulation. The first form is widely found, particularly in the jelly-fishes, echinoderms, numerous vermes, mussels, tunicates, fishes, and, finally, many amphibians. Though it may sound improbable, interior fertilization can take place without preceding copulation, while, on the other hand, in a few animals with external fertilization there is also a kind of copulative act performed.

While generally the male semen is secreted as a fluid, in some animals so-called spermatophores or 'sperm-cartridges' are formed. These are delicate capsules of many shapes and often highly complex construction, which contain a large number of mature spermatozoa. During pairing time we may often notice a very attractive spectacle in many of the tritons. The male has 
then put on its most brilliant nuptial dress, and performs before its mate the queerest contortions. Finally his efforts are rewarded with success, for the sexual desire is aroused in the female. The triton now deposits on the ground, before the eyes of his chosen mate, several spermatophores. The female crawls upon them and takes them up with her sexual organs, in which they open and liberate the spermatozoa, when fertilization takes place. We find a similar process in our native myriapods, the Scolopendra. Here the male attaches his spermatophores with selfspun threads to the earth; then the female receives them in her sexual organs.

Frogs unite for the purpose of fertilization. The male sits on the back of the female, holding her with his fore-legs and waiting until she discharges the ova, when he pours the sperm upon them. Fertilization, therefore, is here external.

In animals which have no external sex-organs, copulation and transmission of the semen is performed by pressing together the sex-apertures. In such case it happens sometimes, as, for instance, in the earth-worm, that both copulating animals become firmly joined together by elastic bands, secreted by a glandular organ, the clitellum. More frequently it happens that the male sexual passage ends in a protruding or protrusible penis which, during copulation, is introduced in the female vaginal orifice, and thus transmits the male sperm-cells with much greater certainty. Sometimes other parts of the body may be employed for this purpose, when they become suitably transformed.

In the crayfish, for instance, it is the two most anterior pairs of abdominal feet that serve as instruments of copulation.

In the male spiders, the palpus has as its point a pear-shaped, sac-like process, furnished with a spiral thread, the 'palpal organ.' Before the spider approaches his mate he fills this sac from the germinal gland with sperm, and thrusts it at the moment of copulation into the vaginal orifice. $\mathrm{He}$ must, however, proceed most cautiously, for the female is in many species considerably larger and stronger. With the strangest contortions the male endeavours to approach the female, but only too often it happens that she rushes upon him and kills him. Even if he has successfully braved all dangers and reached the goal of his desire, he must, after completed copulation, quickly 
run away, unless he wants to serve as a meal for the ravenous female.

Among the cuttle-fishes, too, fertilization takes place by means of spermatophores. These have such:a remarkable structure and, owing to the swelling, perform in the water such strange movements that they have been described as independent parasitic worms. The transference of the spermatophores to the other sex is performed by the 'hectocotylus,' one of the tentacles of the male which has been specially transformed for this purpose. In Argonauta this hectocotylus separates during copulation and enters the mantle-cavity of the female where it continues to live for some time. It was therefore formerly looked upon as the rudimentary male of the Cephalopods.

In dealing with the interesting prozesses which take place during the maturing of the sex-cells and their preparation for the copulative act and copulation itself, we must recall what we have heard about indirect nucleus-division or mitosis. We saw that each individual body-cell of a certain animal-species always contains the same number of chromosomes. All cells, for instance, of Ascaris megalocephala bivalens, have only four chromosomes, all human body-cells sixteen. This normal number is maintained in all descendants by the dividing mechanism which works with mathematical precision. It will be remembered that the chromosomes were regularly doubled before cell-division by longitudinal fission, and that each of the two young daughtercells received half, that is, once more the normal number of chromosomes. These behave in their reproduction almost like independent organisms which reproduce by division.

The act of fertilization consists in the fusion of a male with a female sex-cell. As the ovum as well as the spermatozoon are typical complete cells, we should nearly expect the fertilized ovum to contain double the normal number of chromosomes. But if that were so, the animal originating from the fertilized egg by cell-division would, in its turn, have twice as many chromosomes in each body-cell as its progenitors. The act of copulation would therefore plainly lead to an accumulation of the chromatic elements which would be doubled in each succeeding generation. But that must not be and is, indeed, contrary to all observations. The cell-nuclei of sexually-begotten children and grandchildren have always exactly as many chromosomes as the nuclei of their 
ancestors. Hence it follows of necessity that at a certain time, before the germ-cells unite in the copulative act, there must take place a reduction of the chromosomes to half their normal number. Investigation shows, in fact, that the mature spermatozoa and ova contain only half as many chromosomes as the bodycells, and that only by copulation the normal number is once more restored. If, for instance, an animal species has in its body-cells four chromosomes, their mature sex-cells contain only two, and if the human body-cells contain sixteen, we can say a priori that the mature spermatozoa and ova have only eight chromosomes.

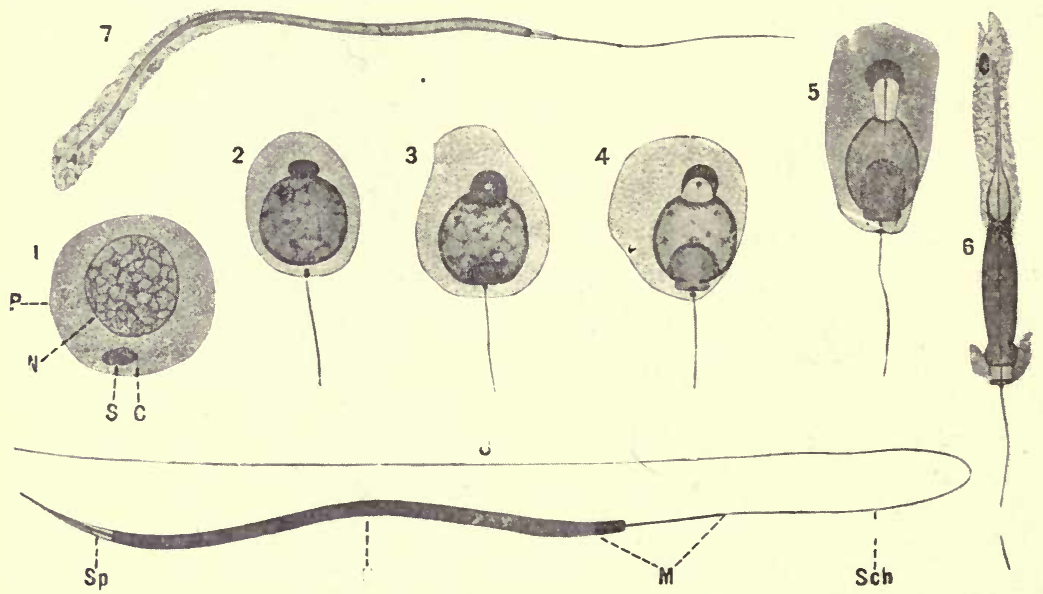

Fig. 71.-Chatge of a SPERmatid in a scuttle-fish (Octopus Defilippi) INTO A SPERMATOZOON.

(1) Spermatid. P, protoplasm ; N, nucleus ; C, centrosome ; S, sphere. (2) The sphere has wandered to one nucleus-pole, the centrosome to the other. (3-8) Gradual transformation. The sphere forms the pointed iend $\mathrm{Sp}$, the nucleus the head $\mathrm{K}$, the centrosome partly the neck M, and, together with part of the protoplasm the tail-thread Sch. the rest of the protoplasm is rejected and perishes.

How is the reduction of the chromosomes in the germ-cells affected?

In the testes of numerous animals may sometimes be distinguished several sharply defined segments in which the gradual formation of the spermatozoa takes place. Usually in the posterior section of the testicle lies the so-called germ-zone, in which by division of the original germ-cells new cells are 
continually formed, the so-called spermatogonies (or spermatoblasts). Adjoining the germ-zone is the zone of growth. In this the spermatogonies develop and become spermatocytes of the first order. These are, according to Yves Delage, the grandfathers of the spermatozoa proper, for from each spermatocyte of the first order originate, by two successive divisions of four cells each, the spermatids, which change into the mature spermatozoa. In the course of this transformation takes place the reduction of the chromatosomes to half the normal number.

I shall describe only the most frequent case, omitting all deviations from this typical process, and choose for our illustration Ascaris megalocephala (the thread-worm of the horse) which, as a result of the experiments of $O$. Hertwig and A. Brauer, is one of the best-known organisms. Like the bodycells of this nematode, so its spermatocytes of the first order contain as yet each four chromosomes. Before they proceed to division, a doubling of the chromosomes takes place and each two of these double-chromosomes approach each other, as if impelled by a mysterious force. In this manner are formed two groups of four, each of which consists of two double-chromosomes. This mutual seeking and uniting of two chromosomes which were separated during the entire previous life of the organism recalls, as Heider justly says, the process of conjugation in unicellulars. Now the whole complicated dividing apparatus of the cell comes again into activity, the centroproceeds the characteristic radiating figure), move to opposite some divides, and the two resulting parts (from each of which nucleus-poles. Now the nucleus-membrane disappears, and before our eyes is formed the 'equatorial plane.' A longitudinal fission of the chromosomes need no longer take place, as the chromosomes have already been doubled.

The remaining course is normal. Two cells are formed, the two spermatocytes of the second order, of which each has again received four, that is, the normal number of chromosomes. But while after each mitosis the nucleus is reconstructed and returns to the rest stage, here the first cell-division is immediately followed by a second. Again the four chromosomes arrange themselves in each of the two spermatocytes of the second order into a group of four, the centrosomes divide and wander to the poles, and again we see the equatorial plane. But 
this time there is no longitudinal fission of the chromosomes; division proceeds forthwith, and into each of the cells forming only two chromosomes are introduced. With that the maturing of the germ-cells is complete, and each of the four spermatids is transformed into a complete spermatozoon which has in its head-nucleus only half the chromatin of the body-cells of the nematode.

In much the same manner proceeds the maturing of the egg-cells, only that here instead of four equivalent cells, one large cell, the ovum proper, and four small cells are formed. The
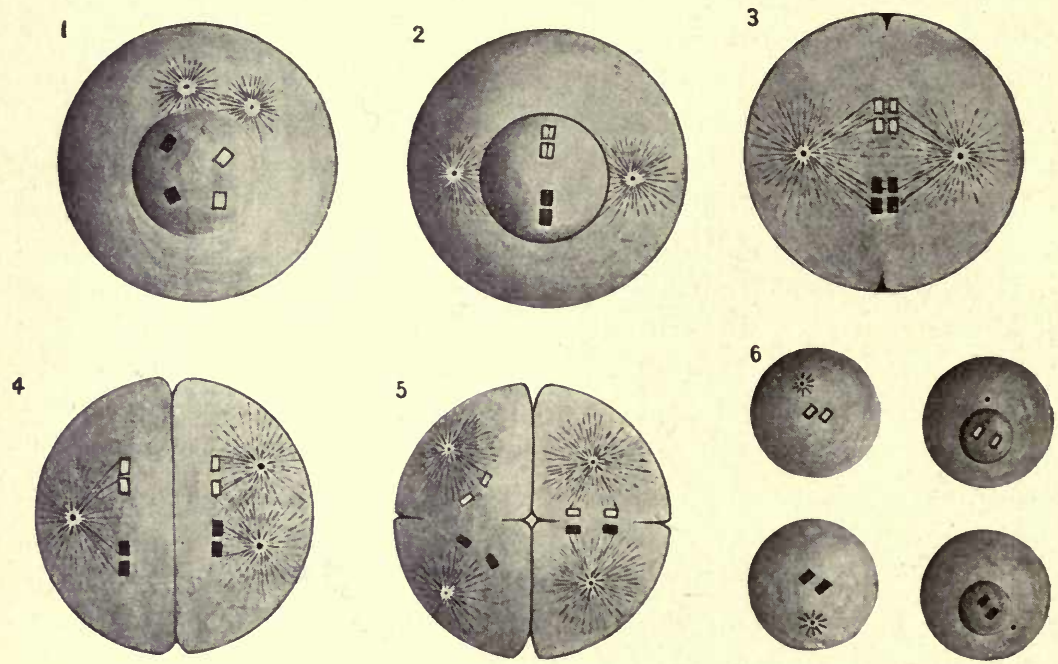

FiG. 72.-DIAGRAM OF a MATURATION DIVISION.

(1) Spermatocyte of first order. 2.4 first maturation division ; (5) second maturation division; (6) the resulting four germ-forming cells, with the nuclear loops reduced by one-half, and changed immediately into spermatozoa. (The maternal and paternal nuclear loops are indicated by white and black squares. respectively.

latter are the so-called 'directive-bodies' which soon perish. We begin again with the grandmother of the matured ovum, the oocyte of the first order. Here, too, the chromosomes have doubled before the division began, and arranged themselves in two groups of four. Now the nucleus moves to the margin of the cell, the dividing apparatus begins to act, and four chromosomes remain in the ovum, while a small quantity of protoplasm 
becomes aggregated around the others. The result of the first division is therefore again two cells, one large and one small, but each with the normal number of four chromosomes. The second division, which follows without an intervening rest-period, effects again a reduction in chromatin, removing two of the chromosomes, each of which is surrounded by a minute quantity of protoplasm from the ovum. In the meantime, the first small cell has once more divided, and with that there have again been formed from the oocyte of the first order four cells, the mature ovum, and the three 'directive-cells' which soon perish without having performed any particular rôle.

It may be asked, Why does Nature act in this case so unjustly? Why do not four normal ova develop from the oocyte? But the reason seems plain: we see here once more manifested the great adaptive faculty of organic genesis. As the egg-cell is to supply the formative matter for the growing embyro, is it not above everything necessary that it is liberally provided with food-material so that it shall be able to fulfil its task? Thus it seems more advantageous that fewer ova are created and that one cell enriches itself at the expense of the other three sister-cells, than that more but weaker germs are produced.

When both kinds of sex-cells have been prepared as described, only then can the process take place at which all these preparations aim, fertilization. It must have been a wonderful impression which Oscar Hertwig received in 1875 when he, first of all men, was able to observe with a microscope these mysterious processes in the ova and spermatozoa of sea-urchins, and thus open a path to a region which the human mind had during thousands of years in vain endeavoured to invade. Even to-day, when anyone with a good magnifying glass can easily observe the spectacle, it never fails to fascinate us. We feel that we stand here on the threshold of one of the profoundest riddles of life.

The process of fertilization is exceedingly simple. As soon as we mix in a drop of sea-water a few mature ova of the seaurchin with spermatozoa, we see that immediately all the spermatozoa rush towards the ova, each one endeavouring to reach an ovum before the others. When a spermatozoon is close to an egg-cell the egg-plasm raises a minute prominence into which 
the spermatozoon penetrates, head forward. Almost at the same moment the egg-plasm becomes rigid, forming a firm cover, the yolk-membrane, which offers an insuperable obstacle to the entrance of other spermatozoa. This is Nature's way of preventing the injurious consequences of over-fertilization, or polyspermy.

Let us now observe, with the aid of the illustrations, the subsequent stages of the fertilization act in Ascaris megalocephala. As soon as the spermatozoon has entered the ovum it turns round so that its central part points to the centre of the ovum. Presently there appears in this central part, which, as we know, corresponds to the centrosome, the familiar radiating figure. Nearer and nearer approach the sperm-head and the egg-nucleus. Consisting at first only of a compact mass of chromatin, the head of the spermatozoon meanwhile becomes enlarged by absorbing fluid, and changes into a typical resting nucleus in which the chromatin lies distributed in the form of a fine net. In the meantime the paternal centrosome has divided and the two new centrosomes have taken up a position on the two opposite points in the egg-plasm. Between them the maternal and the paternal nucleus lie now close together.

Fertilization is now practically at an end, and the second act of the drama commences, the division of the impregnated eggcell, or, in other words, its development. A direct fusion of eggnucleus and sperm-nucleus into the segmentation-nucleus can take place in many cases, but there is no necessity. As a rule we may assume that the processes take place as shown in our iilustration. We see there that now the egg proceeds to fission. In the maternal and paternal nucleus there appear again two chromusomes each. The nucleus membranes disappear and the four nuclear loops arrange themselves in a uniform 'equatorial plane.' Now takes place the familiar longitudinal fission of the chromosomes and the formation of the daughter-planes. At last the division is complete, and each of the two young embryonic cells has once more received four nucleus-loops, of which one half comes from the father, the other from the mother. During the later stages of development division always takes place in exactly the same manner, so that the 'hereditary substance'-for as such we regard the chromatin-due to each body-cell of the developed animal is derived from both parents in the same 

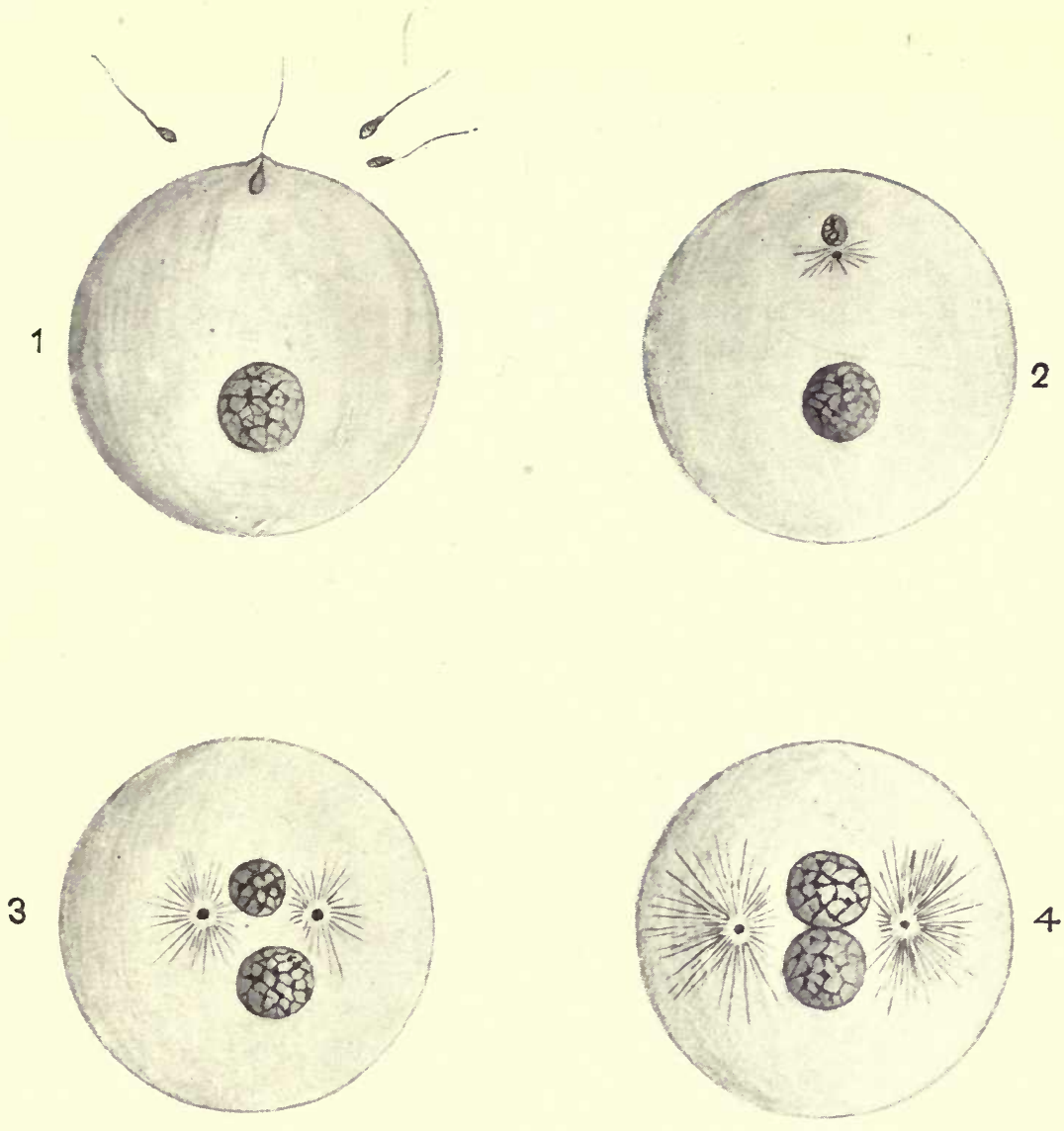

5
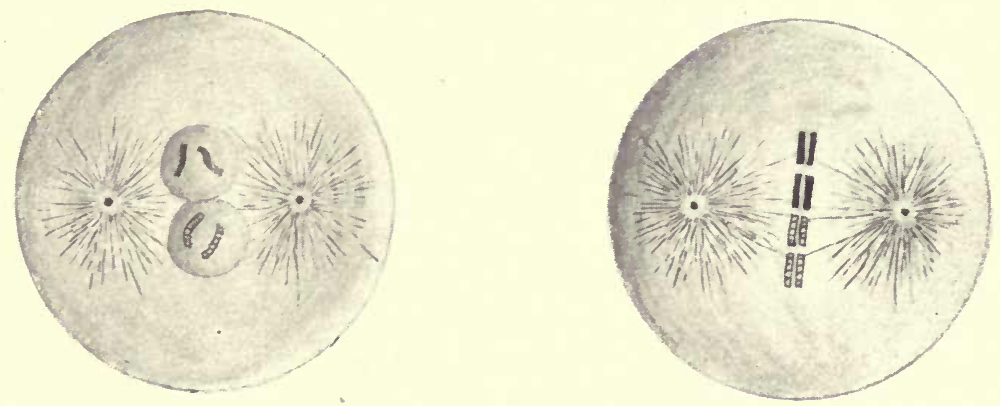

FIG. 73.--FERTILIZATION.

(1) The spermatozoon invades the ovum. (2) The head of the spermatozoon becomes the male nucleus; radiation appears in the centrosome. (3) and (4) The centrosome has divided; both nuclei are close together in the centre of the ovum. (5) The chromatin of the nuclei has closed up and become the chromosome. 6) Beginning of the development. 

proportions. The nucleus of the body-cells has therefore essentially the same structure as the first 'segmentation-nucleus.'

Before we pass on let us shortly sum up the facts which justify us in regarding the chromosomes as the material carriers of heritable characters. In the first place we notice the extreme care with which the 'nuclear-loops' are distributed during cellmultiplication among the daughter-cells. There is no other substance either in the protoplasm or in the nucleus the accurate distribution of which is watched over with the same solicitude.

Again, the 'maturing division' clearly shows that the chromatin possesses a specific vital importance, and the examination of the fertilization-process finally removes all doubt on that point. It is clear that the germ-cells must contain the ' hereditary substance,' for they produce from out of themselves a new organism equal to that by which they were produced. As further the children inherit characteristics from the father and from the mother in equal proportions, the tiny insignificant male germ must of necessity be equivalent to the ovum which far exceeds it in size, and also contain the 'hereditary substance ' of a complete individual. But egg-cell and spermatozoon agree only in the composition of the chromatin elements and in the number of their ' nuclear loops.' If we now add the fact, already known to us, of the strong individual independence of the individual 'nuclear loops,' we cannot escape the conclusion that the chromosomes are the real carriers of the heritable characters.

Moreover, it is possible to demonstrate experimentally that the nucleus and not the protoplasm of the germ-cells determines the development of the growing organisms. By shaking we are able to break the mature eggs of a sea-urchin into several parts which are either nucleated or non-nucleated lumps of protoplasm. If we now bring together, in a drop of sea-water, such nonnucleated fragments with male spermatozoa, the latter behave exactly as if they were dealing with the complete ova: they invade the plasm, or, in other words, perform fertilization.

As the most important part of the egg-cell, its nucleus, is absent we should expect the act of fertilization to remain without results; but, contrary to expectation, this is not the case, for we see that the egg-plasm, which is here only furnished with the sperm-nucleus, proceeds, nevertheless, to division and growth. 
Indeed, Boveri and other investigators succeeded in obtaining from such non-nucleated the fertilized fragments of sea-urchin ova fully developed Pluteus-larvæ which were distinguished from the normal larvæ only by their smaller size, corresponding to the smaller quantity of food material. As in the parthenogenesis of the egg-nuclei, so in cases of fertilization of non-nucleated eggfragments, which we will describe with Rawitz as ephebogenesis, the sperm-nucleus alone suffices to produce a complete organism. These experiments corroborate, therefore, our assumption that only want of protoplasm prevents the spermatozoon from proceeding independently to division and development.

But Boveri carried his experiments still further, and was able to demonstrate that animals bred from non-nucleated fragments possessed only purely paternal characters, and that therefore only the nucleus transmits heritable characters. He proved this by the method of crossing. In the two species of seaurchins, Echinus and Spharechinus, the Pluteus-larvæ differ greatly in the shape of their body and the structure of the limeskeleton. The larva of Echinus is slender, that of Sphærechinus plump. Boveri convinced himself first of all that by a normal process of bastardization, i.e., impregnation of complete ova, or at any rate nucleated egg-fragments, of Sphærechinus with the spermatozoa of Echinus he obtained mixed larvæ which exhibited paternal as well as maternal characteristics, and held the mean between the two extreme types. But if spermatozoa of Echinus invaded non-nucleated fragments of Sphærechinus, the result were larvæ of the pure Echinus type, i.e., larvæ possessing only paternal characteristics. Unfortunately Boveri was unable, owing to technical difficulties, to carry out these impregnating experiments with isolated, non-nucleated egg-fragments, so that his observations are open to objections. But as the nuclei of the larvæ of the pure Echinus type were considerably smaller than the typical bastard-larvæ of the same size-a phenomenon that can only be understood on the assumption that they received only half the normal chromatin quantity, i.e., only one of the two paternal nuclei-it may nevertheless be accepted as proved that they originated from fertilized non-nucleated egg fragments.

However necessary the fertilizing act may be for the begin- 
ning of the development of most animal ova, we are yet able to force many of them by artificial means, often of a very crude kind, to proceed to fission and parthenogenetic development.

Considerable sensation was created in the eighties by the discovery made by Tichomirow, showing that it is possible to bring about a development of the ova of the silkworm, which otherwise stand regularly in need of impregnation, by brushing them, or rubbing them between cloth. The same result was produced by a brief immersion of the ova in concentrated sulphuric or hydrochloric acid. Chemicals, therefore, which under other conditions destroy life are here used to awaken life, a mystery which even to-day has been only incompletely solved. Others made experiments with other animal ova and different means, and obtained similar result. The most important successes in these experiments were achieved by J. Loeb who succeeded in producing complete larvæ out of unfertilized ova of different Echinoderms.

How can we explain this process of artificial parthenogenesis, and how can we bring it in harmony with our hypothesis of the action of the centrosomes during cell-division? As Morgan and afterwards others have shown, the development of the ova taking place during artificial parthenogenesis exhibits the same phenomena as during normal fertilization. In the egg-plasm appear minute granules resembling centrosomes which become the starting point of a radiating figure, arrange themselves in the manner known to us, and apparently regulate the division. We may, therefore, assume that the centrosome which during fertilization is introduced into the ovum by the spermatozoon, forms itself here independently under the influence of certain chemical substances and thus gives the impetus to division. It must however, be understood that this is more a description of what we see than an actual explanation of how the centrosome acts: on that point we are only able to form a very imperfect conception.

As the ova, which were forced into artificial parthenogenesis, had already passed a 'maturing-division,' their nucleus, as well as that of all their descendants, contains only the reduced number of chromosomes. Thus this process is at once perceived as something unnatural, and is at the same time a new proof that 
the egg-nucleus, as well as the sperm-nucleus, each contain the 'primary constituents' of a complete organism. The fertilized egg-cell contains, therefore, within itself potentially the 'rudiments' or 'primary constituents' of two individuals, of which one possesses the paternal, the other the maternal characters. The growing embryo has, therefore, at its disposal each of its characters in duplicate, a fact which, as we shall see later, has an important bearing upon the doctrine of heredity.

While individuals that were produced by artificial parthenogenesis possess in their body-cells only one half of the chromosomes that are possessed by those which originate sexually, we find in those animals that were produced by natural parthenogenesis always the normal number of chromosomes. According to numerous investigators this arises from the fact that in the maturing of the egg-cells only one 'directive-body' is formed, but that the second division, which, as we know, conditions the reduction of the number in the chromosomes, is omitted. In some cases formation of a second 'directive-body' can take place even in ova which develop parthenogenetically, but it remains in the ovum and afterwards fuses again with the eggnucleus, so that here, too, we find the normal number of nuclear loops.

This circumstantial and apparently purposeless procedure may perhaps be explained by assuming that the relevant animals, speaking phylogenetically, have reached the stage of parthenogenetic reproduction since comparatively recent time; they prepare, therefore, their ova for fertilization atavistically and ' cancel' these preparations only at the last moment.

We are now sufficiently prepared for turning our attention to the tineory of heredity. When we have freed this problem of all mystic accretions it resolves itself into this question, How is it that the children resemble their parents? Each single higher organism consists of an enormous number of different cells and cell-products which join together to form tissues and organs, and perform all life-functions. Only one cell-species, the germ-cells, have no share in the labours and cares for the well-being of the individual, for theirs is the higher duty of caring for the preservation of the species. We see that again and again there proceed from these germ-cells all the different kinds of cell- 
forms and become co-ordinate, until finally a new organism has been produced resembling that from which the germ-cells originated. How can we explain this mysterious process?

As far back as 1868 Darwin promulgated his 'Provisional Hypothesis of Pangenesis' to which he was led merely by speculative considerations and entirely without a knowledge of all the delicate processes of which we now know. In the opinion of Darwin it is incorrect to say that the whole organism reproduces; it is rather each individual cell or cell-species which reproduces itself : the nerve-cells reproduce nerve-cells, the musclecells produce muscle-cells, the cells of the blood, blood-cells, and so forth. The reproduction of the cells consists in secreting minute germs which become distributed throughout the entire body, finally to settle down in the germ-cells which are themselves devoid of character and undifferentiated. These minute germs possess great independence and are able to multiply by fission, producing continuously equivalent descendants. If now such germ reaches an embryonic non-differentiated cell it may force it into a definite developmental direction. If, for instance, the little germ of a nerve-cell invades an embryonic cell this becomes a nerve-cell. The more heterogeneous germs an embryocell contains, the richer are its developmental possibilities. As the reproductive cells are able to produce out of themselves the complete organism, they must of necessity contain at least one minute germ of each kind of body-cell. These minute germs are able to remain in a state of inactivity for a considerable time, sometimes throughout several generations, suddenly to proceed once more to reproduction. This explains the appearance of atavism. If the development is to take place normally, it is, of course, necessary that all these minute germs awaken into activity in proper succession.

We see, therefore, that Darwin had already reached the opinion that each heritable characteristic of the paternal organism is bound to a specific material carrier, and must have been deposited in the germ-cells. This essential point in Darwin's doctrine is valid to-day.

Our observations concerning mitotic nucleus-division, maturation-division, and fertilization have led us to the conclusion that the chromatin of the nucleus in its totality is the 
carrier and transmitter of the heritable qualities, and this wonderful substance must therefore contain a corresponding 'rudiment' (Anlage) for each heritable characteristic of the parents. Without this assumption the very elaborate processes in the course of mitosis; which manifestly aim only at the most accurate distribution of the chromosome substance, are without any reason; and only with it can we obtain a teleological conception of these mysterious phenomena.

Investigations of parthenogenesis and ephebogenesis further showed incontestably that the nucleus of the mature ovum, as well as the head-nucleus of the spermatozoon, must contain the complete 'rudiments' (Anlagen) of at least one complete individual. Fertilized egg-cells would, therefore, virtually contain the 'rudiments' of at least two perfect organisms, one of paternal, the other of maternal descent. We may therefore assume that during the embryonic development a struggle for predominance takes place between paternal and maternal "pairs of characters,' and that upon its result depends the question whether afterwards the child shall exhibit a corresponding quality of its father or its mother. The 'rudiment' of the characteristic of the defeated part is of course also contained in its cells, but it remains latent.

Upon the more delicate structure of the 'nuclear loops,' and the distribution and arrangements of the various 'primary constituents' (Anlagen) in them, we have not yet expressed an opinion, as the observations made so far afford no foundation for satisfactory conclusion.

Several years ago Weismann constructed an ingenious theory of heredity in which he undertakes to analyse the organization of the chromosome into the minutest details; but though he seeks to defend his theory with the utmost sagacity, and though he marshals numerous reasons in support, his arguments enter far too much into the region of pure hypothesis and find but little corroboration in the facts of observation. We may therefore content ourselves with a brief sketch of his theory of germ-plasm.

If we examine greatly magnified 'nuclear-loops' of different animals at various stages of development, we see that the apparently uniform ribbons are formed of a large number of 
lamellæ arranged successively one behind the other. According to Weismann, this structure is the rule. He classes each of these tiny plates as an $i d$, and each $i d$ is, according to him, not only the carrier of certain heritable characteristics, but contains already the entire hereditary substance, the 'rudiments' of a complete organism. Most chromosomes or idants contain therefore the entire hereditary substance several times because they are constructed of several $i d s$. Only in animals with minute globular 'nuclear-loops' can they become identical with an $i d$.

Each $i d$ is said to possess a very complex structure and to be composed of smaller units, the determinants. These determinants are 'those parts of the germ-substance which determine a 'heritable part' of the body, i.e., it depends upon their presence in the germ whether a certain part of the body, be it cell-group, single cell, or cell-part, is formed specifically, and the variations of which induce only these definite parts to vary.'

The regions which are singly determinable by the germ are apparently differing in extent, ' according to whether we have to do with large or small, simple or complex organisms.' The unicellular Infusorians probably possess special determinants for a number of their cell-organella ; in the lower uniformly constructed multicellular animals the determinants govern probably larger cell-groups and are therefore present in comparatively small numbers, whilst in the higher animals, in particular, insects and vertebrates, the number of determinants must be enormous, and certainly exceed thousands or even hundreds of thousands, because each independent heritable variation of the organism, no matter how minute, is controlled by one of these determinants.

We see, for instance, in many families that there occurs in the skin in front of the ear a tiny dimple, barely the size of the head of a pin. Weismann was able to observe the transmission of such dimple from grandmother to son and several grandchildren. In his opinion there must, therefore, be present in the germ-plasm of the relevant persons a corresponding minute heritable part, a determinant which effects the unusual development of this little spot. Similarly, a white tuft in a dark head of hair, which is transmissible by heredity, is said to possess a corresponding determinant in the germ-plasm.

These determinants, however, are not by any means the 
smallest units, but in their turn contain an enormous number of biophores which control still smaller parts of the body. Concerning their size it can only be said that they lie far beyond the limit of visibility, and that the minute granules revealed to us in the germ-plasm by the strongest microscope represent always groups of biophores. But these last 'heritable units' must be larger than any chemical molecule because they are themselves constructed of groups of molecules.

In the protozoa the determinants may probably consist of single biophores, in which case biophores and determinants become identical; but in the higher organisms the determinants, as has already been said, are composed of groups of biophores "which joined together by inner forces form a higher life-unit. The determinant must be able to live as a whole, i.e., be able to assimilate, grow, and reproduce by fission, as every other life-unit, and the biophores must be able to vary singly, so that also those individual parts which they control are hereditarily variable." But determinants and biophores are not distributed arbitrarily but each $i d$ has a definite architecture. The hypothetical forces which bind the determinants to their definite position in correlation to the rest Weismann describes as 'vital affinities.' By means of these different hypotheses Weismann now seeks to answer the question as to the causes of the different formation of the cells in the course of evolution. This brings us to the second and more important part of his theory.

Our observations of the process of mitosis impelled us to the assumption that all cell-divisions lead to an equal division of the hereditary substance among the descendants, so that each body-cell contains an equal number of paternal and maternal chromosomes and possesses the 'rudiments' for all heritable characteristics. But Weismann advances a diametrically opposed opinion. He distinguishes sharply between two different kinds of cell-division, homœokinesis and heterokinesis (erbgleiche und erbungleiche Zellteilung), which lead to very different results, though, to judge from external appearances, they seem to proceed on uniform lines.

The first kind of reproduction is the usual, occurring in all those cases where unicellular organisms divide by fission into two equal daughter-organisms, or where the cells of the higher 
organisms produce by fission cells of their own kind. In homœokinesis it is said that there takes place a doubling of the determinants and an equal distribution among the separated halves, respectively among the daughter-chromosomes; but in heterokinesis the determinants group themselves in the $i d$ unequally, so that one $i d$-half contains determinants of one, the other, determinants of another kind. This inequality of the daughter-cells cannot be directly observed, as the determinants lie beyond the limits of visibility, but 'can only be concluded from the different rôle which both daughter-cells play in the further development of the organism.' 'If, for instance, of two sister-cells of the embryo one supplies the cells of the intestinal canal, the other those of the skin and nervous system,' Weismann concludes from that 'that the mother-cell has divided its nuclear substance unequally among the two daughter-cells, so that one received the determinants of the endoderm, the other, those of the ectoderm; or, if on a butterfly-wing a red and black spot lie close together,' it follows according to Weismann " that the stem-cells of these two spots divided unequally, so that one received the 'red,' the other the 'black,' determinants.'

It appears from this that according to Weismann heterokinesis plays the principal part in the development and transformation of the ovum into the complete organism. Through each division of the embryonic cells their germ-plasm suffers a diminution in the number of determinants because the nuclei of the daughter-cells receive always only those groups of determinants which shall afterwards govern their own and their descendants' formation and differentiation. In other words, the germ-plasm of the fertilized egg-cell is divided during the course of its ontogeny into more and more minute groups of determinants, until finally the body-cells of the mature animal possess only their own determinants. Nerve-cells possess, therefore, only nerve-cell determinants, muscle-cells only musclecell determinants; hence they are still able to produce by fission like, but no longer unlike, cells. In order that the embryonic development may proceed normally, forces must be assumed in the organism which watch with the greatest care that the determinants always reproduce at the right moment, and always reach at the right time the right place in the complete body. 
But how is it that the organism can produce germ-cells, i.e., cells which contain the complete germ-plasm with all the determinants? Just as a cell cannot originate otherwise than by fission of an already existing cell, so specific determinants are unable to create themselves anew. If we regard abiogenesis of the simplest 'biophores' conceivable we may with the same right believe that the lowest organisms owed their existence to abiogenesis. It follows that the reproductive cells can only be formed where as yet all determinants of the relevant kind are present, co-ordinated in $i d s$. That is to say: in addition to heterokinesis of the egg-cell there must also take place homœokinesis. This also is said to be actually the case, and certain cells resulting from a division of the ovum are said to receive a small part of the unaltered germ-plasm which they transmit in a similar manner to their descendants. These cells then become the stem-mothers of the sex-cells. In other words, there are certain 'germ-paths' along which the direct transmission of the total hereditary substance proceeds from generation to generation. Thus, in spite of heterokinesis, the continuity of the germ-plasm remains preserved; the descendants possess in their reproductive cells the same number of determinants which accumulated from the parents in the egg-celi during fertilization, and transmit it afterwards to subsequent generations. In Weismann's opinion we must therefore distinguish between the germ-plasm on the one side, and the body or somatic cells on the other.

It cannot be denied that on the basis of Weismann's germplasm theory the marvellous processes of differentiation during the evolution of the egg-cell to the complete organism find a simple and satisfactory explanation. By distributing the determinants of the hereditary substance by heterokinesis among the different descendants of the ovum, and thus determining the characters which the individual cells are to assume, the process of mitotic nucleus-division would represent the means of determining the form. But though a solution would be most acceptable, this hypothesis is confronted with serious objections: for without taking refuge in supernatural, uncontrollable forces, it is inconceivable how the same process of indirect nucleus-division can now lead to an absolutely just and equal division of the heredi- 
tary substance, and then with the same precision to an amazingly complex, unequal distribution of the germ-plasm.

In his earlier writings Weismann stated that the first division of the egg-cell is heterokinetic (erbungleich), and leads to a separation of germ-plasm from soma. If this were true it would naturally follow that only one of the first two segmentationgrooves, the stem-mother of the later sex-cells, contains the entire hereditary substance, while the other, the somatic cells, has already suffered a decrease in the original store of determinants. If it were possible to separate these first two blastomeres artificially without injuring the vitality of the cells, and force them into a separate independent development, the 'primordial cell' might perhaps have prospects of developing into a complete organism, but the somatic cell would at the best be only able to produce partial formations. But numerous experiments made with ova of medusæ, echinoderms, tunicates, the primitive fish Branchiostoma, and higher vertebrates show that isolated segmentation-cells produce only small embryos, proportionate to the smaller quantity of nutritive material. Moreover, the first two blastomeres produce under favourable circumstances not only two complete larvæ, but in many cases, for instance, in medusæ and others of the lower organisms, each of the four, eight, sixteen, and even thirty-two first segmentation-cells is able to develop into a complete embryo. This proves that, at any rate up to this stage, the division of the hereditary substance has been equal, and that all embryo-cells possess the entire hereditary substance.

Apparently contradictory results are shown by certain experiments made with the ova of annelids, snails, mussels, and jellyfishes. In particular in the Ctenophores, complete larvæ are easily distinguished from part-formations by the number of ciliated ribs. In the normal larvæ which have been bred from a complete ovum the number of ciliated ribs is eight. If the first two blastomeres are isolated they continue to develop into embryos, but these possess only four ciliated ribs: and if we finally succeed in inducing blastomeres of the eight-cell stage to develop separately the larvæ possess always only eight ciliated ribs between them.

Weismann regards this result as a proof of heterokinesis, 
and thinks it impossible to escape the conclusion that the rib 'determinants' are only distributed to certain daughter-cells. But we cannot accept this conclusion, for the ova of the Ctenophores are distinguished by a highly differentiated structure, and this may well be the reason why after an experimental operation regulative transformations no longer take place, but partformations develop instead. Again, it is observed in the ova of Echinoderms that the isolated blastomeres divide at first exactly as if they were still connected with the others; in other words, they produce at first part-formations. It might, therefore, seem as if here, too, heterolinesis had taken place, but after some time we observe that regulative transformation-processes set in and that after all normal larvæ develop from the partformations.

This opinion is supported by experiments made with ova of amphibians by Roux, Hertwig, Morgan, and Herlitzlka. If Roux killed one of the first pair of segmentation-globules of a frog-ovum by puncturing it with a hot needle, the sound half continued to develop as if no operation had taken place, i.e., segmentation stages were developed which corresponded to the lateral half of a corresponding normal developmental stage. It even happened sometimes that such section of the ovum developed into a complete lateral half-embryo (Hemi-embryo lateralis). By subsequent regeneration, the so-called post-generation, these half-embryos were sometimes afterwards able to supplement the deficient body-half.

Hertwig repeated Roux's experiments with frog eggs, but reached entirely different results. According to him the surviving blastomeres developed at once complete embryos, which exhibited but slight defects, and even then only in unimportant body parts.

Morgan succeeded in explaining the apparently contradictory results obtained by these two investigators, and demonstrated that the position of the uninjured segmentation-cell after the operation greatly influences its further fate. Even with the naked eye we are able to recognize in the frog-egg a dark side rich in plasm, and a light side rich in yolk; they are usually described as the animal and vegetal poles. During the normal course of development the light-coloured vegetal pole, being 
burdened with the heavy food, is, according to the laws of gravitation, always pointing downwards, whilst the dark animal pole, containing the light formative yolk, is pointing upwards. The entire yolk substance is, therefore, distributed in the ovum bilatero-symmetrically, and, according to all appearances, this arrangement regulates the course of the 'division planes.'

As long as this semi-lateral distribution of the yolk is preserved in the surviving segmentation-cell by the pressure of the egg-half which has been killed, it seems that only a half-formation can develop from it. But if we turn the segmentation-cell in such a manner that the yolk-substances become arranged as they were in the normal ovum, it develops into a complete embryo. Herlitzka's experiments with ova of the salamander point to the fact that in the semi-lateral distribution of the yolk is found the real reason for the imperfect development of the embryo. By means of an ingeniously constructed apparatus Herlitzka succeeded at the two-cell stage in constricting the ovum in the 'division plane,' by means of a fine cocoon thread, and making both blastomeres completely independent of one another. They were afterwards able to round off, the yolk distributed itself in them according to its specific gravity exactly as in the complete ovum, and the two isolated blastomeres developed consequently into two normal embryos.

These experiments proved unambiguously that at least in these cases it is not a deficiency in the nuclear substance but the structure of the egg-plasm which must be held responsible for the appearance of part,formations. That an analogous process goes on in the case of the ova of the Ctenophores is shown by experiments made by Diriesch and Morgan, in which larvæ with a diminished number of ribs were obtained from an unsegmented ovum merely by removing a considerable part of the outer plasm. Although, therefore, the ova possessed their full nuclear material, and consequently the 'determinants' for the full number of ribs, these ' rudiments' (Anlagen) were unable to develop owing to the deficiency in plasm.

Weismann himself has recently admitted that in many animals the first divisions of the ovum are homookinetic, and that only later the 'germ-paths' become separated from the soma.

A certain amount of corroboration of the doctrine of hetero- 
kinesis of the hereditary substance was found by many in Boveri's observations of a 'chromatin-reduction' of the nuclei during the development of the ovum of Ascaris megalocephalus, for in these nematodes it is possible to distinguish already at the stage of the two-cell segmentation the cells of the 'germ-path' from the somatic cells: only the stem-mother of the future reproductive cells retains her nuclear rods unchanged and with her full complement of chromatin, but in the body-cells both ends of the chromosomes are regularly rejected and perish, only the central sections being transmitted to subsequent cell-generations. We cannot pursue this process in its details and must content our selves with the admission that a 'germ-path' can here actually be distinguished from the body-cells, and that the body-cells have suffered a diminution in their 'hereditary substance.' But it seems to me that this fact speaks rather against than for the occurrence of heterokinesis, for if mitosis can already effect a qualitative separation of the 'complement of determinants' and transmit with this hypothetical precision to the body-cells only those 'primary constituents' that belong to them, there would seem to be no need for the subsequent chromatin-reduction. That a qualitative diminution of 'the hereditary substance' does take place subsequent to the division is a sign that simple nuclear division is unable to effect it, but can only always lead to homøokinesis. It can certainly not be denied that direct observation supplies no proof whatsoever of the occurrence of heterokinesis. On the other hand, many arguments may be adduced against this assumption.

Among modern investigators it is in particular O. Hertwig who submitted the doctrine of inequivalent nuclear division to sharp criticism. His statement sums up the case so tersely that I will quote his own words: "What purpose in the life of the cell is served by the division in which nuclear segmentation plays the leading part? Assuredly only the purpose of propagation and reproduction-and these are the means employed by Nature for effecting the preservation of the organism as species. The organism which is perishable as a single individual is multiplied in its characteristics by reproduction and preserved as species.

' Of plants and animals we know from experience that each 
individual of a species is only able to reproduce new individuals of the same species. The theory of heterogeneous generation was soon abandoned as a gross error wherever it was promulgated. Thus it is a universally accepted principle of biology that ' like produces only like,' or better, 'species always produces its species.' Among all unicellular organisms homœokinesis of their cell-organisms is the only method of division that occurs and can occur. On it rests the constancy of the species. If it were possible in any unicellular organism to divide the hereditary substance (idioplasm) into unequal component parts and transmit them unequally to the daughter-cells we should have a case of heterogeneous generation-the origin of two new species from one species. But, as all observations teach us, the characters of the species are even in the unicellular organisms transmitted by division with such minute care that unicellular fungi, algæ and infusorians, even in the millionth generation, are exactly like their ancestors. The process of division, as such, appears therefore, never as a means of generating new species, not even in the unicellular organisms.

' For these reasons it seems to me inadmissible to regard cell-division in the ovum as a means of obtaining diametrically opposed objects, producing now like, now unlike. Here, too, each cell-division can in its very nature be only a homœokinetic one, therefore all the cells that develop from the ovum by reproduction must be carriers of the entire idioplasm, and of equal species.'

Weismann's theory is further met by almost insuperable difficulties in the phenomena of regeneration and asexual reproduction by division and gemmation. As the germ-plasm in the course of the development of the ovum is, according to him, divided into its determinants and, as it were, used up, it can naturally only be capable of producing the single body-parts and organs once. But, as we have seen, numerous lower animals may be divided into several parts, and yet each part may develop once more into a complete organism; other animals are at least able to repair lost extremities; the single cell of a begonia leaf is able to reproduce the entire plant; and finally the ability, under favourable conditions of reproducing the species must, in the opinion of most botanists, be ascribed to every plant-cell: the 
cells must therefore contain the complete idioplasm in spite of heterokinesis. If Weismann, in order to overcome this difficulty, assumes that in cases of this kind the cells in question have been invaded during the division by the active, isolated determinants, and also by complete $i d s$ containing the entire idioplasm (which remained, however, ineffective under normal conditions, and only entered into the development and brought their primary constituents to development under certain conditions), he contradicts with that assumption his own hypothesis. For in that case we should have to reckon, apart from homoekinetic and heterokinetic division, with a third mode of division in which only one part of the $i d s$ is divided, while another part is transmitted to the daughter-cells uncurtailed, as a 'reserve army,' so to speak. In order to satisfy all possibilities, we should have to conceive almost every cell furnished with such latent additional germ-plasm. That the cells contain more 'rudiments' than can usually reach development is proved by many pathological formations, as, for instance, the occurrence of hair or teeth in cysts.

Further, as Hertwig and Driesch have shown, it is possible, by artificially changing the shape of ova by slight pressure and other means, greatly to influence the course of the division process, 'or to throw about the first nucleus-generations in the ovum-cavity like balls,' and yet see ova which have been thus treated yield a normal developmental result. If now the single nuclei were already ' determined ' in their developmental tendency as the result of unequal division of the idioplasm, the ova that have been submitted to pressure would necessarily develop into the queerest malformations. We may therefore assume that the nucleus still possesses all qualities, for only in this manner can we explain its apparently illimitable mutability.

In order to explain the normal course of development we may well dispense with this very circumstantial mechanism which would be necessary for the division of the germ-plasm into its complement of determinants and their distribution. Even when we conceive all cells to be supplied with the full hereditary substance we can comprehend the cause of the processes of transformation which take place during the development of the embryo. It is true that the question why embryonic cells, 
though containing the same 'primary constituents,' will yet assume such widely divergent appearances, forms at first a formidable obstacle. But we must consider that though the nucleus is the real carrier of the heritable qualities the structure of the ovum nevertheless regulates the course of segmentation and the shape of the embryonic cells.

Let us take a simple case. The ovum of the sea-urchin possesses only a small quantity of food-yolk which is almost uniformly distributed throughout the entire plasm. As a result the egg-body meets a division in all parts with approximately equal resistance, and the young segmentation-cells are therefore of approximately equal size. In the frog-egg the vegetal pole we know to be strongly loaded with the solid food-yolk which hinders segmentation, and we see, therefore, that in the animal pole which is poor in yolk the process of division takes place far more easily and rapidly. Thus numerous small plasmic cells are formed here, while at the vegetal end originate large cells full of yolk. In spite of the equivalence of the nuclei, which at this stage we are still able to demonstrate experimentally, the fate of the individual embryonic cells is widely divergent, simply owing to the unequal distribution of the yolk in the ovum. It seems further clear that with progressing division young cells are continually changing their relation to one another and to the growing embryo; that the individual elementary organisms obtain a continually decreasing share in the entire life-work, in proportion as their multiplication proceeds; that, further, in space as well as in time, they meet unequal conditions; and that, therefore, the external factors exercise their influences upon the different cells in a different manner. It is true that we are not in a position exactly to define the stimuli which determine the shape of cells and their special task in the complete organism, and cause only a well-defined part of their inherited 'rudiments' to develop, but we may at least regard it as probable that in the conditions mentioned are given the essential causes for the future determination of the form. The assumption of a differentiating effect of external factors is far more in accord with our observations of the far-reaching influence of environment upon appearance and structure of the developed organisms, and our mind finds in this conception greater satisfaction; for the mysterious process of 
organic development is thereby driven from its isolated position and brought into intimate correlation with the entire genesis of life. The development of the ovum becomes a little wheel in the whole wonderful engine of Nature.

We heard before that during fertilization only one spermatozoon invades the egg, the entrance being immediately closed to the others. In immediate connection with the centrosome, which bas been carried into the ovum by the spermatozoon, is formed the normal bi-polar 'spindle-figure' which divides the nucleus with the accuracy of the most perfect apparatus into two daughter-nuclei equal in volume and value. As Boveri showed, this accurately working apparatus of division suffers serious disturbances when accidentally two spermatozoa simultaneously arrive within the ovum. For each of the two centrosomes behaves as if it were alone in the ovum, and in place of the normal 'spindle' we observe a figure of four poles. Accordingly the egg divides immediately into four cells, but as in such a case the 'nuclear loops' of three nuclei must be distributed among four daughter-nuclei, none of the nuclei obtains the number due to it. Though the vitality is not thereby destroyed, and though the ova continue to develop, the larvæ which emerge exhibit varying defects corresponding to the incomplete store of chromosomes. This phenomenon suggests that the individual nuclear loops are not equivalent to each other, but that to each chromosome is due only part of the 'rudiments' of a complete organism, and that a well-defined selection of nuclear loops is necessary for a normal development. The facts of parthenogenesis and ephebogenesis, when considered with this observation, permit us, therefore, to conclude that the mature ovum as well as the spermatozoon each contain exactly the material for one complete organism.

But while generally no distinction can be made between the individual chromosomes of the nucleus their unequal character is in certain cases distinctly shown by their appearance. Thus the nucleus of the male primary germ-cells of a species of locust, Brachystola magna, contains, according to Sutton's investigations, twenty-four nuclear loops which may be easily distinguished in form and size: eighteen large and six small chromosomes. These may be still further subdivided into twelve degrees of size, so 
that we get in all twelve equal pairs. It is possible to prove that of each of these chromosome-pairs one part is of maternal, the other of paternal origin. We have already assumed that the paternal nuclear loops which became united by fertilization become once more separated during the course of the maturing of the ovum. In this case, owing to the different appearance of the chromosomes the process may be directly observed, for of each pair of nuclear loops only one reaches, during division, the nucleus of the semen-forming cell.

Apart from the investigations of the cells and observations of the processes of fertilization, there is another way which leads us into the mysterious region of heredity: rational breeding experiments. Both ways lead towards the same goal, and if they meet or run parallel, if only for short distances, we can see in that fact a proof that we are on the track of truth.

Half a century ago this second path was chosen by Mendel, an Augustinian priest, in the Queen's cloister at Brün. Rarely has a great success met with a stranger fate. Buried in a little unknown journal, the record of these remarkable experiments slept unnoticed and forgotten, until in the first year of this century the facts which they proved were re-discovered independently and almost simultaneously by three investigators, de Vries, Correns, and Tschermak, and confirmed by new comprehensive experiments. As Correns justly remarked, this long period of oblivion was a heavy loss to science, but fortunate for Mendel's posthumous fame, 'for if his work had been immediately understood we should not now speak of 'Mendel's law' and 'Mendelism.' The rapid advance of science would have soon overtaken the labours of this solitary man and left them far behind.

For his important experiments Mendel employed chiefly peas. From seed merchants he bought thirty-four varieties of peas which differed in various characteristics : the shape of the mature seed, the position of the leaves, the colour of the seeds, etc. By cultivating each kind for two years he determined whether the character of each variety remained constant, and then chose for his experiments only those which had stood the test successfully. For many years Mendel continued his experiments, and only after having made more than ten thousand 'crosses' did he decide 
to publish his results. We shall here consider only some of the most important results at the hands of a few simple instances, and follow not only the experiments of Mendel but also those of more recent investigators.

The case is simplest when both parents used for crossing differ in only one point. In that case we are dealing with two characters, one from the father and one from the mother. Both together are described as 'character-pair.' If, for instance, we cross a red-flowering and a white-flowering pea the colours ' red' and 'white' forms the 'character-pair.' The bastards or hybrids which develop from such cross are all red-flowering; they all follow one of the parents and cannot be distinguished from them. The white colour seems to be entirely suppressed. But if we breed from these red-flowering hybrids and fertilize them with their own pollen we see a remarkable phenomenon. Though in this case the 'father' as well as the 'mother' had red flowers the second hybrid generation produces only 75 per cent. of redflowering descendants, while in the rest the white flower of the one 'parent,' which in the first generation had entirely disappeared in favour of red, reappears here suddenly anew. If the breeding is continued we see that the white-flowering hybrid form under self-fertilization remains from now permanently constant, producing always white-flowering descendants. In the red-flowering variety, however, we find that under equal conditions in all subsequent generations always the same division takes place, i.e., we always obtain 75 per cent. red-flowering 'dividing ' and 25 per cent. white-flowering 'constant' peas.

The same regularity may be observed in crossing two species of nettle, of which one, Urtica patulifera, has dentate, the other, Urtica dodartii, entire leaves. Here in the first generation the ' character-pair' of the parents, dentate and entire leaf, produces exclusively bastards with dentate leaves, indistinguishable from those of the one 'parent.' In the second generation the ' split' takes place, only three-quarters of all descendants having a dentate leaf, while in the rest the suppressed character, the entire leaf, reappears. The further course is identical with the behaviour of the two varieties of peas. From this and other facts Mendel concluded that for each independently inheritable character of the parents there must be present in their idio- 
plasm a corresponding independent rudiment (Anlage): that during crossing and fertilization these 'rudiments' together form in the egg-cell a pair; and that finally during the further development the characteristic feature of 'one 'parent' conceals that of the other. The prevalent character is usually described as the 'dominant,' the other as the 'recessive' character, and the phenomenon itself as the 'rule of prevalence.' 'If,' says Correns, 'the phylogenetic condition of both parents can be determined it is almost always clear that the phylogenetically higher character, i.e., the younger ' rudiment,' dominates.

But this 'rule of prevalence' finds no universal application, for there are numerous cases in which the hybrids of the first generation represent a mixed form and exhibit the characters of their parents jointly. These two extremes are then connected by every conceivable transition form. The following is an instance of the second case. Every one knows the beautiful Mirabilis Jalapa, for its large red, white, yellow, or variegated flowers has made it a favourite garden flower. If we cross a red-flowering with a white-flowering form, the hybrid shows flowers of a light pink shade. If we now breed from these hybrids under strict self-fertilization we shall again observe a remarkable 'Mendelian split,' but this time in somewhat different proportions. The second hybrid generation supplies three different kinds of individuals, half of all descendants showing the intermediate light pink type, 25 per cent. the red, and 25 per cent. the white type. But while the intermediate hybrids continue to 'mendel,' i.e., to produce 50 per cent. of differentiated descendants, the hybrids which had reverted to the form of their 'grandparents' prove themselves perfectly constant. This case illustrates Mendel's rule far more clearly than the instance of pea and nettle, because here the 'splitting' is not obscured by the 'domination' of one character. Is it not strange that when in the crossing of two varieties, differing only in one point, the character of one parent is completely lost in the hybrid generation, or that, as in the Mirabilis Jalapa, only intermediate hybrids originate, in the second generations the characters which were apparently extinct, or at least intermixed, suddenly reappear pure and in fixed proportions? Can cell-investigations or speculation offer a satisfactory explanation of this phenomenon? 
In my opinion the conclusion at which Mendel arrived on the basis of his facts is a simple and natural straightening of all the tangled skeins. Only when we assume that the two ' rudiments' of the paternal organisms which fused during fertilization in the ovum to one pair, once more separate during the formation of
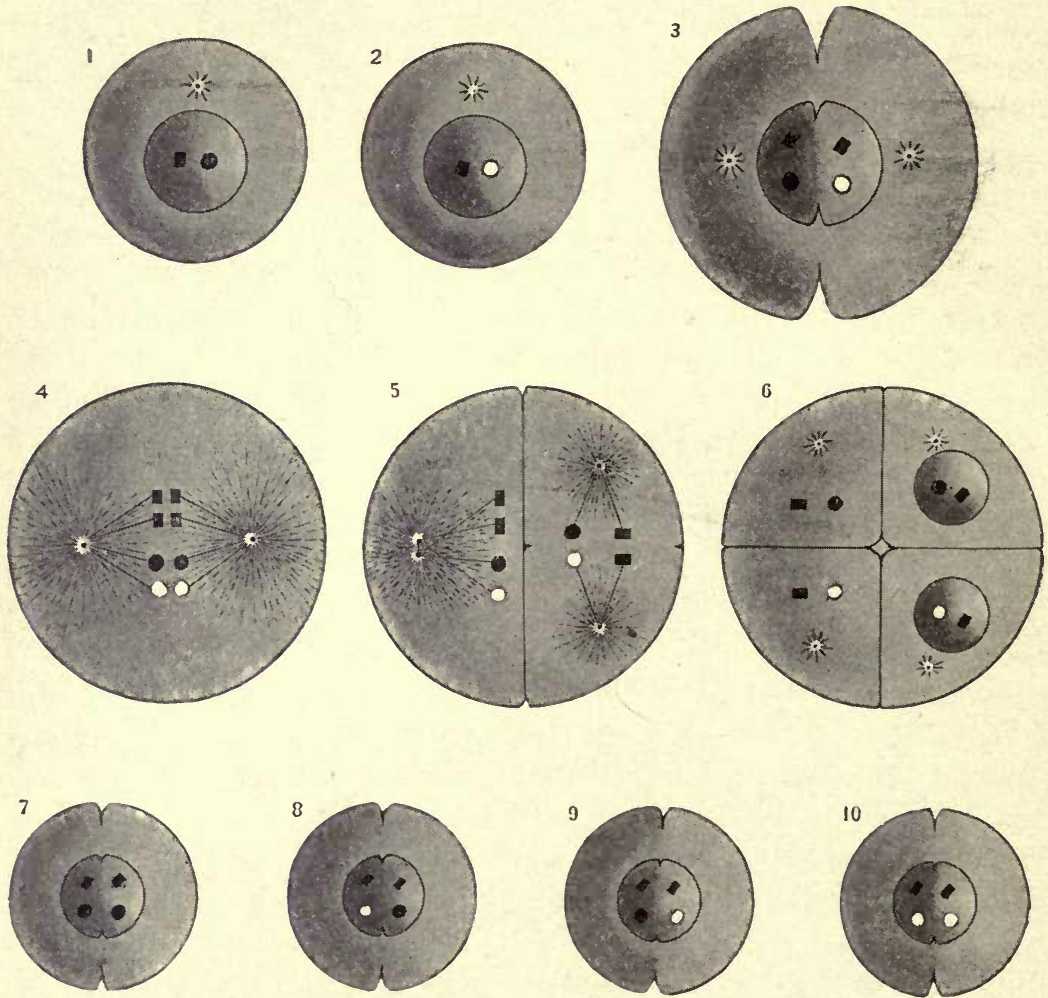

FIG. 74. - MENDEL'S LAW.

(1 and 2) Germ cells of the parents. (3) Their union in the fertilization-act; also diagram of the structure of the body-cells of the first hybrid-generation. (4-6) Germ-cell formation of the hybrids. The germ-cells formed are 'pure.' (7 to 10 ) Fertilization-process during continuation of the breeding; the four possibilities.

the germ-cells of the hybrids, so that one half of the sex-cells receives the 'rudiments' of the paternal character, but the other that of the mother, we can gain a proper perception of the cause of this remarkable phenomenon. The germ-cells of the 
hybrids, therefore, do not possess a hybrid character, like the egg-cell from which they developed, but the germ-cells that are formed are pure, at any rate, with regard to the ' character-pair.

It will already have been observed how fully this assumption agrees with our observations concerning the origin of sexcells, for this separation of the paternal and maternal rudiments takes, of course, place during both 'maturing-divisions' through which all germ-cells have to pass in the course of their development. Let us endeavour to make this clear with an assumed case (compare figs. 72 and 74 ).

Let us assume that the ripe germ-cells of Mirabilis Jalapa contain only two chromosomes, and that one entire nuclear loop is the carrier of the 'rudiments' (Anlagen) of the colour of the flowers. Whether we think of the mother as red-flowering and the father as white-flowering, or vice versâ, is of no importance to the course of the process. In our illustrations the nuclear loops are indicated in the red-flowering parent by a little black, in the white-flowering by a white circle. During the act of fertilization these 'rudiments' of both parents are united in the fertilized eggcell, and all body-cells of the hybrid have the same structure as the ovum. But as in Mirabilis Jalapa both 'rudiments' endeavour in an equal manner to reach development, the hybrid which develops from the egg-cell must take up a middle position between its parents and produce pink flowers. If now these hybrids proceed to the formation of germ-cells, the beforementioned reduction-process sets in, by which the complement of chromosomes is reduced by half and the idioplasm inherited from the mother and father separated. The result of this double division is represented in fig. $\mathbf{7 4}$, 6. Each original germ-cell has producea four mature sex-cells of which two have received the 'rudiments' of the red, two those of the white colour. If we now cross the hybrids there are manifestly four possibilities in the union of germ-cells all having the same prospect of realization (fig. 74, $7-10$ ): either ovum as well as sperm possess only the 'red' chromosome, or of the conjugating sex-cells one is furnished with a 'red,' the other with a ' white rudiment' - this case will naturally occur twice as often as the other-or finally there is the possibility that both germ-cells possess only the white 'rudiment.' Corresponding to the different 'outfit' of 
the fertilized egg-cell, the plants developed from them must naturally vary greatly. If a plant contains only the red, or only the white nuclear loops, it can naturally only produce red or white flowers and must under self-fertilization keep pure in all future generations; but in the case in which the two united germ-cells were differently supplied, where one possessed the paternal, the other the maternal characters, intermediate hybrids with pink flowers will originate, and these will always again produce two kinds of germ-cells, and, therefore, even under selffertilization, always in exactly the same manner 'split' into three kinds of descendants exactly as the hybrids of the first genneration. A simple calculation shows that the 'split'-in perfect accord with Mendel's results-must occur in the proportion of $1: 1: 2$, in other words, the hybrids will always produce 25 per cent. redflowering constant plants, 25 per cent. white-flowering constant plants, and 50 per cent. intermediate 'mendeling' plants.

These results are corroborated by numerous crossing experiments made with animals. The well-known Helix hortensis and Helix nemoralis occur in two varieties, of which one has a shell with a delicate dark ribbon design, while the shell of the other variety is without this ornament. If we pair a 'ribbon snail' with a 'ribbonless snail' we shall obtain only ribbonless descendants. But as Arnold Lang was able to show by the most painstaking experiments extending over several years, the suppressed ribbon design reappears in the second hybrid generation in about 20 per cent. of all the descendants, and remains thence constant in all subsequent generations. The behaviour of the snail is therefore exactly analogous to that of peas with red and white flowers, or the nettles with dentate and entire leaves, in which one character dominates the other.

Poultry-breeders have been puzzled for many years by the fact that the Blue Andalusians, a splendid variety of poultry, the breeding of which is with particular success carried on in England, never breed pure. Even in the best strains only about one-half of the young are Blue Andalusians, while the remainder are spotted or black. The most surprising fact, however, is that while the black and the spotted birds prove constant and continue to breed constant, the blue without exception always produce differentcoloured descendants; if, however, spotted birds are paired with 
black, the first hybrid generation contains only blue birds, which on continued breeding regularly split once more into blue, black, and spotted. We have here doubtless a typical case of Mendelism which may be compared to the behaviour of the two Mirabilis Jalapa races.

As early as 1895 Haacke reported that the crossing of the spotted Japanese dancing mouse with our ordinary grey mouse in the first generation produced only normal young. In subsequent generations the remarkable abnormity reappeared in a number of individuals in the definite proportion demanded by the rule.

Finally, let us consider two interesting instances taken from human life. The first case was observed by Castle on the marriage of a negro-albino with a normal negress. Here albinism proved to be 'recessive.' More remarkable is the second case. In the year 1710, in Brandon, in Suffolk, a child was born of healthy parents, whose entire body, with the exception of the face and inuer hand and feet surfaces, began a few months after birth to be covered with a black horny skin. All the numerous brothers and sisters of this strange child, which appeared to feel quite comfortable in its horny skin and possessed no other defects, were normally formed. When the boy became a man he married a young Irish woman, and all six children of this marriage uniformly exhibited this characteristic of their father. With remarkable tenacity the horny skin was transmitted from generation to generation, but of the three following generations only a part of the descendants had this natural armour, while the others were normal. A descendant of this strange race was the 'porcupine man,' J. Lampert, made famous by the investigations of Tilesius and Darwin, who at the beginning of the last century, in company with his similarly affected younger brother, travelled through England, Germany and France, exhibiting themselves for money. The seven sisters of these two brothers had perfectly pure soft skins. In view of the small number of descendants we are naturally unable to prove a complete agreement with the figures which we should expect under the Mendelian law, but we may, nevertheless, regard this case with a high degree of probability as an instance of the 'rule of prevalence.' The only unexplained feature in this case was that 
only the male children possessed the characteristic horny skin. This was probably only accidental, but may on the other hand provide an opportunity for obtaining information concerning the cause of sex-determination.

As a rule the species employed for hybridization will differ from each other in more than one point, so that we have to direct our attention to two, three, or even more ' character-pairs.' Such cases are particularly instructive because they let us clearly perceive the independence and arbitrary mutability of the different 'rudiments' (Anlagen), and because they show that the various parental qualities may reappear in the hybrids in any combination.

Let us make this clear by choosing the simplest possibility, the difference of only two points, a pea variety with a yellowwrinkled and one with a green-smooth seed. The yellow colour of the seed of one parent and the smooth surface of the seed-shell of the other prove dominant, so that the hybrids of the first generation produce only 'yellow-smooth' peas. As now the two characterpairs, 'yellow-green' and 'smooth-wrinkled,' split independently of each other, the hybrids form in this case four different kinds of germ-cells with the 'rudiments' yellow-wrinkled, yellowsmooth, or green-wrinkled, green-smooth. It is not necessary to mention that here again the egg-cells as well as the male germs are each furnished in perfectly equal proportions with one of these four combinations. If the breeding is continued under strict self-fertilization these four different germ-cells may meet in nine new combinations, which, however, as a result of the prevalence of yellow and smooth produce only four differentiated plants bearing either yellow-smooth, yellow-wrinkled, or greensmooth and green-wrinkled seeds. We see, therefore, that the different parental 'rudiments' can, in fact, come together in every possible combination. If we now consider the frequency of the single characters we obtain again a result which agrees accurately with our calculations, for we find three smooth to each wrinkled and three yellow to each green pea. It is unnecessary to carry this instance further: I would only mention that already in this second generation a certain percentage of each of the four different plants proves constant and that therefore the characters yellow-smooth and green-wrinkled have met in a fixed combination. 
The veil which has so long covered the problem of heredity begins to lift and at least for a short distance we are able clearly to perceive the tangled paths leading into this labyrinth of the numerous cases of the plant and animal kingdom which follow Mendel's law and can be explained rationally, thanks to the results of cell-investigation.

We must, however, never forget that Mendel's law applies only in the case of a proportionally small number of ' characters,' now that there are more instances which do not follow the rule, and in which the result of crossing is essentially different from what the law would lead us to expect. Externally it is impossible to observe in a character whether it will 'mendel' or not; breeding experiments alone can supply the proof. But, as Julius Gross points out, all cases of Mendelism have this in common, in spite of their heterogeneousness, that the 'splitting' characters originated suddenly, by abrupt variation. Wherever we reinvestigate a case it will always be found that 'the Mendelian race represented by one or more was suddenly observed on a flower-bed or in a field of the stem-form, without the presence of the transition-forms between the two types. Indeed it is regarded as a rule for experiments with 'prevalence' and 'splitting' that it is necessary to select two forms which in the first place breed pure, and secondly form sharp contrasts to each other without transition forms. But as for this reason old and good species are excluded there remain on this ground alone only varieties that have suddenly come into being.' 'This empirical result obtained from the facts could also be obtained per deductionem. For varieties that originated gradually and are still connected with the type of the species by transition-forms must in crossing with the species undoubtedly produce intermediate bybrids simply on account of their own variability and their tendency towards the type. Therefore, only forms that have suddenly come into existence can exhibit the phenomena of Mendel's law.' In other words, cases of Mendelism are mutants in the sense of De Vries.

Even in animals or plants in which one or the other character follows the rule of prevalence and splitting we can observe that the other characters of both are found in the hybrids in any proportion. In order to put forward an explanation for this phenomenon we are compelled to leave experiments and venture on the ground of pure speculation; the result will therefore only 
be able to claim a heuristic value. I am following here again essentially the arguments of Gross, because I regard his attempt as comprehensive and intelligible, but disagree with him when he, in accordance with Weismann, conceives the single nuclear loops to be composed of several equivalent $i d s$. I rather believe the simple hypothesis that the different 'primary constituents' are capable of independent reproduction to be an entirely satisfactory explanation. It is also far better supported by the facts of observation.

The fundamental condition of Mendelian 'splitting,' the purity of the germ-cells of the hybrids, is, as we have seen, guaranteed by the process that takes place during the maturing of the ovum and sperm, and it only remains now to explain why, in spite of this purity of the sexual products, most crosses produce mixed forms, and why not all 'character-pairs' behave alike.

Our observations compelled us to assume that each cell of the body of an organism originated bi-sexually contains the complete hereditary substance, as it were, in two 'editions,' from the father and from the mother. While during the nucleus-division the idioplasm becomes visible in the shape of individualized chromosomes, it lies in the meantime during the so-called nucleusrest distributed throughout the entire interior of the nucleus. Only during the preparation for a new reproduction the chromatin fragments collect and arrange themselves once more into the characteristic nuclear rods or loops. We may now contend with some degree of certainty that the chromosomes are not uniform formations, but that they consist of an enormous mass of different 'primary constituents'-(about the nature of which we know nothing) - of which each corresponds to a certain body-part. If the two parents from which each half of the chromosome complement came resembled each other closely the conclusion is not far-fetched that the paternal and maternal rudiments resemble each other; indeed, according to Gross, they are so much alike that they may be arbitrarily exchanged. They are of course always corresponding 'rudiments,' as otherwise the young would exhibit most remarkable defects. When therefore the nucleus awakens from the rest-stage into activity the different pairs of chromosomes reassume once more their definite number and form, but they are no longer the same chromosomes as heretofore. They are no longer purely paternal or purely 
maternal nucleus-loops, but each carries the 'rudiments' of the parents in any conceivable combination. Though now the parental chromosomes are in the case of the germ-cell formations divided by maturity-division each of them will still be composed of 'primary constituents' of a double lineage. Accordingly, the descendants must exhibit the character of both parents in an entirely different combination.

In the majority of cases the paternal and maternal qualities will on an average balance each other; in many individuals the influence of the father will be prevalent, in others that of the mother, and sometimes it may even occur that the type of one of the parents is almost entirely suppressed.

In the cases of Mendelism the proportions are somewhat different; there we may conceive that the 'rudiments' of the 'splitting characters' have gradually become differentiated so much that they may no longer be exchanged one for another, but that all 'rudiments' of the relevant character always meet again in their definite nucleus-loops. However different the combinations of the other rudiments may be, as regards the 'Mendelian rudiments,' always pure sex-cells are formed. Formally this hypothesis suffices for explaining all the manifold phenomena of heredity, but how far it will be possible to support it by facts, or what modifications it will have to undergo, only the future can say.

Our excursions into the region of biology have led us along many sinuous paths, across luxuriant fields and dry deserts, to the high summits of mountains, and through narrow ravines. We have seen what the human mind has achieved in restless labour, and họw Nature has been forced to yield up many profound secrets, but our wanderings have also led us to many locked doors at which we knocked in vain for admission. However great the treasures of knowledge raised in the past and the present, still greater treasures await discovery by future generations. Moreover, who will say that much which is to-day valued as gold may not be rejected as dross by posterity, and much that is regarded to-day as a secure possession of science may not have crumbled away in a few generations?

Der steht wohl niedrig in der Toren Mitte,

Wer blindlings hat das Ja und Nein gefunden,

Nicht unterscheidet, ob es Deutung litte. 


\section{INDEX.}

ABIOG ENESIS, 99,306

Actinia, 181

Adams, 135

Adansia rondeletii, 182

Adaptation, 157

Adelsberg grotto, 193

Adler, 268

Aigner-Abafian, 167

Air-pressure, 32

Albinism, 321

Alca impennis, 23

Aldrovandus, 171

Algce, 64

Alloplectus, 195

Alpine trees, 188

Alteration of generations, 259

Alytes obstetricans, 279

Amblystoma tigrinum, 121

Amœba, 72 ; limax, 31 ; proteus, 212, 240 ; radiosa, 190

Amphimixis, 226, 283

Amphiont, 238

Amphiuma, 16

Anaërobic bacteria, 31

Anal glands, 288

Anaximander, 4

Anchitherium, 113

Ancon sheep, 209

Annelidæ, 132

Anopheles, 237

Ant-eater, 117

Antedon rosacea, 130

Antheridium, 237

-4nthracosaurus, 108

Antitoxin, 48

Ants, 184, 276

Archceopteryx, 14, 110

Arctica caja, 186

Arctic animals, 160
Argonnuta, 291

A ristotle, 6, 87, 282

Armadillidium, 106

Artemia , 81, 198

Ascaris megalocephalus, 81, 291, 293, 296,310

Ascoli, 139

Aspredo lavis, 279

Assapan, 177

Atlantosaurus, 109

Atomistic theory, 86

Auk, great, 23

Aurelia aurita, 260

Auricularia, 129

Autotomy, 170

Axolotl, 121

Bacillus tetani, 48

Balcena, 24, 109

Balcenoptera musculus, 124

Balanoglossus, 129

Barnacle, 65

Barnicle-goose, 132

Barramunda, 18

Bates, 166

Bathybius, 98

Bats, 43

Beatis gemellus, 274

Bedeguar, 267

Bees, 198

Beetroot, 201

Belladonna atropa, 49

Bell-animalcules, 230

Belodon, 109

Belt, 46

Bert, 33

Bessel, 135

Beta vulgaris, 204

Biedermann, 169 


\section{Bilharzia, 287}

Biochemistry, 136

Biophores, 304

Biorhiza renalis, 268

Bipinnaria, 129

Blastomere, 307

Blastula, 117

'Bleeding host,' 190

Blue Andalusian variety of poultry, 320

Bonellia viridis, 287

Boveri, 284, 298, 310, 314

Brachystola magna, 314

Branchiostoma, 12

Branchipus, 198

Brauer, 293

Brine-shrimp, 198

Brontosaurus, 109

Brown-Sequard, 186

Bryozoa, 128, 258

Budding, 255

Bullfinch, 198

Burke, 98

Bursa, 276

Biitschli, 69

Cachalot, 109

Cambrian system, 104

Cameroons, 167

Canalis gyncecophorus, 287

Canaries, 198

Capra ibex, 147

Carboniferous system, 108, 218

Carp, 153, 185

Caryatis viridis, 167

Castration, 148

Cataplexy, 45

Catastrophism, doctrine of, 8

Catheturus lathame, 280

Cats and fertilization of red clover, 156

Caulerpa, 70

Caviare, 153

Cell, discovery of the, 64 ; cell-nucleus, 74,283 ; cell-state, 249 ; cell-theory, 79 ; food-cells, 285

Centrosome, 75, 283

Cephalopoda, 104, 291

Ceratopsidæ, 110

Cercaria, 154

Chætopoda, 128

Chamberlain, H. St., 205
Chameleontidæ, 19

Chamisso, 259

Chemical stimuli, 190, 196

Chill-coma, 31

Chlorophyll, 30

Chromatin, 74, 295; chromatin reduction, 310

Chromatophores, 169

Chromis paterfamilias, 279

Chromosome, 291

Ciliata, 220

Circumcision, 186

Clinostat, 195

Clitellum, 290

Cloë, 289

Cobitis, 42

Cold, effect of, 186

Colour-adaptation, 164

Columbia livia, 143

Conjugation, 225

Constriction, 214

Convergence, phenomenon of, 168

Copernicus, 7

Coral-snake, 165

Corals, 257; corals and sea-anemones, 62

Cordylophora, 193, 199

Coregonus, 35

Corethra, 46

Correlation of parts, 147

Cortical plasm, 222

Cosmozoic theory, 91

Crayfish, 45

Cretaceous period, 108

Crinoidea, 129

Crossbreeds, 202

Cuckoo, 280

Cuttle-fish, 291

Cuvier, 7

Cyclostoma, 12

Cynipidæ, 267

Cysticercus, 262

Cytodes, 69

Dachshund, 209

Daphnia, 133, 263

Darwin, 301, 321

Darwin, Erasmus, 9

Darwinian Theory, 140

Deadly nightshade, 49 
Death's-head moth, 162, 165

Death, what is, 214

Deluge, 84, 293

Desert animals, 161

Determinant, 303

Devonian system, 107

Dilina tilia, 202

Dimorphism, sexual, 286

Dionaa, 66

Diplozoon paradoxum, 287

Dipnoi, 18, 107

Dipterocarpaceans, 178

Directive body, 294, 300

Dog, host of Tania, 263 ; echinococcus, 262.

Domestication of animals, 143

Dominant character (in crossing), 317

Driesch, 309, 312

Driver-ants, 46

Drosera, 65

Dry-coma, 36

$\mathrm{Du}$ Bois Reymond, 59

Duckmole, 117

Duck-mussel, 132, 287

Dujardin, 221

Dusch, 96

Echidna, 117 ; aculeata, 281

Echinodermata, 127, 276

Echinus, 298

Ectocarpus siliculosis, 233

Ectoplasm, 213

Eel, 178

Egg-cells, 116

Ehrenberg, 95, 221

Eimer, 169, 192

Elaps corallinus, 165

Electric organs of ray and eel, 178

Elementary species, 208

Elephant, 151

Embryo, development of, 119

Empedocles, 5

Encystus, 255

Endoplasm, 213

Engelmann, 188

Entomostraca, 133

Eocene strata, 113

Ephebogenesis, 298

Ephemeridæ, 274

Ephippium, 264
Ephyra, 260

Epilepsy, 186

Epistalis, 221

Equatorial plane, 82, 293

Equidæ, 114

Erber, 41

Erythrolampsus, 165

Eudendrium ramosum, 193

Eugaster, 172

Euglypha alveolata, 219

Eunuchs, 148

Eyed hawk-moth, 202

Fasciola hepatica, 154

Fechner, 91

Ferns, 194, 200

Fertility, 151, 153, 224

Fertilization, 117, 156, 229, 270, 289, 295

Feuerbach, 2

Fischer, Emil, 51, 186

Fish-heart, 120

Fittonia, 67

Flat-fishes, 122

Flying-fishes, 15

Flying-membrane, 25

Flying-squirrel, 177

Food, influence of, 198

Foraminifera, 217

Friedenthal, 136

Frog, 290

Funaria hygrometrica, 200

Fungi, 65

Fungus-gardens of ants, 184

Fusulina, 218

Gadus aglefinus, 15

Galen, 7

Galilei, 7

Gall-apples, 267 ; gall-insects, 267

Galle, 136

Gardening-ants, 184

Gasterosteus aculeatus, 276

Gastrula, 118

Gecko, 19

Gemmation, 257

Geometridæ, 165

Geophagus brachyurus, 278

Germ.cells, 246 ; formation of, 282 ; germ-path, 306 ; germ-zone, 292

' Gid,' 262 
Gills, 120

Giraffe, 11

Glands, anal, 288 ; poison, 289 ; sexual, 284

'Glass-rope' sponge, 162

Glow-worm, 163

Goethe, 8, 10, 60, 88

Gooseberry, 204

Grassi, 238

' Gravediggers,' 273

Green birds in Europe, 162

Grew, 68

Gross, Julius, 323

Gryllotalpa, 24

Guillemot, 23

Guinea-pig, 169

Gurnard, 14

'Gutter-fauna,' 38

Gymnophiona, 16

Gymnospore, 238

\section{Haberlandt, 67}

Haeckel, 36, 97, 115, 138, 211, 321

Hamamœeba, 235

Haltica atropa, 49

Hansemann, 139

Harvey, 87

Hatteria punctata, 108

Hawk-moths, 136

Heat-coma, 32

Hectocotylus, 291

Hedgehog, 49, 168

Heider, 293

Heincke, 150

Heliconiidæ, 166

Heliozoa, 72, 243

Helix pomatia, 81 ; hortensis, 320 ; nemoralis, 320

Helmholtz, 91

Hemi-embryo lateralis, 308

Herbst, 253

Heredity, 185, 247; hereditary substance, 83,296

Herlitzka, 308

Hermaphroditism, 285

Hermit-crab, 181

Hertwig, 188, 293, 308, 310, 312

Hesperornis, 114

Heterogony, 267, 270

Heterokinesis, 304
Heymons, 198

Hibernation, 43

Hipparion, 113

Hippocampus antiquorum, 279

Hobbes, 180

Hofer, 185

Hoff, 9

Holothurians, 129

Homœokinesis, 304

Homunculus, 88, 283

Hooke, Robert, 68

Hornet and hornet-moth, 165

Horse, 113

Horse-dung beetle, 274

Hot springs, fauna of, 40

Hunger-culture, 265

Hurley, 180

Hydra viridis, 63, 252 ; grisea, 253

Hydrocaulus, 261

Hydrophilus piceus, 195

Hydrorhiza, 261

Hydrozoa, 241

Hypnosis, 44

Hyracotherium, 113

ICHNEUMON fly, 272

Ichneumonidæ, 255, 272

Ichthyopterigium, 13

Ichthyosaurus, 108

' Id,' ' idant,' 303

Idioplasm, 311

Iguano:ton, 110

Immortality, potential, 214

Immunity, 49

Infusoria, 221

Insectivorous plants, 65

Issakowitsch, 264

Ivy, 194

J̈̈GER, 252

Jelly-fishes, 162

Jurassic period

Kallima, 165

Kangaroo, 281

Kant-Laplace Theory, 85

Kelvin, Lord, 91

Kepler, 7

Kessler, 181

Kircher, 44 
Kiwi, 22

Klebs, 200

Kleinberg, 255

Knot-grass, 196

Koch, W., 37

Korschelt, 76

Kropotkin, 181

Kükenthal, 125

LAMARCK, 10, 185

Lamprey, 12

Lampyris noctiluca, 163

Lancelet, 13

Lang, Arnold, 320

Lange, 157

Laveran, 234

Law of causality, 85 ; of evolution, 85 ; of gravitation, 7, 195

'Leaf-rollers,' 273

Leeuwenhoek, 38, 282

Lemming, 168

'Lemon' butterfly, 192

Lepas anatifera, 132

Lepidosiren, 107

Leptodora hyalina, 134, 162, 289

Lestes sponsa, 274

Leucocyte, 73

Leverrier, 136

Libellula cancellata, 274

Libellulidæ, 274

Liebig, 91

Light, effect of, 177, 188, 192

Lingula, 176

Linnæus, 65

Liver fluke, 153, 270

Liverwort, 194

Lizards, 19

Lockjaw, 48

Locusts, 161

Loeb, 197, 299

' Loopers,' 165

Lophobranchii, 279

Lotsy, 195

' Love-darts,' 288

Lumbricus trapezoides, 255

Lungs, evolution of, 120

Lycana agestis, 192

Lyell, 9

MacFadyen, 41
Macrobiotus hufelandi, 38

Macrogamete, 23:

Macroglossus, 136

Macronucleus,'|223

Maize, 206

Malacostraca, 134

Malaria, 234

Manuring, artificial, 197

Marchantia, 194

Massart, 195

Mastodon, 108

Maturing-division, 299

Maupas, 225

Mayer-Eymar, 174

Medusa, 162

Megusar, 195

Mendel, 202, 315; Mendelism, 315 ; Mendel's law, 315

Mesohippus, 113

Mesozoic formations, 109

Metabolism, 28, 62

Metagenesis, 267

Mice, experiment with, 186 ; Japanese dancing, 145, 321

Micrococcus prodigiosus, 190

Microgamete, 231

Microgaster, 272

Micronucleus, 223

Microstoma, 254

Migration, Theory of, 175

Mimicry, 165

Mimosa pudica, 65

Miocene strata, 113

Mirabilis Jalapa, 317

Miracle-flower, 40 ; miracle-monad, 190

Mithridates, 47

Mitosis, 80, 293

Mohl, Von, 68

Mole, 24, 163

Mole-cricket, 24

Monera, 36

Monont, 236

Morgan, 299, 308

Morula, 117

Moses, 45

Mosquito, 235

Mosses, 200

Moulting of crustaceans, 133

Mud-fishes, 39 ; mud-fly, 275 ; mudjumper, 17 
Müller, 6, 206

Mummy-wheat, 36

Musk-glands, 288

'Mutant,' 323

Mutation, Theory of, 206

Mysidæ, 135

Myxine glutinosa, 286

Nauplius, 133

Nebular Theory, 85

Neoceratodus, 18

Neoscopelus macrolepidotus, 35

Neptune, discovery of planet, 135

Newt, 41

Newton's law of gravitation, 7

Nototrema, 279

Nucleus, 74, 223 ; nuclear loops, 296 ; nucleolus, 79 ; nucleus-corpuscle, 75 ; nucleus-division, 81

'Nun moth,' 155

Nuptial dress, 180

Nurse-generation, 269

Nuttall, 137

Octopus, 182

Oedendorf, 108

Enothera, 206-207

Ontogeny, 115

Oocyte, 239

Oogony, 237

Ophichthys colubrinus, 166

Ophiuroidea, 129, 276

Opuntia, 193

Orchids, 194

Organella, 77

Ornithorhynchus paradoxus, 117, 281

Os centrale, 126

Oscillatoria, 188

Ostrich, 22

Over-fertilization, 296

Oyster, 201

Patogenesis, 271

Pagurus calidus, 181

Palcotherium, 113

Palpal organs, 290

Paludina, 112

Pandorina morum, 244

Paradoxides, 104

Paramcecium, 221
Parnassius apollo, 192

Parrot, 199

Parthenogenesis, 264, 299

Pasteur, 30

Pauly, 175, 185

Pavy, 47

Pelagia notiluca, 261

Pelomyx, 69

Penceus, 134

Penguin, 22

Pentacrinus, 128, 176

Peridinium, 243

Periophthalmus, 17

Peripatus, 111

Peristome-field, 222

Peruvian system, 108

Peysonnel, 62

Pflüger, 101

Phagocyte, 73

Phasmidæ, 165

Phosphorescence, 163

Phyllium siccifolium, 165

Phyllopteryx eques, 165

Phylloxera vastatrix, 269

Physeter macrocephalus, 109

Physiologus, 7

Pictet, 42

Pieridæ, 166

Pigeons, races of, 143

Pigment cells, 169

Pike, 185

Pill-beetle, sacred, 273

Pinnipedia, 24

Pipa americana, 279

Placenta, 237

Planorbis multiformis, 112

Planula, 260

Plant-lice, 269

Plasmodium, 235

Platurus, 166, 168

Platyrhini, 138

Plesiosaurus, 109

Pliny, 6

Pliocene strata, 113

Plumularidæ, 262

Pluteus, 129, 197, 298

Poison gland, 289

Polar bear, 160 ; fox, 160

Polygonum amphibium, 196

Polymorphism, 267 
Polyommatus, 192

Polyspermy, 296

Poplar, 193 ; hawk-moth, 202

Porcupine-man, 321

Potamanthus, 289

Pouchet, 94

Poulton, 136

Power, 42

Prehistoric animals, 109

Preyer, 37, 89

Prickly pear, 193 .

Primary constituents, 228

Privet hawk-moth, 136

Processus vermiformis, 127

Proglottis, 263

Protective coloration, 159 ; resemblance, 165

Proteus, 163, 193

Prothallus, 200

Protohydra, 118

Protonema, 200

Protophyta, 244

Protopterus annectens, 107

Protozoa, 212

Protozoology, 221

Pseudopodia, 72

Pteranodon, 110

Pterodactylus, 25

Pteropus edulis, 25

Pteromys alborufus, 177

Pterosaurians, 110

Ptolemaic system, 86

Quetelet's law, 206

RABBITS, 175 ; rabbit pest, 152

Radiobes, 99

Ramsay, 99

Ratio of reproduction, 151

Rawitz, 298

Ray, 178

Réaumur, 62

Recessive character, 317

Redia, 270

' Red underwings,' 162, 165

Regeneration, 193, 283

Regnard, 35

Remack, 79

Reproduction, 214 ; in freshwater sponges, 258 ; by layers, 258
Rhinoceros-bird, 280

Rhizocrinus, 128

Rhodites rosa, 267

Rhodocera rhamni, 192

Rhynchocephala, 108

Rock-dove, 143

Rosenberger, 136

Rose of Jericho, 40

Rossia macrosoma, 54

Roux, 52, 308

Rudimentary organs, 12, 126

Rügen, 218

Rule of prevalence, 317

SABLE, 160

St. Hilaire, 8

Salamander, 120

Salpa , 162, 259

Samter, 198

Saurians, 26

Sea-anemones, 181 ; sea-cucumbers, 253 ; sea-gull, 20

Seal, 24

Selaginella, 40

Selection, artificial, 142, 203 ; natural, 141; natural selection a doctrine of chance, 173 ; sexual, 179, 288

Self-mutilation, 170

Semnia auritalis, 167

Serpulidæ, 128

Serranus scriba, 286

Sertularidæ, 262

Serum experiments, 136

Sex-nucleus, 223 ; sex-organs, 262 ; sexual glands, 284

Scarabceus, 274

Scent-scales, 288

Schistosomum, 287

Schizopoda, 135

Schleiden, 68

Schmankewitsch, 198

Schopenhauer, 95

Schröder, 96

Schultze, Ferdinand, 95

, Max, 68

Schwagerina, 218

Schwann, 68

Sciurus vulgaris, 177

Scolopendra, 290

Scyphostoma, 260 
Shell-animalcule, 222

Sida crystallina, 266

Siebold, Von, 35, 221

Silk-worm, 299

Silurian system, 106

Siphonophora, 261

Sisiphus sacer, 273

Skinks, 17

Slipper-animalcule, 221

Sluiter, 183

Smerinthus, 202

Solenhofen, 104

Solenostoma, 279

Sommer, 186

Spallanzani, 282

Spermatid, 293

Spermatoblast, 54, 293

Spermatocyte, 54, 293

Spermatogony, 293

Spermatophore, 289

Spermatozoa, 232

Sperm-cartridge, 289

Spharechinus, 298

Sphingidæ, 136

Sphinx ligustri, 136

Spiders, 276, 290

Spindle-figure, 81, 314

Spontaneous generation, 79

Sporocyst, 155, 270

Sporozoa, 234

Squirrel, 177

Standfusz, 186, 192, 202

Starfish, 128, 253

Statoblast, 258

Stegocephala, 108

Stegosaurus, 110

Steinbock, 147

Stentor, 224

Stickleback, 276

Stolo prolifer, 256

Strobila, 260

Struggle for existence, 151

Struggle of the Parts, Theory of, 52

Sturgeon, 153

Stylonychia, 221

Sugar-beet, 204

Sulphuric acid, Verworn's experiment with, 29

Summer-eggs of insects, 265

Sun-animalcules, 72
Sun-dew, 65

Survival of the fittest, 156, 204

Sutton, 314

Symbiosis, 63, 181

Sympathetic coloration, 167

Syngnathus acus, 279

TAdPoles, 198

Tania conurus and T. echinococcus, 262

Taguan, 177

Talegalla, 280

Talpa, 24

Tarentola, 19

Teju, 19

Teliosaurus, 109

Termites, 184

Termitoxenia, 184, 286

Tertiary period, 112

Thalassicola, 76

Thales, 3

Thallus, 194

Theromorph, 108

Thibet, animals of, 168

Tichomirow, 299

Tiger-moth, 191

Tilesius, 321

Tissandier, 33

Transparency of animals, 162

Tree-frog, 169

Trembley, 252

Triassic period, 108

Trichocysts, 223

Trigla hirundo, 15

Trilobites, 104

Triton, 289

Trochophora, 132

Trumpet-animalcule, 223

Tuatara, 108

Tupinambis, 19

Turban-eyes, 289

Turbellaria, 253

Tümpel, 274

UHLENHUT, 139

Uria troile, 23

Vaccination, 48

Vacuole, 213, 222

Vanessa levana, 191

Vanessidæ, 167, 187 
Variability of species, 141

Variations, 142

Venus's fly-trap, 66

Verworn, 28, 76

Vinegar-eelworm, 46

Virchow, 79

Vis vitalis, 47,50

Vital affinity, 304

Vitalism, 51

Volvocidal, 244

Volvox, 245

Vorticella, 221, 230

Vries, De, 206

WAGNER, 69,175

Walking-leaf, 165

Wander-spores, 231

Wasmann, 184

Waste of life in nature, 157

Water-beetle, great, 195
Water-cultures, 197

Water-flea, 133, 263

Water pressure, 34

Weasel, 161

Weismann, 3, 122, 136, 186, 187, 214, $226,264,302,324$

Whales, 23, 123

Winter-eggs of insects, 265

Wöhler, 51

Wolff, G. 203

Wolff, J., 52

Wundt, 57

Xylina vetusta, 165

‘ Yellow underwings,' 166

Zea mays, 206

Zocea, 134 


THIS BOOK IS DUE ON THE LAST DATE STAMPED BELOW

AN INITIAL FINE OF 25 CENTS WILL BE ASSESSED FOR FAILURE TO RETURN THIS BOOK ON THE DATE DUE. THE PENALTY WILL INCREASE TO 50 CENTS ON THE FOURTH DAY AND TO $\$ 1.00$ ON THE SEVENTH DAY OVERDUE.

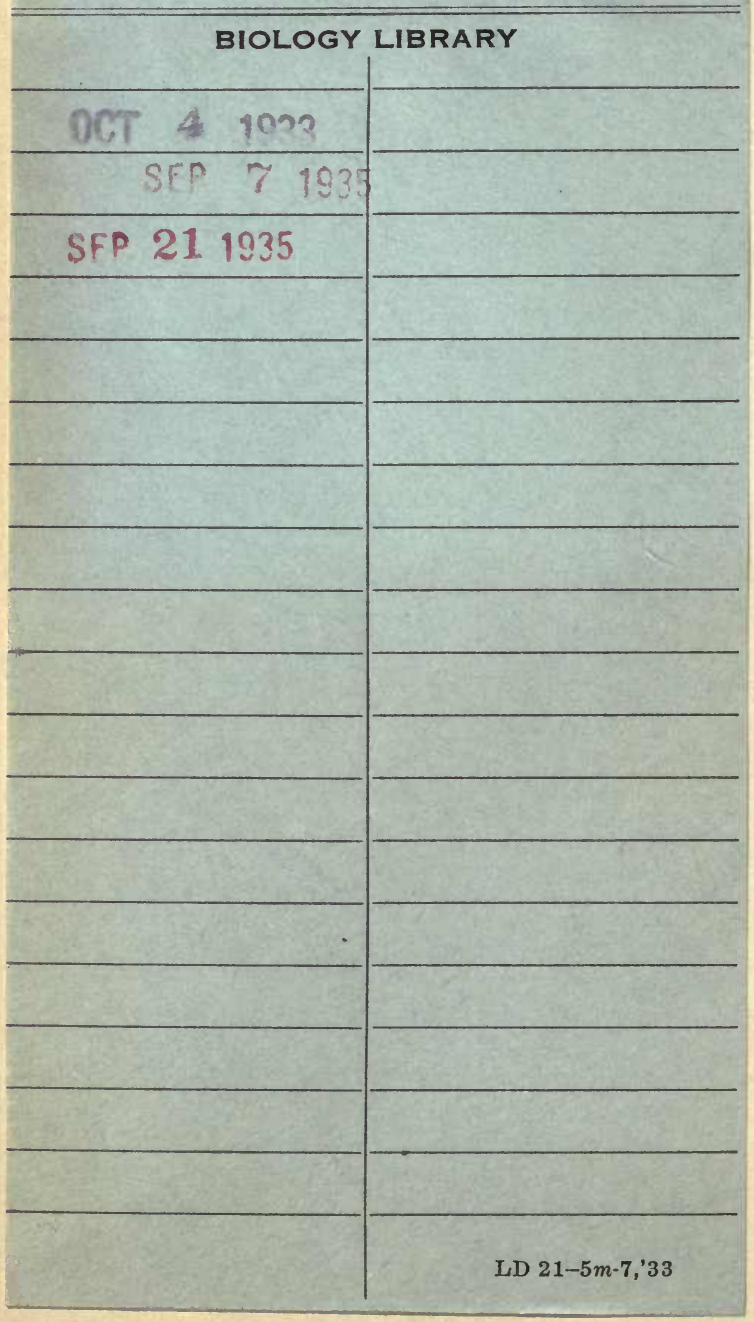




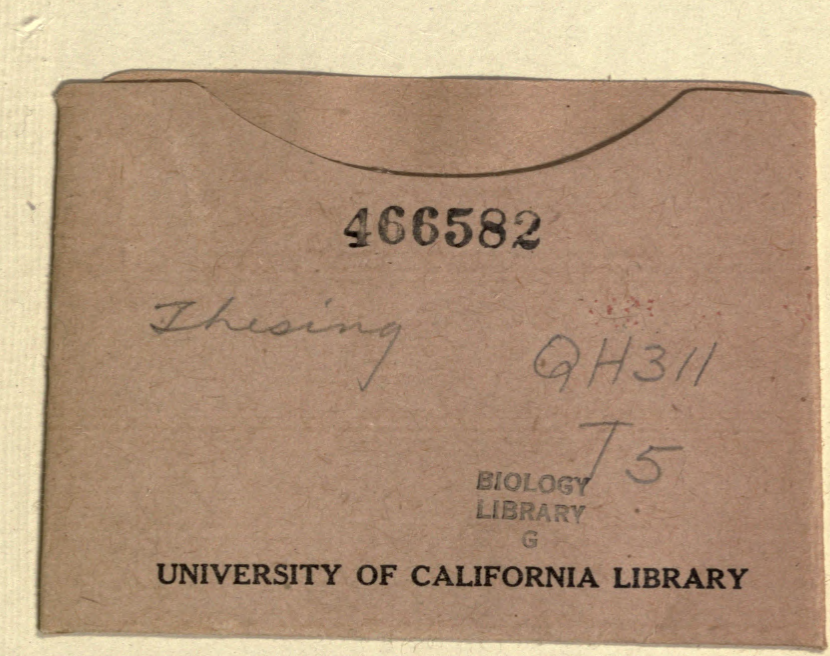


